\author{
Universidad Nacional de La Plata \\ Facultad de Humanidades y Ciencias de la Educación \\ Maestría y Especialización en Escritura y Alfabetización
}

\title{
REFLEXIONES METALINGÜÍSTICAS DE NIÑOS DE PRIMARIA SOBRE ALGUNOS MORFEMAS DERIVATIVOS DEL ESPAÑOL
}

Tesis presentada para la obtención del grado de Magíster en Escritura y Alfabetización

\author{
Presenta \\ Ramiro Roberto PUERTAS
}

Directora de tesis

Dra. Emilia FERREIRO

\author{
La Plata \\ Marzo de 2018
}




\section{A Tomás y Valeria...}

porque nada de lo que soñé, nada de lo que intenté, nada de lo que alcancé, hubiera sido posible sin su compañía, sin sus risas, sin su amor. 


\section{Agradecimientos}

A la Dra. Emilia Ferreiro, por la enorme generosidad con la que me enseñó y me acompañó en esta aventura de aprender.

A la Dra. Mirta Castedo, por haber confiado en que podría hacerlo y por haberme apoyado para que lo lograra.

A los niños y a las niñas con quienes compartí largas horas dialogando y reflexionando sobre la lengua. Todo lo que aprendimos también es de ustedes.

A quienes me ofrecieron su hospitalidad y su amistad en los distintos destinos que conocí y los numerosos kilómetros que recorrí gracias a este trabajo: a Lucas, Leo y Santi en La Plata; a Franco en Córdoba; a mi hermano Rodrigo ("Toto") en Buenos Aires; a la Dra. Mónica Baez en Rosario. Por la hermosa hospitalidad que me brindaron y por haber hecho de mis días en México un viaje inolvidable, agradezco especialmente a Valeria, Arizbeth y a mi amigo Mateo.

A la Dra. María Angélica Möller y Daniela Cabada, por su recibimiento y por todas sus gestiones para llevar adelante el trabajo de campo en la ciudad de Córdoba.

A mis compañeros, maestros y amigos del Instituto de Formación Docente $\mathrm{N}^{\circ} 1$ de Cutral-Có: Luis Solavagione, Rubén “Lupín” López y Miryam Zapata.

A la Fundación Lúminis, por su apoyo a través de la beca "Formador de Formadores".

AI DIE-CINVESTAV, especialmente al personal del Departamento de Investigaciones Educativas (Sede Sur) por su recibimiento y amabilidad.

A la escuela pública argentina, que me formó y en la cual sigo enseñando y aprendiendo. 


\section{Índice}

1. Introducción y marco teórico-metodológico............................................ 1

1.1 Planteo del problema ................................................................................... 1

1.2. Marco teórico-lingüístico .............................................................................6 6

1.3. Antecedentes psicolingüísticos en otras lenguas y sistemas de escritura ............ 11

1.4. Consideraciones metodológicas sobre el diseño de investigación ...................... 21

2. Tarea de Alargar.............................................................................29

2.1. Materiales y consigna ............................................................................ 29

2.2. Elección de fichas como palabras ............................................................ 31

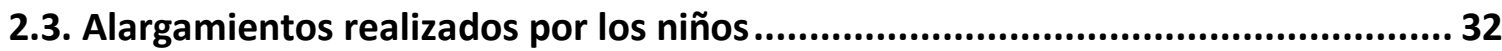

2.4. Grupos evolutivos en tarea de Alargar ....................................................... 40

2.5. Utilización y justificación de bases léxicas y de morfemas derivativos ................ 50

2.6. Observaciones finales sobre la tarea de Alargar ............................................ 67

3. Tarea de Acortar ...........................................................................70

3.1. Materiales y consigna ............................................................................ 70

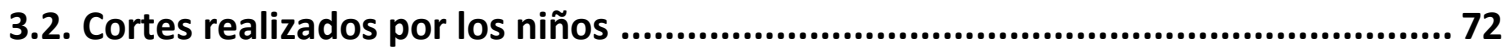

3.3. Grupos evolutivos en la tarea de Acortar ...................................................... 77

3.4. Jerarquización de los morfemas derivativos cortados .....................................90 90

3.5. Las justificaciones de los niños al decidir no cortar ........................................ 104

3.6. Observaciones finales sobre la tarea de Acortar ........................................... 108

4. Integración de datos a través de las tareas de Alargar y de Acortar ..................111

4.1. Los niños a través de las tareas.............................................................. 111

4.2. Jerarquización evolutiva de los morfemas objeto .......................................... 119

4.3. Análisis del desempeño de niños en niveles no coincidentes en las tareas de Alargar y de Acortar ................................................................................... 121

4.4. Observaciones finales ................................................................................ 128 
5. Tarea de Contrastar.......................................................................130

5.1. Materiales y consigna ................................................................................. 130

5.2. Justificaciones de los niños a los contrastes entre morfemas derivativos .......... 132

5.3. Contrastes entre los aumentativos -ON y -OTE ............................................. 135

5.4. Contrastes entre los denominales -ERO e -ISTA ............................................. 140

5.5. Contrastes entre los prefijos negativos IN-y DES-......................................... 146

5.6. Observaciones finales sobre la tarea de Contrastar......................................... 149

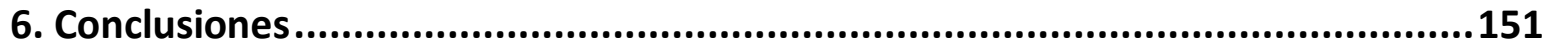

6.1. Recapitulación de aportes destacados del análisis de las tareas ........................ 160

6.2. Aportes específicos sobre el proceso de reflexión metalingüística en torno a morfemas derivativos del español .................................................................... 160

6.3. Consecuencias metodológicas del diseño utilizado para la investigación psicolingüística

6.4. Posibles extensiones para investigaciones psicolingüísticas dentro del marco epistémico utilizado ........................................................................................ 168

6.5. Reflexiones en torno a las implicancias educativas ........................................ 170

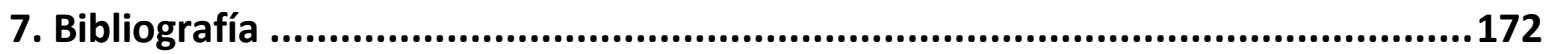




\section{Introducción y marco teórico-metodológico}

\subsection{Planteo del problema}

Los hablantes de una lengua, con o sin entrenamiento lingüístico, somos capaces de interpretar que las palabras están sujetas a procesos que cambian sus significados mediante la modificación de algunos segmentos. Podemos, por ejemplo, reconocer que entre las palabras perro y perra la modificación de un segmento produce una variación en cuanto al sexo del mismo animal al que se refiere el significado de la palabra. Sin embargo, si bien la lengua es segmentable para los hablantes no todas las segmentaciones están disponibles de la misma manera. Es decir, hay algunas segmentaciones más naturales que otras en el sentido de que no requieren ningún entrenamiento previo. Distintas investigaciones han mostrado que adultos hablantes de una lengua que aún no saben escribir (Morais, Cary, Alegría y Bertelson, 1979; Read, Zhang, Nie y Ding, 1986) o niños que están en proceso de aprender la lengua escrita (Ferreiro, 2000 y 2006) utilizan la sílaba como unidad para realizar recortes en las emisiones lingüísticas: "un recorte en sílabas es un buen intento por producir unidades igualables y, por lo tanto, contables" (Ferreiro, 2002:166). Por el contrario, la segmentación fonémica de las emisiones lingüísticas parece estar estrechamente relacionada con la alfabetización y con la práctica de escritura (Morais, Alegría y Content 1987, Vernon y Ferreiro, 1999). En el caso de las unidades morfológicas nos encontramos además frente a unidades mínimas de sentido, a diferencia de lo que ocurre con las sílabas o los fonemas. Esta problemática de los niveles y las unidades de análisis de la lengua nos instala en uno de los temas centrales de la psicolingüística que se ocupa del desarrollo: la dicotomía entre las unidades teóricas y las unidades prácticas de la lengua.

Las investigaciones psicolingüísticas sobre la llamada "conciencia lingüística" -linguistic awareness- (que desde sus inicios han privilegiado el estudio de la "conciencia fonológica", definida como la capacidad de manipular las unidades fónicas mínimas de la 
lengua y evaluada a través de tareas de omisión, agregado y sustitución de fonemas) se han interesado recientemente por la "conciencia morfológica", que caracterizan como "the ability to consciously consider the morphological units within words, including the explicit understanding of the relation between base words [...] and related inflected and derived words" (Apel y Lawrence, 2011:1312). Dos cuestiones generales nos interesa problematizar al respecto. En primer lugar, en estas investigaciones se plantea la toma de conciencia como una especie de mecanismo de alumbramiento de unidades (fonémicas o morfológicas) preexistentes a nivel inconsciente en los hablantes, lo que implica el pasaje de un estado de no-conciencia a uno de conciencia sobre determinados aspectos de la lengua. En La prise de conscience Jean Piaget advertía que:

"Pour le sens commun des psychologues, la prise de conscience ne consiste qu'en une sorte d'éclairage ne modifiant ni n'ajoutant rien, sinon la visibilité à ce qui était donné avant qu'on y projette la lumière. [...] entre l'inconsciente et la conscience, il faut bien que le passage de l'un à l'autre exige des reconstructions et ne se réduise pas simplement à un processus d'éclairement" (Piaget, 1974:261).

Se torna relevante entonces preguntarnos si se trata de una cuestión de estados de conciencia (tener / no tener conciencia morfológica) o si podemos tratar las segmentaciones e interpretaciones que los hablantes dan a los morfemas como un proceso dinámico que implica una reelaboración de conocimientos lingüísticos. En este sentido, nos inclinamos por recurrir a la noción de "reflexión metalingüística" en lugar de "conciencia" (awareness) para hablar acerca de los procesos mediante los cuales los hablantes dan cuenta de las segmentaciones morfológicas de su lengua.

La segunda observación inicial tiene que ver con las unidades mismas sobre las que un hablante puede reflexionar. Tanto los estudios sobre la psicogénesis de la lengua escrita (Ferreiro, Pontecorvo, Ribeiro Moreira y García Hidalgo, 1996; Ferreiro y Teberosky, 1979) como los estudios sobre la génesis histórica de las palabras (Parkes, 1993; Saenger, 1997; Zamudio, 2010) han dado cuenta del rol definitorio de la escritura en la constitución de las palabras como unidades. Para la tradición lingüística, en cambio, la noción de palabra siempre ha sido problemática $y$, o bien ha sido rechazada como una 
noción preciéntifica ${ }^{1}$, o bien ha sido planteada como una noción preexistente a la escritura (Lara, 2006). En el caso de la palabra escrita reencontramos a su vez la unidad teórica morfema -la unidad significativa o gramatical mínima- que gráficamente tiene una extensión variable y que no siempre da pistas gráficas claras sobre sus límites (por ejemplo la palabra que en algún momento se escribió como pre-escolar y en las últimas versiones normativas españolas es aceptada solo bajo las formas preescolar o también prescolar, RAE/ASALE, 2010). En general, los aspectos morfológicos de la lengua han sido abordados desde una tradición lingüística que mayormente no presta atención al papel que juega la escritura en la determinación de las unidades lingüísticas y de sus relaciones. Esto se debe principalmente al rol subsidiario y de simple código de transcripción de la lengua oral que desde sus orígenes la lingüística moderna ha dado a la escritura (BlancheBenveniste, 2002; Ferreiro, 1999a). Ferdinand de Saussure, en el Cours de linguistique générale (obra publicada originalmente en 1916 por Charles Bally y Albert Sechehaye a partir de apuntes de los cursos que dictó Saussure) sostenía que la única razón de ser de la escritura era representar la lengua oral, verdadero y legítimo objeto de estudio para la lingüística ${ }^{2}$. Pero no solamente dejaba fuera del objeto de estudio a la escritura, sino que también la acusaba de ejercer una "tiranía" sobre la lengua oral: "I'écriture voile la vue de la lange: elle n'est pas un vêtement, mais un travestissement" (Saussure, 1995:51-52). La psicolingüística centrada en la adquisición de la lengua escrita nos permite replantear estos problemas para indagar cómo los niños van reflexionando sobre los procesos morfológicos y, en definitiva, cómo conciben las unidades morfológicas y sus relaciones en el proceso mismo de construcción de la palabra en la escritura.

\footnotetext{
${ }^{1}$ Al respecto Fernando Lara sostiene que "[d]esde hace más de medio siglo todas las corrientes de la lingüística [...] han tomado la palabra como elemento de los sistemas lingüísticos (central para la fonología, la morfología y la sintaxis), aunque poniendo en duda su existencia real como unidad verbal en favor, sobre todo, del fonema y el sintagma. Lo común en un curso de lingüística es usar palabras, usar la palabra palabra para darse a entender, pero desestimarla como fenómeno unitario y disolverla en la morfología. La unidad palabra viene a quedar reducida en los cursos a una extraña manía verbal de los hablantes de lenguas como el español o, en general, de las lenguas de Occidente en cuyas culturas se inventó la ciencia del lenguaje, que no tiene más definición que el aparecer entre dos espacios en blanco en un texto escrito -como aquí- o entre dos pausas al hablar" (Lara, 2006:9-10).

2 "Langue et écriture sont deux systèmes de signes distincts; l'unique raison d'être du second est de représenter le premier; l'objet linguistique n'est pas défini par la combinaison du mot écrit et du mot parlé; ce dernier constitue à lui seul cet objet" (Saussure, 1995:45).
} 
En el presente trabajo nos proponemos conocer cómo niños que están en escolaridad primaria reflexionan sobre algunos morfemas en palabras escritas que dan cuenta de procesos de derivación. Es decir, nos interesa saber qué tipo de hipótesis crean los niños sobre la estructura de las palabras y los significados asociados a ellas, así como también los retos cognitivos que enfrentan para comprender el funcionamiento de estos procesos en la lengua.

La tradición lingüística distingue entre una morfología flexiva y una morfología derivativa (Pena, 1999; Varela Ortega, 2005). Mientras que en el caso de la flexión las modificaciones morfológicas no provocan cambios gramaticales en las palabras (entre las formas canto y cantamos no hay cambio en el significado ni en la categoría verbal de la palabra sino en la información gramatical relativa a la persona que desarrolla la acción), están determinadas por la sintaxis y se caracterizan por ser automáticas y productivas, en el caso de la derivación la modificación de la palabra implica la formación de nuevos temas y el consecuente cambio en el significado (añadir des- para formar desarma agrega la idea de reversión de la acción a la que se refiere el verbo). Además, la derivación -a diferencia de la flexión- puede implicar el cambio de categoría gramatical de la palabra (si añadimos la forma -dor a la base verbal arma se produce la derivación armador, forma sustantiva con un significado agentivo relacionado al verbo que transformó). Como señalan Velázquez y Ferreiro (2014), el subsistema morfológico de la derivación en español es más extenso que el de la morfología flexiva, aunque en las gramáticas de referencia es este último el que obtiene un mayor tratamiento (RAE/ASALE, 2009). Aun así, la lengua española presenta una morfología extensa y variada, imposible de abarcar por completo en una investigación. Por tales motivos, decidimos trabajar con procesos morfológicos de derivación $\mathrm{y}$, además, seleccionamos solamente algunos morfemas derivativos del español.

Partimos del supuesto de que los niños son capaces de elaborar hipótesis acerca de cómo una palabra escrita puede incorporar varios significados en distintos segmentos y también acerca de cómo se vinculan esos significados. Ferreiro ha señalado en varias oportunidades que en el proceso de adquisición de la lengua escrita los niños tienen que 
pasar de un "saber-hacer con el lenguaje" a un "pensar sobre el lenguaje", y esta "reconversión del lenguaje de un instrumento de acción en un objeto de pensamiento supone grados variables de objetivación y de fragmentación del habla, diferentes de los que operan en la comunicación oral" (2002:167). Durante el proceso de adquisición de la lengua oral los niños ciertamente utilizan los morfemas derivativos en tanto unidades prácticas (Pérez Pereira y Singer, 1984), pero lo hacen como una unidad prácticamente inseparable de las bases léxicas, salvo en esporádicas ocasiones en que son capaces de realizar lo que Gombert (1990) denomina reflexiones epilingüísticas ${ }^{3}$. Es nuevamente la escritura -como en el caso de la construcción de la noción de palabra gráfica- la que ha jugado históricamente un papel importante en la definición de los morfemas como formas libres o ligadas (Alvar y Pottier, 1983), distinción que alude a la posibilidad de que los morfemas puedan "aparecer como palabras independientes" o que vayan "necesariamente adosados a otros morfemas" (Di Tullio, 2005:34).

Por último, señalamos que gran parte de las investigaciones sobre cómo los hablantes reflexionan sobre aspectos morfológicos se han realizado en inglés o en lenguas caracterizadas por una "ortografía profunda" y con tareas que no siempre distinguen claramente el papel que la escritura juega en los diseños (Apel, 2014). El análisis de los datos, además, se realiza mayormente desde una visión dicotómica entre lo correcto y lo incorrecto desde el punto de vista gramatical, y prácticamente no se les solicitan a los sujetos explicaciones o justificaciones de sus respuestas. En nuestra investigación nos hemos propuesto un abordaje diferente del problema: en primer lugar, nos interesamos por una visión procesual de las reflexiones metalingüísticas de los niños sobre los morfemas en las palabras escritas; en segundo lugar, trabajamos sobre el español, que es una lengua tradicionalmente caracterizada con una "ortografía superficial" y para la cual no existen muchos estudios de reflexión metalingüística sobre los morfemas; en tercer lugar, abordamos el estudio de algunos procesos morfológicos de derivación.

\footnotetext{
3 “Activités épilinguistiques: comportements précocement avérés qui s'apparentent aux comportements métalinguistiques mais que no son pas [...] contrôles consciemment par les sujets, d'une maîtrise fonctionnelle de règles d'organisation ou d'usage de langue"' (Gombert, 1990:27).
} 
Nuestras preguntas de investigación son:

- ¿Cuáles son los desafíos conceptuales que enfrentan niños de escolaridad primaria para aislar, comprender y reflexionar sobre algunos morfemas derivativos presentados en palabras escritas?

- ¿Cómo interpretan niños de escolaridad primaria los distintos significados asociados a diversos segmentos de la palabra escrita y cómo explican las relaciones entre estos significados?

- ¿Cómo interpretan los niños de escolaridad primaria los morfemas derivativos cuando están asilados y en relación con las bases léxicas en palabras derivadas?

Tanto el proceso de construcción del problema de investigación como el de las decisiones metodológicas que serán descriptas más adelante se llevó a cabo en permanente interacción con la Dra. Emilia Ferreiro tomando en consideración los resultados que casi al mismo tiempo iba obteniendo Alejandro Velázquez, quien realizó una investigación sobre los procesos de reflexión metalingüística de morfemas flexivos y derivativos con niños mexicanos de escolaridad primaria (Velázquez y Ferreiro, 2015; Velázquez, 2017).

\subsection{Marco teórico-lingüístico}

La gramática tradicional no definió con precisión la unidad palabra ${ }^{4}$, sin embargo estableció que la Morfología se ocuparía de estudiar "la estructura interna de la palabra" (Di Tullio, 2005:33). Si tomamos, por ejemplo, una serie de palabras para comparar como

\footnotetext{
${ }^{4}$ Sobre las dificultades de la lingüística para definir la unidad palabra Béguelin comenta que "[c]ada vez que se intenta extremar un punto de vista y definir el concepto de palabra apelando a un único tipo de pertinencia, aparecen los contraejemplos. Ahora bien, si admitimos, siguiendo a Martinet, 1966, que la palabra no es una noción formal, debe parecernos muy natural que los criterios para identificarla sean múltiples y que en el análisis aparezcan fenómenos de vacilación, de disenso y de superposición. Al ser producto de una construcción no explícita, la palabra [...] es una herencia social. Con todo lo aproximativo y lo arbitrario que esto puede acarrear, el criterio de la demarcación gráfica continúa siendo el más sólido" (2012:38).
} 
pluma, plumas, plumero y cortaplumas, encontramos una forma común pluma que expresa en principio una idea particular ("cada una de las formaciones córneas de que está cubierto el cuerpo de las aves" según el diccionario), mientras que las demás formas parecen agregar otros significados: "más de una pluma", "atado de plumas que sirve para limpiar" o "navaja para cortar plumas". A su vez, las formas que se agregan a pluma pueden aparecer como parte de otras palabras $(-s,-e r o)$ o incluso como palabras en sí mismas (corta). Es decir, "en una sola palabra puede combinarse más de un formante, con un significado y un sonido (o forma fonética) asociados" y esas "unidades mínimas" que se encuentran al analizar la estructura interna de la palabra, y "que constan de forma fonética y de un significado, son denominadas morfemas" (Di Tullio, 2005:33).

Desde el pensamiento gramatical griego hasta fines del siglo XIX la palabra fue considerada como el signo lingüístico mínimo. El lingüista polaco Baudoin de Courtenay, a partir de sus trabajos de lingüística comparativa, acuñó el término morfema para designar "la notion de signe linguistique minimal, ce qui rassemble en une clase tous les éléments infra-lexicaux: racines, radicaux, affixes dérivationnels et désinences flexionnelles" (Kerleroux, 2006:2313). Sin embargo, como señala Stephen R. Anderson, fue el trabajo realizado por el estructuralismo sobre el fonema ("a minimal distinctive element of sound structure") el que sirvió como modelo para el desarrollo posterior del análisis morfológico en la versión tradicional vigente en nuestro días.

"If we assume that words are composed of minimal signs or morphemes [...] the phonemic model can be directly extended to accommodate morphological analysis. We can, that is, treat the morphemes of a language as the distinctive elements of word structure, and regard them as related to their concrete phonemic instantiations in the same way as phonemes are related to phonetic segments" (1995:12).

Varios son los problemas, sin embargo, que los lingüistas (Anderson, 2015; Aronoff y Fudeman, 2011; Pena, 1995 y 2000) señalan a la hora de una definición y clasificación sistemática de los morfemas y de las relaciones morfológicas en diversas lenguas: cómo tratar los casos de morfema-cero o morfema vacío, o las particularidades de la reduplicación o la apofonía, el marcaje acentual, la metátesis o la conversión. Por estos 
motivos, algunos lingüistas como Jesús Pena (1995) proponen partir de la concepción del morfema como una noción compleja y multidimensional que reúne varias propiedades:
a) ser constituyente mórfico del significante de la palabra;
b) tener función distintiva;
c) asociarse a un determinado significado;
d) presentar correspondencia biunívoca entre significante y significado.

Algunas de estas propiedades son más prototípicas que otras: mientras que todo morfema tiene que ser un constituyente mórfico del significante de la palabra muy pocos morfemas presentan una correspondencia biunívoca entre significado y significante. Esta definición multidimensional, sin embargo, permite una clasificación gradual de los morfemas que, según cómo realizan cada uno de los atributos mencionados, serán más o menos representativos del prototipo de unidad morfema en una lengua.

"Para que una unidad gramatical mínima pueda considerarse morfema, la propiedad básica o indispensable será la de ser constituyente mórfico del significante de la palabra como signo [...] y, a partir de ahí, el morfema será gradualmente más regular, más sistemático, productivo, etc., en la medida en que posea más propiedades definitorias del morfema, hasta acercarse al prototipo o ejemplar central, que es el que reúne todas las propiedades" (Pena, 1995:137).

Otras distinciones importantes dentro de la morfología son aquellas relativas a las clasificaciones de los morfemas (considerando distintos criterios lingüísticos). Señalamos algunas de esas definiciones (Pena, 2000) que nos serán de utilidad en la descripción y análisis de nuestros datos. En primer lugar, a partir de criterios semánticos las gramáticas tradicionales distinguen por un lado la morfología léxica que se ocupa del análisis de la estructura de las palabras existentes y de las pautas que permiten construirlas o extraerlas a partir de otras, y por otro lado la morfología flexiva que estudia las variaciones de una misma palabra (RAE/ASALE, 2009). La diferenciación entre raíces y afijos expresa, grosso modo, esta distinción centrada en la significación de las formas morfológicas. Por otra parte, según los morfemas tengan o no autonomía en las construcciones sintácticas podemos distinguir entre morfemas libres y morfemas ligados. Por último, siguiendo un 
criterio distribucional se puede elaborar una clasificación de los morfemas desde el punto de vista de su modo de adjunción. Distinguimos, entre otros, morfemas que: a) preceden la raíz (el prefijo re- en resaltar); b) de aquellos que suceden la raíz (el sufijo -az en vivaz). Estas propiedades permiten diferenciar los procesos de flexión y los de derivación, "o si se prefiere, la flexión de temas de la formación de nuevos temas de palabras" (Pena, 1999:4329). En el Cuadro 1 sintetizamos las características más relevantes de ambos procesos y sus diferencias.

Cuadro 1 - Características y diferencias entre la derivación y la flexión (según Pena, 1999 y Varela Ortega, 2005)

\begin{tabular}{l|l}
\multicolumn{1}{c|}{ Derivación } & \multicolumn{1}{c}{ Flexión } \\
\hline Es menos externa que la flexión (nub-os-os). & Es más externa que la derivación (nub-os-os). \\
\hline $\begin{array}{l}\text { Puede cambiar la categoría gramatical de la } \\
\text { palabra base (nube > nub-os-o). }\end{array}$ & $\begin{array}{l}\text { No puede cambiar la categoría gramatical de } \\
\text { la palabra (nubos-o > nubos-a). }\end{array}$ \\
\hline $\begin{array}{l}\text { Los significados expresados son inherentes al } \\
\text { significado de la palabra, sin relevancia para el }\end{array}$ & $\begin{array}{l}\text { Los significados expresados son contenidos } \\
\text { obligatorios desde el punto de vista del } \\
\text { somponente sintáctico. }\end{array}$ \\
\hline $\begin{array}{l}\text { El significado de las unidades sintácticas. } \\
\text { adquirir significados irregulares hasta llegar a } \\
\text { desaparecer la relación semántica con la }\end{array}$ & $\begin{array}{l}\text { El significado de una forma flexiva es siempre } \\
\text { predecible o regular (instruye > instruyen). }\end{array}$ \\
palabra base de la derivación (instruir > $>$ \\
instrumento).
\end{tabular}

El caso de los morfemas derivativos es interesante en tanto éstos se sitúan en una zona intermedia entre lo léxico y lo gramatical: los parámetros descriptos anteriormente parecen aproximarlos a los morfemas gramaticales, sin embargo al mismo tiempo codifican información léxica. Jesús Pena propone denominarlos "morfemas léxicos gramaticalizados" por constituir

"la primera gramaticalización del léxico, ya que funcionarían como la categorización o clasificación primaria de los significados léxicos. Su peculiaridad consistiría en codificar mediante un significante propio, individualizado y recurrente determinados contenidos o parcelas del contenido léxico" (1999:4324). 
En este trabajo de tesis utilizaremos una dicotomía construida a partir de los términos teóricos provistos por la lingüística, de modo tal de facilitar la exposición y la lectura de los datos. Hablaremos entonces de bases léxicas frente a morfemas derivativos, teniendo en cuenta las siguientes aclaraciones:

- que tanto las bases léxicas como los afijos derivativos son morfemas;

- que en nuestro diseño de investigación trabajamos tanto con bases léxicas monomorfémicas como plurimorfémicas (lo que hace que en algunas bases léxicas incluyan algún morfema derivativo, pero como parte de una base que puede recibir nuevamente un proceso de derivación: por ejemplo la base léxica marino que puede derivarse nuevamente en submarino);

- que las bases léxicas son en todos los casos formas libres mientras que los morfemas derivativos no lo son (y esto tanto desde el punto de vista sintáctico como también siguiendo criterios propios de la escritura, es decir, las formas libres se pueden escribir separadas mientras que las formas ligadas siempre forman parte de una palabra gráfica);

- que las bases léxicas siempre tienen un significado completo mientras que los morfemas derivativos categorizan información léxica pero no tienen un significado en sí mismos.

En el Cuadro 2 destacamos las características fundamentales de la dicotomía terminológica que utilizaremos.

\section{Cuadro 2 - Dicotomía terminológica utilizada en la tesis}

\begin{tabular}{l|l}
\multicolumn{1}{c|}{ Bases léxicas } & \multicolumn{2}{c}{ Morfemas derivativos } \\
\hline $\begin{array}{l}\text { - Tienen un significado léxico completo y } \\
\text { autónomo. }\end{array}$ & $\begin{array}{l}\text { - Categorizan información léxica pero no } \\
\text { tienen un significado léxico completo y } \\
\text { autónomo. } \\
\text { - Son siempre formas sintácticas y escritas } \\
\text { libres. }\end{array}$ \\
$\begin{array}{l}\text { Son formas ligadas y no pueden aparecer } \\
\text { nunca como formas libres en la escritura. }\end{array}$
\end{tabular}




\subsection{Antecedentes psicolingüísticos en otras lenguas y sistemas de escritura}

La mayor parte de las investigaciones psicolingüísticas que indagan sobre los conocimientos morfológicos de los hablantes de una lengua toman como marco de referencia los estudios de la llamada conciencia lingüística (linguistic awareness) y, además, se han realizado principalmente en lenguas con deep orthography como el inglés o el francés. Estas investigaciones se basan en los siguientes postulados:

- La ortografía del inglés es morfofonémica (Chomsky y Halle, 1968) y está fundada en representaciones léxicas profundas que forman parte del conocimiento de los hablantes de esa lengua 5 .

- Para todos los hablantes de una lengua el "léxico mental adulto" está organizado morfológicamente (Kuo y Anderson, 2006).

- Para aprender a leer primero se pasa por una etapa alfabética basada en un principio fonético (a cada grafema se asigna un fonema) y sólo en un estadio ulterior se llega a una etapa ortográfica en la que los sujetos comprenden otros aspectos de la escritura de su lengua, entre ellos los morfológicos (Ehri, 1997; Frith, 1985; Nunes, Bryant y Bindman, 1997).

El interés práctico de estas investigaciones radica en las correlaciones encontradas con el nivel de habilidad lectora, tanto en lo que concierne a la decodificación de las palabras como en lo que respecta a la búsqueda de un indicador de las implicancias sintácticas en la comprensión lectora (Bryant, Nunes y Bindman, 1997 y 2000; Carlisle, 2003; Deacon y Bryant, 2006; Deacon, Kirby y Bell-Casselman, 2009; Kemp y Bryant, 2003; Wolter, Wood y D'zatko, 2009, entre otros). En el caso de la lengua española, considerada tradicionalmente como una lengua de ortografía superficial por acerarse al ideal una letra-

\footnotetext{
${ }^{5}$ Al respecto Zamudio realiza observaciones interesantes al sostener que "[...] estos estudios toman como modelo las palabras ortográficas para crear las representaciones léxicas de su teoría y vuelven después sobre ellas, para presentarlas como evidencia de las representaciones supuestas". Agrega además que "[...] al identificar las representaciones ortográficas con las representaciones léxicas que se adquieren vía la escucha, convierten las palabras de la escritura inglesa contemporánea en representaciones lingüísticas y psicológicas anteriores a esa, negando así la condición histórica de la ortografía inglesa" (2010:49).
} 
un sonido (RAE/ASALE, 2010), los estudios sobre el conocimiento morfológico de los hablantes son escasos (Defior, Alegría, Titos y Martos, 2008; Domínguez, Cuetos y Seguí, 2000; González Sánchez, Rodríguez Pérez y Gázquez Linares, 2011) y consisten en variaciones de los diseños experimentalistas predominantes en lengua inglesa.

El rango de edad predominante de los niños en estos estudios es de 6 a 10 años. Además, en la mayoría de ellos, con el objeto de establecer correlaciones con las tareas propuestas se utilizan otros tipos de indicadores tales como conciencia fonológica, coeficiente intelectual, conocimiento de vocabulario o memoria verbal de corto plazo.

En cuanto a lo metodológico, se utilizan mayormente tareas acotadas que, como señala Kenn Apel, atienden solo a algún aspecto puntual de lo morfológico en el lenguaje, además de no distinguir claramente entre el uso de la lengua oral y de la lengua escrita, o en todo caso de $\operatorname{ambas}^{6}$ (2014). Existe consenso entre los investigadores sobre el hecho de que los niños tienen "conciencia morfológica" sobre los aspectos flexivos (Kuo y Anderson, 2006) antes que sobre los aspectos derivativos de la lengua (caracterizados generalmente como más diversos y menos productivos que los anteriores). A continuación describiremos los antecedentes más destacados de las investigaciones que se inscriben en la llamada "conciencia morfológica" y que abordan específicamente aspectos relativos a los procesos de derivación o a los morfemas derivativos, en distintas lenguas y en distintos sistemas de escritura.

En uno de sus trabajos iniciales sobre la morfología derivativa en inglés, Tyler y Nagy (1985) se preguntan acerca de cómo la información sintáctica propia de los sufijos derivativos es recuperada en la comprensión de oraciones. Sostienen que en la lengua escrita los morfemas derivativos otorgan pistas (clues) esenciales para compensar rasgos de la comunicación oral que no son representados en lo escrito (por ejemplo los aspectos

\footnotetext{
${ }^{6}$ Si bien Kenn Apel no tematiza ni reflexiona en torno a las relaciones entre la lengua oral y la escritura (como gran parte de los investigadores experimentalistas), sí aborda el problema de las diversas definiciones de morphological awareness. Apel sostiene que "the term 'morphological awareness' implies an awareness of these small units of meaning. Given that morphemes occurs in spoken and written language, morphological awareness necessarily involves an awareness of both spoken and written morphemes, including an understanding of what written affixes [...] look like orthographically. [...] Unfortunately, current definitions used by researchers and authors come up short in defining morphological awareness at this level of detail" (2014:198).
} 
prosódicos) y que la morfología derivativa del inglés es "compleja y opaca" (y por lo tanto difícil de aprender) ${ }^{7}$. Trabajan con más de cien adolescentes estadounidenses de los grados $10^{\text {mo }}$ y $11^{\text {no }}$ (no hay precisión sobre las edades) y, además de un test inicial sobre vocabulario, los niños realizan dos tareas centradas en los morfemas derivativos: a) en la primera leen oraciones con pares de palabras contrastantes en cuanto a los afijos derivativos (deceptive/deception) y eligen entre opciones de paráfrasis que las explican; b) la segunda es una tarea de completamiento (fill-in-the-blank o cloze task) en la que eligen entre cuatro opciones para completar una oración, en todos los casos las cuatro opciones corresponden a palabras con la misma raíz pero con morfemas diferentes (analytic, analytical, analyze y analysis). Uno de los problemas centrales de estas tareas (y una problemática persistente a lo largo de todas las investigaciones) es cómo "controlar" el conocimiento específico que los sujetos tienen sobre una palabra como una totalidad en sí, de modo tal de poder garantizar que la tarea permita dar cuenta del análisis de la estructura interna de la palabra (es decir, analizar por ejemplo el significado de la palabra submarino como producto del análisis del proceso de derivación que implica agregar el prefijo sub- a la base léxica marino y no simplemente por conocer el significado de la palabra submarino como una totalidad). Para controlar esta variable incluyen en su diseño oraciones en las que los niños eligen entre pseudopalabras elaboradas a partir de raíces inexistentes pero que no infringen las reglas combinatorias de la lengua más un morfema convencional. De esta forma intentan que los sujetos se centren en las diferencias léxicas y sintácticas propias de los morfemas. Todas las tareas son analizadas en términos dicotómicos (correcto o incorrecto). Sus resultados muestran una correlación entre los "buenos lectores" y el uso de la información sintáctica de los morfemas derivativos, aunque señalan que persisten ciertas dificultades para poder interpretar esta información sintáctica de los morfemas ("when combined with difficult syntax, derivational suffixes are a problem rather than a help, specially to lower ability students", 1985:52).

\footnotetext{
${ }^{7}$ Al respecto sostienen: "[...] much in English derivational morphology is complex and opaque, and thus difficult to learn. To a large degree, this is due to the fact that derivational suffixes in English do not have one-to-one semantic and syntactic relationships. This suggests that speakers will acquire derivational morphology relatively late and that they may vary widely in their mastery and use of morphology, particularly in their use of suffixal information which is most variable" (Tyler y Nagy, 1985:9).
} 
En un estudio posterior (1987) solicitan a niños estadounidenses de $4^{\text {to }}, 6^{\text {to }}$ y $8^{\text {vo }}$ grado escolar la realización de tareas de multiple choice tratando de dar cuenta de tres aspectos distintos de los morfemas derivativos: conocimiento léxico (reconocer que mar y marino comparten morfemas); conocimiento sintáctico (cambios categoriales que introducen los morfemas derivativos); y conocimiento distribucional (qué morfema selecciona cada base para la derivación). En sus conclusiones destacan que estos conocimientos se adquieren en distintos momentos del desarrollo de los niños.

Por otro lado, Nagy, Diakidoy y Anderson (1991) postulan distintos niveles de conocimiento sobre la estructura interna de las palabras (particularmente en cuanto a la morfología derivativa):

i) El reconocimiento de relaciones morfológicas entre distintas palabras (thanks en Thanksgiving);

ii) La capacidad de distinguir entre raíces y pseudo-raíces (agree en agreement, pero no sea en season);

iii) El conocimiento individual de las partes de la palabra (prefijos, raíces y sufijos de una lengua)

iv) El conocimiento de la estructura interna de la palabra y de sus relaciones morfológicas.

En su investigación, además de una tarea de multiple choice en la que los niños eligen entre distintas oraciones escritas cuál utiliza correctamente una palabra derivada, incluyen una tarea de discriminación de raíces (stem discrimination test) en la que solicitan encerrar con un círculo las raíces dentro de las palabras y evitar hacerlo cuando solamente se trata de una palabra que comparte letras pero no morfemas con otra (por ejemplo fat en father). Los autores señalan que aún los niños de grados más avanzados en su estudio (high school) mostraron una tendencia a encontrar "little words in big words" (1991:16), es decir, a encerrar en un círculo tanto las raíces dentro de la palabras como series de letras que pueden constituir otra palabra no relacionada morfológicamente. 
Interesados en conocer las correlaciones entre la comprensión lectora y el conocimiento sobre los morfemas, Singson, Mahony y Mann (2000) realizan con niños de 8 a 11 años un test de comprensión de lectura, un test de inteligencia y un test de sufijos derivativos, adaptado del cloze task descripto anteriormente. Seleccionan el rango de edad de los niños teniendo en cuenta que tanto las teorías de adquisición de la escritura (Henderson, 1985) como las del desarrollo del vocabulario que utilizan (Anglin, 1993) indican que es entre los grados $3^{\text {ro }}$ y $5^{\text {to }}$ en que los conocimientos morfológicos empiezan a jugar un rol demostrable en la escritura y la lectura de los niños. En sus resultados indican que estos conocimientos contribuyen como un indicador en sí mismo a la comprensión lectora, aunque en una magnitud pequeña que se acrecienta con la edad.

Otro tema que han abordado las investigaciones en lengua inglesa es el de las relaciones entre el conocimiento de la estructura de las palabras y la comprensión de las llamadas "palabras complejas" (es decir, multimorfémicas en este caso por tratarse de formación de palabras a través de procesos de derivación). Carlisle (2000) solicita a niños de $3^{\text {ro }}$ y $5^{\text {to }}$ la realización de dos tareas: a) un test de lectura de palabras con derivaciones transparentes y con cambios (shifts) tanto fonológicos como ortográficos, tarea en la que los niños reciben puntuación si leen el ítem en menos de 2 segundos o si lo hacen sin vacilaciones o correcciones; b) un test escrito (test of morphological structure) en el que los niños deben completar oraciones en un caso derivando una palabra (farm $\rightarrow$ farmer) o mediante el proceso inverso de "descomponer" una forma ya derivada (improvement $\rightarrow$ improve). Además, los niños realizan un test sobre conocimiento de vocabulario en el que la entrevistadora solicita que definan una palabra derivada y que den un ejemplo de uso. Los resultados muestran una correlación significativa entre los puntajes obtenidos en las tareas y la capacidad de definir las palabras complejas, es decir palabras multimorfémicas que provienen de procesos de derivación. Carlisle señala que los niños tuvieron más dificultades para producir que para descomponer estas formas derivadas.

Deacon y Bryant (2005) interesados en la relación entre el conocimiento morfológico y la escritura (spelling) en palabras derivadas del inglés solicitan a niños de 7 a 9 años de escuelas públicas británicas una tarea de escritura de palabras para completar 
oraciones que alterna dos variantes por cada ítem: en un caso (clue condition) la palabraobjeto también es a su vez parte de la oración bajo otra de sus formas (object $\rightarrow$ objection); en el otro caso (no clue condition) la palabra-objeto que deben escribir no está presente en la oración. Además, en las palabras-objeto distinguen aquellos casos de derivación transparente (ill $\rightarrow$ illness) de aquellos en los que la derivación produce cambios fonológicos y por lo tanto la relación entre ambas formas es opaca (sign $\rightarrow$ signal). Los resultados muestran que aún los niños más pequeños pueden usar sus conocimientos morfológicos sobre las raíces para escribir palabras derivadas, inclusive en los ítems con cambios fonológicos. Una pregunta interesante que se hacen es ¿cómo es que los niños se dan cuenta de que los morfemas están representados en la escritura? ${ }^{8}$ Plantean tres posibilidades:

i) que los niños tengan conciencia de los morfemas en la lengua oral;

ii) que la exposición a la escritura (exposure to the orthography) provoque que los niños relacionen (match) el lenguaje que escuchan con las escrituras que ven;

iii) que los niños trasladen las hipótesis que tienen sobre la lengua oral a la escritura de las palabras derivadas: "Even before they have learned to read or write, they may already have the idea that written language represents the units, include morphemic ones, used in oral languages" (2005:387).

Deacon y Bryant (2006b) comparan cómo niños de 7 a 9 años de escuelas públicas británicas escriben palabras con flexión o derivación que comparten sonidos con otras palabras monomorfémicas (messily / message). Nuevamente sus resultados indican que la escritura de las secuencias iguales en los pares de palabras fue siempre mejor cuando en el ítem se puede reconocer una raíz.

En un estudio reciente Apel y Henbest (2016) indagan acerca de las correlaciones entre el conocimiento del significado de los afijos derivativos y la comprensión lectora. Elaboran una tarea oral y escrita en la que solicitan a niños estadounidenses de 6 a 9 años

8 "The origin of children's knowledge is another important question: How is that children come to realise that morphemes are represented in the orthography" (Deacon y Bryant, 2005:386). 
(que asisten a escuelas públicas) que a partir del significado inventado de una pseudopalabra elijan entre cuatro opciones con derivaciones -también inventadas- a partir del uso de morfemas existentes en la lengua. En sus resultados dan cuenta de una correlación entre el conocimiento del significado de los afijos derivativos y la comprensión de las palabras complejas (aunque en realidad se trata de pseudopalabras).

Colé y otros (2012) abordan para el caso del francés la relación entre el conocimiento morfológico y la decodificación de palabras complejas. Trabajan con niños franceses de 7 y 8 años en dos tareas basadas en pseudopalabras (que además incluyen pseudo-sufijos) y palabras poco frecuentes. En ambas tareas un programa de computadora graba y mide el tiempo que los niños emplean en reconocer y leer en voz alta cada ítem. En sus resultados reportan que los niños franceses son sensibles a las unidades morfológicas en palabras derivadas que nunca han leído (porque son inexistentes) o que son infrecuentes en la lengua oral. También en lengua francesa Fejzo (2016) presenta a niños francófonos de 8 y 9 que asisten a escuelas públicas canadienses tareas de escritura de formas derivadas o de formas a partir de derivados, incluyendo pseudopalabras derivadas. En todos los casos se trata de completamiento de oraciones. En sus resultados destaca que los niños enfrentaron grandes dificultades para escribir los morfemas-meta de su diseño (sobre todo con prefijos y bases), y esto lo atribuye a los rendimientos por debajo del promedio en los test de "conciencia fonológica" y lectura de palabras que completaban su diseño. Destacamos que en la discusión de sus datos reaparece un problema persistente en la bibliografía reseñada: saber cuáles son las causas del acrecentamiento en la posibilidad de reflexionar sobre los aspectos morfológicos de la lengua (o del acrecentamiento de la "conciencia morfológica" en los términos en los que estas investigaciones lo plantean). Al respecto, Fejzo sostiene que se trataría de "a circular causality relationship [...] increasing experience with written language serves as a catalyst for the development of metalinguistic capacities [...], this causality suggest that morphological awareness on his turn, helps to improve the spelling abilities" (2016:222). La circularidad de su conclusión es explícita. 
A diferencia del inglés y el francés, que son lenguas con ortografías profundas, el griego es considerado una lengua transparente que, sin embargo, cuenta con varias alternativas gráficas para la escritura de algunas vocales. En algunos casos, las decisiones sobre el grafema correcto en la escritura de las vocales están guiadas por razones morfológicas. Diamanti y otros (2014) estudian cómo niños griegos de 8 a 13 escriben las vocales en palabras con procesos de flexión y derivación en las que el conocimiento del afijo es el que garantizaría el uso del grafema ortográficamente correcto. El diseño incluye tareas de escritura de palabras (pares sustantivo-adjetivo) y de oraciones con palabras. En sus resultados destacan que los niños enfrentaron las mayores dificultades a la hora de escribir correctamente los afijos derivativos (antes que los flexivos o las raíces). Por eso sugieren que a nivel escolar es necesaria una "enseñanza sistemática y explícita" de la escritura de los afijos derivativos. En un estudio anterior, Chliounaki y Bryant (2003) ya habían abordado el problema de la escritura de vocales en afijos derivativos en griego y habían retomado la idea de un estadio fonológico inicial en la escritura de los niños, antes de alcanzar una comprensión de lo morfológico: "children tend to learn about the basic grapheme-phoneme correspondences in their script before they begin to tackle the links between morphology and spelling" (2003:41).

El portugués es una de las lenguas romances caracterizada por una "ortografía superficial". Da Mota (2008a y 2008b) realiza con niños de $1^{\circ}$ y $2^{\circ}$ grado una serie de tareas sobre morfología derivativa inspiradas en las investigaciones de morphological awareness: a) una tarea de decisión morfosemántica (similar a las judgment task de la bibliografía en inglés) en la que se presenta a los niños una serie de palabras que incluyen dos palabras derivadas (descolorir y destorcer) y una palabra que comparte letras pero no morfemas con las demás (deslizar) y se les pide que elijan las que se parecen; b) una tarea de asociación morfo-semántica en la que se pide a los niños que indiquen entre pares de palabras cuáles están vinculados morfológicamente y cuáles sólo comparten letras (pedra/pedreiro frente a panda/pandeiro); c) una tarea de analogía gramatical (analogy task también utilizada en las investigaciones en inglés). Las consignas y los ejemplos descriptos son orales, aunque no se indica si los niños cuentan con los ítems por escrito a 
la hora de resolver las tareas. En sus aportes resalta la controversia acerca del procesamiento "implícito o explícito" de los morfemas y a partir de sus resultados afirma que "a habilidade de refletir sobre os morfemas que compõe as palavras se desenvolve ao longo dos primeiros anos de escolarização. Estes resultados indicam também, que [...] desde a primeira série esta habilidade está presente, ainda que de forma rudimentar" (2008a:121).

El caso del hebreo es interesante porque representa un terreno distinto al de las lenguas alfabéticas antes reseñadas. Las investigaciones psicolingüísticas (Levin, Ravid y Rapaport, 2001; Ravid y Schiff, 2006; Vaknin-Nusbaum, Sarid y Shimron, 2016, entre otras) la presentan como una lengua propicia para los estudios de morphological awareness ya que, por un lado, se trata de una lengua sintética con una alta densidad morfológica en cuanto a su estructura lingüística, y por otro lado, su sistema de escritura refleja de una forma más directa esa infraestructura morfológica de la lengua oral ${ }^{9}$. En particular, los autores destacan que además de los casos de morfología lineal como los ejemplos citados en otras lenguas (es decir, la adición concatenativa de un afijo a una raíz, por ejemplo en hebreo kadur 'pelota' + im 'sufijo de plural' forma kadurim 'pelotas') la morfología hebrea presenta numerosos casos de formación de palabras no lineal. Desde el punto de vista lingüístico, se trata de una raíz consonántica (root) en la que se "incrustan" distintos patrones (pattern) vocálicos formando así series discontinuas en cuanto a la información morfológica. Por ejemplo, la raíz $s-x-k$ que significa 'jugar' se combina con el patrón verbal $\mathrm{CiCeC}^{10}$ para formar sixek 'jugó', con el patrón nominal miCCaC para formar misxak 'juego' o con el patrón agentivo CaCCan que forma saxkan 'jugador'. Sin embargo, teniendo en cuenta que las vocales son indicadas con diacríticos para los lectores iniciales, Ravid y Schiff sostienen que "while spoken roots and patterns are discontinuous, abstract,

\footnotetext{
9 "Hebrew, as a Semitic writing system, represents morphemes of the spoken language in a clear, concrete and distinguishable manner. This may be explained in that the consonantal root appears in writing as a fixed letter cluster while the vowels, when expressed by diacritics, are generally placed above and below the root letters, in contrast to being inserted in between root's consonants. So the Hebrew writing system, while having complicated and rich morphological structures, is from another perspective morphologically more transparent than it is in other languages" (Vaknin-Nusbam, Sarid y Shimron, 2016:232).

10 En la descripción de los patrones la letra " $C$ " indica que va la consonante de la raíz y las vocales en minúscula indican el patrón derivativo.
} 
intertwined entities, written Hebrew guides its writers/readers towards a more concrete and discrete perception of morphemes" (2006:793). Interesados en las correlaciones entre el desempeño en tares de conocimiento morfológico y la comprensión lectora Vaknin-Nusbam, Sarid y Shimron (2016) trabajan con niños de $2^{\circ}$ grado (que leen textos con diacríticos) y de $5^{\circ}$ grado (que ya no leen en la escuela textos con diacríticos) de escuelas públicas del norte de Israel. Solicitan tres tareas de lectura que consisten en elegir la forma que no corresponde a la familia en una serie de palabras, elegir entre un conjunto de derivaciones la forma correcta de infinitivo para una palabra, e identificar determinadas flexiones o derivaciones entre un conjunto de formas de una misma palabra. En sus resultados, los autores destacan que no encontraron diferencias entre el desempeño de los niños de $2^{\circ}$ y de $5^{\circ}$ grado. Para explicar estos resultados los autores sugieren que el papel del sistema de escritura hebreo podría ser determinante ya que al representar las raíces morfémicas como conjuntos fijos de letras (fixed clusters of letters) facilitaría su lectura (decoding) aún para los niños más pequeños ${ }^{11}$.

Por último, haremos referencia a un estudio en una lengua cuya escritura no es alfabética, como es el caso del chino. Se trata de un sistema de escritura radicalmente distinto a los reseñados anteriormente en el que, además, cada carácter generalmente representa un morfema y con estos caracteres se construyen a su vez palabras complejas (Ku y Anderson, 2003). En un estudio reciente Zhang (2014) solicita a niños chinos de 7 años la realización de tareas con material escrito entre las que destacamos: i) una tarea de reconocimiento de morfemas en la que los niños tienen que indicar si una raíz y una forma derivada están relacionadas semánticamente; ii) una tarea de discriminación de morfemas en la que se les presenta a los niños una serie de tres palabras que comparten un carácter que solamente en dos casos es un morfema derivativo. Las correlaciones entre el

\footnotetext{
${ }^{11}$ La cita completa es: "One possible explanation for the absence of differences in this regard may be associated with the morphological transparency of the Hebrew writing system, which, perhaps, facilitates morphological decoding even for very young readers. In this system, vowels, if indicated, are usually represented by diacritic above and/or below the written word, leaving the consonantal letter sequence of the root morpheme as a fixed cluster of letters, standing in the same order. [...] it may be the advantage derived from morphological transparency is already influential in $2^{\text {nd }}$ grade. As reading fluency improve, this transparency makes it possible to use morphological units as a bridge between the written word and their meanings in the mental lexicon" (Vaknin-Nusbam, Sarid y Shimron, 2016:239). [El resaltado es nuestro]
} 
desempeño en estas tareas y otros test específicos sobre habilidades de inferencia léxica y conocimiento de vocabulario lo llevan a postular que también en el caso del chino la habilidad de segmentar y extraer información morfológica parcial de las palabras incide en el desarrollo de la comprensión lectora y del vocabulario de los niños.

El antecedente inmediato de nuestra investigación es la tesis doctoral de Alejandro Velázquez (2017) sobre reflexión morfológica de niños en escolaridad primaria. No solamente porque aborda la lengua española, sino también por el marco teóricometodológico utilizado. Velázquez presenta a parejas de niños de 7, 9 y 11 años, tareas con materiales escritos que consisten en: i) alargar sobre secuencias gráficas verbales; ii) alargar sobre morfemas libres y ligados; iii) acortar palabras gráficas; iv) contrastar sustantivos con bases compartidas; y v) contrastar formas de un mismo verbo. Además de solicitar a los niños que realicen distintas acciones en las tareas, en todos los casos pide justificaciones sobre las respuestas que elaboran. Entre sus conclusiones destacamos: la relevancia que los niños dan a las palabras gráficas y a las bases léxicas sobre los afijos, el tratamiento diferenciado que dan a los morfemas flexivos y a los derivativos ya que los primeros no son justificables cuando están separados de la palabra gráfica, y las dificultades que presentan los casos de polisemia y de sinonimia.

\subsection{Consideraciones metodológicas sobre el diseño de investigación}

Con la expectativa de obtener nuevos datos sobre las reflexiones metalingüísticas que involucran procesos morfológicos nos propusimos un abordaje metodológico diferente, que no estuviera solamente centrado en la realización de tareas acotadas y cuyas respuestas fueran tratadas en términos dicotómicos (correcto vs. incorrecto). Para

ello, consideramos central proponer a los niños tareas que involucraran material escrito (y acciones sobre el material escrito) y principalmente solicitar explicaciones y justificaciones de sus respuestas. Además, decidimos trabajar con parejas de niños y no de forma individual que es la modalidad predominante en las investigaciones reseñadas. Se trata, 
en todos los casos, de decisiones metodológicas fundadas en un marco epistémico que impactan directamente en la construcción y el análisis de los datos. En este apartado comentaremos estas variables y sus implicancias en nuestro diseño de investigación.

Las tareas propuestas a los niños (que describiremos respectivamente en cada capítulo) se integran en entrevistas flexibles, inspiradas en las entrevistas clínico-críticas de origen piagetiano y que han sido utilizadas extensivamente por Ferreiro en sus investigaciones. En estas entrevistas los niños tienen la posibilidad de resolver las tareas pero también de elaborar explicaciones verbales sobre lo que piensan, siempre y cuando el entrevistador logre instalar un verdadero "diálogo intelectual"12. Nos proponemos comprender las razones de las dificultades que los niños enfrentan al reflexionar sobre algunos procesos morfológicos de derivación de su lengua, superando un abordaje que solamente dé cuenta de qué es lo que pueden y lo que no pueden hacer. En principio, esto constituye una aproximación diferente al problema ya que, como vimos en los antecedentes comentados, en distintas investigaciones los niños reciben evaluaciones o puntuaciones por sus respuestas pero prácticamente en ningún caso son consultados o se les solicita explicación de las razones que los llevan a resolver de tal o cual manera las tareas. Se trata, entonces, de una "entrevista en contexto de acción" en la que diseñamos situaciones que plantean problemas y

"los niños entrevistados realizan acciones y producen verbalizaciones que nos permiten acercarnos a sus modos de pensar. Las acciones y verbalizaciones son el resultado de la situación que están resolviendo, del diálogo con el entrevistador y del diálogo entre los niños que componen la pareja entrevistada" (Kriscautzky y Ferreiro, 2018:20).

Los fundamentos por los cuales consideramos imprescindible dialogar con los niños son de distinto orden: en primer lugar son argumentos prácticos, ya que al solicitar tareas difíciles para los niños se impone la necesidad de sostener y acompañar sus

\footnotetext{
${ }^{12}$ En un texto en el que reflexiona sobre las implicancias de concebir al niño como un posible interlocutor intelectual del adulto (posibilidad poco explorada por gran parte de las investigaciones psicolingüísticas evolutivas) Ferreiro sostiene que en las entrevistas clínico-críticas "[e]l adulto que interroga ya no es quien sabe sino quien quiere saber. Este cambio de posición no puede anular, por supuesto, las relaciones de poder entre el adulto y el niño. Sin embargo, cuando el interés del adulto es legítimo, el diálogo intelectual puede instalarse" (Ferreiro, 1999b:28)
} 
esfuerzos cognitivos con el propósito de que todos puedan dar el máximo; además son teóricos porque sostenemos que los niños piensan sobre la realidad y sobre la lengua (que en el caso de la lengua escrita es también un objeto del mundo sobre el que las sociedades realizan diversas prácticas) y creemos que ellos pueden ayudarnos a interpretar lo que hacen; y por último también hay razones epistemológicas, porque retomando lo planteado por Piaget, consideramos que la objetividad no es un dato de partida sino un dato de llegada que está dado por los esquemas interpretativos del sujeto, y por ende, cuanto más desarrollados son (lo que implica una mayor actividad del sujeto) mejor es la comprensión del objeto.

Todas las tareas de nuestro diseño, además, involucran el uso de material escrito lo que da a los niños la posibilidad de realizar acciones sobre estos materiales: los niños juegan a alargar palabras con fichas que tienen escrituras, a acortar palabras con tijeras en fichas de cartulina o a contrastar palabras imantadas en tiras con sintagmas escritos (ver descripción destallada en cada capítulo). Esto permite a los niños ensayar soluciones y contrastar alternativas antes de proponer lo que cada uno considera como la respuesta final a una tarea. Como señalan Baez y Ferreiro

"[e]n las investigaciones sobre la comprensión del lenguaje (oral o escrito) es deseable que el dato a ser analizado no sea homogéneo con el objeto de indagación. Dicho de otra manera, que la comprensión se muestre en acto y no únicamente a través de verbalizaciones" (2013:258).

Por otro lado, utilizamos material escrito porque nos proponemos explícitamente reflexionar en torno al papel que la escritura juega en la determinación de las unidades y las relaciones morfológicas. En la mayoría de las investigaciones esta problemática no está tematizada, y en muchos casos se trata explícitamente a la lengua escrita como una transcripción de la oralidad en la que los sujetos en proceso de adquisición de la escritura reencuentran unidades preexistentes como representaciones psicológicas en el léxico mental. Enfatizamos tanto el papel que juega la escritura en la reflexión metalingüística (Lara, 2012 y Olson, 1994) como la concepción de la lengua escrita como un sistema de 
representación (Blanche-Benveniste, 2002) que redefine las unidades de la lengua en un nuevo nivel de conceptualización del objeto ${ }^{13}$.

Otra variable en nuestro diseño fue entrevistar a los niños en parejas. Además de que la participación simultánea de dos niños en una misma tarea posibilita en principio la aparición de respuestas diversas (discordantes, con algunas variaciones o francamente opuestas) lo que en principio es ya un estímulo para la discusión, Ferreiro señala que:

"El uso de parejas es un recurso metodológico que permite a los niños explicitar con más pertinencia las razones que justifican una cierta decisión, ya que explicarle a un compañero -sobre todo cuando éste no comparte la misma opinión- tiene mucho más sentido que explicarle a un adulto que supuestamente 'ya sabe'” (2013:10).

Entrevistamos en todos los casos parejas conformadas por un niño y una niña del mismo grado escolar por razones de orden práctico, ya que esta conformación permitía que las diferencias marcadas entre los timbres de voz facilitaran el reconocimiento de los turnos de habla al momento de la transcripción.

Por enfocar nuestro trabajo desde una perspectiva evolutiva realizamos entrevistas con niños de distintas edades. Decidimos no entrevistar niños de primer grado ya que existía la posibilidad de que algunos niños no pudieran leer autónomamente el material escrito o que la lectura les demandara demasiado esfuerzo. El hecho de tener que leer varios ítems escritos y además realizar acciones con estos materiales y justificarlas podría haberse tornado una tarea excesivamente demandante aún para niños de primer grado que pudieran leer por sí mismos. Por estas razones, decidimos que el punto de partida serían los niños de $2^{\circ}$ grado. Por otro lado, cuando hablamos de lo evolutivo hacemos referencia a un continuo en el que introducimos cortes para poder entender el proceso que implica el desarrollo. Interrogamos entonces niños de grados escolares no continuos

\footnotetext{
${ }^{13}$ El planteo de este problema en palabra de Ferreiro: “Es preciso desvincularse de una visión ontológica según la cual hay 'cosas' (en sentido absoluto) y 'signos' (también en un sentido absoluto). Es mucho más adecuada la noción piagetiana de sistemas jerárquicos que se constituyen sobre la base de otros, en donde las unidades de un nivel no se transforman necesariamente en las unidades del otro nivel. De hecho, las unidades se redefinen en cada nivel. No se trata, entonces, de una cadena de símbolos que se sustituyen mutuamente (símbolos orales sustituidos por símbolos escritos). Se trata de otro nivel de organización. Para la escritura, el lenguaje es objeto $a$ otro nivel, y esto supone que las unidades de la escritura no están predeterminadas por el habla, sino que deben ser redefinidas" (Ferreiro, 1999a:70).
} 
$\left(2^{\circ}, 4^{\circ}\right.$ y $6^{\circ}$ grado) con la expectativa que estos cortes nos permitirían encontrar mayores diferencias de desarrollo y así trazar distintos momentos de comprensión de aspectos morfológicos en el continuo evolutivo de los niños.

Teniendo en cuenta que uno de nuestros propósitos es comprender cómo los niños interpretan los distintos significados que integran una palabra derivada y cómo interpretan los morfemas derivativos cuando están asilados, otra decisión metodológica relevante fue usar palabras aisladas en nuestras tareas. En las investigaciones comentadas, sobre todo aquellas que indagan las implicancias sintácticas de los morfemas en la comprensión lectora, se impone el uso de palabras en contextos oracionales o textuales. En nuestro caso, decidimos prescindir de las pistas que un texto puede sugerir para explorar las interpretaciones infantiles y los contextos o ejemplos que los mismos niños podían restituir para las distintas palabras del diseño. Velázquez y Ferreiro también argumentan al respecto del uso de palabras aisladas afirmando que:

"Sin duda, el texto hace más evidentes las diferencias sintácticas en las palabras modificadas, pero su desventaja consiste en imponer, o al menos sugerir, una única interpretación, lo que quisimos evitar. Con las palabras aisladas, los niños nos hicieron evidentes interpretaciones plausibles no previstas en el diseño. Actualizaron contextos de uso que un único texto hubiera limitado" (2015:72).

Al respecto de la decisión de trabajar con palabras también se plantea una problemática persistente en la bibliografía del tema y es aquella relativa a la necesidad de controlar la variable del conocimiento léxico a través de la utilización de pseudopalabras en las tareas. Como señala Ferreiro (2012) el hecho de incluirlas implica ya una decisión al respecto de lo que es la lengua o la lectura ${ }^{14}$. En el caso de los estudios de morphological awareness hemos reseñado un uso extensivo de pseudopalabras que se forman con una

\footnotetext{
14 "Los investigadores experimentales se dan amplios márgenes de libertad para inventar pseudopalabras a fin de controlar tal o cual variable. Las pseudopalabras son aquellas que podrían existir porque no violan las reglas combinatorias propias de una lengua en cuestión (por ejemplo, tramidad es un buen candidato a sustantivo en español, similar a bondad, fealdad y otros, pero no existe en ningún diccionario). Cuando se determina el nivel de lectura de niños o adultos presentando listas de pseudopalabras, ya se está tomando una decisión acerca de lo que es leer. En efecto, los sujetos no pueden atribuir ningún significado a las pseudopalabras porque son presentadas dentro de listas, fuera de algún contexto que les permitiría elaborar una significación tentativa. En tales diseños, los 'buenos lectores' son buenos decodificadores y nada más" (Ferreiro, 2012:250).
} 
raíz inventada pero que no viola las reglas combinatorias de la lengua más un afijo real de esa misma lengua (e inclusive pseudo-morfemas derivativos, es decir, afijos inexistentes en la lengua). Sin embargo, aún en los casos en que estas pseudopalabras se presentan a los niños en contextos oracionales que sugieren información sintáctica o categorial, se trata de tareas en las que se les solicita a los niños pensar, producir o interpretar formas inexistentes de su lengua. Hemos preferido la presentación de palabras frecuentes y familiares para los niños, con la expectativa de que durante los intercambios que siguen a cada una de las consignas el entrevistador pudiera entablar un diálogo que permitiera conocer las interpretaciones de los niños.

El entrevistador, por su parte, tenía una serie de restricciones estrictas durante el intercambio de modo tal de no sugerir respuestas ni direccionar las interpretaciones de los niños. Destacamos que el entrevistador:

- No dio ejemplos de cómo realizar las tareas.

- Se abstuvo de calificar cualquier producción de los niños como correcta o incorrecta.

- A excepción del término palabra no propuso ninguna terminología metalingüística y solamente retomó algún término cuando uno de los niños lo utilizaba en sus explicaciones.

- Se refirió en todo momento a las fichas que contenían morfemas derivativos o bases léxicas como "pedacitos", con el propósito de no sugerir una clasificación inicial del material.

- Se abstuvo de anteponer el artículo definido para referirse a las fichas (por ejemplo consultar ¿qué significa ble? en lugar de ¿qué significa el/la ble?).

Como señalan Kriscautzky y Ferreiro (2018) en los diseños experimentales clásicos el experimentador "interviene lo menos posible y siempre de la misma manera para garantizar la objetividad" (2018:18). En la metodología de entrevista flexible que utilizamos, en cambio, el papel del investigador es

"extremadamente activo, aunque hable poco. Durante toda la entrevista trata de formularse hipótesis sobre las razones de lo que ve y escucha, haciendo continuamente inferencias que le permiten (idealmente) diseñar en el momento mismo variantes al problema para confirmar o descartar sus hipótesis. Por eso esta metodología se suele llamar 'verificación de hipótesis sur le vif', o sea, 'en caliente', en el transcurso de la misma entrevista. No es una metodología fácil de aprender 
porque exige del investigador una reconversión radical con respecto a la relación adulto-niño" (2018:18).

Las entrevistas fueron grabadas en audio digital, con una duración promedio entre 45 y 60 minutos, y se realizaron en un espacio apartado dentro de las escuelas en las que trabajamos. Además de la grabación de audio, se realizaron notas de campo para indicar las acciones que los niños realizaban con los materiales escritos (alargamientos, cortes, rectificaciones, etc.). Con estos registros se elaboraron los protocolos de las entrevistas. La explicitación de las decisiones sobre el proceso de transcripción es una tarea ineludible en la investigación psicolingüística ${ }^{15}$ ya que no se trata en absoluto de un proceso mecánico:

"Al escribir y transcribir entran en juego diferentes aspectos. Mientras que en el acto de escribir se trazan o hacen visibles las representaciones psicológicas del lenguaje, en el de transcribir hay un ingrediente más: el habla. El transcriptor interpreta la emisión oral de acuerdo con los parámetros propios de la recepción auditiva y elige las formas gráficas que proporcionen una imagen visual cercana a la interpretación que se va forjando. Esto plantea diversos problemas de redefinición de los signos gráficos mismos, que no sólo tienen que ver con los objetivos que se persigue al poner por escrito una muestra del habla, sino con los nuevos modos de simbolizar que se les destine" (Zamudio, 2010:241).

Cuando el objeto sobre el que se reflexiona es además la lengua, como es nuestro caso, los criterios que se seleccionan para realizar la transcripción son determinantes en la construcción del dato a ser analizado. En nuestros protocolos establecimos las siguientes convenciones:

- Realizar una transcripción léxico-ortográfica del intercambio oral en toda la entrevista.

- No utilizar mayúsculas ni signos de puntuación ${ }^{16}$, a excepción del signo de pregunta final (?) ya que la entonación final ascendente constituye un caso de reconocimiento fácil.

\footnotetext{
${ }^{15}$ Compartimos con Möller y Ferreiro el propósito de reflejar "de la manera más neutral y confiable posible" los intercambios y las acciones registradas en las entrevistas. La transcripción "constituye, de por sí, un primer análisis de los datos; en investigación psicolingüística es ineludible la explicitación de los criterios utilizados ya que afecta la construcción misma del dato sobre el que se trata" (2013:205).

16 De lo contrario, insertar signos de puntuación en el registro escrito del discurso oral implicaría la toma de decisiones sobre diferentes criterios posibles: textuales, lógico-sintácticos y prosódicos. Como sostiene Celia Zamudio: "el uso de la puntuación en las transcripciones involucra un compromiso entre los sentidos del discurso, sus aspectos prosódicos y los usos de la puntuación contemporánea, un arbitraje que, por el hecho
} 
- Distinguir los turnos de habla señalando el nombre del niño y la abreviación "Ent." para identificar al entrevistador, seguido en todos los casos de dos puntos y dando saltos de línea cuando termine su turno ${ }^{17}$.

- Indicar entre corchetes aclaraciones sobre lo que no queda registrado en el habla (gestos, entonaciones, acciones de los niños con el material escrito, etc.).

- Indicar con una barra inclinada (/) las pausas en el discurso y cuando había un silencio prolongado indicarlo con una serie de dos barras inclinadas (//).

- Distinguir con versalitas cuando los niños leían o se referían al material escrito de las tareas.

Estas convenciones no son propias del presente estudio sino que han sido adoptadas en otras investigaciones previas (Baez, 2009; Dávalos, 2016; Möller, 2010, entre otras) siguiendo los mismos fundamentos teóricos (Blanche-Benveniste, 1998; Zamudio, 2004 y 2010).

Concluimos este apartado con una síntesis de los principales aspectos metodológicos de nuestro diseño: i) realizamos entrevistas flexibles inspiradas en el método clínico-crítico a 30 parejas conformadas por un niño y una niña, distribuidos en 10 parejas de $2^{\circ}$ grado, 10 de $4^{\circ}$ y 10 de $6^{\circ}$; ii) todos los niños entrevistados asistían a dos escuelas primarias públicas de la ciudad argentina de Córdoba Capital y en todos los casos fueron seleccionados por sus maestras de grado; iii) cada pareja de niños realizaba una serie ordenada de tres tareas (alargar, acortar y contrastar) en una entrevista que duraba entre 45 y 60 minutos; iv) todas las tareas involucraban material escrito y consignas que invitaban a los niños a realizar distintas acciones con dichos materiales.

de quedar sujeto a la decisión del transcriptor, difícilmente puede ser repetido por otros transcriptores" (Zamudio: 2004:323).

17 "La disposición gráfica una proposición-una línea no sólo permite aislar cada una de [las] unidades [del discurso oral], sino evitar el tener que integrarlas en un conglomerado oracional siguiendo criterios que no siempre son lingüísticos ni transparentes. [...] El ordenamiento de las proposiciones en líneas sucesivas y sin ninguna puntuación pone al descubierto la mayor autonomía de éstas en el discurso" (Zamudio, 2004:444). 


\section{Tarea de Alargar}

\subsection{Materiales y consigna}

La primera de las tareas de nuestro diseño de investigación es la tarea de Alargar. En ella presentamos a cada uno de los niños de la pareja un conjunto de fichas transparentes que tenían escritas en letra imprenta mayúscula bases léxicas o morfemas derivativos (que si bien son formas ligadas están presentadas en las fichas como si fueran formas libres). Las primeras son distintas en cada uno de los conjuntos e incluyen bases sustantivo-adjetivas (OFICIAL y MARINO) ${ }^{18}$, sustantivo-verbales (ARMA, CUENTO), adjetivoverbales (ACTIVA), sustantivas (FLOR, RELOJ, FUTBOL) y verbales (COMUNICA, PINTA). Además, presentan formas variadas en cuanto a la cantidad de sílabas (desde la unisilábica FLOR a la tetrasilábica comUNiCA) y a la cantidad de material gráfico. En todos los casos buscamos trabajar con bases léxicas familiares y de uso habitual para los niños.

En cuanto a los morfemas derivativos, éstos constituyen dos conjuntos iguales para cada uno de los niños y constan de cinco sufijos (-ON, -ERO, -DOR, -ISTA y -BLE) y tres prefijos (SUB-, IN- y DES-), aunque la forma -IN puede utilizarse también como sufijo de diminutivo. En la elección de los morfemas derivativos también consideramos su composición gráfica, ya que se trata mayormente de formas compuestas por tres letras y solamente en dos casos ( $\mathrm{IN}-\mathrm{y}-\mathrm{ON})$ formas que están al límite de la cantidad de letras que lo harían interpretable para niños en proceso de adquisición de la lengua escrita (Ferreiro, 2006). En el Cuadro 3 vemos cómo estaba constituido cada uno de los conjuntos.

\footnotetext{
18 Indicamos en versalitas las fichas que constituían el material escrito en la tarea de Alargar. Los morfemas derivativos se indican además con un guion para resaltar que se trata de una forma ligada (mientras que las bases léxicas son formas libres). El guion, por supuesto, no formaba parte del material escrito en las fichas transparentes reales con las que trabajaron los niños.
} 
Cuadro 3. Conjuntos de fichas para alargar

\begin{tabular}{cccc}
\hline & Conjunto 1 & \multicolumn{2}{c}{ Conjunto 2 } \\
\hline \multirow{2}{*}{ Bases léxicas } & $\begin{array}{c}\text { Morfemas } \\
\text { derivativos }\end{array}$ & Bases léxicas & $\begin{array}{c}\text { Morfemas } \\
\text { derivativos }\end{array}$ \\
\hline OFICIAL & ON & MARINO & ON \\
FLOR & ERO & RELOJ & ERO \\
CUENTO & DOR & PINTA & DOR \\
ACTIVA & ISTA & COMUNICA & ISTA \\
ARMA & BLE & FUTBOL & BLE \\
& SUB & & SUB \\
& IN & & IN \\
& DES & DES \\
\hline
\end{tabular}

\section{Procedimiento}

Para iniciar el juego entregábamos a un niño el Conjunto de fichas 1 y al otro niño el Conjunto de fichas 2. Las fichas estaban dispuestas como un mazo y ordenadas de modo tal que no hubiera tarjetas contiguas que sugirieran posibles alargamientos. Cada uno de los niños trabajaba en un tablero de $45 \times 35 \mathrm{~cm}$. que servía como un espacio de trabajo delimitado para diferenciar las combinaciones que iba realizando. A continuación dábamos la siguiente consigna oral:

Fíjense en estas fichas y dejen adentro del tablero las que ustedes están seguros que son palabras.

Luego de dar unos minutos para que eligieran entre sus fichas cuáles consideraban como palabras, solicitábamos la lectura en voz alta de las mismas, sin pedir ningún tipo de justificación acerca de sus decisiones en ese momento. La lectura de las fichas era importante para asegurarnos que los niños, sobre todo los de segundo grado, pudieran hacer una lectura convencional de las fichas. En aquellos casos en los que los niños no leyeron correctamente la ficha, les solicitamos que volvieran a leerla o también pedimos a su compañero que la leyera, proponiendo así relecturas hasta poder alcanzar la lectura convencional.

Una vez que los niños habían leído las fichas seleccionadas como palabras dentro de sus tableros, continuábamos con la segunda parte de la consigna: 
Ahora fijense cómo pueden alargar estas palabras usando las fichas que dejaron a un costado del tablero. Pueden poner las fichas de este lado o de este lado [señalando ambos lados de las fichas respectivamente] y que quede una palabra más larga. Luego tenemos que explicar las que alargaron o dar un ejemplo de cómo usarlas.

A continuación los niños se tomaban unos minutos para realizar sus alargamientos y recién entonces comenzábamos con el intercambio para contrastar las series realizadas y solicitar explicaciones de cada una de ellas.

En todos los casos alentamos a los niños durante el intercambio a continuar buscando nuevas combinaciones, ya sea con las bases léxicas o con los morfemas derivativos que no habían utilizado, así como también explorando otras posibilidades para las fichas que sí habían logrado combinar. Luego de cierto tiempo de buscar nuevas combinaciones el entrevistador también consultaba acerca de la posibilidad de alargamientos que los niños no habían realizado con el propósito de poder realizar posteriormente contrastes entre los niños de la pareja. Otro aspecto a destacar es que las fichas por ser transparentes permitían realizar superposiciones entre letras, de esta manera, se podía realizar la combinación de las fichas CUENTO y -ON, superponiendo la vocal final de la primera con la inicial de la segunda. Cuando los niños exploraban o consultaban sobre esta posibilidad, el entrevistador los alentaba a buscar también este tipo de superposiciones en otras fichas.

\subsection{Elección de fichas como palabras}

Al solicitar a los niños que eligieran cuáles de las fichas de sus conjuntos estaban seguros que eran palabras se dieron pocos casos ( 7 sobre 60 ) en los que un niño dejó un morfema derivativo dentro del tablero o una base léxica fuera del tablero. Además, en los siete casos se trató solamente de una ficha del conjunto que recibía cada niño. Prácticamente todos estos siete niños rectificaron su decisión al momento de leer en voz alta las fichas elegidas como palabras en sus tableros. Solamente Lucía $\left(2^{\circ}\right)$ y Román $\left(6^{\circ}\right)$ 
dejaron DES- como palabra dentro del tablero, aún luego de la lectura en voz alta. El niño de $6^{\circ}$ dio una buena explicación de su elección diciendo que DES- es de dar / del verbo dar / espero que des limosna a los pobres, ofreciendo inclusive un ejemplo de uso, en tanto que la niña de $2^{\circ}$ no justificó su decisión pero dejó la ficha DES- en el tablero sin usar durante el intercambio. Es interesante destacar que DES- es la única ficha entre las que propusimos como morfemas derivativos que, interpretada como una forma conjugada del verbo dar, puede ser una forma libre y por lo tanto ser considerada por los niños como palabra al mismo nivel que las demás bases léxicas.

Estas decisiones de los niños en cuanto a cuáles fichas eran o no palabras nos dan un punto de partida alto para todos los grados escolares. Los niños entrevistados no tuvieron problemas en distinguir entre bases léxicas (formas libres y con significado pleno) y morfemas derivativos (formas ligadas que están presentadas en el juego como formas libres y que categorizan información léxica pero no tienen un significado léxico completo y autónomo) entre las fichas que dispusimos para ellos.

\subsection{Alargamientos realizados por los niños}

La tarea de Alargar se caracterizó por una dinámica que ciertamente tornó compleja la labor de registro, análisis e interpretación de los datos. Recordemos que luego de la primera clasificación del material entre las fichas que ellos consideraban como palabras, el entrevistador presentaba la consigna central de la tarea y cada niño exploraba y realizaba combinaciones con sus fichas (morfemas derivativos iguales y bases léxicas distintas para ambos conjuntos). Denominaremos iniciales a los alargamientos resultantes de esta primera parte. Una vez que comenzaba el intercambio podían surgir nuevos alargamientos, ya sea porque cada niño encontraba una nueva combinación para las fichas que no había usado o combinaciones alternativas a las ya realizadas, o bien porque un niño proponía combinaciones con las fichas en el tablero de su compañero. Denominaremos finales a los alargamientos que aparecieron durante el intercambio. 
Una primera dificultad para el tratamiento cuantitativo de los alargamientos realizados tiene que ver con que no contamos con un número determinado de combinaciones esperadas. Si bien en nuestro diseño previmos alargamientos convencionales, también se presentaba la posibilidad de que los niños realizaran y justificaran alargamientos plausibles aunque no convencionales ( $y$ en este sentido nuestra expectativa también era conocer cómo interpretaban los niños los procesos de derivación en estos casos no esperados). Por otro lado, está la cuestión de cómo tratar los casos en los que los niños realizan un alargamiento simultáneo a ambos lados de la base léxica, es decir, con un prefijo y con un sufijo. Ciertamente, el hecho de que presentáramos a los niños un conjunto de bases léxicas inferior al conjunto de morfemas derivativos de alguna manera sugería que las bases léxicas podían ser reutilizadas con más de un morfema o que una misma base podía recibir más de un morfema. En estos casos, es imprescindible considerar si se trata de un alargamiento doble (que en principio indicaría un mejor desempeño en la tarea) o si se trata de dos alargamientos distintos pero reutilizando la misma base léxica (que también indicaría un mejor desempeño ya que son casos en que se logra considerar más de una opción de derivación para cada base léxica). Estos últimos casos los denominaremos reutilización de morfemas o de bases léxicas. Otra pregunta central es cómo tratar los alargamientos no esperados y no convencionales, es decir, ¿̇e trata de exploraciones guiadas por alguna reflexión sobre cómo funcionan los morfemas derivativos al ser agregados a una base o simplemente de "errores" de los niños? Estas variables serán tratadas de modo particular a lo largo del capítulo. Sin embargo, nos parece importante contar con una primera impresión general de la cantidad de alargamientos que los niños realizaron según el grado escolar para tener un punto de referencia inicial a la hora de analizar cualitativamente tanto los alargamientos como las justificaciones que los niños elaboraron.

En la Gráfica 1 podemos ver la cantidad de alargamientos simples y esperados realizados por los niños de cada grado escolar (sin incluir en el conteo los alargamientos dobles ni los alargamientos no esperados que serán tratados más adelante), distinguiendo solamente entre los alargamientos iniciales y los finales. En los iniciales y en el total de 
alargamientos (es decir, la suma de alargamientos simples iniciales y finales indicados en la gráfica y que corresponde a un total de 98 para $2^{\circ}$ grado, 110 para $4^{\circ}$ grado y 126 para $6^{\circ}$ grado) es donde encontramos un aumento progresivo en la cantidad de combinaciones. En la consideración de los alargamientos finales, es decir los que se dieron durante el intercambio, llama la atención que en $4^{\circ}$ grado se hicieron menos combinaciones que en $2^{\circ}$ grado, sin embargo hay que tomar estas cantidades con cierta precaución ya que dependen directamente del punto de partida que conforman los alargamientos iniciales

Gráfica 1 - Total de alargamientos esperados realizados según grado escolar, distinguiendo iniciales y finales y excluyendo alargamientos dobles. Los alargamientos finales se agregan a los iniciales. En cada grado, 20 niños entrevistados en parejas.

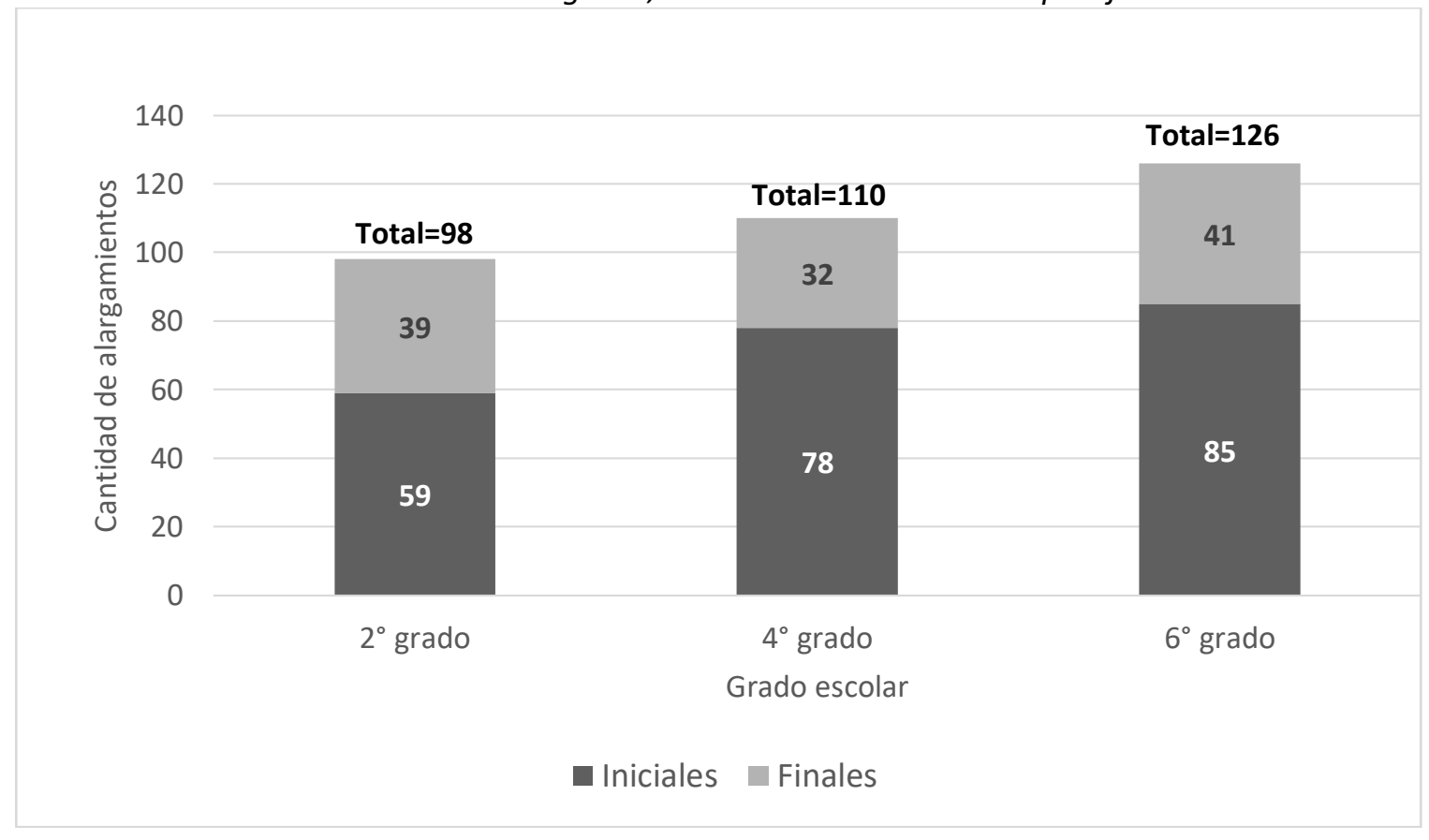

Una cuestión central que se impone para iniciar el análisis es saber si todos los niños de cada grado escolar realizaron alargamientos de la misma manera y, además, cómo justificaron esas combinaciones. Veamos a continuación una pareja de cada grado para conocer cómo alargaron y cómo justificaron, antes y durante el intercambio, los alargamientos realizados. Comencemos por Josefina y Gonzalo, pareja de $2^{\circ}$ grado. La niña solamente utiliza sufijos para elaborar tres combinaciones y deja dos bases léxicas sin utilizar, CUENTO y ARMA. No elabora justificación durante el intercambio para la serie 
OFICIAL ISTA ${ }^{19}$. Sobre FLOR|ERO dice es donde se ponen las flores y sobre ACTIVA|DOR es como si fuera un enchufe que activa. Durante el intercambio realiza un alargamiento con prefijo, DES|ARMA, y lo justifica en interacción con su compañero:

Ent.: vos qué decías Josefina?

Josefina: desarma arma [leyendo la seria para sí]

Gonzalo: desarma

Ent.: qué es desarma?

Gonzalo: desarma

Josefina: desarma como un juguete cuando

Gonzalo: [interrumpiendo] tenés un robot lo querés hacer por otro mejor y lo desarmás

Gonzalo, por su parte, realiza combinaciones con todas las bases léxicas disponibles. Sobre la serie SUB|MARINo dice que es un barco que va abajo el agua. También alarga la serie FUTBOL|ERO y RELOJ|ON, y las justifica como un jugador de fútbol y un reloj grandote como el de Londres. Sobre la combinación PINTA|BLE mantiene el siguiente intercambio:

Ent.: y acá qué quiere decir esto? [señalando PINTA|BLE]

Gonzalo: pintable

Josefina: no sé

Gonzalo: una máquina pintadora

Ent.: qué es así cuando está solito? [señalando solo la ficha PINTA]

Gonzalo: pinta

Josefina: pinta / es un

Gonzalo: yo / yo pinto

Josefina: estás pintando

Ent.: si yo le pongo esta [señalando BLE] cambia?

Josefina: pintable es como si fuera un señor / creo que es como si fuera

Gonzalo: es un señor que pinta

Josefina: que pinta como las paredes de la casa

Gonzalo: hay uno que se llama Da Vinci ${ }^{20}$

Por último, realiza también al inicio la serie COMUNICA|DOR y la justifica diciendo que es el lugar / o sea una casita donde hay un teléfono y te comunicás. Durante el

\footnotetext{
${ }^{19}$ La barra vertical ( |) indica la combinación de dos fichas distintas.

${ }^{20}$ En la transcripción de los diálogos utilizamos la barra inclinada (/) para indicar un cambio entonativo o una pausa. Si la pausa es más prolongada, utilizamos doble barra (//). Las razones para evitar la puntuación están expuestas en la sección 1.4 .
} 
intercambio, Gonzalo agrega la combinación COMUNICA|BLE y la explica como algo que se comunica / es como comunicador. También realiza otro alargamiento sobre la misma base léxica con el prefijo DES-, DES|COMUNICA, pero no lo justifica ${ }^{21}$. Se trata de una pareja que trabajó activamente y en colaboración para elaborar justificaciones sobre los alargamientos, aunque no lograron encontrar combinaciones para algunas bases léxicas del conjunto propio o del compañero durante el intercambio. Sobre las dificultades para justificar las combinaciones con el sufijo -BLE volveremos en detalle en la sección 4 de este capítulo 2.

Veamos ahora qué sucedió con Diego y Carmela, pareja de $4^{\circ}$ grado. Al inicio de la tarea ambos niños realizan alargamientos con todas las bases léxicas utilizando tanto sufijos como prefijos. Diego explica IN|ACTIVA utilizando como ejemplo la grabadora que usamos en la entrevista y dice ahora está activa pero / antes al principio está inactiva o sea que no la activaste, e inclusive el niño explora cuál es el significado que IN- agrega a la serie diciendo in es como que todavía no / no activa. Sobre la serie CUENT|ON dice que es un cuento grande o sea / es como un súper cuento que tiene un montón de páginas. Sin embargo, la serie FLOR|ERO le resulta difícil de justificar. Diego comienza comparándola oralmente con florería y hasta esboza una justificación de plural, pero Carmela es quien propone el significado convencional de la palabra derivada:

Ent.: qué es florero?

Diego: es una florería no sé // florero que muchas flores / qué se yo

Carmela: no / como la maceta / no?

Ent.: cómo una maceta? cuéntenme cómo es

Diego: sí claro florero es como

Carmela: como un

Diego: como algo que tiene las flores

Carmela: donde podés meter las flores

También en el caso de ARMA|DOR Diego arriba a una justificación en el intercambio con su compañera. Carmela explica inicialmente que ARMADOR significa alguien que arma pero luego dudan a partir de las distintas interpretaciones categoriales que le dan a la

\footnotetext{
${ }^{21}$ Las justificaciones más interesantes de los niños serán retomadas y analizadas en detalle en la sección 4 de este capítulo 2.
} 
base léxica. Mientras la niña comienza interpretando la base como verbo, Diego advierte que también puede ser interpretada como sustantivo (la posibilidad de considerar dos significados distintos -semántica y categorialmente- es un indicio avanzado de reflexión metalingüística que retomaremos más adelante):

Diego: arma es

Carmela: alguien que arma

Diego: no

Carmela: no / es armar algo

Diego: para mí es las armas de qué se yo / de las pistolas

Ent.: y lo que dice Carmela puede ser? // vos [refiriéndose a la niña] decías el que arma algo

Diego: [interrumpiendo] no pero eso lo que dice que arma algo sería armador

Ent.: ajá

Diego: pero si dice arma algo sería como él [enfatizando] arma

Carmela: se significa las dos cosas / puede ser él arma o puede ser arma de pistola

Ent.: y armador qué sería? [señalando ARMA|DOR]

Carmela: alguien que arma cosas / no?

Diego: sí [dudando] // eso estaba pensando

Ent.: pero estabas inseguro / por qué?

Diego: $\mathrm{mmm}$ no sé porque

Carmela: como que no suena

Con la última base léxica de su conjunto Diego realiza la combinación OFICIAL|ISTA pero no logra justificarla. Carmela, por su parte, también realiza alargamientos iniciales con todas las bases léxicas de su conjunto. Justifica RELOJ|ERO diciendo que es alguien que hace relojes y arma durante el intercambio la serie RELOJ|ISTA que no logra justificar. Con la base léxica FUTBOL alterna los sufijos -ERO e -ISTA, explica que FUTBOL|ISTA es alguien que trabaja y que le dan dinero mientras que sobre FUTBOL|ERO dice a este le gusta nada más. Sobre PINTA|BLE explica que se puede pintar y sobre COMUNICA|DOR dice me parece que es algo con lo que se comunica, a lo que su compañero Diego agrega la interpretación agentiva diciendo que es como la persona que se comunica. El único alargamiento con prefijo que realiza Carmela es SUB|MARINO y lo justifica diciendo alguien que vive en el mar / debajo del mar. En el intercambio, Diego parece nuevamente centrarse en el significado del prefijo para explicar el alargamiento de su compañera diciendo eso lo vimos también en clase que sub era como un prefijo / que significa / abajo / [señalando SUB|MARINO] o sea 
abajo del mar. En esta pareja de $4^{\circ}$ encontramos un incremento en la cantidad de combinaciones antes y durante el intercambio. Además, los niños también dan cuenta de una colaboración permanente en las justificaciones de los alargamientos lo que permite que aparezca la problemática de la interpretación de las derivaciones así como también de la categoría gramatical de las bases léxicas.

Veamos por último lo realizado por Gerardo y Luana, pareja de $6^{\circ}$ grado. La niña deja la base léxica RELOJ sin alargar. Utiliza dos prefijos en sus combinaciones, SUB- y DES-. Sobre SUB|MARINO dice que es como un medio de transporte que se usa para ir digamos debajo del mar y sobre DES|PINTA justifica el agregado diciendo pinta sería digamos como que alguien está pintando y despinta sería como que alguien se confundió y le saca la pintura. En cuanto a la serie COMUNICA|DOR admite que el significado puede vincularse tanto a un objeto como a un sujeto: puede ser un aparato con el que la gente se comunica o si no / una persona. Esta posibilidad de que un mismo significante acepte una interpretación referido a lo "humano" y a lo "no-humano" es también un indicador avanzado de reflexión metalingüística. Con la base léxica FUTBOL propone la alternancia de sufijOS -ERO e -ISTA y explica el contraste entre sufijos diciendo yo le suelo decir futbolero a la gente que le gusta mucho el fútbol / que está todo el día hablando de fútbol, mientras que FUTBOLISTA es como el jugador / un alguien que juega al fútbol. Iniciado el intercambio, Luana le sugiere a su compañero el alargamiento FLOR|ISTA y lo justifica como la persona que vende flores / se dedica a las flores y consultada puntualmente por cómo cambia -ISTA a la base léxica sostiene que FLOR|ISTA es de la familia de palabras de flor pero / digamos es la persona. Gerardo, por su parte, había realizado inicialmente la combinación FLOR|ERO explicándola como un objeto que contiene las flores. También al inicio realiza un alargamiento doble (es decir, un prefijo y un sufijo simultáneamente sobre la misma base léxica) en DES|ACTIVA|DOR y lo justifica como un objeto que desactiva algún coso. Durante el intercambio también realiza otro alargamiento doble: a partir de la combinación inicial ARMA|BLE agrega el prefijo DES- que justifica como que el objeto se puede desarmar. El caso de la base léxica CUENTO es interesante, Gerardo realiza dos alargamientos con los sufijos 
-ON e -ISTA pero antes de comenzar a justificar surge el problema de la interpretación categorial de la base léxica por sí misma:

Ent.: cuento así solo [señalando solo la ficha CUENTO] qué es?

Gerardo: y cuento / sería el sustantivo de cuento / un cuento

Luana: o también

Gerardo: el verbo

Luana: claro un verbo

Gerardo: yo cuento [haciendo gesticulaciones de estar contando algo] / una historia algo así

Pero además, cuando comienza a explicar la serie CUENT|ON surge un nuevo problema al interpretar la base léxica de la derivación como "cuenta", en el sentido de factura que se abona, o "cuento" en el sentido de relato. La derivación con el sufijo -ON borra las huellas de la vocal que permitiría saldar la diferencia entre las posibles bases.

Ent.: qué es cuentón?

Gerardo: como una cuenta / suponte que vos vas a un mercado te comprás muchas cosas y te da cuentón

Ent.: ajá / y qué cambia de cuento a cuentón?

Gerardo: y cuento sería más el sustantivo / bah los dos serían el sustantivo pero les cambia el significado también

Ent.: cómo se los cambia?

Luana: para mí

Gerardo: [interrumpiendo] porque cuento significa como un libro / es un cuento pero un cuentón sería la factura / para mí

Ent.: para vos Luana?

Luana: o si no suponete cuentón / yo escuché que hay gente que dice cuentón del libro que le encantó [enfatizando]

También en el caso de la combinación SUB|OFICIAL que realizó Gerardo se da un intercambio sobre las dos posibilidades de interpretación categorial de la base léxica (OFICIAL Como adjetivo o como sustantivo) y sobre la función que cumplen los pedacitos que se agregan:

Ent.: qué es suboficial?

Gerardo: suboficial sería antes de que esté oficialmente / una réplica sería

Ent.: [señalando solo la ficha OfICIAL] y oficial qué es?

Gerardo: que es / suponte que yo te digo tengo la pelota oficial del mundial

Luana: si no también puede ser la persona / por ejemplo el policía / hay gente que le dice oficial 
Ent.: puede ser las dos cosas?

Gerardo: sí

Ent.: y suboficial?

Gerardo: para mí es una réplica / por ejemplo yo tengo la pelota suboficial del mundial

Ent.: ajá / y qué quiere decir este pedacito? [señalando SUB]

Gerardo: me parece que / más que un significado tiene / le cambia el significado / o sea este conjunto de letras [señalando SUB] más que tener un significado le cambia el significado a las palabras

Iniciado el intercambio, Gerardo propone con las fichas de su compañera la combinación MARIN|ERO y la justifica como la persona que maneja algún barco. La pareja de $6^{\circ}$ da cuenta de una mayor utilización de bases léxicas y morfemas en sus combinaciones, incluyendo casos de alargamiento doble o de reutilización de bases y morfemas. En las justificaciones, además, aparecen con más frecuencia reflexiones sobre la posibilidad de que una base léxica o una derivación se refiera a más de un significado y también intentos por dar cuenta del significado de algunos morfemas derivativos aislados.

Como podemos ver en las parejas citadas como ejemplos, existen diferencias en cuanto a la cantidad de alargamientos realizados pero, sobre todo, respecto de las posibilidades de justificar esas combinaciones y los cambios que se producen al agregar prefijos o sufijos, de proponer interpretaciones alternativas para las bases léxicas y también a la hora de interpretar el significado de esas "partecitas" que los mismos niños habían separado como no-palabras pero ahora reencuentran en formas alargadas que las integran. En la próxima sección abordamos el problema de cómo clasificar en grupos a los niños para poder dar cuenta de su desempeño en esta tarea de Alargar.

\subsection{Grupos evolutivos en tarea de Alargar}

Una primera variable para analizar el desempeño de los niños es la consideración cuantitativa de los alargamientos realizados. Para ello, asignamos a las combinaciones realizadas por cada niño un valor compuesto por el número de morfemas derivativos 
utilizados a izquierda de una barra diagonal y por la cantidad de bases léxicas utilizadas a derecha de la diagonal. Si los alargamientos realizados por un niño reciben, por ejemplo, un valor de 3/3, esto significa que combinó 3 morfemas derivativos con 3 bases léxicas, es el caso de Josefina ( $2^{\circ}$ grado) en los ejemplos presentados en la sección anterior. Teniendo en cuenta que todos los niños entrevistados realizaron al menos un alargamiento, el número a la derecha de la barra puede adquirir un valor entre 1 y 5, que es el rango de bases léxicas disponibles. Cuando un niño reutiliza una base léxica con distintos morfemas derivativos o cuando un niño realiza un alargamiento doble el número a la izquierda de la diagonal es mayor al número de la derecha. En los ejemplos descriptos anteriormente, esto correspondería a lo realizado por Gerardo ( $6^{\circ}$ grado): por un lado dos alargamientos con morfemas derivativos distintos para la misma base léxica en CUENT|ISTA Y CUENT|ON, por otro lado un alargamiento doble en DES|ACTIVA|DOR, le otorgan un valor de 7/5 a su desempeño en la tarea. Esta forma de representar la cantidad de alargamientos realizados por un niño tiene la ventaja de indicar en el mismo valor $(n / n)$ la cantidad de bases léxicas y morfemas derivativos utilizados, así como también la existencia o no de reutilización de bases y alargamientos dobles. Para la asignación de un valor a lo realizado por cada niño consideramos solamente los alargamientos iniciales. Como mencionamos en el apartado anterior, una vez iniciado el intercambio, no siempre es factible determinar si cada niño elabora por su cuenta una nueva combinación, si lo hace a partir de tomar en consideración lo que realizó su compañero (ya que en sus conjuntos comparten los morfemas derivativos) o si es a partir del diálogo con el entrevistador (o con el compañero) que "encuentra" una nueva combinación.

Por otro lado, el segundo eje para analizar el desempeño de los niños tiene que ver con la consideración de cuáles fueron las combinaciones realizadas -qué bases léxicas y qué morfemas derivativos fueron utilizados- y cómo fueron justificadas. Algunos morfemas derivativos fueron particularmente difíciles de utilizar (el prefijo negativo IN-), mientras que otros resultaron más disponibles para realizar combinaciones (los denominales -DOR e -ISTA) o para dar interpretaciones adecuadas (el aumentativo -ON). Además, las justificaciones que los niños elaboraron para sus combinaciones nos permiten 
conocer cómo interpretan los procesos de derivación, si pueden explicar los cambios que implica el agregado de un morfema y eventualmente si pueden atribuir significado a los morfemas cuando están aislados.

Por último, también incorporamos la consideración de los alargamientos no esperados pero plausibles que realizaron los niños ${ }^{22}$. En todos los casos, fue determinante la evaluación de las justificaciones. Aun cuando algunos niños produjeran una serie morfofonológicamente plausible pero inexistente en la lengua, por ejemplo RELOJ|ISTA o PINTA|DOR, consideramos importante saber cómo justifican el proceso de derivación, es decir, cómo modifica el morfema derivativo a la base léxica. También es importante saber si los niños que realizan estas combinaciones las consideran como posibles aunque no convencionales y si pueden relacionarlas con aquellas palabras de la lengua que ya cumplen el papel que ellos le atribuyen a esas series plausibles (postular, por ejemplo, la plausibilidad de la forma PINTA|DOR pero reconociendo a la vez "pintor" como forma convencional de ese significado en nuestra lengua o, en todo caso, atribuyendo a PINTA|DOR una especificación semántica no disponible aún en la lengua).

Es importante señalar que por tratarse de un estudio evolutivo y por concebir al desarrollo como un continuo, la clasificación propuesta realiza cortes con el propósito principal de caracterizar y comprender las acciones y justificaciones de los niños para esta tarea. Sin embargo, sostenemos que el desarrollo es un proceso continuo y que seguramente hay niños en momentos de transición entre niveles que, con el objeto de organizar la descripción, presentamos como discontinuos. De hecho, algunos de los niños interrogados se encuentran en estos puntos intermedios y sus acciones o sus justificaciones se corresponden con algunas de las características de dos niveles contiguos. A continuación presentamos cada uno de los tres grupos principales.

\footnotetext{
22 En algunos pocos casos algunos niños realizaron series no admisibles desde el punto de vista lingüístico, solamente plausibles en el sentido de que en la tarea nosotros proponíamos la consigna de realizar alargamientos entre fichas que contenían series de letras (algunas que eran palabras plenas y otras que no). Algunos niños realizaron alargamientos como SUB|RELOJ, MARINO|DOR O ACTIVA|SUB, pero en todos los casos se trató de una o dos de estas combinaciones no convencionales junto con otros alargamientos esperados y por lo tanto convencionales. Durante el intercambio, todos estos niños rectificaron estas combinaciones.
} 


\section{Nivel I}

En este grupo encontramos niños con valores iguales a ambos lados de la diagonal y que además son iguales o menores a 3. Por lo tanto, ninguno de los niños de este grupo realizó alargamientos con todas las bases léxicas de su conjunto así como tampoco alargamientos dobles.

Por otro lado, en sus combinaciones utilizaron siempre entre uno y tres morfemas derivativos. La mayoría de los niños no usó prefijos: sobre un total de 44 morfemas utilizados en este nivel I apenas 6 corresponden a los sufijos SUB- y DES-, mientras que INno fue utilizado en ningún caso. Por otro lado, más de la mitad de las combinaciones corresponden a los denominales -ERO, -ISTA y -DOR (29 sobre 44). Tanto -ON como -BLE fueron los sufijos menos utilizados, pero la situación parece no ser idéntica en ambos casos. El sufijo -BLE presentó dificultades a la hora de recibir una justificación aceptable (como veremos en la sección 2.5) mientras que en el caso de -on la baja frecuencia de uso está vinculada a las bases léxicas disponible que francamente no sugerían su combinación y en el caso más sugerente, es decir CUENTO, la combinación implicaba la superposición de la letra final de la base con la letra inicial del morfema. La disponibilidad de -ON como aumentativo está documentada a nivel oral inclusive con niños más pequeños (Pérez Pereira y Singer, 1984; Rodríguez Cuevas, 2018).

En este nivel, además, se ubica la mayoría de los alargamientos no esperados: 16 solo en este nivel I sobre un total de 26. Estos alargamientos no esperados incluyen formas plausibles morfo-fonológicamente aunque no convencionales (PINTA|DOR, ARM|ISTA, OFICIA|BLE, OFICIAL|ERO, RELOJ|ISTA), así como también aumentativos y diminutivos no convencionales (FUTBOL|IN, FUTBOL|ON, FLOR|IN, CUENT|IN). Entre los primeros, solamente los niños que realizaron la combinación PINTA|DOR pudieron elaborar justificaciones como alguien que pinta (Belén, $2^{\circ}$ ) o alguien que pinta mucho y como que es famoso pintando (Martín, $2^{\circ}$ ). Esta última interpretación sugiere la posibilidad de que los niños estén buscando una especificación semántica aún no disponible en la lengua: pintor como una persona que tiene el oficio o el trabajo de pintar frente a pintador* una persona que se dedica a pintar cuadros artísticamente. 
Entre las parejas descriptas como ejemplo, Josefina de $2^{\circ}$ grado pertenece a este nivel I. En la tarea de alargar obtuvo un valor de 3/3 ya que utilizó tres morfemas (los tres sufijos denominales disponibles: -ISTA, -ERO y -DOR) y tres bases léxicas para alargar (dejando las bases CUENTO y ARMA sin utilizar al inicio). No elaboró ninguna justificación para la serie OFICIAL|ISTA, mientras que interpretó instrumentalmente el agregado de los sufijos en las series FLOR|ERO Y ACTIVA|DOR.

En cuanto a las justificaciones, en este nivel encontramos una primacía de ejemplos de uso, es decir justificaciones centradas en el "yo" (introducidas en algunos casos por las frases es como si o es por ejemplo): Camila $\left(2^{\circ}\right)$ dice sobre ARMA|DOR yo a veces tengo bloques y voy armando un auto / y entonces eso es armador. Encontramos también algunos pocos casos de amalgama, es decir, de interpretaciones en las que los niños recortan en un segmento gráfico continuo dos series de significado pleno que se pueden yuxtaponer. Matías $\left(4^{\circ}\right)$ nos da un ejemplo notable: al justificar la combinación COMUNICA | BLE dice que es una comunicación por cable. Por último, hay algunos intentos de parafrasear los significados que agrega el morfema derivativo: Candela $\left(4^{\circ}\right)$ justifica que ACTIVA|DOR es una persona o un objeto que activa las cosas. No hay en este nivel intentos de dar cuenta del significado de los morfemas cuando están aislados.

\section{Nivel II}

En este segundo grupo encontramos niños con valores iguales a ambos lados de la diagonal y que son iguales o mayores a 4. No todos los niños de este grupo realizan alargamientos iniciales con todas las bases léxicas, pero la mayoría alcanza esta situación durante el intercambio. No hay alargamientos dobles iniciales ni tampoco finales.

Los niños de este grupo utilizan siempre cuatro o más morfemas derivativos para sus combinaciones. A diferencia del nivel I, la mayoría de los niños utiliza prefijos en los alargamientos iniciales, y quienes no lo hacen en la situación inicial durante el intercambio realizan alargamientos con prefijos. Hay un incremento generalizado en el uso de los morfemas derivativos con respecto al grupo anterior y además aparecen alargamientos con el prefijo negativo IN-. 
Se reduce a 5 el número de alargamientos no esperados. Hay dos combinaciones aumentativas no convencionales, ARM|ON y OFICIAL|ON, propuestas con cierta duda y rectificadas durante el intercambio. Encontramos tres alargamientos de PINTA|DOR justificados siempre como alguien que pinta o una persona que pinta. Luciano, por ejemplo, consultado por qué es lo que cambia de PINTA a PINTA|DOR dice: pinta sería como un verbo como si te dan una orden pintá esto / pintador no sería como una orden / sería la persona que está pintando o el que pinta.

De las parejas comentadas en el apartado anterior, Gonzalo de $2^{\circ}$ grado y Diego de $4^{\circ}$ grado se encuentran en este nivel II. Ambos niños realizan alargamientos iniciales con todas las bases léxicas, utilizando mayormente sufijos pero también un prefijo cada uno. Diego incluso utiliza prefijo IN- en la serie IN|ACTIVA, y además en su justificación intenta dar cuenta del significado aislado del morfema (un indicador de rendimiento máximo de reflexión metalingüística sobre los morfemas como desarrollaremos más adelante).

Con respecto a las justificaciones, se generaliza en este segundo nivel la presencia de paráfrasis sobre los significados que agregan los morfemas. Julián $\left(4^{\circ}\right)$, por ejemplo, explica que ACTIVA|BLE significa que se puede activar mientras que ARMA|DOR es un hombre que arma, parafraseando las ideas de "posibilidad de realizar la acción indicada por la base" y "sujeto que realiza la acción indicada por la base" respectivamente. Continúan en este nivel las justificaciones con ejemplos de uso y en algunos pocos casos también con interpretaciones de amalgama. Lo que comienza a aparecer incipientemente es la presencia de algunos intentos por dar cuenta del significado de los morfemas derivativos aislados: Lorena $\left(6^{\circ}\right)$, por ejemplo, justifica la combinación DES|ACTIVA como puede ser para desactivar algo y luego agrega des sería su antónimo / es lo contrario a la palabra en referencia a la base léxica ACTIVA. Por último, destacamos que en este nivel también comienza a aparecer el planteo de que una misma base léxica o alargamiento tenga más de un significado, en los ejemplos presentados vimos que Diego $\left(4^{\circ}\right)$ plantea que la base léxica ARMA puede ser interpretada como sustantivo o como verbo. 


\section{Nivel III}

Los niños de este tercer grupo reciben valores diferentes a ambos lados de la diagonal y además estos valores son iguales o mayores a 4. Es decir que se trata de niños que, o bien reutilizan alguna básica léxica con más de un morfema derivativo, o bien realizan un alargamiento doble utilizando simultáneamente un prefijo y un sufijo sobre la misma base léxica. Se incluyen además en este grupo, los niños que obtuvieron un valor de 5/5 (es decir que no realizaron un alargamiento doble o no reutilizaron bases léxicas al inicio), pero que durante el intercambio agregaron alargamientos reutilizando bases léxicas y en sus justificaciones se encuentra al menos un intento de explicar el significado de un morfema aislado.

Por tratarse de niños que comienzan alargando con todas las bases léxicas o lo hacen con cuatro bases léxicas pero con algún alargamiento doble, todos en este nivel III utilizan cinco morfemas derivativos o más en sus combinaciones. Además, todos los niños utilizan tanto prefijos como sufijos. Hay un incremento generalizado en el uso de los morfemas derivativos.

Hay solamente 5 alargamientos no esperados en este grupo: Delfina $\left(2^{\circ}\right)$ combinó la serie OFICIAL|ERO y luego en el intercambio la rectificó, Néstor ( $6^{\circ}$ ) alargó RELOJ|ISTA y dijo un señor que vende relojes, y finalmente tres combinaciones de PINTA|DOR justificadas como alguien que pinta. En los tres casos, además, los niños plantean la forma pintor para referirse a la misma idea.

De los ejemplos introductorios presentados, Carmela de $4^{\circ}$ grado y la pareja de $6^{\circ}$ grado compuesta por Gerardo y Luana son niños que pertenecen a este tercer nivel. Carmela realiza alargamientos con todas sus bases léxicas y junto con su compañero sostienen que el prefijo SUB- aislado significa abajo. Durante el intercambio aceptan la posibilidad de la combinación SUB|OFICIAL propuesta por el entrevistador:

Ent.: y mirá / podría ser así? [armando SUB|OFICIAL]

Diego: suboficial [leyendo para sí] sí claro porque / qué se yo abajo del oficial / no sé

Carmela: no / es oficial / a ver / es como / no es un oficial pero es casi [enfatizando] un oficial sería

Ent.: y acá es casi? [señalando SUB|MARINO] 
Carmela: [interrumpiendo] lo anterior [refiriéndose a la explicación de SUB|OFICIAL] no / este es

Diego: submarino

Carmela: como abajo

Diego: o sea abajo del mar

Ent.: y pueden ser distintas estas? [señalando SUB en SUB|MARINO y SUB|OFICIAL]

Diego: sí

Carmela: cuando vos le ponés el eeeh / el artículo solo / significa lo mismo / pero / depende del sustantivo que le pongas cambia

Carmela no solamente intenta asignar un significado al morfema aislado ( $\mathrm{SUB}=a b a j o$ ) sino que además plantea la posibilidad de que un mismo prefijo tenga dos significados distintos según con qué base léxica se una. Se trata de un ejemplo de rendimiento alto en cuanto a las posibilidades de reflexión metalingüística de los niños sobre las "partecitas" (que la niña llama artículos en su justificación) con las que están trabajando y que saben que no son palabras. Luana, la niña de la pareja de $6^{\circ}$ grado reutiliza al inicio la base léxica FUTBOL en las combinaciones FUTBOL|ERO y FUTBOL|ISTA, justificando además con un contraste pertinente entre gente que le gusta mucho el fútbol y el jugador / un alguien que juega al fútbol. Gerardo, el niño de $6^{\circ}$ grado, inicia con un alargamiento doble (DES|ACTIVA|DOR) y también con reutilización de base léxica (CUENT|ISTA Y CUENTION).

En lo que respecta a las justificaciones, en este tercer grupo encontramos más intentos de dar cuenta del significado de los morfemas aislados, particularmente del prefijo SUB- como abajo y del sufijo -BLE que en palabras de Sabrina $\left(6^{\circ}\right)$ significa que se puede hacer algo. También encontramos más casos en los que los niños plantean la posibilidad de que una base o un alargamiento tenga más de un significado: Gerardo ( $6^{\circ}$ ) plantea primero que CUENTO puede interpretarse como sustantivo y como verbo, y que, a su vez, la combinación CUENT|ON puede venir de CUENTO como un libro o de CUENTO como la factura.

El Cuadro 4 presenta de manera resumida el desarrollo de las variables presentadas a lo largo de los tres niveles descriptos para esta tarea de Alargar. 
Cuadro 4. Caracterización de los niveles en la tarea de Alargar palabras

\begin{tabular}{|c|c|c|}
\hline Nivel I & Nivel II & Nivel III \\
\hline \multicolumn{2}{|c|}{ Valores iguales a ambos lados de la diagonal } & $\begin{array}{l}\text { Valores diferentes a ambos } \\
\text { lados de la diagonal }\end{array}$ \\
\hline $\begin{array}{l}\text { Valores iguales o menores } \\
\text { a } 3\end{array}$ & \multicolumn{2}{|c|}{ Valores iguales o superiores a 4} \\
\hline $\begin{array}{c}\text { Utilización de } 1 \text { a } 3 \\
\text { morfemas derivativos }\end{array}$ & $\begin{array}{l}\text { Utilización de } 4 \text { o más } \\
\text { morfemas derivativos }\end{array}$ & $\begin{array}{l}\text { Utilización de } 5 \text { o más } \\
\text { morfemas derivativos }\end{array}$ \\
\hline \multicolumn{2}{|c|}{$\begin{array}{c}\text { No hay alargamientos dobles o reutilización de bases } \\
\text { léxicas o morfemas }\end{array}$} & $\begin{array}{c}\text { Presencia de alargamientos } \\
\text { dobles o reutilización de } \\
\text { bases léxicas o morfemas }\end{array}$ \\
\hline $\begin{array}{c}\text { Mayor presencia de } \\
\text { alargamientos no } \\
\text { esperados }\end{array}$ & \multicolumn{2}{|c|}{ Menor presencia de alargamientos no esperados } \\
\hline $\begin{array}{l}\text { Primacía de justificaciones } \\
\text { con ejemplos de uso }\end{array}$ & $\begin{array}{c}\text { Generalización de } \\
\text { justificaciones que } \\
\text { parafrasean el significado } \\
\text { que agregan los morfemas }\end{array}$ & $\begin{array}{c}\text { Intentos de otorgar } \\
\text { significado a los morfemas } \\
\text { aislados }\end{array}$ \\
\hline
\end{tabular}

Esta caracterización permite ver lo planteado al inicio de este apartado sobre la jerarquización de las variables para analizar el desempeño de los niños en la tarea de Alargar. En primer lugar, consideramos que los alargamientos iniciales son los que dan cuenta de las acciones de combinación de bases léxicas y morfemas derivativos que cada niño puede hacer por sí mismo. La dinámica cambiante y compleja de la interacción en parejas con el entrevistador durante el intercambio nos lleva a considerar con cierta precaución los alargamientos finales que surgen durante el intercambio. Por estos motivos, las variables del eje cuantitativo presentadas en el Cuadro 4 se refieren siempre a los alargamientos iniciales. El incremento en la cantidad de alargamientos a través de los niveles tiene que ver entonces con cuántas bases léxicas y con cuántos morfemas derivativos logran utilizar, y además si en un conjunto de fichas que tiene más morfemas que bases logran reutilizarlas o realizar un alargamiento simultáneo con prefijo y sufijo sobre la misma base (acción que caracteriza exclusivamente a los niños del nivel III). Por otro lado, en el Cuadro 4 podemos ver que la utilización de morfemas y bases en alargamientos plausibles pero no convencionales se concentra en el nivel I. El segundo eje de análisis tiene que ver con qué bases léxicas y morfemas utilizaron y cómo los justificaron. La próxima sección está dedicada a tratar en profundidad este tema. 
Por otro lado, veamos en el Cuadro 5 la distribución de los 60 niños interrogados en estos grupos principales según su grado escolar:

Cuadro 5 - Distribución de los 60 niños en niveles de tarea de Alargar según grado escolar ( $n=60)$

\begin{tabular}{c|ccc|c}
$\begin{array}{c}\text { Grado } \\
\text { escolar }\end{array}$ & Nivel I & Nivel II & Nivel III & Total \\
\hline $2^{\circ}$ & 11 & 7 & 2 & 20 \\
$4^{\circ}$ & 5 & 9 & 6 & 20 \\
$6^{\circ}$ & 3 & 6 & 11 & 20 \\
\hline Total & 19 & 22 & 19 & 60
\end{tabular}

En los niveles I y III encontramos, en principio, una distribución que se corresponde con los grados escolares: de los 19 niños que componen el nivel inicial 11 pertenecen a $2^{\circ}$ grado, mientras que de los 19 niños que conforman el nivel más avanzado 11 son de $6^{\circ}$ grado. El segundo nivel es el único con una distribución similar en los tres grados escolares.

Si retomamos ahora la consideración de la cantidad de alargamientos realizados pero esta vez a partir de los agrupamientos de niveles podemos representar en un cuadro: i) los alargamientos simples y esperados (es decir, los realizados con la utilización solamente de un prefijo o de un sufijo para alargar la base léxica); ii) los alargamientos dobles (simultáneos y no simultáneos); y iii) los alargamientos no esperados (o sea, plausibles pero no convencionales desde el punto de vista lingüístico).

Cuadro 6 - Alargamientos simples y esperados, alargamientos dobles y alargamientos no esperados según niveles en tarea de Alargar, considerando solo alargamientos iniciales

\begin{tabular}{cccc} 
Alargamientos & $\begin{array}{c}\text { Nivel I } \\
(\mathbf{n = 1 9})\end{array}$ & $\begin{array}{c}\text { Nivel II } \\
(\mathbf{n}=\mathbf{2 2})\end{array}$ & $\begin{array}{c}\text { Nivel III } \\
(\mathbf{n = 1 9})\end{array}$ \\
\hline $\begin{array}{c}\text { Alargamientos } \\
\text { simples y esperados }\end{array}$ & 44 & 90 & 88 \\
\hline $\begin{array}{c}\text { Alargamientos } \\
\text { dobles }\end{array}$ & 0 & 0 & 10 \\
\hline $\begin{array}{c}\text { Alargamientos no } \\
\text { esperados }\end{array}$ & 16 & 5 & 5
\end{tabular}


En el Cuadro 6 podemos ver el incremento de alargamientos simples y esperados entre el nivel I y el nivel II. Podría parecer llamativo que en el Nivel III no hay un incremento de alargamientos simples y esperados con respecto al Nivel II (aunque se duplican con respecto al Nivel I), pero se impone la consideración de la aparición de alargamientos dobles en este nivel lo que incrementa de hecho la cantidad de morfemas derivativos utilizados. El Cuadro 6 nos permite ver también la concentración de alargamientos no esperados en el Nivel I. Podemos decir que, en principio, estar en un nivel más avanzado supone poder realizar un mayor número de combinaciones esperadas e inclusive, solamente en el nivel más avanzado, considerar la posibilidad de realizar combinaciones simultáneas a derecha y a izquierda de una base.

\subsection{Utilización y justificación de bases léxicas y de morfemas derivativos}

En esta sección nos centraremos en las frecuencias de utilización de los morfemas derivativos y de las combinaciones realizadas con las bases léxicas, haciendo énfasis en los aspectos cualitativos, es decir en las justificaciones verbales que los niños dieron a los procesos de derivación. Es preciso aclarar que a pesar de que los dos conjuntos de fichas que recibía cada miembro de la pareja no son del todo equiparables -ni en las categorías gramaticales de las bases léxicas ni en las combinaciones potenciales con los morfemas derivativos-, a la hora de elaborar el diseño de investigación nuestro interés fue ofrecer posibilidades de exploración lo más cercanas posibles en ambos conjuntos. La Gráfica 2 muestra la frecuencia de utilización de cada morfema derivativo en los tres niveles planteados en el apartado anterior, solamente considerando alargamientos iniciales.

Los sufijos son más utilizados en general que los prefijos. Estos son datos coincidentes con otros autores que sostienen la precedencia evolutiva de los sufijos (Fejzo, 2016). Ciertamente, hay una diferencia entre enunciar una base léxica y luego un modificador a esa base como en FUTBOL|ISTA, y enunciar primero el modificador (que como vimos en el apartado, solamente para algunos niños del nivel III tiene un significado 
cuando está aislado) antes de saber a qué base se puede aplicar (por ejemplo suB- en SUB (OFICIAL). Por otra parte, entre los sufijos, los morfemas denominales de nuestro diseño (-ERO, -ISTA y -DOR) son los más utilizados en los tres niveles. Por su parte, el sufijo -BLE recién parece estar más disponible para los alargamientos en el nivel más avanzado. La poca disponibilidad de -ON está directamente condicionada por las bases léxicas presentadas en el diseño. Entre los prefijos, el negativo IN- es el que parece presentar mayores dificultades para poder ser utilizado en combinaciones. Comencemos por ver lo realizado por los niños con los sufijos de nuestro diseño.

Gráfica 2 - Frecuencia de utilización de morfemas derivativos en alargamientos iniciales, según nivel en tarea de Alargar

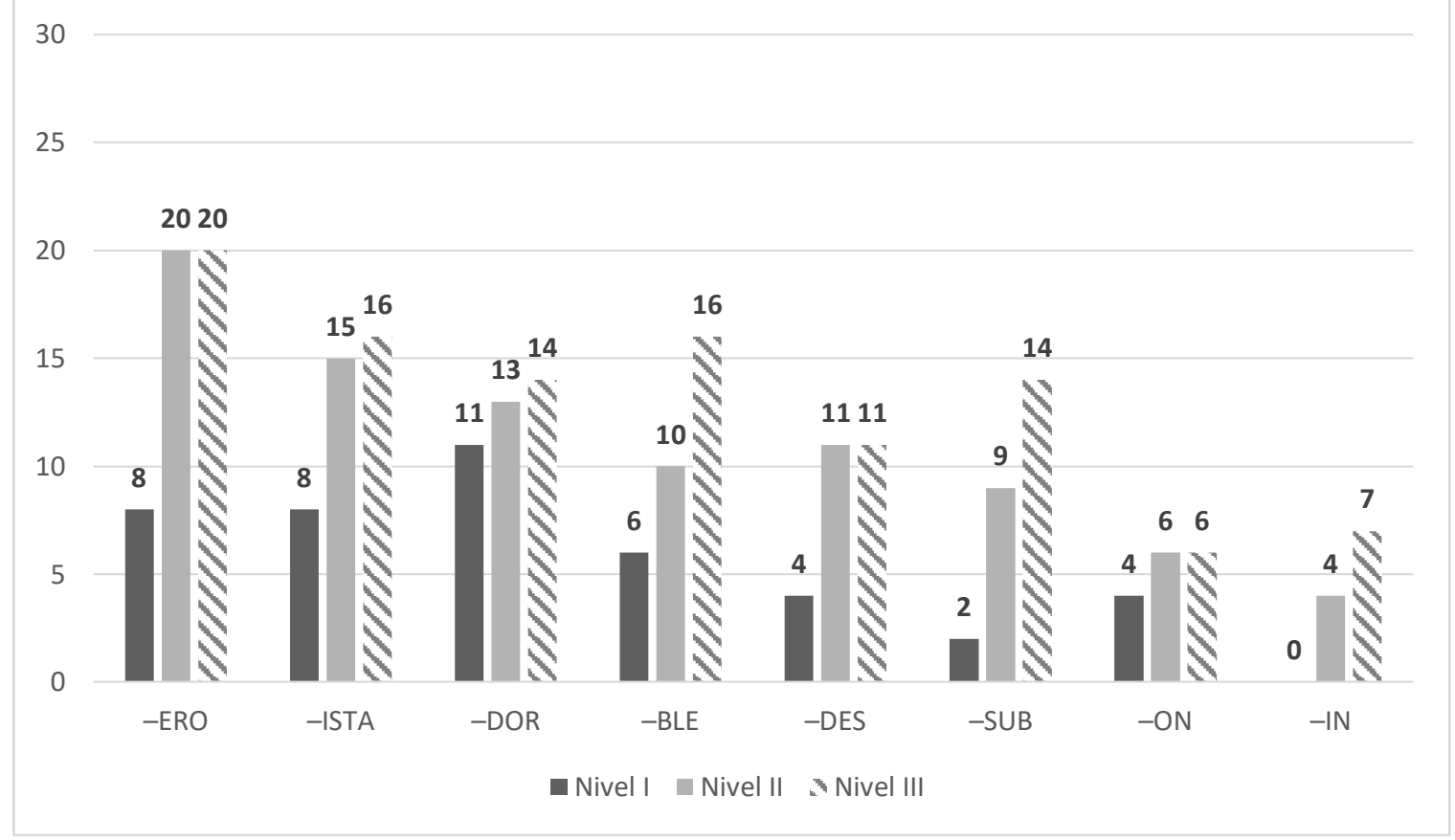

El sufijo más utilizados por todos los niños fue -ERO. La serie FLORERO fue realizada por 19 niños sobre 3023, RELOJERO 10/30, FUTBOLERO 9/30, MARINERO 8/30 y finalmente CUENTERO solo recibió 2/30 combinaciones. Entre los alargamientos posibles distinguimos derivaciones sustantivas que designan "oficios y ocupaciones" (RELOJERO y MARINERO) y

\footnotetext{
${ }^{23}$ Teniendo en cuenta que cada niño de una pareja recibía un conjunto con bases léxicas distintas, para cada alargamiento tenemos un máximo potencial de 30, es decir: en total 30 niños recibían las fichas de un conjunto mientras los otros 30 niños del corpus recibían las bases léxicas del otro conjunto (ver Cuadro 3).
} 
también derivaciones en las que "el sustantivo que constituye la base designa aquello que se tiene por afición" (FUtBolero y CUENTERO) (RAE/ASALE, 2009:126). A diferencia de estos casos en que hay una referencia agentiva en la derivación, en FLORERO encontramos que el sufijo aporta un significado instrumental de "recipiente o contenedor" del sustantivo indicado por la base léxica (RAE/ASALE, 2009:126). Veamos por separado las justificaciones agentivas e instrumentales a lo largo de los tres niveles planteados.

Desde el nivel I los niños parecen no tener mayores problemas para justificar el significado que agrega el sufijo -ERO en series como RELOJERO O MARINERO. Siempre encontramos referencias pertinentes a:

- Persona que trabaja en algo relacionado con la base: Isabella (nivel $1-4^{\circ}$ ) MARINERO una persona con el trabajo de ayudar al capitán del barco; Román (nivel $\mathrm{III}-6^{\circ}$ ) RELOJERO es el que trabaja en una relojería y que arregla relojes

- Persona que fabrica o vende el sustantivo designado por la base: Clara (nivel II $4^{\circ}$ ) RELOJERO es el que vende relojes; Laura (nivel III $-6^{\circ}$ ) RELOJERO es una persona que vende reloj / que hace reloj y que los vende.

La serie FUTBOLERo presenta en los niños del nivel I y II cierta inestabilidad entre la interpretación convencional de "sujeto aficionado por el deporte fútbol" o la interpretación agentiva "jugador de fútbol", significado para que el que la lengua dispone de la forma FUTBOLISTA. Más adelante trataremos con mayor detenimiento este tema de los esquemas rivales para la formación de palabras. Por ahora, adelantamos que los niños del nivel I y II igualan las series FUTBOLERO y FUTBOLISTA al ser consultados por sus significados. Veamos dos ejemplos:

- Martín (nivel $1-2^{\circ}$ ) justifica FUtBOLERo como alguien que juega al fútbol y cuando en el intercambio surge la posibilidad de contrastarlo con FUTBOLISTA el niño agrega futbolista es igual / es alguien que juega al fútbol.

- Marcos (nivel II $-4^{\circ}$ ) explica primero que fUtBolero sería como un hombre que juega al fútbol y luego en el intercambio agrega FUTBOLISTA sería lo mismo que futbolero.

Es en el nivel III en el que encontramos el nivel más alto de reflexión en torno al contraste entre las formas con -ERO y con -ISTA:

- Darío (nivel III - $4^{\circ}$ ) FUtBolero es cuando te gusta el fútbol / FUTBOLISTA ahí es el jugador de fútbol / cuando juega 
- Luana (nivel III $-6^{\circ}$ ) suelo decir futbolero a la gente que le gusta mucho el fútbol / que está todo el día hablando de fútbol mientras que FUTBOLISTA es como el jugador I un alguien que juega al fútbol.

Por otro lado, la interpretación instrumental de FLORERO como maceta o lugar donde se ponen las flores está extendida en los niños de todos los niveles:

- Camila (nivel I- $2^{\circ}$ ) es como un tarro grande que le ponés tierra plantas una semilla $y$ ahí va creciendo una flor

- Luna (nivel II - $4^{\circ}$ ) donde ponen las plantas/por ejemplo yo me compro una planta y me compro un florero así le pongo agua y pongo la planta

- Gerardo (nivel III $-6^{\circ}$ ) un objeto que contiene las flores

Aunque el sufijo -ERo fue el más utilizados por los niños y en la mayoría de los casos recibió justificaciones pertinentes, dar cuenta del significado del morfema cuando está aislado fue una tarea sumamente difícil. Un factor que parece incidir en este sentido es el hecho de que el morfema sirve para derivar sustantivos que se refieren tanto a objetos como a personas, y que además indica ideas agentivas distintas como "ocupación" o "afición". Consultado por el significado del morfema aislado, Pablo (nivel III - $4^{\circ}$ ) sostuvo que -ERO significa un montón de cosas porque acá es que vende [en FLORERO y RELOJERO] acá es que juega al fútbol [FUTBOLERO] y acá es que navega [MARINERO] / el significado depende de la raíz.

El segundo sufijo más utilizado fue -ISTA. Las series realizadas incluyen FUTBOLISTA con 17/30 combinaciones, OFICIALISTA 13/30, FLORISTA $8 / 30$ y un único alargamiento para CUENTISTA. En el caso de FUTBOLISTA encontramos la justificación generalizada en todos los niveles de "jugador de fútbol". Apenas en el nivel II encontramos un caso llamativo de interpretación de amalgama: Emiliano $\left(2^{\circ}\right)$ dice que FUTBOLISTA es como un jugador que sabe mucho de fútbol y juega muy bien / un jugador más listo y más goleador / es como listo en el fútbol. Se trata de un intento de encontrar dos segmentos con significados plenos aunque combinados dentro de una misma serie. También resultó interesante que con la base léxica FUTBOL varios niños pudieron contrastar las formas FUTBOLERO y FUTBOLISTA durante el intercambio. Entre los contrastes propuestos distinguimos: a) una mayoría de justificaciones convencionales ya sea sobre el contraste "fanático/jugador" o 
"amateur/profesional"; b) algunos niños (todos del nivel I y II) que no encontraron diferencias entre las dos formas y se refirieron a ambas como el "sujeto que juega al fútbol"; c) algunas justificaciones inesperadas (todas también del nivel I y II) entre las que destacamos:

- Sujetos con diferencias calificativas: Matias (nivel $1-4^{\circ}$ ) - FUTBOLERO es una persona que juega al fútbol / que le pega muy fuerte al arco / el futbolista también le puede pegar pero no tan fuerte como el futbolero.

- Sujetos que realizan distintas acciones: Clara (nivel II - $4^{\circ}$ ) - FUTBOLERO sería como un hombre que enseña a jugar al fútbol / futbolista es cuando jugás y futbolero cuando enseñás.

- Sujeto singular vs. sujeto plural: Luciano (nivel I- $6^{\circ}$ ) - FUTBOLISTA como jugador de fútbol / un [enfatizando] hombre que juega - FUTBOLERO muchos hombres que juegan al fútbol.

El alargamiento FLORISTA interpretado como "sujeto que vende flores" tampoco presentó problemas para los niños de los tres niveles. De hecho, a diferencia del contraste de sufijos con la base FUTBOL, el par FLORERO/FLORISTA recibió siempre justificaciones adecuadas, es decir, “objeto" para -ERO y “ocupación” para -ISTA: Josefina (nivel I - $2^{\circ}$ ) sostuvo que FLORERO es donde se ponen las flores mientras que FLORISTA es alguien que vende flores en un vivero.

Otro caso interesante con el sufijo -ISTA fue el alargamiento OFICIALISTA. A diferencia de las combinaciones anteriores en las que el sufijo producía derivaciones agentivas vinculadas a "ocupación o profesión", en este caso -ISTA designa aquello de lo que se es partidario, con una referencia a las convicciones políticas (OFICIALISTA es "quien apoya al gobierno oficial"). Ninguno de los 5 niños del nivel I que realizó el alargamiento pudo justificarlo. De todas las bases léxicas que admitían alargamientos esperados con -ISTA (FUTBOL, RELOJ y FLOR) OFICIAL es la única que puede ser interpretada categorialmente como sustantivo o como adjetivo. En los pocos intentos de justificación que registramos aparece una dificultad vinculada con la interpretación sustantiva de la base léxica OFICIAL="policía". En los 3 niños del nivel II que elaboraron justificaciones encontramos:

- una interpretación de amalgama - Luis $\left(2^{\circ}\right)$ para mí es como el policía que te atiende y te da una lista / por ejemplo vos querés sacar a un ladrón y te da una lista de quiénes son 
- un tipo de policía: Tobías $\left(6^{\circ}\right)$ oficial de oficina / no salís a atrapar gente / policía de las oficinas

- una interpretación gradativa de -ISTA como si indicara posición de rango inferior: Luna $\left(4^{\circ}\right)$ el suplente / sería una persona que se está por recibir de oficial.

Tampoco los niños del nivel III que alargaron OfICIALISTA elaboraron justificaciones. A diferencia de los niños del nivel inicial, en este caso, durante el intercambio descartaron la forma por considerarla no convencional. Veamos el diálogo entre Genaro y Carolina, pareja de $4^{\circ}$ grado:

Ent.: oficial qué es?

Genaro: oficial sería un policía

Carolina: un policía [dudando] // no sé

Genaro: sí

Carolina: oficial es como un jefe

Ent.: y oficialista?

Carolina: $\mathrm{mmm}$ creo que no significa nada

Genaro: no / está mal redactado / yo no sé cómo decirlo pero para mí está mal redactado

Al igual con -ERO, todos los niños encontraron difícil la tarea de explicar el significado de -ISTA cuando está aislado. Gerardo $\left(6^{\circ}\right)$, niño presentado en los ejemplos introductorios (sección 2.3) ${ }^{24}$ y que realiza y justifica alargamientos con -ISTA, consultado por el significado del morfema dice no quiere decir nada / sería como un sufijo.

El tercer sufijo denominal más utilizado es -DOR. Con la base léxica comunica los niños realizan 14/30 alargamientos, mientras que con ARMA encontramos 13/30 y con ACTIVA 11/30. En general, estas combinaciones reciben interpretaciones agentivas o instrumentales. La serie ARMADOR es la única que recibió en los tres niveles la interpretación agentiva de "sujeto que realiza la acción de armar". Encontramos, sin embargo, una interpretación desviante que surge a partir de la posibilidad de interpretar la base léxica ARMA como verbo pero también como sustantivo ("arma de fuego"). En este sentido, algunos niños de los niveles I y II justificaron ARMADOR como el calificativo "persona armada":

\footnotetext{
${ }^{24}$ Cuando remitimos a otros fragmentos de la tesis la indicación "sección 2.3.", por ejemplo, significa
} "capítulo 2, sección 3". 
- Valeria (nivel $1-2^{\circ}$ ) gente que está armada por las dudas

- Guadalupe (nivel II - $2^{\circ}$ ) alguien que está muy armado / tiene muchas armas

- Luna (nivel $\mathrm{II}-4^{\circ}$ ) una persona que está armada

En estos casos la interpretación sustantiva de la base léxica parece primar a la hora de considerar el significado final de la combinación con el morfema derivativo. En otros casos, como el de la pareja de $4^{\circ}$ grado presentada en los ejemplos introductorios, Diego (nivel II) y Carmela (nivel III) plantean la posibilidad de interpretar la base como verbo y como sustantivo pero en la justificación del alargamiento se centran en el significado agentivo de "persona que realiza la acción indicada por la base léxica", es decir, ARMADOR como alguien que arma cosas.

En el caso de las series COMUNICADOR y ACTIVADOR encontramos una alternancia de interpretaciones agentivas e instrumentales. Para COMUNICADOR prima en los tres niveles la interpretación agentiva: Carmela (nivel III $-4^{\circ}$ ) sostiene que COMUNICADOR es como la persona que comunica / vos sos un comunicador o sea que vos comunicás lo que pasa a tu lado. En todos los casos se trata de interpretaciones agentivas e instrumentales excluyentes entre sí.

Por otro lado, con la serie ACTIVADOR encontramos en los tres niveles una primacía de la interpretación instrumental: Tamara (nivel $1-2^{\circ}$ ) dice sobre ACTIVADOR son las teclitas de la luz vos las prendés y estás activando la luz y eso sería como un activador. Con la base léxica ACTIVA, además, encontramos los dos únicos casos en que los niños plantean la posibilidad de que una derivación con -DOR pueda interpretarse tanto agentiva como instrumentalmente (lo que sería el punto máximo de reflexión metalingüística para estos $\operatorname{casos}^{25}$ ): Candela (nivel $1-4^{\circ}$ ) sostiene que ACTIVADOR es una persona o un objeto que activa las cosas, mientras que Tiago (nivel III $-6^{\circ}$ ) explica que INACTIVADOR es alguien que inactiva algún dispositivo / es lo opuesto a activador / también creo que es un botoncito vos lo tocás y desactiva tal dispositivo.

\footnotetext{
25 “El sufijo - dor puede expresar los significados 'agentivo' e 'instrumental'. En principio, estos significados parecen ser diferentes; pero resulta que hay nombres en -dor con significado agentivo (decorador, diseñador, constructor) con significado instrumental (congelador, grapadora, secador) y con ambos significados -agentivo e instrumental- (agitador, programador, soldador)" (Pena, 2003:512).
} 
Por último, mencionamos que encontramos pocos casos en los que niños que utilizaron el sufijo -DOR en sus alargamientos se centraron solamente en la base verbal a la hora de justificarlos, como si el agregado gráfico del morfema no implicara ninguna modificación en la interpretación verbal de la derivación. Se trata de niños del nivel I y II:

- Luciano (nivel $1-6^{\circ}$ ) ACTIVADOR yo diría cuando activás algo / porque está activado.

- Renata (nivel $11-2^{\circ}$ ) comUNiCAdOR es como que te comunicás con él / como el celular pero te comunicás o hablás

A pesar de que el sufijo -DOR parece estar disponible en niños de los tres niveles para realizar combinaciones, no parece fácil la tarea de atribuirle significado cuando está aislado. Agustín (nivel II $-4^{\circ}$ ) consultado por qué significa la ficha -DOR dice que no quiere decir nada / no tiene significado.

El sufijo deverbal -BLE fue utilizado con las cuatro bases léxicas disponibles en nuestro diseño: con ARMA y PINTA recibió 10/30 alargamientos respectivamente, con COMUNICA 8/10 y finalmente con ACTIVA 4/10. En su interpretación más productiva -BLE tiene un significado de "potencialidad y pasividad" (Lázaro Mora, 1999) y admite la paráfrasis "que puede ser + participio de la base léxica" (RAE/ASALE, 2009:146). Así, COMUNICABLE, por ejemplo, sería "que puede ser comunicado".

Este sufijo fue particularmente difícil de interpretar para los niños del nivel inicial. En algunos casos alargaron pero no elaboraron justificaciones, mientras que en otros los niños centraron su interpretación en el significado verbal de la base léxica. Entre estos últimos hay casos interesantes en que los niños parecen interpretar que el agregado gráfico de -BLE modifica algún complemento propio del verbo, por ejemplo, la indicación de singular vs. plural en el complemento argumental ${ }^{26}$ : Belén (nivel $1-2^{\circ}$ ) sobre COMUNICABLE dice como que se comunica con todos, en tanto que Martín (nivel $1-2^{\circ}$ ) sostiene que es como comunicarte con alguien. Ciertamente, las derivaciones deverbales en -BLE "presentan comportamientos sintácticos que los vinculan con el verbo de la base"

\footnotetext{
${ }^{26}$ Para José-Álvaro Porto Dapena "la acción de comunicar implica un destinatario que, aun en el caso de que no se exprese, se halla de algún modo sobreentendido, si bien de una manera inconcreta y general" (Porto Dapena: 2002:15).
} 
(RAE/ASALE, 2009:147). En las justificaciones de Martín y Belén encontramos una centración en la acción verbal de la base más una especificación (uno vs. muchos) para un complemento pertinente al verbo (comunicarse "con alguien"), aunque no hay referencias a la idea de potencialidad que agrega el sufijo. También en este nivel I tenemos una justificación de amalgama: para Matías (nivel $1-4^{\circ}$ ) comunicable es comunicación por cable, lo que constituye un intento de encontrarle sentido a la forma que se agrega, pero en este caso utilizando la sílaba final de la base léxica para "leer" otra palabra de sentido pleno como cable (y que además constituye un sintagma nominal coherente semánticamente con el significado de la base comUNICA).

En el nivel II se generaliza la justificación de las series a través de una paráfrasis centrada en la idea de "posibilidad" más las bases léxicas en infinitivo. Con la única excepción de Gonzalo (nivel II $-2^{\circ}$ ) quien interpretó agentiva e instrumentalmente PINTABLE como una máquina pintadora o un señor que pinta, el resto de los niños del nivel II elaboró justificaciones centradas en la posibilidad realizar la acción:

- Lucía (nivel II - $2^{\circ}$ ) PINTABLE que se puede pintar

- Julián (nivel II-4 $4^{\circ}$ ACTIVABLE que se puede activar

- Tobías (nivel II $-6^{\circ}$ ) ARMABLE un objeto armable / que lo podés armar y desarmar

En el nivel III encontramos una generalización de las justificaciones con paráfrasis centradas en la idea de "posibilidad de realizar la acción indicada por la base léxica" y también los únicos intentos de dar cuenta del significado del morfema cuando está aislado. Veamos el intercambio entre Tiago y Natalia (nivel III $-6^{\circ}$ ) justificando el alargamiento ARMABLE:

Tiago: armable es / por ejemplo las cajas de Lego / los Legos son unos juguetes / no? / unos bloquecitos

Ent.: ajá

Tiago: son armables / en la caja te sale el juguete y el juguete es armable porque viene con los bloques para que vos lo armés

Ent.: y qué quiere decir esta partecita? [señalando BLE]

Tiago: como que se puede [enfatizando] hacer tal

Natalia: claro / algo posible 
Se trata de un rendimiento máximo de reflexión metalingüística que solamente encontramos en niños del nivel más avanzado. Es más, aun niños de nivel III como Gerardo, que obtuvieron un valor alto en esta tarea de Alargar (niño de $6^{\circ}$ grado con un valor de $7 / 5$ en la tarea) y elaboraron justificaciones pertinentes, dan cuenta de las dificultades que implica asignarle significado a "estas partecitas": consultado sobre qué significa -BLE Gerardo dice para mí no sé si tiene mucho [significado] / me parece que más / cuando vos le ponés ese sufijo o prefijo cambia el significado de la palabra / pero ese sufijo prefijo no tiene un significado.

Por último, el sufijo menos utilizado en la tarea de Alargar fue el aumentativo -on. Como indicamos anteriormente (sección 2.3), esto se debió principalmente a la escasa disponibilidad para combinar con las bases léxicas seleccionadas en nuestro diseño. La serie CUENTON fue realizada 9/30 veces, mientras que RELOJON recibió 7/30 alargamientos. Todas las justificaciones de RELOJON, en los tres niveles, se basaron en la interpretación convencional del sufijo como aumentativo: Matias (nivel $14^{\circ}$ ) me parece que sería un reloj grande, Gonzalo (nivel II $-2^{\circ}$ ) un reloj grandote / como el reloj de Londres, Natalia (nivel III $-6^{\circ}$ ) un reloj muy grande.

En el caso de CUENTON, en cambio, encontramos sorprendentemente una interpretación aumentativa y también una apreciativa. Entre estas últimas tenemos los ejemplos de Jazmín (nivel $1-4^{\circ}$ ) que explica la serie como un cuento hermoso o sea por ejemplo la abuela te cuenta un cuento y vos decís / uh abuela eso fue un cuentón; y también de Jeremías (nivel II $-4^{\circ}$ ) que dice como que estuvo muy bueno el cuento / un cuentazo. En el último caso, además, el niño propone oralmente una nueva derivación con otro sufijo, -AzO, que también agrega un significado meliorativo equivalente a -ON.

Un aspecto que nos interesa destacar es que las interpretaciones aumentativas del sufijo -ON presentaron diversos matices para explicar la dimensión del "aumento" en la derivación de CUENTON, algo que no habíamos previsto en nuestras hipótesis iniciales. Destacamos las siguientes:

- El aumento en el tamaño y en la antigüedad del cuento: Camila (nivel $1-2^{\circ}$ ) un cuento antiguo y grande. 
- La idea de una antología que contiene gran cantidad de cuentos: Matías (nivel I $4^{\circ}$ ) - CUENTON a lo mejor tiene muchos cuentos o un cuento grande / un cuento con varios adentro.

- El aumento en cantidad de páginas: Martín (nivel II - $4^{\circ}$ ) - CUENTON es como un súper cuento que tiene un montón de páginas.

- El aumento en el tiempo que implica leer un cuento: Ulises (nivel II - $4^{\circ}$ ) - CUENTON es algo que dura mucho / que casi no termina de leerlo.

Si bien se trata del sufijo menos utilizado en la tarea de Alargar por razones vinculadas con el diseño de los materiales, y no encontramos ningún intento de dar cuenta del significado del morfema cuando está aislado, todos los niños de los tres niveles que utilizaron -ON no tuvieron ninguna dificultad en justificar la derivación aumentativa o apreciativa en las combinaciones realizadas. Además, la variedad de referencias aumentativas (número de páginas, tiempo de lectura, antologías) es sorprendente ya que el material presentado no permitía suponer tal diversidad en la variable cuantitativa.

En cuanto a los prefijos, DES- es el morfema más utilizado (inclusive el más utilizado por los niños del nivel I: 4 alargamientos en este nivel, frente a 2 con SUB- y ninguno con $\mathrm{IN}-$ ). Las combinaciones registradas son: DESPINTA 9/30, DESACTIVA 6/30, DESCUENTO 5/30, DESARMA 4/30 y DESCOMUNICA 2/30.

Distinguimos primero el caso de DESCUENTO, que siempre fue interpretado nominalmente por los niños como "rebaja en el precio de un producto", es decir, una forma lexicalizada en la que DES- no aporta el significado negativo asociado al prefijo. En los tres niveles los niños no tuvieron dificultades para justificar en este sentido la combinación: Candela (nivel $1-4^{\circ}$ ) vas a un negocio y te tienen que hacer un veinte por ciento de descuento / entonces de los mil que vos pagaste te descuentan veinte pesos; Guadalupe (nivel II $-2^{\circ}$ ) como diciendo dos por uno o sea te llevás dos / sería como una promo; o Tiago (nivel III - $6^{\circ}$ ) cuando le restás el precio a algún objeto.

En las demás combinaciones, el prefijo DES- agrega a las bases el significado de "acción contraria o reversiva" (RAE/ASALE, 2009:188) a la referida por la base léxica. Los niños del nivel I enfrentaron ciertas dificultades para poder justificar sus combinaciones. En todos los casos registrados encontramos justificaciones tautológicas o ejemplos de uso que no logran dar cuenta del significado que agrega el prefijo: Emanuel (nivel $1-2^{\circ}$ ) dice 
que DESARMA es por ejemplo cuando alguien arma algo y después lo desarma, y Catalina (nivel $1-6^{\circ}$ ) que es un verbo / él está desarmando un barco.

Los niños del nivel II también recurren en sus explicaciones a ejemplos de uso, aunque en algunos casos hay referencias indirectas a realizar una acción contraria a la indicada por la base: sobre DESPINTA Florencia (nivel II $-4^{\circ}$ ) dice es como sacar la pintura y sobre DESACTIVA Agustín (nivel II $-4^{\circ}$ ) mi primo desactiva la luz / la apaga y se corta todo.

En el nivel III continúan las justificaciones con ejemplos de uso (Natalia, $6^{\circ}$, DESPINTA cuando vos despintás algo / pintás una pared pero después la despintás porque no te gustó el color) y algunas también con referencias indirectas a una acción contraria a la indicada por la base (Lucas, $2^{\circ}$, DESPINTA sería como que alguien por ejemplo se confundió y saca la pintura). A diferencia de los niveles anteriores, en este grupo más avanzado encontramos 5 casos en los que el prefijo DES- fue utilizado junto a otros sufijos (-BLE y -DOR) en alargamientos dobles. En todos estos casos los niños se centraron en los sufijos a la hora de justificar las series y solamente en un caso encontramos una referencia a la idea de "negación", lo que parece indicar que en presencia de estos otros morfemas el prefijo DES- es más opaco para los niños. En los casos en que el alargamiento doble incluía el sufijo -BLE encontramos siempre interpretaciones que parafrasean la idea de "posibilidad de realizar la acción referida por la base léxica":

- Delfina (nivel III $-2^{\circ}$ ) DESARMABLE que se puede desarmar

- Darío (nivel III $-4^{\circ}$ ) DESPINTABLE que se puede borrar

- Pedro (nivel III $-6^{\circ}$ ) DESACTIVABLE que se puede desactivar / es un adjetivo

Cuando el alargamiento doble incluía el sufijo -DOR las justificaciones de los niños se centraron en la interpretación agentiva de "sujeto que realiza la acción indicada por la base verbal" y solamente en un caso esta interpretación fue acompañada con una referencia a la negatividad que agrega el prefijo:

- Gerardo (nivel III $-6^{\circ}$ ) DESACTIVADOR un objeto que desactiva algún coso

- Lara (nivel III - $4^{\circ}$ ) DESACTIVAdOR es un hombre que desactiva cosas / activador es una persona que activa / lo antónimo de desactiva 
En el siguiente intercambio de Darío y Paula, niños de $4^{\circ}$ grado y pertenecientes al nivel III, podemos ver las dificultades que los niños enfrentan para reflexionar sobre el significado que agrega el prefijo DES- a las series disponibles en nuestro diseño:

Ent.: pinta así [señalando PINTA] qué es?

Darío: pinta es / es cuando pintás cuando pintás las paredes

Ent.: y despinta? [señalando la combinación DES|PINTA]

Darío: es cuando lo sacás cuando

Paula: cuando lo estás despintando

Darío: o borrando

En.: y este [señalando DES] lo pongo [combinando DES|ARMA] / lo cambia?

Paula: si porque tiene des

Ent.: qué quiere decir esto? [señalando DES]

Paula: que eh / que lo que / o sea que lo cambia / en este caso lo desarma y en este lo despinta [señalando DES|ARMA Y DES|PINTA respectivamente]

Darío: con la raíz / la raíz puede cambiar / pero el prefijo o el sufijo también puede ser el mismo de acá / no ves? / des y des [señalando DES en DES|ARMA Y DES|PINTA]

Ent.: $y$ estos [señalando DES en ambas combinaciones] quieren decir lo mismo cuando están con distintas raíces?

Darío: sí

Ent.: qué quiere decir?

Darío: $\mathrm{mmm}$ [dudando]

Ent.: estos [señalando las fichas DES de ambos niños] los habían dejado afuera del tablero ustedes?

Paula: no / no son palabras

Darío: es como habíamos hecho antes / son sufijo y prefijo y si mezclás un sufijo o un prefijo con una raíz se forma otra palabra

En el intercambio, los niños dan ejemplos de uso para las dos derivaciones con DESy, consultados por el significado del morfema aislado, lo explican tautológicamente aunque postulan que para ambas (DESARMA y DESPINTA) DES- tiene el mismo significado. Sin embargo, es destacable que los niños puedan elaborar una distinción pertinente desde el punto de vista lingüístico: hay "pedacitos" que no son palabras (y que ellos inclusive nombran utilizando terminología metalingüística-escolar como sufijo y prefijo) pero que sirven para unirse a raíces para formar otra palabra. Es interesante lo que sucede más adelante cuando el entrevistador les propone la combinación DESCUENTO:

Ent.: y lo puedo hacer con este? [sugiriendo el alargamiento DES|CUENTO]

Darío: descuento [probando el alargamiento y leyendo para sí]

Paula: si 
Darío: sí es cuando te descuentan plata del cajero

Ent.: y es lo mismo que me decían de desarma y despinta?

Paula: si

Darío: sí porque lo único que cambia es la raíz

Paula: y además / que vas sacando el des [señalando DES] significa que vas sacando

Ent.: antes me dijiste que cuento era una narración [refiriéndose a un momento anterior del intercambio con los niños]

Paula: sí / pero también al agregarse prefijos y sufijos cambia la palabra / y puede ser que al cambiarla no sea un sufijo o un prefijo

Ent.: ajá / ahí qué es para vos en descuento? [señalando DES en DES|CUENTO]

Darío: ahí descuento es una palabra / entera

A pesar de las dificultades que los niños encuentran para dar cuenta del significado del morfema, en el intercambio reflexionan sobre una distinción lingüística también muy pertinente: hay alargamientos que comparten series gráficas pero no morfemas, es decir, DES- en DESARMA y DESPINTA significa reversión de la acción (significa que vas sacando dice Paula) mientras que la misma serie gráfica en DESCUENTO es una parte inseparable de la serie completa, es una palabra entera como lo explica Darío.

El segundo prefijo más utilizado por los niños fue el locativo suB-: 18/30 veces en SUBMARINO y 7/30 en SUBOFICIAL. En el primer caso el prefijo tiene un sentido locativo y denota "posición inferior", mientras que en el segundo encontramos un sentido "gradativo y escalar" como extensión del primer significado, es decir, en SUBOFICIAL el prefijo denota "rango o nivel inferior en una jerarquía" (RAE/ASALE, 2009:186).

Los niños de los tres niveles no tuvieron dificultades en justificar los alargamientos de SUBMARINO con referencias directas a la idea de "barco que va por abajo del agua": Belén (nivel $1-2^{\circ}$ ) es como un barco pero que está cubierto y está abajo del agua; Renata (nivel II $-2^{\circ}$ ) es como una nave que va bajo del agua; y Ariadna (nivel III $-6^{\circ}$ ) es un medio de transporte que puede ir por el agua / pero abajo del agua. Solamente en niños del nivel III encontramos justificaciones con intentos de explicar el significado del morfema cuando está aislado: por ejemplo Román (nivel III $-6^{\circ}$ ) dice sub significa abajo mientras que Néstor (nivel III $-6^{\circ}$ ) dice sub significa por abajo.

En el caso de los alargamientos de SUBOfICIAL la situación es diferente. En primer lugar, señalamos que solamente los niños de nivel II y III realizaron este alargamiento y a 
excepción de un único caso los niños interpretaron siempre la base léxica nominalmente como OFICIAL="policía". Si bien en las justificaciones encontramos la idea de "rango inferior en una jerarquía", los niños elaboraron otras interpretaciones con matices interesantes para explicar el significado del prefijo:

- debajo del oficial - Pedro (nivel III $-6^{\circ}$ ) debajo del oficial / de que su puesto está debajo del oficial

- el segundo - Lorena (nivel II - $6^{\circ}$ ) sería como el segundo oficial

- el suplente - Nicolás (nivel II $-2^{\circ}$ ) cuando un oficial falta al trabajo va el suboficial / es un policía suplente al otro

- que se está preparando para - Paula (nivel III - $4^{\circ}$ ) sería el que se está preparando para ser oficial.

Solamente hay un caso en el que Gerardo (nivel III $-6^{\circ}$ ) interpreta la base léxica como adjetivo: suboficial sería antes de que esté oficialmente / una réplica sería / por ejemplo yo tengo la pelota suboficial del mundial. La variedad de matices en la interpretación de SUBOFICIAL tampoco estaba prevista en nuestras hipótesis iniciales sobre las posibles justificaciones de los niños.

Por último, el prefijo (y el morfema derivativo de todos los disponibles en nuestro diseño) menos utilizado por todos los niños fue el prefijo negativo y privativo IN-. Ningún niño del nivel I lo utilizó en sus alargamientos. Los niños del nivel II y III elaboraron 6/30 alargamientos con las bases ACTIVA y cOMUNICA respectivamente. Entre los niños del nivel II encontramos justificaciones variadas. Entre ellas distinguimos:

- Justificación centrada en el significado de la acción verbal sin referencia a la negación o privación: Luis (nivel II $-2^{\circ}$ ) INACTIVA puede ser cuando te suena / inactiva sería una alarma inactiva que te avisa algo / que hace como ruido

- Paráfrasis negativa de la acción indicada por la base verbal: Abril (nivel II $-6^{\circ}$ ) INACTIVA por ejemplo una alarma está inactiva / no está activada

- Ejemplo de uso más intento de explicar el significado del morfema aislado: Diego (nivel III $-4^{\circ}$ ) INACTIVA la grabadora ahora está activa pero cuando antes al principio / está inactiva o sea que no la activaste / in ese [señalando la ficha IN] es no.

Entre los niños del nivel III encontramos varios casos de alargamientos dobles con el prefijo IN- más los sufijos -DOR y -BLE. A diferencia de lo que ocurrió con el prefijo 
negativo DES-, en este caso, las justificaciones de los niños parecen centrarse en la idea de negación que aporta el prefijo IN-. Veamos algunos ejemplos:

- Pablo (nivel III - $4^{\circ}$ ) INCOMUNICABLE que no me puedo comunicar

- Laura (nivel III - $6^{\circ}$ ) INPINTABLE ${ }^{27}$ que no se puede pintar / es como lo contrario de pintable

- Román (nivel III - 6 $6^{\circ}$ INCOMUNICADOR sería como alguien que no comunica

Si bien varios niños parafrasean la idea de negación de las bases verbales (no comunica, es lo contrario de, no está activada), son muy pocos los que además logran atribuir un significado al morfema cuando está aislado. Citamos como ejemplo el la pareja de $4^{\circ}$ grado de Julián y Clara, ambos niños del nivel II, que aceptan la forma INACTIVA propuesta por el entrevistador y mantienen el siguiente diálogo:

Julián: inactiva

Ent.: qué es?

Julián: que no la podés activar

Clara: in in es

Julián: que no lo podés activar

Clara: por ejemplo esto [señalando IN] lo usarías para inapropiado o sea que no se puede

Ent.: y qué es inapropiado?

Clara: inapropiado es las cosas que te dicen que no [enfatizando] podés hacer / o sea inapropiado es que podés romper un televisor y te dicen no porque es inapropiado

Ent.: ajá / y qué quiere decir este pedacito? [señalando IN]

Clara: el in

Julián: sería que no se puede hacer

Clara: significa no

A partir de revisar la frecuencia de utilización de los morfemas derivativos de nuestro diseño en los niveles evolutivos planteados para la tarea de Alargar (ver Gráfica 2), podemos ver que no todos los sufijos y prefijos se encuentran disponibles de la misma manera para realizar derivaciones con las bases léxicas de nuestro diseño. Pero además, a la hora de considerar las justificaciones que los niños elaboran para sus alargamientos también encontramos diferencias entre los morfemas derivativos y entre un mismo

\footnotetext{
${ }^{27}$ Combinada de esta manera se trata de una forma incorrecta, ya que el prefijo IN- presenta la restricción
} gráfica de adoptar la forma IM- delante de " $\mathrm{b}$ " $\mathrm{y}$ " $\mathrm{p}$ ", como sucede por ejemplo en imbatible o impensable. 
morfema y las distintas bases léxicas con las que fue utilizado. Estas consideraciones nos advierten, en principio, sobre la necesidad de superar una concepción de los morfemas objeto de nuestro diseño como unidades homogéneas de la lengua.

Por otro lado, vimos que para analizar las posibilidades de reflexión metalingüística de los niños sobre los morfemas, es necesario poner en correspondencia las acciones que realizan (considerar cuantitativamente los alargamientos pero también qué morfemas derivativos utilizan y con qué bases léxicas) con las justificaciones que elaboran para cada una de ellas. Los tres sufijos denominales de nuestro diseño (-ERO, -ISTA y -DOR) parecen estar más disponibles para realizar combinaciones en los tres niveles propuestos para la tarea. Sin embargo, a la hora de ponderar las justificaciones para cada caso vimos que la interpretación instrumental de FLORERO como "maceta" y las agentivas de RELOJERO y MARINERO como “ocupación u oficio" parecen ser más estables que la interpretación de FUTBOLERO como "alguien aficionado por el deporte referido por la base léxica". De la misma manera, los niños de los tres niveles no encontraron mayores problemas para la interpretación agentiva de FLORISTA o FUTBOLISTA, mientras que la serie OFICIALISTA fue particularmente difícil de justificar. El sufijo -DOR, por su parte, nos permitió explorar las alternancias entre una interpretación agentiva (referida al mundo de lo humano) y una instrumental (referida a los objetos), y también nos mostró la inestabilidad que generó la serie ARMADOR, cuya base léxica podía ser interpretada tanto verbal como nominalmente y sugerir una derivación calificativa como “persona que está armada". El aumentativo y apreciativo -on fue el sufijo menos utilizado, probablemente porque las bases propuestas no lo permitían, pero al mismo tiempo no presentó dificultades para ser justificado en ninguno de los tres niveles. Además, la combinación CUENTON nos permitió explorar matices inesperados en cuanto a las "dimensiones del aumento de tamaño". El sufijo -BLE fue particularmente opaco para los niños del nivel inicial y en las justificaciones pertinentes de los niños más avanzados encontramos mayormente paráfrasis centradas en la idea de "posibilidad de realizar la acción indicada por la base".

Los prefijos, por otro lado, parecen estar menos disponibles que los sufijos a la hora de realizar combinaciones. El negativo $\mathrm{IN}-$ fue sin dudas el más opaco y difícil para 
todos los niños entrevistados. De hecho, se trata del único morfema que no fue utilizado por los niños del nivel inicial y el menos utilizados en los niveles siguientes. En este sentido, encontramos datos coincidentes a nivel oral en una tesis de Maestría en proceso en el DIE-Cinvestav, bajo la dirección de Emilia Ferreiro (Rodríguez Cuevas, 2018). El prefijo DES- fue utilizado con todas las bases verbales disponibles, pero presentó dificultades a la hora de las justificaciones: en la mayoría de los casos los niños justificaron tautológicamente el significado, o dieron ejemplos de uso pero sin llegar a referirse directamente a la idea de contrariedad o reversión de la acción indicada por la base léxica. Por último, el locativo SUB- recibió siempre justificaciones pertinentes en SUBMARINO, mientras que en SUBOFICIAL a las interpretaciones de "rango inferior en una jerarquía" se sumaron algunas con matices interesantes para especificar diferencias en la gradación.

El análisis de este apartado, además, nos permitió ir precisando los distintos tipos de justificaciones elaboradas por los niños: desde los ejemplos de uso centrados en el yo de la enunciación y con referencias al aquí y ahora de la comunicación, los pocos casos de amalgama que constituyen un intento de interpretar dos formas plenas y con significado en la combinación realizada, los intentos de parafrasear los significados que agrega el morfema, hasta los intentos de explicar el significado del morfema cuando está aislado y que representaría un máximo de rendimiento en las posibilidades de reflexión metalingüística de los niños.

\subsection{Observaciones finales sobre la tarea de Alargar}

Recapitulando lo analizado en la tarea de Alargar, destacamos los puntos más salientes que serán retomados y modulados en el capítulo siguiente:

- Los niños no mostraron mayores dificultades para distinguir entre el material escrito propuesto aquellos segmentos que eran palabras (formas autónomas 
con significado pleno) de aquellas que no lo eran porque constituyen de hecho morfemas derivativos (formas ligadas y sin significado pleno).

- En los niveles descriptos para analizar el desempeño de los niños en la tarea pudimos constatar un incremento progresivo en la cantidad de combinaciones realizadas, pero sobre todo, en la selección y posición de los morfemas utilizados: inicialmente los niños utilizan casi exclusivamente sufijos, luego alternan sufijos y prefijos, y solamente en el nivel más avanzado pueden utilizar un prefijo y un sufijo simultáneamente sobre la misma base léxica.

- En cuanto a las justificaciones, también encontramos una progresión que inicia con los ejemplos de uso (que son intentos de interpretar el morfema derivativo como una parte todavía no aislable de la palabra), las interpretaciones de amalgama (que constituyen los primeros intentos de aislar dos segmentos distintos pero de significado pleno dentro de una misma palabra), las paráfrasis (que constituyen intentos pertinentes de justificar el significado que el morfema añade a la palabra derivada) y finalmente los intentos de explicar el significado aislado de los morfemas derivativos (que constituyen el punto de rendimiento más alto alcanzado por los niños). Sin embargo, al respecto de este último, es necesario señalar que los niños no parecen aceptar que los morfemas tengan significado en sí, sino que cambian el significado de las palabras en un determinado sentido.

- Por último, los morfemas objeto de nuestro diseño no pueden ser tratados como unidades lingüísticas homogéneas y la posibilidad de utilizarlos e interpretarlos depende en gran medida de las bases léxicas con las que fueron combinados. En este sentido, registramos casos como el aumentativo -ON que parece disponible para ser interpretados por los niños ya desde el nivel inicial, mientras que otros como el prefijo negativo $\mathrm{IN}$ - parecen particularmente opacos. También encontramos que sufijos muy utilizados, como los denominales -ERO, -ISTA y -DOR, son ciertamente difíciles de justificar cuando están aislados. 
El problema central que enfrentan los niños en esta tarea de Alargar es cómo utilizar esos "pedacitos" que no son palabras para formar nuevas palabras a partir de otras conocidas, y cómo interpretar esos procesos de modificación. En general, los niños de los tres niveles parecen saber que si agrego una forma escrita que no es palabra (los morfemas derivativos) a otra que sí es palabra (las bases léxicas) algo en el orden del significado cambia. Es decir, el agregado gráfico implica en principio cambio semántico. Pero, ¿se trata de algo que sucede con todos los morfemas derivativos por igual? El análisis de las acciones y justificaciones de los niños parece indicar que no: hay morfemas que son, en general, más opacos que otros. Más aún, ¿el cambio semántico que genera un morfema derivativo es algo “objetivable" más allá de las palabra que lo incluye? Aún con las restricciones y limitaciones del material lingüístico utilizados en nuestro diseño, los niños dieron cuenta en sus intercambios de los desafíos cognitivos que implica atribuir un significado a los morfemas cuando están aislados, sobre todo, cuando derivan significados diferentes según con qué base se utilizan. ¿Se trata, entonces, de que los niños no pueden dar cuenta de esas unidades mínimas de significado? Veamos qué nos pueden aportar en este sentido los datos de la próxima tarea. 


\section{Tarea de Acortar}

\subsection{Materiales y consigna}

En la tarea de Acortar cada niño recibía un conjunto de seis tarjetas de cartulina de $5 \mathrm{~cm}$. x $15 \mathrm{~cm}$. con palabras familiares y de uso habitual escritas en mayúscula imprenta. Como se muestra en el Cuadro 7, cada conjunto contenía cuatro ítems diferentes entre sí y dos coincidentes (DESTINO y AUTOMOVILISTA).

\begin{tabular}{cc} 
Cuadro 7 - Conjuntos de fichas para tarea de acortar palabras \\
Conjunto 1 & Conjunto $\mathbf{2}$ \\
\hline INOLVIDABLE & INSOPORTABLE \\
DESPEGABLE & DESARMABLE \\
AUTOMOVILISTA & AUTOMOVILISTA \\
PAPELON & NARIZON \\
LADRON & RENGLON \\
DESTINO & DESTINO \\
\hline
\end{tabular}

De las seis tarjetas de cada conjunto, tres podían recibir un corte doble ya que tenían a la vez un prefijo y un sufijo (AUTOMOVILISTA, DESPEGABLE, INOLVIDABLE, DESARMABLE e INSOPORTABLE). La cuarta tarjeta de cada conjunto podía recibir un único corte en la posición de sufijo (PAPELON y NARIZON respectivamente). Por último, cada conjunto tenía dos tarjetas problematizadoras que comparten letras pero no morfemas con el resto (la mencionada tarjeta DESTINO común a ambos conjuntos y las tarjetas LADRON para uno de los niños y RENGLON para el otro). A excepción del prefijo AUTO- que aparece por primera vez en esta tarea, el resto de los morfemas derivativos (los prefijos IN- y DES-, y los sufijos -BLE, -ISTA y -ON) también fueron utilizados en la tarea anterior de Alargar (sección 2.1).

\section{Procedimiento}

Para dar inicio a la tarea entregábamos a cada niño uno de los conjuntos descriptos. Antes de plantear la consigna solicitábamos que cada uno leyera en voz alta las fichas que les habían tocado diciendo: 
Les voy a dar estas fichas y, como no todas son las mismas que las del compañero, quiero que las lean para estar seguro de que las entendemos.

Al igual que en la tarea de Alargar, en este caso también era importante que el punto de partida para empezar a buscar posibles cortes fuera la lectura convencional del material escrito de cada ficha. En el caso de que alguno de los niños no leyera correctamente la tarjeta, solicitábamos nuevamente la lectura o la colaboración del compañero, proponiendo así relecturas hasta alcanzar la lectura convencional.

A continuación entregábamos una tijera a cada uno de los niños y planteábamos la siguiente consigna:

Hasta ahora estuvimos alargando palabras. Ahora de lo que se trata es de acortarlas. Hay que ver qué le pueden quitar de este lado o de este lado [señalando ambos lados de una ficha] y que lo que les quede tenga que ver con la palabra que cortaron.

El señalamiento de los extremos de las tarjetas tenía que ver, en principio, con indicar a los niños la posibilidad de focalizarse en eventuales prefijos o sufijos en el material escrito. La restricción final de la consigna -que lo que les quede tenga que ver con la palabra que cortaron- fue incluida debido a que en las fichas ciertamente se pueden encontrar series de letras que forman palabras (cortar por ejemplo NO en DESTINO o VIDA en INOLVIDABLE) aunque no estén relacionadas con procesos de derivación como los que nos proponíamos comprender ${ }^{28}$. Como se verá más adelante, esta restricción fue recuperada durante el intercambio para abordar los casos en los que los niños realizaron cortes no esperados en las fichas. Al igual que en la tarea de Alargar cada uno de los niños trabajó en un tablero que, por un lado, servía como un espacio de trabajo delimitado y, por el otro, nos permitía distinguir lo realizado por cada niño con sus materiales. Resta agregar

\footnotetext{
${ }^{28}$ Corresponde precisar que el par de palabras que elegimos para la derivación con prefijo IN- y sufijo -BLE presenta diferencias en cuanto a la estructura de la palabra. Mientras que para INOLVIDABLE los niños llegan mediante el corte de prefijo y sufijo a la forma conjugada OLVIDA, en el caso de INSOPORTABLE se pueden cortar esos mismos prefijos y llegar a SOPORTA, forma verbal conjugada que a su vez puede recibir un nuevo corte del prefijo so alcanzando así PORTA (que es a su vez forma verbal conjugada de la raíz PORT-). Aun así, ningún niño identificó so- como prefijo. En cambio, como veremos más adelante, aislaron la forma PORTABLE, posiblemente por el renovado uso de la palabra que hacen los nuevos dispositivos electrónicos.
} 
por último que en aquellos casos en los que un niño se retractó de un corte, se puso a disposición una cinta scotch con la que podían rectificar el corte realizado.

Una vez que los niños habían terminado de realizar cortes en sus respectivos conjuntos de fichas, solicitábamos justificaciones de los cortes realizados y también consultábamos a los niños acerca de las relaciones entre las series que quedaban como resultado de los cortes. Cuando una ficha no había sido cortada o cuando habían realizado un solo corte en fichas que admitían dos, el entrevistador centraba la atención de los niños en esas fichas para ver si podían realizar otros cortes. En cuanto a los cortes no esperados, cuando los niños no lograban justificarlos el entrevistador les proponía que buscaran otros cortes o que justificaran por qué no se podía cortar. También en el caso de esta tarea el intercambio se caracterizó por una dinámica cambiante en la que los niños agregaron, rectificaron o propusieron nuevos cortes a su compañero.

\subsection{Cortes realizados por los niños}

El hecho de que los niños realizaran cortes en fichas con material escrito implicó que la tarea de Acortar fuera más resultativa que la tarea previa de Alargar. Denominaremos iniciales a los cortes que los niños realizaron luego de recibir la consigna. Una vez iniciado el intercambio, el entrevistador invitaba a los niños a explorar nuevos cortes en las fichas que no habían cortado o que admitían más de un corte, o bien los niños encontraban nuevos cortes en sus fichas o sugerían cortes en las fichas de sus compañeros. Denominaremos finales a los cortes que aparecieron durante el intercambio.

Si bien se trata de una tarea más resultativa que la anterior, a la hora de dar cuenta de los cortes que realizaron los niños hay que considerar dos variables que son complejas de combinar. Por un lado, en nuestro diseño había cuatro fichas por conjunto en las que esperábamos que los niños realizaran cortes (tres fichas que admitían cortes dobles y una que admitía un único corte), es decir, cuatro fichas en principio cortables. Cortar prefijos o sufijos en estas fichas -y particularmente hacerlo de forma simultánea cuando es posible- 
sería un indicador de que los niños pueden reconocer y aislar morfemas derivativos en las series que les presentamos, mientras que la acción contraria de no cortar en series que incluyen un prefijo o un sufijo nos indicaría que los niños no pudieron leer los morfemas objeto en esas tarjetas. Pero en nuestro diseño también incluimos una situación problematizadora con las series que comparten letras pero no morfemas derivativos. En estos casos no cortar la ficha es indicador de un mejor desempeño, sobre todo si tenemos en cuenta que los niños han trabajado previamente con las mismas series de letras (DES- y -ON para el caso de las fichas problematizadoras en cada conjunto) presentadas como formas libres y que ellos utilizaron para combinar. En ambos casos -cuando esperábamos que cortaran y cuando esperábamos que no cortaran- las justificaciones juegan un papel fundamental. Por último, el hecho de que en la tarea presentáramos fichas y tijeras e invitáramos a cortar también implicó que algunos niños realizaran cortes no esperados. En algunos casos se trató de formas convencionales y existentes en la lengua, mientras que en otros casos el corte generó series no convencionales y agramaticales. Veamos cómo se desempañaron en la tarea las mismas parejas de los tres grados escolares utilizadas como ejemplo en el capítulo anterior (sección 2.3).

Comencemos por la pareja de $2^{\circ}$ grado conformada por Josefina y Gonzalo. La niña realiza al inicio tres cortes esperados en tres fichas. Corta DESPEGA BLE $^{29}$ y dice que DESPEGA es como despegar el cohete y DESPEGA; BLE como alguien que despega un cohete. En PAPEL 'ON corta el sufijo -ON y lo interpreta como aumentativo: es un papel como de este tamaño [indicando algo grande con sus manos]. Por último, corta sólo el sufijo en la serie AUTOMOVIL' ISTA y mantiene junto con su compañero el siguiente intercambio:

Ent.: qué es automovilista?

Josefina: es un señor que arregla autos

Ent.: y automóvil?

Josefina: automóvil son unos autos muy geniales para mí / auto es un auto [señalando AUTO en la ficha que Gonzalo cortó AUTO; MOVILISTA]

Gonzalo: un auto común y corriente

Ent.: auto es lo mismo que automóvil?

Josefina: es distinto

Gonzalo: automóvil es más bueno

\footnotetext{
${ }^{29}$ Para indicar los cortes realizados en una ficha utilizamos una barra vertical discontinua ( $\left.\begin{array}{l}1 \\ 1\end{array}\right)$.
} 
Josefina: ah puedo cortar el móvil / puedo cortarlo y auto puede quedar sola [alcanzado en su serie el corte doble AUTO', MOVIL, ISTA] / puede ser

Ent: móvil qué es? tiene que ver con automovilista?

Josefina: móvil / móvil es como un auto / es algo que un automóvil / móvil es algo fantástico

Sugerir un nuevo corte -aún cortes pertinentes- no implica en todos los casos poder justificarlo. Durante el intercambio, Josefina también logra aislar el prefijo IN- en INOLVIDABLE pero no logra justificar las series resultantes: olvidable es como si una persona está ahí y se olvida / inolvidable es como si una persona se siente olvidable / o sea es como olvidable. La niña también corta exhaustivamente la ficha DES ' PEGA y en este caso sí explica que PEGA puede recibir dos significados: pega es como si pegaras una figurita / o también pega es como [haciendo el gesto de golpear con un puño] te pega algo así.

Gonzalo, por su parte, realiza cortes en las cuatro fichas que los admitían, pero en la ficha INSOPORTABLE realiza solamente el corte del sufijo -BLE lo que deja un segmento agramatical, INSOPORTA, que resulta imposible de interpretar:

Ent.: cómo lo cortaste? contame [señalado la ficha que el niño cortó INSOPORTA ' BLE] Josefina: es insoportable

Ent.: qué es insoportable?

Josefina: insoportable es cuando alguien no te / te / es como si una madre le dijera a una niña sos insoportable / así como si estuviera enojada

Gonzalo: porque

Josefina: como que ella le dice quiero ir al cine quiero ir al cine [imitando la voz de una niña más pequeña] como si fuera eso

Ent.: ajá

Gonzalo: insoporta no sé qué es

Josefina: [hace gestos de no saber qué es]

Ent.: lo podríamos cortar de otra forma?

Gonzalo: por? / acá le cortó acá y acá [sugiriendo el corte INSO! POR!'TA]

Ent.: tiene que ver con insoportable? por?

Josefina: [riéndose] no sé

Ent.: algo que tenga que ver con insoportable se le puede sacar?

Gonzalo: no / para mí no

Sobre DESARMA| BLE Gonzalo sostiene que es algo o alguien que desarma y sobre NARIZ, ON que es una nariz grandota. Por último, corta el prefijo en AUTO, MOVILISTA y lo interpreta como un acortamiento del sustantivo AUTOMOVIL, aunque con un contraste 
llamativo: mientras que AUTO es un auto común y corriente, AUTOMOVIL es más bueno. La interpretación apreciativa le permite diferenciar el significado de ambas series. Durante el intercambio, Gonzalo no agrega más cortes.

Continuemos con la pareja de $4^{\circ}$ grado constituida por Diego y Carmela. Al inicio la niña realiza el corte DESPEGA|BLE e interpreta la serie completa como que se puede despegar, sobre DESPEGA dice puede ser dos cosas / por ejemplo pego una figurita en el álbum y la despego / si no puede ser un avión o un cohete que despega. Realiza un corte simple en AUTOMOVIL, ISTA y un corte doble en IN OLVIDA;BLE. Sobre esta última va realizando interpretaciones de cada una de las series resultantes: IN | OLVIDA 'BLE que no se puede olvidar, OLVIDABLE que sí se puede olvidar y en OLVIDA agrega con este olvida, lo que sugiere que las dos primeras formas las interpreta adjetivalmente (como la posibilidad o no de hacer algo) y la última verbalmente. En PAPELON corta el sufijo -ON y dice: pasar un papelón si desarmaste tu cuarto y te regañan. Luego, en el intercambio, surge la posibilidad de la interpretación aumentativa (posibilidad rechazada por Diego):

Diego: puede ser papelón

Carmela: un papel grande

Diego: no

Ent.: también puede ser un papel grande?

Diego: más que todo es cuando / me hiciste hacer un papelón ahí al frente

Carmela no corta las series DESTINO ni LADRON y sobre esta última sostiene que no la cortó porque ladr no es nada y la serie -ON no es artículo así que no cuenta / es parte del sustantivo. Durante el intercambio agrega un corte en DES! PEGA y dice que la serie DESsignifica lo contrario de pega. Por su parte Diego al inicio realiza cuatro cortes simples: sobre IN 'SOPORTABLE dice que soportable es que se puede soportar. En DESARMA; BLE retoma las justificaciones pertinentes que dio en la tarea de Alargar mientras que sobre el corte en AUTOMOVIL'ISTA no agrega nada en el intercambio. Para justificar la serie que cortó NARIZ, ON recurre a la idea de aumentativo. No corta DESTINO y dice que tino no es una palabra / y si cortás desti tampoco es nada. También deja RENGLON sin cortar porque rengl no es ninguna palabra. Durante el intercambio y a partir de la sugerencia de su compañera realiza el corte doble en IN ; SOPORTA ; BLE y corta en DES ; ARMA. Como podemos 
ver, en esta pareja se incrementa la cantidad de cortes realizados y además aparece la posibilidad de trabajar desde el inicio a ambos lados de una ficha.

Finalmente, veamos los cortes realizados por la pareja de Gerardo y Luana, de $6^{\circ}$ grado. El niño realiza al inicio los tres cortes dobles esperados en IN OLVIDA BLE, DES ; PEGA ; BLE Y AUTO; MOVIL' ISTA. Sobre el primero dice que IN, OLVIDA 'BLE es que no te podés olvidar mientras que OLVIDABLE es que sí podés olvidar, aclarando que IN- significa negativo. Justifica convencionalmente las modificaciones que los morfemas realizan a la base léxica PEGA y sostiene además que DES- también sería el negativo. En el caso de AUTO! MOVIL'ISTA Gerardo duda en su justificación ya que reaparece nuevamente con fuerza la interpretación de AUTO- como un acortamiento de AUTOMOVIL y no como un prefijo:

Ent.: y auto qué es? [señalando AUTO]

Gerardo: eh auto sería el sustantivo [rearmando AUTO' MOVIL]

Ent.: y automóvil?

Luna: es lo mismo

Gerardo: también

Ent.: es lo mismo? / no cambia?

Gerardo: $\mathrm{mmm}$ [dudando]

Ent.: estás dudando Gerardo?

Gerardo: parece que estos [señalando MOVIL e ISTA] serían los dos sufijos

Sobre la serie PAPELON Gerardo dice primero que sería cuando vos estás en un papelón que sería un lío / es otra forma de decir. Luego acepta que puede ser un papel grande pero aclara yo siempre digo papelazo cuando es un papel grande, recuperando otro morfema aumentativo (-AZO) con mucha vigencia en el uso oral de la lengua. No corta LADRON pero sí realiza un corte no esperado en DES 'TINO que justifica en el siguiente diálogo:

Gerardo: yo pensé / suponte acá en tino podés usarlo / no es una palabra pero es un conjunto de letras que lo podés usar para ponerle más sufijos o prefijos

Ent.: como por ejemplo?

Gerardo: en vez de destino podés poner eh / intestino suponte

Ent.: y acá [señalando DES] es el negativo de tino? [refiriéndose a lo que había dicho el niño anteriormente]

Luana: no

Ent.: vos no lo cortaste este Luana [señalando DESTINO sin cortar en el tablero de la niña] / por qué? 
Luana: porque para mí destino es una palabra / o sea que si le cortás algo para mí que no / como te dije antes no tiene sentido / es distinto [refiriéndose a DESTINO y el ejemplo de intestino que dio su compañero] / o sea no tiene nada que ver para mí Gerardo: no / no tiene

Luana por su parte corta IN ; SOPORTABLE y sostiene que la serie sin cortar es alguien que no podés soportar y el resultado del corte es algo que sí te lo podés soportar. Sobre el corte AUTOMOVIL' ISTA dice que la serie completa es la persona que maneja el automóvil y si le sacás el ista sería digamos el objeto. Realiza el corte doble en DES!ARMA!'BLE y retoma las justificaciones convencionales que dieron en la tarea de Alargar. Para justificar la serie que cortó NARIZ, ON dice que -ON para mí es como que lo agranda a la palabra o sea / lo que estás diciendo como que lo agranda. Deja sin cortar DESTINO y RENGLON, diciendo sobre el último que no lo cortó porque para mí si le sacás el on digamos lo que te resta no tiene sentido / no es una palabra. Durante el intercambio completa el corte doble en IN ; SOPORTA ; BLE. Encontramos consolidada en esta última pareja la posibilidad de aislar morfemas a ambos lados de las fichas, así como también de elaborar justificaciones para interpretar las relaciones que los morfemas mantienen con las bases.

\subsection{Grupos evolutivos en la tarea de Acortar}

Para considerar el desempeño de los niños en esta tarea de Acortar tomamos como variables los dos ejes también utilizados en los agrupamientos de la tarea de Alargar (sección 2.4), es decir, la consideración de la cantidad de cortes realizados (eje cuantitativo) y el análisis de qué morfemas derivativos fueron aislados y cómo fueron justificados los cortes (eje cualitativo). Con respecto al eje cuantitativo, otorgamos al desempeño de cada niño un valor compuesto por dos números separados por una diagonal: el número a la izquierda de la diagonal indica la cantidad de morfemas derivativos que logró aislar en sus cortes, mientras que el número a la derecha de la diagonal indica la cantidad de bases léxicas que recibieron cortes. A Josefina $\left(2^{\circ}\right)$, niña 
presentada como ejemplo introductorio (sección 3.2), le corresponde entonces un valor de $3 / 3$ ya que realizó tres cortes en tres bases léxicas distintas: DESPEGA 'BLE, PAPEL' ON Y AUTOMOVIL', ISTA. Por su parte, Luana, la niña de la pareja de $6^{\circ}$ grado, obtuvo un valor de 5/4 en tanto logró aislar cinco morfemas en cuatro bases léxicas distintas. Teniendo en cuenta que todos los niños entrevistados realizaron al menos un corte, el rango del número a la derecha de la diagonal es siempre de 1 a 4 . Cuando el número a la izquierda de la diagonal es mayor, es porque existió un corte doble en alguna de las fichas. Se trata, por ejemplo, de Luana, quien realizó el corte doble DES!ARMA|BLE junto con los cortes simples IN ; SOPORTABLE, NARIZ; ON y AUTOMOVIL;'ISTA. Para asignar un valor al desempeño de los niños en la tarea optamos por considerar los cortes iniciales, es decir, los que se realizaron antes del intercambio. La dinámica del diálogo entre la pareja de niños y el entrevistador vuelve difícil la tarea de precisar cuándo un corte que surge una vez iniciado el diálogo es un corte nuevo que un niño encuentra en sus fichas o cuándo el corte es sugerido por su compañero o por las preguntas del entrevistador (recordemos que en esta tarea de Acortar hay tarjetas exactamente iguales para ambos niños y otras que comparten una estructura derivativa equivalente).

Por otro lado, también es necesario considerar los cortes no esperados. La consigna y el material que planteamos a los niños incluyen fichas en las que esperábamos cortes y fichas en la que esperábamos que no cortaran. Sin embargo, en ambos casos los niños podían hacer cortes no esperados. En este sentido, nos interesa evaluar si los niños cortan series esperadas (los morfemas derivativos objeto) pero que generan segmentos agramaticales (cortar solo el sufijo -BLE en la serie INOLVIDABLE lo que genera como resultado una serie que no es gramatical) o si realizan un corte para aislar otra palabra dentro de la que le presentamos pero sin aislar los morfemas objetos esperados (cortar por ejemplo VIDA en INOL' VIDA!'BLE O POR en INSO'POR!'TABLE). En ambos casos nos interesa saber cómo justifican estos cortes, cómo interpretan las relaciones morfo-semánticos con la ficha antes de ser cortada y, sobre todo, si durante el intercambio pueden cambiar el corte por uno que considere la restricción de la consigna que lo que les quede tenga que ver con la palabra que cortaron. 
Con respecto a las fichas en las que esperábamos que los niños no realizaran cortes, inicialmente a la hora de elaborar el diseño consideramos que abstenerse de cortar en una situación que sugiere lo contrario es una conducta particularmente evolucionada. Sin embargo, como veremos en detalle más adelante, en las entrevistas encontramos que todos los niños de $2^{\circ}$ grado se abstuvieron de cortar esas tarjetas, lo que nos da un punto de partida muy alto en los niños estudiados con respecto a nuestras expectativas iniciales. Por otro lado, algunos niños de grados superiores sí realizaron un corte en al menos una de esas dos tarjetas problematizadoras. Esta situación nos lleva a excluir la consideración de esta variable realizar un corte en una ficha que no admitía cortes como indicador de evolución y, en todo caso, evaluar tanto la posición de los cortes que realizaron como a la justificación que pueden ofrecer los niños.

Por último, está la consideración de cuáles fueron los morfemas derivativos aislados por los niños y cómo justificaron los cortes realizados (es decir, la relación entre las partes resultantes de la acción de cortar, y eventualmente, el significado de cada una de ellas). El análisis de las justificaciones que los niños elaboraron para sus cortes es también otro criterio importante a tener en cuenta al momento de evaluar las acciones realizadas. Describimos a continuación los tres grupos principales en los que clasificamos a los niños según su desempeño en la tarea de Acortar.

\section{Nivel I}

En este grupo ubicamos a los niños con valores iguales a ambos lados de la diagonal y que además son valores iguales o menores a 3. Es decir que estos niños no realizan cortes con todas las bases léxicas que admiten cortes ni tampoco realizan cortes dobles.

El sufijo aumentativo -ON es el más aislado en este grupo y tanto para la ficha NARIZON como para PAPELON recibe justificaciones de aumentativo: vimos en los ejemplos introductorios (sección 3.2) que Gonzalo decía sobre NARIZ, ON que era una nariz grandota, otro ejemplo es Belén $\left(2^{\circ}\right)$ quien cortó PAPEL;ON y lo explicó como un papel grande. Esta última ficha recibe en algunos casos la interpretación lexicalizada de "situación 
embarazosa o ridícula". En el nivel inicial, apenas dos niños plantean que la ficha pueda recibir tanto esta interpretación lexicalizada como la aumentativa. Por otra parte, el prefijo AUTO- y el sufijo -BLE también están entre los más aislados por estos niños, aunque el primero no es interpretado en ningún caso como prefijo sino como el acortamiento de AUTOMÓVIL, y el sufijo -BLE, como veremos en detalle más adelante, es difícil de justificar (solo la mitad de los niños de este nivel que lo aislaron pudieron justificarlo). Al igual que en la tarea de Alargar, los prefijos negativos DES- e IN- fueron los menos aislados y parecen ser los más opacos para los niños de este nivel inicial. Sin embargo, a pesar de los pocos casos registrados, las fichas con IN- parecen ser más accesibles para la justificación: Florencia $\left(4^{\circ}\right)$ explica que IN, OLVIDABLE es que no me lo puedo olvidar / olvidable sí se puede olvidar. En cambio, en las justificaciones sobre los cortes con DES- encontramos ciertas dificultades para interpretar el sentido que agrega el prefijo. Agustín (4\%), por ejemplo, dice que DES |'PEGABLE es cuando se despega y también que podés despegar. Cuando explica la serie sin el prefijo parece repetir la misma interpretación: PEGABLE es que la cinta la podés despegar / que se despega y se pega.

Por otro lado, en este grupo se concentra la mayoría (13 sobre un total de 20) de los cortes no esperados. En algunos caso se trata de cortes que buscaban aislar otras palabras no vinculadas morfológicamente con las fichas presentadas (INSO'PORTABLE, INOL' VIDA 'BLE, LA, DRON y PA PELON) y en otros casos se trata de cortes de series esperadas (los morfemas derivativos objeto) pero que daban como resultado un segmento agramatical (INSOPORTA ' BLE e INOLVIDA' BLE). En ambos casos, los niños no pudieron rectificar los cortes o completarlos con otros plausibles durante el intercambio.

En cuanto a las fichas problematizadoras, la mayoría de los niños de este grupo no realizan ningún corte, lo que en principio sería un indicador de mejor desempeño. Sin embargo, como veremos más adelante en este capítulo, cuando los niños son consultados en el intercambio acerca de por qué no realizaron cortes en estas fichas los motivos que aluden se refieren a que no encontraron nada para cortar o a que no se podía.

De las parejas comentadas como ejemplos introductorios, los dos niños de $2^{\circ}$ grado corresponden a este nivel inicial: Josefina realizó tres cortes simples en tres bases 
(obtuvo un valor 3/3), mientras que Gonzalo lo hizo en tres fichas que admitían cortes (también con un valor de 3/3).

Una cuestión interesante desde el punto de vista psicolingüístico tiene que ver con analizar dónde centran la atención cognitiva los niños en sus cortes. Es decir, un niño que realiza el corte DESPEGA BLE, en sus justificaciones ¿se centra solamente en un segmento conocido dentro de un segmento mayor que también puede interpretar?, ¿̇o se centra también en la serie gráfica que "sobra" a partir del corte y que es un morfema derivativo? O, si se tratara de una conducta aún más evolucionada, ¿puede centrarse en las dos "partes" resultantes de su acción de cortar e intentar coordinar sus significados? Vimos que en las fichas con el sufijo -ON los niños de este nivel inicial no presentan dificultades en centrarse alternadamente en la serie gráfica que resultó de sus cortes (NARIZ O PAPEL) y esas mismas series con el segmento que cortaron (NARIZ; ON Y PAPEL;ON). Pero con el sufijo -BLE no sucede lo mismo: los niños no parecen aislar el sufijo en sí, sino reconocer una base léxica menor dentro de las fichas (por ejemplo DESPEGA en DESPEGABLE). Esto parece suceder, entre otros casos, con Dante $\left(2^{\circ}\right)$ quien corta DESPEGA BLE y dice sobre DESPEGA alguien que despega ponele un cohete, cuando el entrevistador rearma la serie completa DESPEGA 'BLE el niño explica que puede decir lo mismo que despega. Los cortes del prefijo AUTO- como acortamiento y las explicaciones tautológicas de los pocos cortes del prefijo DES- también parecen constituir casos de centración exclusiva en "lo que dejan" a partir del corte y que siempre coincide con bases léxicas familiares que los niños pueden justificar (en el análisis de la tarea de Alargar también dimos cuenta de las dificultades que el prefijo DES- presentó a los niños a la hora de ser justificado, ver sección 2.5).

\section{Nivel II}

En este grupo ubicamos a niños con valores iguales a ambos lados de la diagonal y que además son valores iguales a 4. Se trata, por lo tanto, de niños que realizan cortes con todas las fichas que admiten $\operatorname{cortes}^{30}$, aunque no logran realizar un corte doble ${ }^{31}$.

\footnotetext{
30 Incluimos en este grupo tres casos en que los niños cortan todas las fichas que admitían cortes pero en un caso se trata de un corte no esperado. Renata $\left(2^{\circ}\right)$ corta INOL;VIDA BLE, Delfina corta INSO!PORTABLE Y
} 
El sufijo aumentativo -ON es aislado por todos los niños de este grupo a excepción de Laura $\left(6^{\circ}\right)$, quien da una justificación interesante acerca de por qué decidió no cortar:

Luciano: ahí pudiste haber cortado on [sugiriendo a su compañera el corte PAPEL;ON] / podés haber formado papel

Laura: no [riéndose]

Ent.: por qué con la cortaste? contame

Laura: porque pensé en cortarla pero después dije no

Ent.: por qué?

Laura: no me pareció cortarla

Ent.: qué quiere decir papelón? [señalando la ficha sin cortar PAPELON]

Laura: como que hay mucho desastre / lío

Ent.: a ver / vos me decís que papelón es que hay mucho desastre y lío / vos me decías Luciano que la corte / como Luciano me dijo acá si yo tengo on y nariz [señalando la ficha que el niño cortó NARIZ; ON] quiere decir que es una nariz grande Luciano: [asiente]

Laura: si yo lo corto queda papel / acá es distinto [señalando la ficha sin cortar PAPELON] / o sea papel no tiene nada que ver con papelón

Ent.: ajá

Laura: papelón sería como un desastre y papel / no tienen nada que ver / él dijo [refiriéndose al entrevistador y la consigna que dio al iniciar con el juego de acortar] que vos tenés que cortar por ejemplo no sé narizón / nariz tiene que tener algo que ver con narizón antes de cortarla

Ent.: este on [señalando ON en NARIZ, ON] es igual a este [señalando ON en PAPELON] terminan iguales

Laura: [interrumpiendo] es otro significado de la palabra / o sea la puedo cortar y queda palabra pero no tiene nada que ver con papelón papel

Laura $\left(6^{\circ}\right)$ parte de interpretar PAPELON en su derivación lexicalizada (es otro significado de la palabra), por eso no acepta que -ON sea aumentativo como en la ficha NARIZ, ON que cortó su compañero. En este nivel encontramos una interpretación aumentativa generalizada, un incremento en las interpretaciones que aceptan para PAPELON tanto la interpretación lexicalizada y la aumentativa, así como también la aparición de intentos de explicar el significado del morfema cuando está aislado: Jeremías $\left(4^{\circ}\right)$ consultado por el significado de -ON dice queda como más grande e inclusive recupera

AUTO; MOVI: LISTA; y por último, Julián $\left(4^{\circ}\right)$ corta INSO'PORTABLE. En todos los casos los niños justifican adecuadamente las formas plenas que logran aislar, y además durante el intercambio rectifican sus cortes.

31 Incluimos también en este segundo grupo el caso de Guadalupe quien realizó el corte AUTOMOVIL', ISTA y justo antes de iniciar el intercambio, observando el tablero de su compañero Emiliano, agregó el corte doble en AUTO' MOVIL' ISTA, aunque en el intercambio no pudo justificarlo. 
lo realizado en la tarea previa de Alargar y agrega como en cuentón. El prefijo AUTOcontinúa entre los más usados aunque los niños de este nivel tampoco logran justificarlo como prefijo sino como el acortamiento de AUTOMÓVIL. El sufijo -BLE, por su parte, comienza a recibir justificaciones que parafrasean la idea de posibilidad de realizar la acción indicada por la base verbal: Andrés $\left(6^{\circ}\right)$ dice sobre DESPEGABLE algo que se puede despegar mientras Catalina $\left(6^{\circ}\right)$ sobre DESARMABLE explica que se puede armar y desarmar. A diferencia del nivel anterior, ahora encontramos un incremento en los cortes del prefijo negativo $\mathrm{IN}^{-}$, con justificaciones que parafrasean la idea de negatividad e incluso con intentos de explicar el significado del morfema cuando está aislado. Ulises $\left(4^{\circ}\right)$ comienza explicando su corte IN, OLVIDABLE diciendo que es que no se puede olvidar y OLVIDABLE que se puede olvidar. Luego participa del siguiente intercambio:

Ent.: esta partecita [señalando IN] lo cambia cuando lo ponés?

Ulises: sí

Jazmín: inolvidable / insoportable vendría a ser lo mismo

Ent.: conocen otras donde esto también lo cambie?

Ulises: eh / inalcanzable que no lo podés alcanzar

Jazmín: intranquilo

Ent.: esta puede ir sola? [señalando IN]

Ulises: no / sería como más o menos una raíz / la raíz de alguna sílaba / o sea si vos pegás una palabra con otra te queda / una frase / pero si vos pegás una sílaba una / eh / una raíz con otra te queda una palabra que significa algo distinto Jazmín: como que es una familia

Ulises: $o$ en este caso [señalando IN, OLVIDABLE] te queda lo contrario a lo que pusiste

Ulises $\left(4^{\circ}\right)$ enfrenta la dificultad de nombrar esas "partecitas" (raíz, silaba) que no son palabras, pero logra explicar que con el prefijo IN- te queda lo contrario, lo cual es un logro importante en términos de reflexión metalingüística. Finalmente, DES- e -ISTA son los menos utilizados en este grupo y, como veremos en el próximo apartado (sección 3.4), aún presentan cierta inestabilidad en las justificaciones.

En este grupo encontramos apenas 4 alargamientos no esperados. Se trata de formas plausibles, por ejemplo, Renata $\left(2^{\circ}\right)$ corta INOL ' VIDA 'BLE y Delfina INSO 'PORTABLE. Las niñas logran justificar las formas plenas que aíslan (VIDA, PORTABLE y LISTA) y durante el intercambio rectifican sus cortes. 
Al respecto de las fichas que no admitían cortes y que efectivamente no cortaron, los niños utilizan en sus justificaciones referencias a la falta de sentido de las series que les quedarían o rechazan finales que consideran imposibles: Luna $\left(4^{\circ}\right)$, por ejemplo, justifica que no corta -ON en LADRON porque no queda una palabra / si yo le corto esto va a decir ladr / y eso no es una palabra, y Andrés $\left(6^{\circ}\right)$ dice que no cortó DESTINO porque es como ladrón / no tiene ni prefijo ni sufijo / si sacás des no te queda una palabra. Es decir, se trata de niños que oralmente prueban segmentaciones y las rechazan argumentando que las series resultantes no son palabras. De los ejemplos introductorios, Diego $\left(4^{\circ}\right)$, se ubica en este nivel II: realizó cortes simples con las cuatro fichas cortables (un valor de 4/4).

Con respecto a las centraciones cognitivas de los niños en las partes resultantes de sus cortes, en este nivel hay algunos avances en la posibilidad de considerar tanto el significado de la nueva base léxica que resulta del corte como de esas partecitas que las modifican. Las interpretaciones negativas del prefijo $\mathrm{IN}-$ (te queda lo contrario a lo indicado por la base léxica) dan cuenta de esta posibilidad de considerar coordinadamente la relación semántica entre lo que dejan y lo que sacan los niños al cortar las fichas. Sin embargo, con morfemas como AUTO- o como -BLE encontramos también centraciones exclusivas en lo que dejan como resultado del corte. El caso de Ulises ( $4^{\circ}$ ) es interesante, ya que en el intercambio alcanza (a partir de su corte inicial del prefijo) el corte doble en AUTO' MOVIL' ISTA, eso le permite ir elaborando justificaciones sobre las distintas partes:

- AUTO'MOVIL'ISTA sería una persona que vende automóviles

- AUto'movil es el auto que nosotros conducimos

- AUTO es igual a automóvil / se va a entender igual

- MOVIL que se puede mover.

A pesar de poder dar cuenta de cada una de las partes por separado y de la derivación agentiva de AUTOMOVILISTA, no logra considerar la serie gráfico AUTO- como prefijo ni relacionarla con el significado que le atribuye a la base léxica MOVIL.

\section{Nivel III}

En el nivel más avanzado se encuentran los niños con valores diferentes a ambos lados de la diagonal y que además son valores iguales a 4. Son los niños que realizan 
cortes con todas las fichas que los admitían y que además realizaron al menos un corte doble. Incluimos además en este grupo cuatro $\operatorname{casos}^{32}$ de niños que inicialmente realizan cortes simples en todas las fichas cortables (un valor de 4/4, es decir, sin cortes dobles al inicio), pero que en sus justificaciones incluyen más de un intento por otorgar significado aislado al morfema y durante el intercambio alcanzan el valor máximo esperado para esta tarea (7/4, o sea, tres cortes dobles en las fichas que lo admitían más un corte simple en la ficha con el sufijo aumentativo).

El sufijo -ON es aislado por todos los niños de este grupo. En el caso de NARIZON es justificado siempre como aumentativo, y en el caso de PAPELON se generaliza la explicación que admite tanto la interpretación lexicalizada como la aumentativa:

Ent.: y acá qué tenías? [señalando PAPEL;ON]

Paula: papelón

Ent.: qué es?

Paula: es un papel / muy grande

Darío: un papelón o que te portaste mal

Paula: son dos significados diferentes

Ent.: $y$ eso puede ser?

Paula: si

Ent.: o sea que si yo

Paula: [interrumpiendo] pero si fuera / para mí en este caso [enfatizando] por cómo es la raíz sería papelón que sería un papel muy grande

Ent.: ajá / y cómo te darías cuenta si fuera el otro papelón? [refiriéndose al otro significado]

Paula: y si ahí está / porque es una misma palabra / este sería un sufijo [señalando la serie ON que cortó en PAPEL; ON]

Ent.: y en el otro papelón? [refiriéndose al otro significado que sugirió su compañero]

Paula: en cambio en el otro sería una palabra completa

La ficha PAPELON permitió reflexiones interesantes sobre la posibilidad de que una palabra tenga más de un significado y también posibilitó que los niños pudieran explicar en qué contextos un mismo segmento gráfico como -ON aporta o no el significado de aumentativo. Hay un incremento, además, en los intentos de explicar el significado aislado del sufijo: Luana $\left(6^{\circ}\right)$, por ejemplo, dice a partir de su corte NARIZ;ON que es como una

\footnotetext{
${ }^{32}$ Se trata de Darío $\left(4^{\circ}\right)$, Tobías $\left(6^{\circ}\right)$, Pedro $\left(6^{\circ}\right)$ y Lorena $\left(6^{\circ}\right)$.
} 
nariz muy grande / on para mí es como que lo agranda a la palabra o sea lo que estás diciendo como que lo agranda. Se trata de una reflexión metalingüística destacable, en la que Luana pasa de interpretar que el sufijo "agrande el objeto" (centrándose en el referente extralingüístico), a "agranda la palabra" para finalmente formular la justificación "agranda lo que estás diciendo" (centrándose ahora en elementos de la lengua).

En este grupo se encuentran varios casos de máximo rendimiento en las reflexiones metalingüísticas de los niños. Carmela $\left(4^{\circ}\right)$, en su justificación sobre PAPELON, admite la posibilidad de los dos significados y también intenta explicar el significado aislado del sufijo: papelón significa como que hiciste lío / también puede ser papel grande / on significa grande. Por su parte, Genaro $\left(4^{\circ}\right)$, al justificar el corte DESARMA BLE parafrasea la idea de posibilidad pero con una referencia explícita a la idea de una situación futura y potencial que aún no fue realizada: que se puede desarmar pero no lo estoy desarmando.

Con el sufijo -BLE aumenta la cantidad de cortes y encontramos, en primer lugar, paráfrasis de la idea de posibilidad: Gerardo $\left(6^{\circ}\right)$ por ejemplo, sostuvo que IN OLVIDA ; BLE es que no te podés olvidar mientras que OLVIDA!BLE es que sí te podés olvidar. Veamos el ejemplo de $\operatorname{Azul}\left(6^{\circ}\right)$ que plantea un contraste similar, IN-=no se puede / -BLE=es más fácil (en el sentido de que es posible que ocurra).

Ent.: qué es inolvidable? [señalando la ficha que la niña cortó IN, OLVIDA! BLE]

Azul: que que no lo vas a olvidar más / como que es inolvidable // olvidable que se olvida más fácil / y olvida como que alguien olvida algo / estas dos casi son lo mismo [señalando OLVIDA y OLVIDA;BLE] y esta [señalando IN;OLVIDA;BLE] sería el contrario de esas dos

Ent.: con esta [señalando IN] cambia?

Leonel: claro sí

Azul: se hace el contrario

Por otro lado, varios niños intentaron dar cuenta del significado del sufijo -BLE cuando está aislado: Carmela $\left(4^{\circ}\right)$, por ejemplo, dice sobre DESPEGA BLE que se puede despegar / ble significa que sí se puede.

El prefijo IN- es el otro morfema aislado por casi todos los niños de este nivel avanzado. Los niños logran dar cuenta del significado negativo del prefijo junto con el de potencialidad del sufijo-BLE: Abril $\left(6^{\circ}\right)$ dice sobre IN ' SOPORTA 'BLE que no se puede soportar 
/ si alguien no te cae bien es insoportable / soportable sería que sí se puede soportar. La situación es distinta respecto al prefijo DES-. Si bien aumenta la cantidad de cortes del prefijo, encontramos dos situaciones distintas en cuanto a las justificaciones: algunos niños elaboran interpretaciones centradas en la idea de posibilidad del sufijo -BLE sin ninguna referencia sobre la negación que aporta el prefijo, para Lucas $\left(2^{\circ}\right)$ DES ${ }_{1}^{\prime}$ PEGA $\left.\right|_{1} ^{\text {BLE }}$ es algo que se puede despegar y pegar mientras que DES, PEGA es un verbo; otro niños, en cambio, logran elaborar una justificación sobre el significado del prefijo aislado, Darío $\left(4^{\circ}\right)$ a partir del corte dice que lo podés desarmar más / des es como lo contrario.

El aislamiento de AUTO-, por su parte, sigue siendo opaco en tanto morfema derivativo. Sin embargo, en este nivel inicial encontramos el único caso de una pareja de $6^{\circ}$ grado, Pedro y Sabrina, que plantea la posibilidad de que AUTO- sea interpretado como acortamiento de AUTOMOVIL (un transporte / automóvil es lo mismo) y también como un prefijo que es posible encontrar en otras palabras de la lengua (auto autobiografía / autocontrol por ejemplo). Por último, el sufijo -ISTA es el menos utilizado y en algunos casos no registramos justificaciones. Sin embargo, la interpretación agentiva está consolidada: para Luana $\left(6^{\circ}\right)$ AUTOMOVILISTA es la persona que maneja el automóvil y para Nestor $\left(6^{\circ}\right)$ un chico que maneja un auto.

Por otra parte, en este nivel III encontramos solamente 3 cortes no esperados en la ficha problematizadora DES 'TINO. Lara $\left(4^{\circ}\right)$ y Tobías $\left(6^{\circ}\right)$ rechazan y rectifican el corte durante el intercambio, se trata de niños que aislaron el prefijo DES- en las otras fichas disponibles. En el apartado anterior (sección 3.2) vimos la justificación de Gerardo $\left(6^{\circ}\right)$, quien dice yo pensé / suponte acá en tino podés usarlo / no es una palabra pero es un conjunto de letras que lo podés usar para ponerle más sufijos o prefijos / en vez de destino podés poner intestino suponte. Se trata de intentos de aislar series gráficas que encuentran como morfemas en otras fichas o que potencialmente podrían usarse para generar nuevas series, intentos realizados por niños que obtuvieron valores muy altos en la tarea (Gerardo 7/4, Lara 6/4, Tobias 4/4 inicial llegando a 7/4 durante el intercambio).

Desde el punto de vista psicolingüístico, en este grupo encontramos una extensión de los casos de centración coordinada entre lo que cortan y lo que dejan como resultado 
de los cortes. Los niños de este nivel más avanzado pueden dar cuenta del significado aislado de la mayoría de los morfemas objeto (a excepción de AUTO- que sigue siendo opaco en tanto prefijo, en parte porque el material propuesto no permitía contrastes con otras bases como ocurría con otros prefijos) y además logran elaborar justificaciones que dan cuenta de cómo se modifican las bases léxicas que ellos conocen. Sin embargo, podemos preguntarnos si los niños están considerando que los morfemas tienen un significado en sí mismos o si se trata más bien de "modificadores del significado" de las bases léxicas que sí reconocen como plenas semánticamente y autónomas gráficamente. En el capítulo 2 vimos como Darío y Paula en la tarea de Alargar nos explicaban que al agregarse prefijos y sufijos cambia la palabra (sección 2.3), ahora en la tarea de Acortar continúan su justificación diciendo que los sufijos y prefijos significan [enfatizando] palabras pero no son en sí palabras. Aun en niños que logran elaborar las justificaciones y reflexiones metalingüísticas más avanzadas sobre las bases léxicas y sobre los morfemas derivativos encontramos que estas últimas -como ya nos explicó Gerardo ( $6^{\circ}$ ) en la tarea de Alargar- le cambian el significado a la palabra pero no tienen un significado por sí solo, al menos de la misma manera que las palabras plenas.

El Cuadro 8 presenta de manera resumida el desarrollo de las variables presentadas a lo largo de los tres niveles descriptos para esta tarea de Acortar.

\begin{tabular}{|c|c|c|}
\hline Nivel I & Nivel II & Nivel III \\
\hline \multicolumn{2}{|c|}{ Valores iguales a ambos lados de la diagonal } & $\begin{array}{c}\text { Valores diferentes a ambos } \\
\text { lados de la diagonal }\end{array}$ \\
\hline $\begin{array}{c}\text { Valores iguales o menores } \\
\text { a } 3\end{array}$ & \multicolumn{2}{|c|}{ Valores iguales a 4} \\
\hline $\begin{array}{c}\text { Aíslan de } 1 \text { a } 3 \text { morfemas } \\
\text { derivativos }\end{array}$ & $\begin{array}{c}\text { Aíslan } 4 \text { morfemas } \\
\text { derivativos }\end{array}$ & $\begin{array}{c}\text { Aíslan } 5 \text { o más morfemas } \\
\text { derivativos }\end{array}$ \\
\hline \multicolumn{2}{|c|}{ No hay cortes dobles } & Presencia de cortes dobles \\
\hline $\begin{array}{c}\text { Mayor presencia de cortes } \\
\text { no esperados }\end{array}$ & \multicolumn{2}{|c|}{ Menor presencia de cortes no esperados } \\
\hline $\begin{array}{l}\text { Primacía de justificaciones } \\
\text { con centraciones } \\
\text { exclusivas o alternadas } \\
\text { entre "lo que queda" y "lo } \\
\text { que sobra" al cortar }\end{array}$ & $\begin{array}{l}\text { Aparición de justificaciones } \\
\text { con centraciones } \\
\text { coordinadas entre "lo que } \\
\text { queda" y "lo que sobra" al } \\
\text { cortar }\end{array}$ & $\begin{array}{l}\text { Primacía de justificaciones } \\
\text { con centraciones } \\
\text { coordinadas entre "lo que } \\
\text { queda" y "lo que sobra" al } \\
\text { cortar }\end{array}$ \\
\hline
\end{tabular}


Como comentábamos al inicio de este apartado, entre los niveles descriptos hay una progresión cuantitativa tanto en la cantidad de fichas que reciben cortes como en los morfemas derivativos aislados. En el nivel II los niños logran aislar morfemas en todas las bases léxicas disponibles para cortar, pero solamente en el nivel III pueden hacerlo simultáneamente a ambos lados de una ficha, es decir, aislando al mismo tiempo un prefijo y un sufijo. Por otra parte, los cortes no esperados están concentrados en el nivel inicial, lo que sugiere que estas exploraciones, que en la mayoría de los casos no pueden justificar ni rectificar, se reducen notablemente a partir del nivel II. Por último, con respecto a las centraciones cognitivas de los niños en sus justificaciones, encontramos una progresión que va desde una centración alternada entre "lo que queda del corte" (que coincide siempre con una base léxica conocida por los niños) y "lo que me sobra del corte" (los morfemas objeto del diseño), hacia una centración coordinada entre las bases y los morfemas derivativos que también supone poder explicar los cambios semánticos generados en la derivación. El punto máximo de esta progresión lo encontramos en la posibilidad de los niños de asignar un significado al morfema cuando está aislado. En el próximo apartado (sección 3.3.) analizaremos en detalle qué morfemas derivativos fueron aislados en cada nivel y cómo fueron justificados.

El Cuadro 9 muestra la distribución de los 60 niños interrogados en los grupos evolutivos según su grado escolar:

Cuadro 9-Distribución de los 60 niños en niveles de tarea de Acortar según grado escolar $(n=60)$

\begin{tabular}{c|ccc|c}
$\begin{array}{c}\text { Grado } \\
\text { escolar }\end{array}$ & Nivel 1 & Nivel 2 & Nivel 3 & Total \\
\hline $2^{\circ}$ & 12 & 5 & 3 & 20 \\
$4^{\circ}$ & 6 & 7 & 7 & 20 \\
$6^{\circ}$ & 3 & 7 & 10 & 20 \\
\hline Total & 21 & 19 & 20 & 60
\end{tabular}

En general, podemos decir que la distribución en niveles corresponde con los grados escolares: en el nivel inicial encontramos una mayoría de niños de $2^{\circ}$ grado, mientras que en el nivel más avanzado priman los niños de $4^{\circ}$ y $6^{\circ}$ grado. El nivel II es el que muestra una distribución más pareja en los tres grados escolares. 
Teniendo en cuenta la conformación de cada nivel en la tarea de Acortar, podemos representar en un cuadro la cantidad de cortes simples esperados, cortes dobles (esperados según el diseño pero difíciles evolutivamente) y cortes no esperados. Todos ellos antes de iniciar el intercambio:

Cuadro 10 - Cortes simples y esperados, cortes dobles (esperados pero difíciles) y cortes no esperados según niveles en tarea de acortar, considerando solo cortes iniciales

\begin{tabular}{cccc} 
Cortes realizados & $\begin{array}{c}\text { Nivel I } \\
(\mathrm{n}=\mathbf{2 1})\end{array}$ & $\begin{array}{c}\text { Nivel II } \\
(\mathrm{n}=19)\end{array}$ & $\begin{array}{c}\text { Nivel III } \\
(\mathrm{n}=\mathbf{2 0})\end{array}$ \\
\hline $\begin{array}{c}\text { Cortes simples y } \\
\text { esperados }\end{array}$ & 54 & 69 & 58 \\
\hline Cortes dobles & 0 & 1 & 21 \\
\hline Cortes no esperados & 13 & 4 & 3
\end{tabular}

El Cuadro 10 da cuenta de la progresión en cantidad de cortes simples esperados entre el nivel I y II. Al igual que en el análisis de los alargamientos realizados por nivel (sección 2.3), resulta llamativo en principio que en el nivel más avanzado encontremos menos cortes simples que en el intermedio. Sin embargo, se impone la consideración de los cortes dobles que están concentrados en el nivel III (21 sobre los 22 registrados en total, en segundo renglón de este cuadro 10). Por lo tanto, los niños del nivel III realizaron un número mucho mayor de cortes y son los únicos que pueden considerar simultáneamente cortes a ambos lados de las bases léxicas. El último renglón del Cuadro 10 también nos permite ver la concentración de cortes no esperados en el nivel I.

\subsection{Jerarquización de los morfemas derivativos cortados}

A diferencia de la tarea anterior de Alargar, en la que las posibilidades de combinación no tenían una previsión inicial precisa, en el caso de la tarea de Acortar sí contamos con una referencia de los cortes posibles esperados: en cada conjunto teníamos 4 fichas cortables que admitían un máximo de 7 cortes (tres fichas que admitían cortes 
dobles y una que admitía corte simple, con un valor máximo de 7/4) y 2 fichas que no admitían corte. Otra diferencia con la tarea de Alargar, es que en esta tarea de Acortar los niños recibían fichas idénticas (DESTINO y AUTOMOVILISTA) y fichas con los mismos morfemas derivativos y procesos de derivación, sólo que con bases léxicas distintas (por ejemplo, INOLVIDABLE e INSOPORTABLE, ambas con el prefijo negativo IN-y el prefijo potencial -BLE). En este apartado analizaremos la frecuencia de los cortes para cada par de fichas equivalentes en ambos conjuntos, centrándonos específicamente en los aspectos cualitativos de las justificaciones de los cortes realizados por los niños y las posibles relaciones entre las partes resultantes del corte.

La Gráfica 3 nos permite tener una primera impresión general sobre la frecuencia con que cada morfema derivativo fue aislado.

Gráfica 3 - Frecuencia de cortes de morfemas derivativos según nivel en tarea de Acortar

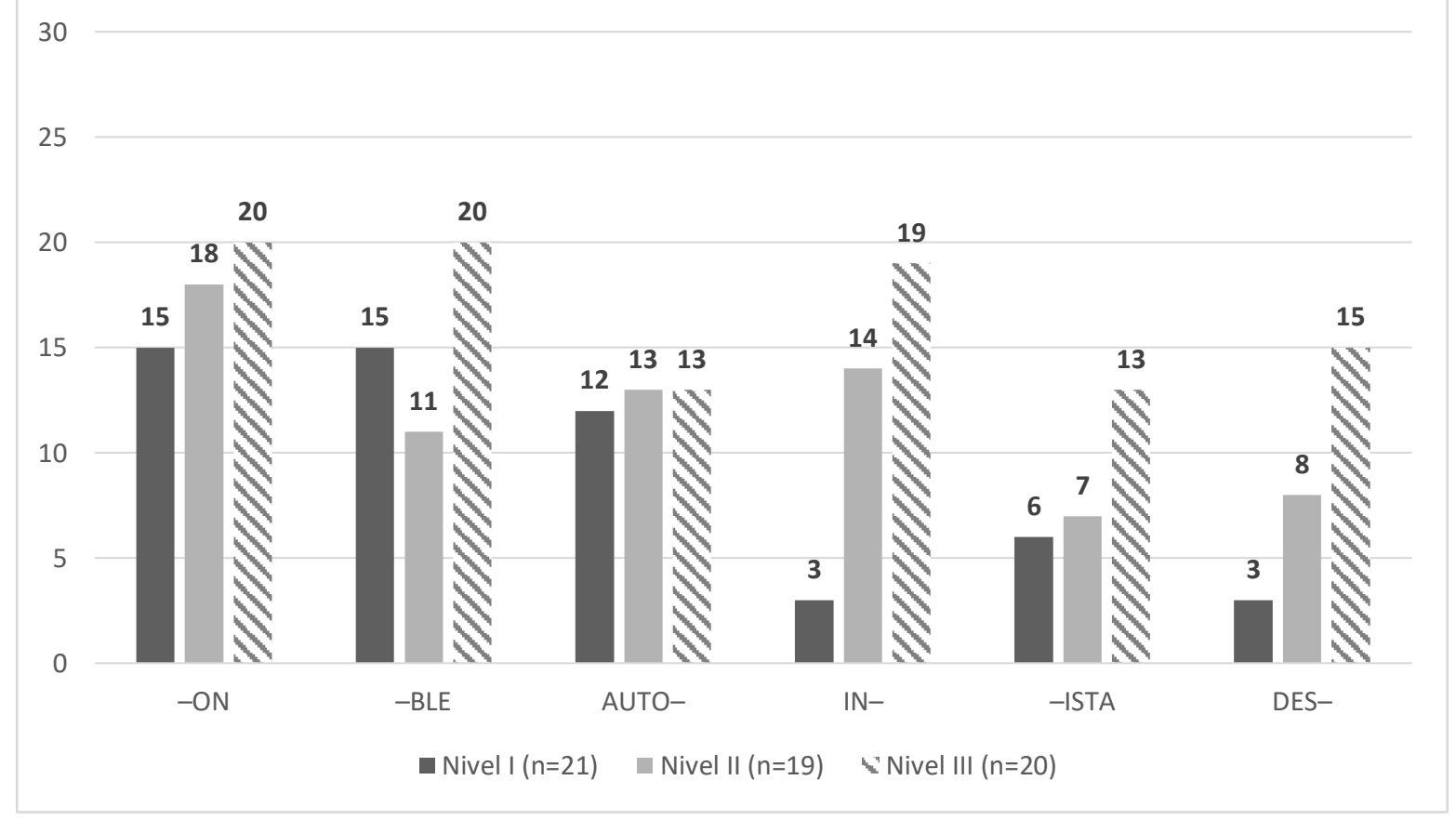

Sin embargo, hay que tomar esta representación como una primera aproximación a lo realizado por los niños ya que presenta algunas particularidades: por un lado, en cada grupo evolutivo para la tarea de Acortar encontramos niños que recibieron tanto el Conjunto 1 como el Conjunto 2 (sección 3.2), lo que implica que en algunos casos hay que considerar en detalle si hay diferencias en los cortes según las distintas bases léxicas; por 
otro lado, el morfema -BLE es el único que está disponible en dos fichas distintas por conjunto lo cual implica un número potencial de cortes mayor al resto de los morfemas ${ }^{33}$.

A partir de esta aproximación cuantitativa general, es necesario analizar qué sucedió particularmente con los cortes en cada ficha, cómo justificaron e interpretaron esos segmentos que pudieron aislar y, sobre todo, qué relaciones plantearon entre los mismos morfemas derivativos con las distintas bases léxicas. Con el propósito de presentar de forma más ordenada el análisis de las justificaciones, a continuación comentaremos conjuntamente cada par de fichas con morfemas derivativos equivalentes, tomando como punto de partida los cortes totales realizados a cada ficha y describiendo las interpretaciones registradas en los distintos niveles.

Comencemos por analizar los cortes en las únicas fichas de ambos conjuntos que solamente admitían un corte esperado, es decir las fichas que incluían el sufijo -oN. La ficha PAPELON recibió 27 cortes sobre 3034, mientras que NARIZON lo hizo 26/30. Al igual que en la tarea de Alargar (sección 2.5), desde el nivel inicial los niños no encuentran mayores problemas en justificar el sufijo en la ficha NARIZON como aumentativo: Jazmín (4º nivel I) la explica como alguien que tiene una nariz muy grande y Leonel ( $6^{\circ}$ - nivel II) afirma que es como si fuera una nariz grande. Inclusive, en el nivel inicial encontramos un intento interesante de explicar el significado del sufijo cuando está aislado: Isabella $\left(2^{\circ}-\right.$ nivel I) dice que on no es una palabra pero nariz sí y narizón lo hace más grande a la nariz. En el nivel III encontramos el único caso en que una pareja plantea que el sufijo -on puede ser interpretado como aumentativo y también como apreciativo: Lorena $\left(6^{\circ}\right)$, recuperando lo que planteó sobre CUENTON en la tarea de Alargar, dice que NARIZON puede ser una nariz grande o muy buena.

\footnotetext{
33 Hacemos esta aclaración, aunque esta posibilidad de recibir más cortes que los demás por estar presentes en dos fichas por conjunto está condicionada por la restricción de las derivaciones adjetivas que incluyen el prefijo IN-. En estos casos, o bien se realiza el corte simple del prefijo, o bien ser realiza el corte doble. Pero debido al proceso de derivación (olvida $\rightarrow$ olvidable $\rightarrow$ inolvidable y soporta $\rightarrow$ soportable $\rightarrow$ insoportable), no puede aislarse solamente el sufijo -BLE.

34 Teniendo en cuenta que entrevistamos 30 parejas de niños ( 10 de $2^{\circ}$ grado, 10 de $4^{\circ}$ y 10 de $6^{\circ}$ ) y que cada pareja recibía un par de fichas distintas, en el caso de las fichas NARIZON, PAPELON, INOLVIDABLE, INSOPORTABLE, DESPEGABLE y DESARMABLE tenemos un máximo de 30 posibles cortes. Como la ficha AUTOMOVILISTA es compartida por ambos niños de cada pareja, el máximo de cortes para esta última es de 60.
} 
La ficha PAPELON, por otro lado, nos permitió explorar cuáles eran las posibilidades de los niños de atribuirle el significado lexicalizado de "situación ridícula o embarazosa", el significado aumentativo de "papel grande" o la posibilidad de que reciba ambas interpretaciones (lo que en principio constituiría un punto alto de rendimiento en términos de reflexión metalingüística). En el nivel I y II encontramos una primacía de interpretaciones alternadas, es decir, o bien interpretan PAPELON como aumentativo o bien como forma lexicalizada. La forma exclusivamente aumentativa, sin embargo, tiende a decrecer de un nivel a otro: 3 casos en el nivel inicial, frente a 1 en los niveles II y III. Por el contrario, la justificación que plantea dos posibles interpretaciones para PAPELON se incrementa de un nivel a otro: 2 casos en el nivel I frente a 7 en el nivel III. El contraste semántico entre una forma lexicalizada y una forma derivada con el sufijo aumentativo resultó propicio para que los niños reflexionen sobre el significado que el segmento gráfico -ON aporta a la base léxica. Es decir, cuando un niño -por ejemplo Román $\left(6^{\circ}-\right.$ nivel III)- justifica PAPELON como pasar vergüenza y como papel grande ¿el segmento -ON quiere decir lo mismo? En la sección 2.3 vimos una explicación interesante de Paula $\left(4^{\circ}\right)$ quien sostuvo que todo depende de cómo es la raíz, si se trata de papelón como papel muy grande entonces -ON sería un sufijo. En cambio, si significa que te portaste mal (o sea, la interpretación lexicalizada) entonces sería una palabra completa.

En los tres niveles los niños parecen tener las condiciones psicolingüísticas para aislar y justificar la derivación aumentativa del sufijo -ON. Se trata, además, de un sufijo sobre el que los niños desde niveles iniciales pueden elaborar intentos de explicar cómo modifica el significado de las bases léxicas e inclusive reflexionar en niveles avanzados cómo una misma palabra puede incluirlo como un modificador que aumenta el tamaño o como parte de la palabra entera. Estos datos son coincidentes con los registrados a nivel oral por niños preescolares en la tesis de Maestría en desarrollo de Monserrat Rodríguez Cuevas bajo la dirección de Emilia Ferreiro (Rodríguez Cuevas, 2018:4).

Continuemos con el par de fichas que tenían el prefijo negativo IN- y el sufijo -BLE, es decir, las fichas INOLVIDABLE e INSOPORTABLE. Estas fichas presentan la particularidad de poder recibir un corte simple solamente del prefijo, ya que el proceso de derivación 
negativa se hace a partir de una base adjetiva: olvida $\rightarrow$ olvidable $\rightarrow$ inolvidable. Es decir, que los cortes esperados se corresponden o bien al corte simple del prefijo o bien al corte doble del prefijo y el sufijo (situación solamente registrada en los niños del nivel más avanzado). Si consideramos el total de cortes realizados tenemos 19/30 cortes para INOLVIDABLE y $17 / 30$ para INSOPORTABLE. En INOLVIDABLE 15/30 son cortes simples y 4/30 son dobles, mientras que en INSOPORTABLE $14 / 30$ son cortes simples y $3 / 30$ son dobles.

En primer lugar, mencionamos que el prefijo IN-, al igual que en la tarea de Alargar (sección 2.4) fue particularmente opaco para los niños del nivel I: solamente 3 sobre los 21 niños que ubicamos en este nivel inicial lograron aislarlo. Sin embargo, la presencia del sufijo -BLE parece sugerir un eje de contraste "con prefijo IN-=no se puede" frente a "sin prefijo IN-=sí se puede": Florencia $\left(4^{\circ}\right)$ sostuvo que INOLVIDABLE es que no me lo puedo olvidar mientras que olvidable sí se puede olvidar, Clara $\left(4^{\circ}\right)$ que INOLVIDABLE significa que vos querés olvidar algo pero no podés mientras que olvidable es que lo olvidás.

En el nivel II no sólo encontramos un incremento significativo de los cortes del prefijo (14 sobre 19 niños de este nivel II lo aíslan), sino que se generalizan los intentos de dar cuenta del significado del morfema cuando está aislado. Ya vimos en el apartado 3 de este capítulo que Ulises ( $4^{\circ}$ - nivel II) explica que con IN- te queda lo contrario a lo que pusiste en la base léxica. Otros niños de este nivel II también se refieren al prefijo como el antónimo (Pablo $4^{\circ}$ ) o lo contrario (Laura y Luciano, ambos de $6^{\circ}$ ). Esta interpretación de la negatividad del prefijo (basada en el contraste "con IN- no se puede/con -BLE sí se puede") posibilita que durante el intercambio prácticamente todos los niños del nivel II (y del nivel III) que habían aislado solamente el prefijo, alcancen el corte doble en la ficha. Luciano y Laura (ambos de $6^{\circ}$ y del nivel II) parten de cortar y justificar el prefijo como lo contrario y durante el intercambio recurren a una referencia temporal interesante para justificar la idea de potencialidad del sufijo:

Ent.: y este que cortaron acá [señalando el corte IN;SOPORTABLE en el tablero del niño] cómo era?

Laura: insoportable

Luciano: cuando no soportás a alguien

Ent.: y si vos le sacás ese? [señalando IN]

Laura: soportable sería 
Luciano: [interrumpiendo] cuando lo soportás

Laura: que sí [enfatizando] lo soportás pero insoportable es que no [enfatizando] 10 soportás

Ent.: ustedes me habían dicho que este [señalando IN] qué era? [refiriéndose a un intercambio en la anterior tarea de Alargar]

Laura: el contrario

Ent.: y acá es lo mismo? [señalando la ficha IN, OLVIDABLE en el tablero de la niña]

Laura: in / inolvidable / sí / sí [toma la ficha y realiza el corte OLVIDA ' BLE]

Ent.: ah cortaste ble también?

Laura: olvida / olvidable [mostrando con las fichas el corte realizado]

Ent.: cambia?

Luciano: el pasado y el futuro es ese

Ent.: cuál es el pasado?

Luciano: olvida

Laura: olvida

Ent.: y olvidable?

Laura: el futuro

Se trata de un ejemplo muy interesante, ya que para abordar la idea de potencialidad del sufijo -BLE los niños recurren a la dimensión temporal que permite precisar que se trata de una acción posible pero aún no realizada. Se trata, junto con el ejemplo de Genaro comentado en la sección 3.3, uno de los pocos casos en que los niños logran especificar este carácter de "futuro posible" para el sufijo.

Por último, en el nivel más avanzado casi todos los niños aíslan IN- (19 sobre 20) y además en sus justificaciones se generaliza la posibilidad de centrarse coordinadamente en el significado negativo del prefijo (in es el antónimo; in significa negativo o que no; con in sería el contrario; in significa que no) y el de potencialidad del sufijo (que sí se puede hacer). En los casos de cortes dobles también se mantiene el contraste "IN-=no se puede" / "-BLE=sí se puede":

- Azul ( $6^{\circ}$ - nivel III) inolvidable es que no lo vas a olvidar más / con in sería el contrario / olvidable que se olvida más fácil

- Abril ( $6^{\circ}$ - nivel III) insoportable que no se puede soportar / si alguien no te cae bien es insoportable / soportable que sí se puede soportar

La presencia del prefijo IN- en series que también incluían el sufijo -BLE parece facilitar la posibilidad de aislar y de justificar el significado que aporta el prefijo en niños 
de este nivel (no así en niños de los niveles previos). La construcción derivativa de las fichas presentadas (INOLVIDABLE e INSOPORTABLE), de hecho, podría constituir un caso que sugiera esta interpretación (al menos para los niños de niveles avanzados) ya que como comenta la Gramática de la Real Academia "abundan los adjetivos en -ble que contienen prefijos negativos (in-V-ble): indudable, inmutable, inolvidable, insondable, invencible, a menudo de uso más frecuente que las correspondientes formas no prefijadas" (RAE/ASALE, 2009:146).

Veamos ahora lo sucedido con el par de fichas que incluía conjuntamente el prefijo negativo DES- y el sufijo -BLE (correspondientes a las fichas DESPEGABLE y DESARMABLE). En este caso, las fichas admitían tres posibilidades: un corte simple del prefijo DES-, un corte simple del sufijo -BLE, o un corte doble de ambos morfemas. Si consideramos los cortes totales, se trata de las fichas que más cortes recibieron: 28/30 para DESPEGABLE y 29/30 para DESARMABLE. La ficha DESPEGABLE recibió 14/30 cortes del sufijo, 10/30 cortes del prefijo y 4/30 cortes dobles, mientras que DESARMABLE recibió 17/30 cortes del sufijo, 8/30 cortes del prefijo y $4 / 30$ cortes dobles.

Las justificaciones que los niños de los tres niveles elaboraron sobre las fichas con DES- y -BLE dan cuenta de cierta progresión en la posibilidad de considerar el sentido negativo del prefijo y el potencial del sufijo, pero al mismo tiempo advierten sobre la persistencia de ciertas dificultades presentes en todos los niveles. En primer lugar, hay justificaciones centradas en el significado lexicalizado de las bases verbales (DESPEGA y DESARMA) que son explicaciones tautológicas sin referencias a la reversión del prefijo aun cuando logran aislarlo. Veamos el siguiente intercambio de Belén ( $2^{\circ}$ - nivel I) para explicar su corte DES' PEGABLE:

Ent.: qué es pegable?

Belén: algo / que se puede pegar

Ent.: y despegable?

Belén: despegable / que lo despegás / por ejemplo / vos pegás esto [señalando el papel pegado a las fichas de cartulina] y después lo / lo despegás

Belén $\left(2^{\circ}\right)$ logra dar cuenta de la derivación adjetiva (PEGABLE que se puede pegar) pero no parece poder dar cuenta del significado del segmento que sí puede aislar en su 
corte. En otros casos, hay niños que cortaron el sufijo pero también enfrentaron dificultades similares para justificarlo:

Ent.: vos acá cortaste desarma [señalando la ficha que el niño cortó DESARMA;BLE] / qué es desarma?

Luciano: vos desarmás algo

Laura: lo desarmás

Ent.: y desarmable?

Laura: y desarmable es que / no sé

Luciano: sería lo mismo

Laura: entonces por qué lo cortaste? [dirigiéndose a su compañero]

Ent.: puede ser lo mismo desarma que desarmable?

Luciano: quise achicar la palabra

Laura: es lo mismo

Ent.: si yo pongo ble [señalando BLE en DESARMA 'BLE] no cambia nada? Luciano: no

Laura: desarmable [leyendo para sí la ficha] / no

Luciano $\left(6^{\circ}\right.$ - nivel II) logra centrarse en DESARMA, una base con significado que puede aislar aunque su justificación sea la repetición conjugada de la base verbal. Sin embargo, no logra centrarse en -BLE, eso que queda como resultado de achicar la palabra. Es interesante, porque son niños que en otros casos no aceptan que si algo cambia gráficamente en las palabras el significado pueda permanecer inalterado. En segundo lugar, también encontramos algunas interpretaciones agentivas (o agentiva e instrumental en un caso), poco numerosas en cantidad pero presentes en los tres niveles. Tomemos por ejemplo tres niños que pertenecen a los tres niveles:

- Gonzalo ( $2^{\circ}$ - nivel I) DESARMA'BLE algo o alguien que desarma

- Lucía ( $2^{\circ}$ - nivel II) DES I ARMABLE es alguien que desarma

- Lara (4 - nivel III) DES I ARMA, BLE una persona que desarma algo

Si nos focalizamos en las interpretaciones adecuadas de los morfemas derivativos, encontramos que en el caso de estas fichas con DES- y -BLE, a diferencia de lo que ocurrió con las que tenían el prefijo negativo $\mathrm{IN}-$, los niños encuentran muchas dificultades para centrarse coordinadamente en los significados que aportan ambos morfemas. Hay muy pocos casos en los que los niños enfatizan la negación o reversión del prefijo: Marcos $\left(4^{\circ}-\right.$ nivel II) explica que DESARMABLE significa que es imposible de desarmar y Laura (6 $6^{\circ}$ nivel II) 
parafrasea el agregado del prefijo diciendo que DESPEGABLE sería lo contrario de pegable. En las justificaciones de los niveles II y III encontramos, en cambio, una primacía de justificaciones centradas en el significado de potencialidad del sufijo, más allá que en el corte hayan aislado el prefijo, el sufijo o ambos:

- Jeremías (4 - II) DES I ARMABLE el ejemplo de telescopios fijos y los telescopios desarmables / que se pueden desarmar

- Lucas $\left(2^{\circ}\right.$ - III) DES! PEGA!'BLE algo que se puede despegar y pegar

- Genaro (4 - III) DESARMA!'BLE que se puede desarmar

- Luana $\left(6^{\circ}-\right.$ III) DES!ARMA!'BLE que se puede desarmar

Esta primacía de la interpretación potencial y pasiva de las fichas ("que se puede hacer la acción designada por la base léxica") que nos muestran los ejemplos parece haber tornado más opaca la presencia del prefijo DES- y, en comparación con los casos del morfema negativo IN-, encontramos muchos menos intentos de dar cuenta del significado del morfema cuando está aislado (concentrados además solo en el nivel más avanzado).

Entre los pocos intentos de interpretar el significado del prefijo DES- aislado, registramos la justificación de la pareja de $6^{\circ}$ conformada por Gerardo y Luana (ver sección 3.2): DES- sería el negativo; y también el ejemplo de Azul (6º - nivel III):

Ent.: qué es desarma?

Azul: desarmar algo / una acción de desarmar

Leonel: por ejemplo una bici / la estás desarmando [explicando con gestos]

Ent.: y qué hacés?

Leonel: le sacás las ruedas el asiento

Azul: la separás

Ent.: con esta [señalando DES] cambia?

Azul: sí

Ent.: cómo cambia?

Leonel: eh / los / o sea

Azul: el contrario sería referido a armar

Ent.: cómo el contrario? a ver contame

Azul: claro

Leonel: de armar es el contrario / sería desarmar

Azul: o sea vos estás armando una bici / y después la desarmás

Por su parte, el sufijo -BLE recibió una cantidad mayor de intentos de justificación cuando estaba aislado: Pedro $\left(6^{\circ}\right.$ - nivel III) dice ble significa de que se puede hacer y 
Román $\left(6^{\circ}\right.$ - nivel III) ble significa que sí se puede hacer la acción indicada por la raíz. Incluso Andrés ( $6^{\circ}$ nivel II) nos explica que en PEGABLE la serie -BLE como que lo hace adjetivo a PEGA que sería como un verbo.

En las justificaciones de las fichas con el prefijo DES- $y-B L E$ encontramos entonces una primacía de interpretaciones focalizadas en la idea de potencialidad y pasividad del sufijo. Parece difícil para los niños de los tres niveles centrarse en la idea de reversión (lo que en algunos pocos casos los niños designan como lo contrario) de la acción indicada por las bases verbales PEGA y ARMA. Una dificultad adicional en este caso, puede ser el hecho de que se trata de dos formas polisémicas: PEGA admite la interpretación "unir dos cosas" pero también la de "dar un golpe", sin embargo la derivación con DES- solamente indica reversión de la acción en el primero de los casos "separar dos cosas que han sido unidas". A su vez, la forma derivada DESPEGA tiene un significado lexicalizado "dicho de un medio de transporte que levanta vuelo". Genaro y Carolina ( $4^{\circ}-$ nivel III), para justificar el corte DES!'PEGA|'BLE de la niña, dan cuenta de esta complejidad de sentidos: PEGA es pegar [con golpe de puño] y otra que también es un verbo / es una acción de pegar con plasticola / por ejemplo yo pego la fotocopia, DESPEGABLE que la puedo volver a sacar [la fotocopia], PEGABLE que te puedo pegar y DESPEGA el cohete

Por su parte, la base léxica ARMA puede recibir una interpretación verbal ("unir piezas entre sí") o una sustantiva ("objeto o instrumento para combatir"). Algunos niños dan cuenta de esta doble referencia de la base léxica, Marcos ( $4^{\circ}$ - II) por ejemplo dice que hay un arma, haciendo el gesto de una pistola con la mano, y un arma de armar / verbo. Sin embargo, a diferencia de las interpretaciones agentivas desviantes que surgieron con la base léxica ARMA y el sufijo -DOR en la tarea de Alargar (sección 2.5), en la situación de Acortar, la presencia del prefijo DES- parece sugerir a todos los niños la interpretación verbal, aun cuando los niños advierten la polisemia de la base:

Ent.: y no le podemos sacar un pedacito más a ese? [señalando la ficha que quedó DESARMA en el tablero del niño]

Carolina: desarma arma / arma [enfáticamente y sugiriendo el corte DES I ARMA] Genaro: pero [dudando] / no tiene nada que ver con desarmable [cortando la ficha DES I'ARMA]

Carolina: pero arma por ejemplo él arma 
Genaro: ah es un verbo también

Carolina: él arma una torre

Ent.: y desarma?

Genaro: no / desarma / ahí es él saca todos los ladrillos y listo / no queda más torre Carolina: desarma es que desarmó la torre

Genaro parece partir de la interpretación sustantiva (aunque esto no es explícito) y es Carolina quien introduce la interpretación verbal de la base. Solamente cuando surge esta posibilidad Genaro acepta que DESARMA tenga que ver con ARMA. Estos ejemplos nos instalan en una pregunta fundamental: ¿es aislable el significado de los morfemas derivativos? Es decir, aun cuando los niños aíslan el segmento correspondiente a un morfema (DES-) en una tarea que les propone realizar un corte en una palabra (DESPEGABLE O DESARMA) ¿en qué se centran para justificar esos cortes? En los intercambios registrados vimos que aun en casos en los que realizan los cortes esperados, las justificaciones parecen centrarse en segmentos plenos que los niños pueden interpretar por separado.

Por último, veamos lo sucedido con la ficha AUTOMOVILISTA que incluye el prefijo AUTO- y el sufijo -ISTA. Recordemos que se trata de la única ficha que admitía dos cortes compartida por los niños de cada pareja. El total de cortes realizados es de 56/60: registramos a su vez 30/60 cortes simples del prefijo AUTO-, 19/60 cortes simples del sufijo -ISTA y $7 / 60$ cortes dobles.

Todos los aislamientos del prefijo AUTO- corresponden a una interpretación plena del segmento, es decir, como acortamiento de AUTOMOVIL y no como un morfema derivativo en si $^{35}$. La familiaridad de la palabra AUTO para los niños parece opacar cualquier posibilidad de llegar a partir de esta ficha a la consideración del prefijo reflexivo. En todos los casos que los niños cortaron el prefijo tuvimos la oportunidad de solicitar un contraste, ya sea con AUTOMOVILISTA o con AUTOMOVIL. Algunos niños abordaron la cuestión de la convivencia de dos formas distintas (AUTO y AUTOMOVIL) con el mismo significado: Tiago ( $6^{\circ}$ - nivel III) sostuvo que automóvil y auto es lo mismo / un sinónimo / nada más que el auto

\footnotetext{
35 Jesús Pena explica que "el acortamiento (inglés clipping, alemán Wortkürzung) consiste en la sustracción de una o más sílabas de la palabra, que está también disponible en su forma plena: colegio $\rightarrow$ cole, bolígrafo $\rightarrow$ boli, motocicleta $\rightarrow$ moto [...]. Con relación a la palabra base, la palabra acortada permanece adscrita a la misma clase de palabras, expresa el mismo género y mantiene el mismo significado" (2000:250).
} 
está resumido, Jeremías ( $4^{\circ}$ - nivel II) que automóvil es la palabra verdadera / auto es como para cortarla, y Ulises $\left(4^{\circ}\right.$ - nivel II) nos explicó que si se usa uno u otro se va a entender igual. Solamente niños de los niveles I y II trataron de establecer algún tipo de diferencia entre estas formas: vimos en la sección 3.2 cómo Gonzalo ( $2^{\circ}$ grado - nivel I) distinguía AUTOMOVIL como unos autos que son muy geniales y AUTO como un auto común y corriente. Pero también hay otros ejemplos: para Renata $\left(2^{\circ}\right.$ - nivel II) auto sería el auto que vos manejás de verdad / automóvil sería el del control remoto / el que tiene baterías, mientras que para Clara ( $4^{\circ}$ - nivel I) AUTO sería como un auto de colección / y automóvil sería uno de esos que andan por las calles. En estos niños parece prevalecer la idea de que si algo cambia en la palabra, es decir si hay un agregado o un recorte gráfico, entonces tiene que haber alguna diferencia en el significado. Sin embargo, la mayoría de los niños explicó con tautologías el corte, mostrándose inclusive sorprendidos como si la pregunta fuera una obviedad: un auto / es un auto (Melina, $2^{\circ}$ - nivel I).

La única excepción a esta interpretación de AUTO- como forma plena la encontramos en la pareja de Pedro y Sabrina (ambos $6^{\circ}$ - nivel III), quienes elaboran como punto de partida la interpretación de acortamiento ya comentada, pero durante el intercambio sugirieron la posibilidad de que AUTO sea interpretado como una "partecita" que también encontramos en otras palabras:

Pedro: aunque auto puede ser por ejemplo / eeeh acá no tengo un ejemplo [buscando entre sus fichas]

Ent.: qué me querías contar?

Pedro: no sé cómo / no sé

Ent.: es lo mismo auto que automóvil me dijiste recién

Pedro: sí / pero también se puede sacar de auto por ejemplo

Sabrina: auto / autobiografía

Pedro: autocontrol por ejemplo

Ent.: a ver cómo es eso? // yo te voy a escribir lo que vos me dijiste [escribe AUTOBIOGRAFÍA Y AUTOCONTROL] / autobiografía y autocontrol qué es?

Sabrina: que podés controlarte

Ent.: y vos me decís que esto [señalando AUTO en AUTOCONTROL] es igual a eso? [señalando AUTO en AUTO' MOVIL' ISTA]

Pedro: es distinto / porque sería por ejemplo que él lo puede manejar / como una persona / que él lo puede manejar / y lo otro sería el auto

Ent.: vos decís que automóvil quiere decir que él lo puede manejar?

Pedro: sí / sería como autobiografía / que lo hace una persona 
Ent.: auto de automóvil tiene que ver con auto de autobiografía

Pedro: y sí / o sea sería como alguien que puede [enfatizando] manejar

Por otra parte, los niños de los tres niveles recurrieron mayormente a una interpretación agentiva del sufijo denominal -ISTA. La ficha completa AUTOMOVILISTA fue justificada por la mayoría de los niños con paráfrasis que se referían a la idea de "sujeto que conduce/repara/o vende automóviles":

- Josefina $\left(2^{\circ}\right.$ - nivel I) es un señor que arregla autos

- Ulises (4 - nivel II) sería una persona que vende automóviles

- Genaro (4 ${ }^{\circ}$ - nivel III) un hombre que conduce un auto

Aun así, encontramos algunos casos de interpretaciones desviantes de la derivación con -ISTA. Al igual que en la tarea de Alargar (sección 2.5) hay interpretaciones de amalgama (aunque poco frecuentes): Guadalupe $\left(2^{\circ}\right.$ - nivel II), por ejemplo, sostiene que es como un señor que puede arreglar un auto y es listo. Otra interpretación desviante, que incluso está presente en los niveles avanzadas, es la locativa: Leonel $\left(6^{\circ}-\right.$ nivel II) explicó que AUTOMOVILISTA es un lugar / esta ruta son para automovilistas, mientras que Luis $\left(2^{\circ}\right.$ - nivel III) sostuvo que automovilista es un lugar donde llevás el auto y te lo pueden arreglar. Podemos comparar esta situación con lo sucedido con la serie FLORERO en la tarea de Alargar (sección 2.4). Se trata, en ambos casos, de palabras familiares y fáciles para los niños en tanto componentes léxicos. En FLORERO, sin embargo, la interpretación conflictúa con maceta y esto dio lugar a interpretaciones locativas: FLORERO como florería.

Al igual que en la tarea de Alargar (sección 2.5), el análisis de la frecuencia de los cortes y las justificaciones nos muestra que no todos los morfemas objeto están disponibles de la misma manera para los niños. En la tarea de Acortar, además, estamos considerando una acción distinta: en este caso, nosotros entregamos a los niños fichas con palabras y sugerimos la acción de "quitar un segmento" (o varios) y que "quede otro segmento" que tenga que ver con la palabra antes de ser cortada. A excepción del prefijo reflexivo AUTO-, todos los otros morfemas derivativos disponibles para ser cortados ya habían sido presentados como formas libres en la tarea de Alargar. En este sentido, el análisis de los cortes y las justificaciones nos permitió adentrarnos en el problema de la 
centración cognitiva al cortar la ficha y producir "un segmento que elijo cortar" y "un segmento que me queda como resultado de cortar". Es decir, ¿los niños cortan una base léxica menor y un morfema derivativo en la ficha?, o bien ¿cortan una base léxica menor que conocen y como un "resto" de ese corte queda un segmente gráfico que para la mirada del lingüista es un morfema derivativo? Y si es así, ¿qué es para los niños ese "pedacito" que sobra al cortar y qué diferencias había antes de ser cortado? Es determinante para este análisis la consideración de los niveles y de las restricciones lingüísticas de cada una de las fichas presentadas a los niños.

Lo que parece estar en juego es la posibilidad de centrarse alternada o coordinadamente entre los segmentos resultantes del corte. En el nivel inicial predomina la centración exclusiva en bases léxicas plenas y familiares para los niños, lo que genera un segmento "sobrante" que no intentan interpretar cuando está aislado y que en algunos casos es incluso opaco antes de ser separado por el corte. Un paso siguiente, es poder justificar las relaciones de modificación entre las bases léxicas plenas y los segmentos que sobran del corte: en estos casos los niños pueden parafrasear el agregado semántico del morfema, por el ejemplo, explicar la derivación en -BLE como "que se puede hacer la acción indicada por la base" o la derivación en -ISTA como "es alguien que trabaja o vende el objeto referido por la base". El punto máximo es la centración coordinada entre las bases léxicas y los morfemas derivativos que resultan del corte, se trata del momento en que los niños cortan formas plenas que conocen pero al mismo tiempo pueden justificar cómo el segmento sobrante las modifica y eventualmente dar cuenta del significado que este segmento menor (que no es palabra) tiene cuando está aislado. Dos aclaraciones nos parecen necesarios sobre esta visión procesual de las centraciones cognitivas de los niños en la tarea de Acortar: en primer lugar, si bien ubicamos a cada niño en uno de los tres niveles propuestos, a lo largo de la tarea encontramos justificaciones diversas de un mismo niño; en segundo lugar, hay que considerar cada morfema derivativo en forma particular (ya que aun siendo todos morfemas derivativos productivos en la lengua española, no todos parecen estar disponibles de la misma forma para los niños) y, además, evaluar cada morfema en relación con las bases léxicas disponibles en la tarea. 


\subsection{Las justificaciones de los niños al decidir no cortar}

Nuestro diseño también incluía fichas problematizadoras con palabras que comparten letras pero no morfemas con el resto de las fichas de cada conjunto. Incluimos para ambos conjuntos la ficha DESTINO, que comparte inicio con DESPEGABLE y DESARMABLE, y las fichas RENGLON y LADRON (una para cada conjunto respectivamente) que comparten final CON PAPELON y NARIZON. En una tarea con una consigna y materiales que sugiere la acción de realizar cortes en un conjunto de fichas, abstenerse de realizar un corte (sobre todo de segmentos gráficos que recibieron cortes en otras fichas y que ya habían sido presentados como formas libres en la tarea de Alargar) en principio es un indicador de una conducta evolucionada. Sin embargo, los cortes no esperados en estas fichas problematizadoras fueron mínimos: apenas 2/30 en LADRON y 5/60 en DESTINO, mientras que ninguno de los 30 niños que recibió RENGLON ensayó algún corte. En la sección 3.3, analizamos en general los casos de cortes no esperados cuando elaboramos la descripción de los niveles para la tarea de Acortar. En este apartado, nos centraremos en los argumentos que los niños elaboraron para abstenerse de cortar segmentos gráficos que cortaban en otras fichas.

Una primera cuestión tiene que ver con cómo evaluar la decisión de no realizar un corte. Recordemos que durante el intercambio el entrevistador invitaba a los niños a justificar los cortes realizados pero también a realizar nuevos cortes. Esto generó que en algún punto del intercambio, los niños dieran cuenta de por qué no realizaron cortes en las fichas problematizadoras $y$, además, por qué no podrían realizarlo durante el intercambio aun cuando se les sugiriera hacerlo. Si bien la acción de abstenerse de realizar cortes en las fichas problematizadoras está generalizada en todos los niveles, es en los motivos por los cuales no realizaron cortes donde encontramos diferencias.

Una de las razones presentes en todos los niños entrevistados, y que además es la más común en el nivel inicial, es que lo que resulta del corte no es una palabra. Veamos el siguiente intercambio de Emanuel y Carla, pareja de $2^{\circ}$ y del nivel I:

Ent.: miren / acá ustedes me dicen que narizón [señalando la ficha que cortaron NARIZ;ON] le sacaron este pedacito [señalando ON]

Emanuel: sí 
Ent.: renglón termina igual [señalando ON en la ficha RENGLON]

Emanuel: sí

Ent.: y no se lo sacaste / contame cómo te diste cuenta y acá lo sacaste [señalando NARIZ;ON] y acá no [señalando RENGLON]

Emanuel: ren glón [leyendo para sí la ficha]

Carla: porque me parece

Emanuel: si lo sacaba no iba a ser nada

Ent.: ajá

Emanuel: no iba a entender

Carla: porque no / porque no existe esa palabra [señalando RENGL en RENGLON]

Los niños logran elaborar una justificación, que en términos cognitivos, es además una reflexión interesante ya que están argumentando sobre una acción posible que no realizaron (un corte potencial en todo caso) y por lo tanto apoyándose gráficamente en la ficha para ensayar segmentaciones que ellos mismos descartaron. El argumento de que un segmento gráfico no es palabra va acompañado en la mayoría de los casos con una referencia a la falta de significado. En el diálogo anterior, Carla es quien concluye afirmando que no pueden cortar -ON en RENGLON porque no existe esa palabra, mientras que su compañero Emanuel se centra en la falta de significado: no iba a ser nada / no iba a entender. En otros casos la referencia al sentido es más explícita, Camila y Martín (pareja de $2^{\circ}$ grado y del nivel I) no cortan la ficha DESTINO, el niño dice sino quedaría tino y la niña agrega porque no tiene sentido la palabra que es tino.

Una justificación que solamente encontramos en los niños de nivel inicial es que no cortaron porque no encontraron algo para cortar. Esta parece ser la justificación menos elaborada, ya que no hay referencias a los posibles resultados de la segmentación ni tampoco al sentido asociado a esos segmentos: por ejemplo Valeria $\left(2^{\circ}-\right.$ nivel I) explica que no cortó DESTINO porque no encontré nada / no hay otra cosa que lleve des. Belén $\left(2^{\circ}-\right.$ nivel I) ensaya oralmente algunas segmentaciones pero también se centra solamente en el hecho de no encontrar un corte:

Ent.: y este [señalando DESTINO] no lo cortaste

Belén: no se me ocurría nada

Ent.: empieza como despegable [señalando la ficha que cortaron DES!'PEGABLE] no se puede cortar igual?

Belén: destino / desti [leyendo para sí la ficha] / no se me ocurre nada 
Por último, en el nivel inicial encontramos un caso interesante. Melina $\left(2^{\circ}\right.$ grado nivel I) hace referencia en su justificación de no cortar a que en la palabra RENGLON no se trata del proceso de derivación aumentativa (es el único caso del nivel I, aunque a partir del nivel II aumenta la presencia de esta justificación): un renglón no puede ser / una regla gigante sería / no existe la palabra de esa regla / sería regla gigante / pero no.

En el nivel II volvemos a encontrar el argumento de que lo que resulta del corte no es una palabra: Luna ( $4^{\circ}$ - nivel II) no cortó LADRON porque no queda una palabra / si yo le corto esto va a decir ladr y eso no es una palabra. Aparecen en este nivel II justificaciones vinculadas a que el corte generaría un final gráfico imposible: Leonel ( $6^{\circ}-$ nivel II) no cortó RENGLON porque acá ge ele / no se puede / no es una palabra tampoco / rengl no es una palabra si vos le sacás, y Luciano $\left(6^{\circ}\right.$ - nivel II) porque si no acá no lleva vocal / quedaría mal. Como se ha señalado en estudios anteriores, los niños desde etapas tempranas del aprendizaje de la lengua escrita tienen ideas sobre las formas gráficas posibles de una lengua y cuando ya han comprendido la alfabeticidad del sistema raramente en sus escrituras aparecen violaciones al sistema gráfico (Ribeiro Moreira y Pontecorvo, 1996).

Otro argumento nuevo en este nivel II es el que plantea que una ficha no es cortable porque constituye una palabra entera, es decir, sin segmentos menores que sean palabras. Delfina $\left(2^{\circ}\right.$ - nivel II), en el siguiente intercambio, elabora una justificación interesante sobre las palabras completas y las palabras ocultas:

Ent.: no se puede cortar? [señalando la ficha LADRON sin cortar]

Delfina: no

Entrevistador: por qué?

Delfina: porque yo no lo tengo [refiriéndose a que esa ficha no es de su conjunto] / él sí [refiriéndose a su compañero] / y además que ladrón es solo una palabra y no tiene nada

Ent.: ajá

Delfina: por ejemplo / eh [dudando] / no nada [sin completar lo que estaba por decir]

Ent.: esta [señalando LADRON] es una palabra que no tiene nada me decís

Delfina: sí

Ent.: y esta sí? [señalando la ficha que cortó NARIZ, ON]

Delfina: [interrumpiendo] que no tiene palabras / eh / ocultas 
Ent.: palabras ocultas / a ver contame cómo es eso / esta [señalando LADRON] no tiene una palabra oculta?

Delfina: no ninguna / solo tiene eh / una palabra completa / no se puede romper

Hay unos pocos casos en este nivel II en el que los niños recurren al uso de terminología metalingüística para explicar estas diferencias entre fichas con palabras completas y fichas con palabras más prefijos y sufijos: Andrés $\left(6^{\circ}\right.$ - nivel II) dice que las fichas problematizadoras no se pueden cortar porque es como que estas [refiriéndose a NARIZON Y PAPELON] tienen prefijo o sufijo / y estas no [refiriéndose a LADRON y RENGLON].

Finalmente, en el nivel más avanzado reencontramos argumentos ya utilizados en niveles anteriores. Azul ( $6^{\circ}-$ nivel III) sostiene que lo que resulta del corte no es palabra porque ladr no es palabra / no existe, Tiago $\left(6^{\circ}\right.$ - nivel III) rechaza el final gráfico del posible corte de RENGLON porque acá te queda ren rengl enfatizando la pronunciación y señalando el segmento -GL- en la ficha, Tobías ( $6^{\circ}$ - nivel III) explica que no se trata del proceso de derivación aumentativa que ya habían justificado porque dice ladrón / ladrón normal / si tendría que decir algo que fuera grande ladrón sería ladronzón o algo así.

Se profundizan en este nivel las reflexiones en torno a cuándo una ficha no es cortable porque constituye en sí una palabra entera. Durante el intercambio en la tarea de Alargar, cuando fue consultada por el significado aislado de los morfemas derivativos Carmela $\left(4^{\circ}-\right.$ nivel III) se refirió a los morfemas como los artículos. Para explicar por qué no cortó la ficha LADRON retoma el mismo término y dice esto [señalando ON y LADRON] no es artículo así que no cuenta / es parte del sustantivo y más adelante agrega sobre DESTINO se supone que un artículo es lo que se pone a la palabra y como esto no es una palabra [señalando TINO en DESTINO] es parte del sustantivo. Aun cuando no estén utilizando la terminología metalingüística convencionalmente, en este nivel los niños elaboran ideas en torno a dos tipos de segmentos distintos: "los que tienen significado en sí mismos" y "los que sirven para modificar el significado de los primeros". En el intercambio de Darío y Paula, pareja de $4^{\circ}$ grado y del nivel III, encontramos esta distinción que parece constituir el punto más alto de reflexión metalingüística sobre la distinción palabra/morfema. Mientras Darío está justificando sus cortes, comienza a ordenar espontáneamente las fichas cortadas entre "las que son raíces" y "las que son sufijos y prefijos": 
Darío: eh mirá estas son / son [arma una fila en su tablero con las fichas que cortó: IN, DES, ISTA, BLE y ON]

Ent.: estás haciendo una lista ahí / de qué? a ver contame

Darío: son sufijos y prefijos

Ent.: leémelos a ver

Darío: in des ista ble on / porque las otras son mirá [armando una nueva fila en su tablero con las fichas que le quedaron SOPORTA, ARMA, NARIZ, DESTINO, RENGLON y AUTOMOVIL]

Ent.: pero acá también tiene on [señalando on en RENGLON] / ahí no es sufijo?

Paula: no

Darío: no porque es una palabra entera

Paula: no es una palabra [corrigiéndose] no es una raíz / todo eso sería la raíz [señalando con el dedo la ficha RENGLON completa]

Ent.: ajá / y te das cuenta porque hay que mirar la palabra me dijiste vos [refiriéndose a un intercambio anterior con la niña]

Paula: sí / hay que ir probando / sacándole / o sea no cortándole pero por ejemplo tapándolo y viendo lo que te queda / si es una palabra verdadera o

Darío: [interrumpiendo] así yo hice así / lo tapaba y veía

Ent.: y esas son palabras o no? [señalando la fila en la que el niño dejó IN, DES, ISTA, BLE Y ON]

Paula: no / son sufijos

Darío: sufijos y prefijos

Paula: y prefijos

Ent.: no son palabras los sufijos y prefijos?

Paula: no

Dario: no

Paula: significan [enfatizando] palabras pero no / no son en sí palabras

Esta caracterización de segmentos que no son en sí palabras pero que significan parece ser el punto más alto de justificación de los morfemas derivativos para los niños del nivel más avanzado y sirve tanto para justificar los cortes realizados como para justificar por qué no realizar un corte en una ficha que incluye un segmento de letras que coincide con otro que sí aislaron, pero que en este contexto es parte de la palabra.

\subsection{Observaciones finales sobre la tarea de Acortar}

Para sintetizar el análisis del desempeño de los niños en la tarea de Acortar, podemos decir que: 
- En los tres niveles descriptos pudimos dar cuenta de un incremento progresivo en la cantidad de cortes realizadas, pero principalmente, en la posibilidad de realizar cortes simultáneos sobre la misma base léxica.

- Las justificaciones de los niños sobre los cortes nos permitieron dar cuenta de las centraciones cognitivas que orientaron la acción de cortar: inicialmente los niños realizan cortes centrándose en un segmento pleno menor dentro de las fichas que pueden justificar y lo que queda es un sobrante del que no pueden dar cuenta; luego los niños pueden centrarse alternadamente en el segmento que cortan (que coincide con bases léxicas que pueden justificar) y en ese mismo segmento unido a lo que quedó del corte (que es una base léxica derivada de la anterior y que también pueden justificar); solamente en el nivel más avanzado los niños pueden centrarse coordinadamente en todas las partes resultantes de sus cortes e intentar justificar el significado de los morfemas derivativos cuando están aislados.

- En cuanto a las justificaciones que los niños elaboraron para decidir no realizar cortes en fichas que compartían letras pero no morfemas, también encontramos una progresión: inicialmente los niños no cortan porque no encuentran nada para cortar; luego recurren a justificaciones centradas en el aspecto semántico (no es posible cortar porque quedan segmentos sin significado) o en criterios gráficos (no es posible cortar porque quedan finales gráficos imposibles en nuestra lengua); finalmente, los niños se centran en la distinción entre palabras completas y palabras que tienen prefijos o sufijos lo que nos permite suponer que los niños distinguen entre segmentos de letras que son iguales pero solo en algunos casos son morfemas derivativos.

- Al igual que en la tarea de Alargar (sección 2.6), también el análisis del desempeño de los niños en la tarea de Acortar nos permitió registrar que los morfemas no parecen ser para los niños unidades lingüísticas homogéneas y que además la posibilidad de aislarlos y justificarlos depende en gran medida de las bases léxicas con las que se encuentran. 
La pregunta fundamental en esta tarea de Acortar tiene que ver con comprender en qué se centran los niños para realizar un corte. En la tarea proponíamos materiales puntuales (fichas y tijeras) y una consigna que efectivamente invitaba a los niños a poner la tijera en un lugar específico de las fichas y generar, al menos, dos segmentos menores. Pudimos constatar que inicialmente los niños parecen centrarse exclusivamente en bases léxicas menores que reconocen dentro de las fichas que propusimos y entonces el segmento que sobra de la acción de cortar coincide con un morfema derivativo para la mirada lingüística, pero para estos niños parece ser una especie de "resto gráfico" que difícilmente pueden interpretar. En el nivel III, en cambio, los niños pueden centrarse coordinadamente en las partes resultantes del corte e intentar inclusive justificar el significado de los segmentos aislados que constituyen morfemas derivativos. Pero a esta altura se impone otra pregunta central: ¿̇están los niños entrevistados en nuestro trabajo interpretando estos segmentos como unidades mínimas de significado?, es decir, ¿constituyen los morfemas para ellos unidades con "una forma fonética y un significado" (Di Tullio, 2005:33) tal como describe la lingüística? Incorporando el análisis de la tarea de Alargar al de la tarea de Acortar realizado en este capítulo, podemos decir que en las respuestas registradas lo que parece primar es la interpretación de los morfemas derivativos como "modificadores del sentido" de otros segmentos que sí pueden explicar y que coinciden con lo que los niños reconocen como palabras. 


\section{Integración de datos a través de las tareas de Alargar y de Acortar}

\subsection{Los niños a través de las tareas}

En el presente capítulo intentaremos integrar los datos presentados en los capítulos anteriores (capítulos 2 y 3) con el propósito de analizar evolutivamente las reflexiones metalingüísticas de los niños sobre los morfemas derivativos objeto. Tanto en la tarea de Alargar como en la de Acortar agrupamos a los niños en tres niveles. En el Cuadro 11 ubicamos a todos los niños interrogados ${ }^{36}$ según su nivel en la tarea de Alargar (orientación horizontal) y según su nivel en la tarea de Acortar (orientación vertical). Los cuadros sombreados indican los niveles coincidentes para ambas tareas.

A simple vista, el cuadro nos permite ver que más de la mitad de los niños se encuentran ubicados en la línea diagonal que dibujan los cuadros con los grupos coincidentes (38 niños sobre un total de 60 niños entrevistados $=63.33 \%$ ). Por otro lado, en todos los cuadros con cruces de niveles encontramos al menos un caso, aunque en los cruces de niveles no contiguos (nivel I en Alargar y nivel III en Acortar, o viceversa) es donde se da la menor cantidad. Es decir, cuando hay discrepancia entre niveles, lo más probable es que se trate de niveles contiguos.

\footnotetext{
${ }^{36}$ Se utilizan las siguientes distinciones tipográficas para indicar los grados escolares: cursiva $\left(2^{\circ}\right.$ grado), normal ( $4^{\circ}$ grado), VERSALITAS ( $6^{\circ}$ grado).
} 
Cuadro 11 - Todos los niños entrevistados $(n=60)$ según niveles en tareas de Alargar y Acortar

\begin{tabular}{|c|c|c|c|c|}
\hline & \multicolumn{3}{|c|}{ Tarea de Alargar } \\
\hline & & Nivel I & Nivel II & Nivel III \\
\hline \multirow{3}{*}{ 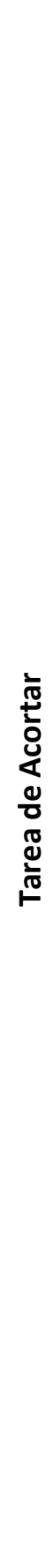 } & $\overline{\bar{d}}$ & $\begin{array}{c}\text { Dante } \\
\text { Camila } \\
\text { Martín } \\
\text { Rodrigo } \\
\text { Josefina } \\
\text { Valeria } \\
\text { Gerónimo } \\
\text { Belén } \\
\text { Emanuel } \\
\text { Carla } \\
\text { Melina } \\
\text { Jazmín } \\
\text { Isabella } \\
\text { Matías } \\
\text { TAMARA }\end{array}$ & $\begin{array}{l}\text { Gonzalo } \\
\text { Clara } \\
\text { Agustín } \\
\text { Florencia } \\
\text { EZEQUIEL }\end{array}$ & ARIADNA \\
\hline & $\frac{\bar{D}}{\frac{\bar{\alpha}}{z}}$ & $\begin{array}{l}\text { CATALINA } \\
\text { LUCIANO }\end{array}$ & $\begin{array}{c}\text { Lucía } \\
\text { Renata } \\
\text { Nicolás } \\
\text { Guadalupe } \\
\text { Jeremías } \\
\text { Ulises } \\
\text { Marcos } \\
\text { Julián } \\
\text { Luna } \\
\text { Diego } \\
\text { ANDRÉs }\end{array}$ & $\begin{array}{c}\text { Delfina } \\
\text { Pablo } \\
\text { NATALIA } \\
\text { LEONEL } \\
\text { TIAGO } \\
\text { LAURA }\end{array}$ \\
\hline & $\frac{\equiv}{\frac{D}{2}}$ & $\begin{array}{l}\text { Candela } \\
\text { Genaro }\end{array}$ & $\begin{array}{c}\text { Emiliano } \\
\text { Luis } \\
\text { AzUL } \\
\text { ABRIL } \\
\text { TOBÍAS } \\
\text { LORENA }\end{array}$ & $\begin{array}{c}\text { Lucas } \\
\text { Carolina } \\
\text { Lara } \\
\text { Darío } \\
\text { Paula } \\
\text { Carmela } \\
\text { LUANA } \\
\text { GERARDO } \\
\text { ROMÁN } \\
\text { PEDRO } \\
\text { SABRINA } \\
\text { NÉSTOR }\end{array}$ \\
\hline
\end{tabular}

Por otro lado, si consideramos solamente a los 38 niños que están en niveles coincidentes, también podemos observar que en principio la progresión de niveles corresponde con la de los grados escolares. Tal como muestra el Cuadro 12, en el nivel I-I 
encontramos una primacía de niños de $2^{\circ}$ grado, mientras que los niños de $6^{\circ}$ grado se concentran en el nivel III-III 37 .

Cuadro 12 - Niños en niveles coincidentes en tareas de Alargar y Acortar, según grado escolar $(n=38)$

\begin{tabular}{|c|c|c|c|c|}
\hline & \multicolumn{3}{|c|}{ Niveles coincidentes en tareas de Alargar y Acortar } \\
\hline & & $\begin{array}{c}\text { Nivel I-I } \\
(n=15)\end{array}$ & $\begin{array}{c}\text { Nivel II-II } \\
(n=11)\end{array}$ & $\begin{array}{c}\text { Nivel III-III } \\
(n=12)\end{array}$ \\
\hline \multirow{3}{*}{$\begin{array}{l}\frac{1}{0} \\
\frac{0}{0} \\
\frac{0}{0} \\
\frac{0}{0} \\
y\end{array}$} & $2^{\circ}$ & 11 & 4 & 1 \\
\hline & $4^{\circ}$ & 3 & 6 & 5 \\
\hline & $6^{\circ}$ & 1 & 1 & 6 \\
\hline
\end{tabular}

Sin embargo, más allá de esta correspondencia del desempeño en los niveles con los grados escolares, para una investigación de corte psicogenético como la nuestra es fundamental tratar de dar cuenta evolutivamente de los retos cognitivos que enfrentan los niños para analizar los segmentos que constituyen la palabra. En este sentido, los indicadores que encontramos para integrar ambas tareas son:

- Las acciones (de combinar en la tarea de Alargar o de aislar en la tarea de Acortar) realizadas por los niños sobre las bases léxicas y los morfemas derivativos propuestos en nuestro diseño.

- Las centraciones de los niños en los segmentos que componen las palabras de nuestro diseño al momento de realizar las acciones de combinar o aislar.

- Las justificaciones de los niños sobre los distintos segmentos que componen las palabras y las relaciones que mantienen entre ellos.

A partir de considerar estas variables podemos distinguir en los tres grupos coincidentes un posible proceso de reflexión metalingüística de los morfemas derivativos objeto y las bases léxicas de nuestro diseño. Veamos por separado estas variables en cada uno de estos niveles.

37 Designamos los niveles coincidentes utilizando números romanos y un guion, así la expresión "nivel I-I" designa a los niños que en ambas tareas están en el grupo inicial. 


\section{Nivel I-I}

En este momento inicial los niños actúan casi exclusivamente a la derecha de las bases léxicas, es decir, combinan o aíslan solamente los sufijos. Una posible explicación para esto es que es más fácil pensar primero sobre una base léxica conocida y a partir de esta considerar un segmento que la modifique. En todo caso, los niños enfrentaron grandes dificultades para interpretar prefijos aislados y luego seleccionar bases léxicas para combinar. Esta anterioridad evolutiva de los sufijos está presente en otras investigaciones (Fejzo, 2016). No se registraron al inicio ni durante el intercambio intentos de realizar acciones simultáneamente a ambos lados de una base léxica.

Una pregunta central tiene que ver con analizar en qué se centran los niños para combinar o aislar segmentos. En la tarea de Alargar, los niños de este nivel I-I parecen partir de una base léxica conocida (por ejemplo ARMA) y a partir de esta pasar a otra base léxica también conocida pero de mayor extensión (ARMADOR). En la tarea de Acortar, el proceso es similar aunque inverso, a partir de una base léxica más extensa (DESARMABLE por ejemplo) los niños parecen encontrar una base léxica conocida menor (DESARMA). Dos cuestiones se desprenden al respecto. En primer lugar, ¿qué sucede entre una base léxica inicial que pueden aumentar o acortar y la nueva base resultante de esas acciones? Las justificaciones de los niños nos muestran que ya desde el nivel inicial son capaces de elaborar interpretaciones y, en todo caso, plantear relaciones semánticas de familiaridad. Lo que parece no ser todavía observable, al menos para todos los morfemas derivativos objeto de nuestro diseño, es la relación derivativa que hay entre dos palabras que comparten una base léxica en común pero difieren en la presencia de un morfema derivativo. En segundo lugar, surge también otro interrogante: ¿qué es ese segmento que sirve tanto para "agregar" y formar una palabra conocida como para "quitar" y obtener una palabra conocida? Creemos que ese segmento es para los niños de este nivel I-I una especie de "resto gráfico" difícil de justificar, pero sobre el que encontramos dos afirmaciones generalizadas: no tienen sentido y no pueden estar aislados (recordemos que todos los niños interrogados no tuvieron dificultades en distinguir cuáles segmentos eran palabras al iniciar la primera de las tareas). Josefina $\left(2^{\circ}\right.$ - nivel I-I) nos ayuda a entender 
este problema cuando, al ser consultada por el significado de los morfemas aislados, dice: es como si estas fueran unas vocales de estas palabras. Luego agrega como si esa fuera una letra que faltaba en las otras palabras. Es decir, por un lado hay palabras que los niños pueden justificar porque significan, y por otro lado, "segmentos sueltos" que no tienen significado aislado. Encontramos entonces una centración exclusiva en bases léxicas consideradas como un todo completo (ya sea que incluyan o no los prefijos o sufijos disponibles).

De hecho, los niños de este nivel I-I utilizan los términos letras, sílabas o palabras para referirse a los morfemas derivativos, todas expresiones escolares comunes que tienen como centro de referencia la unidad palabra. Es más, quienes utilizan el término palabra para referirse tanto a las bases léxicas como a los morfemas derivativos enfrentan el problema del "significado pleno". Se trata de una situación que genera conflictos y reinterpretaciones durante el intercambio. Tamara $\left(6^{\circ}-\right.$ nivel I-I), por ejemplo, al inicio sostiene que los morfemas derivativos son palabras pero algunas veces se usan para terminación de otras pero lo mismo siguen siendo palabras porque son palabras. Esta distinción conceptual incipiente expresada con el mismo término genera varios conflictos cuando intenta justificar las relaciones entre las bases y los morfemas. Más adelante Tamara agrega sí son palabras pero no tienen significado.

Otra pista de que los niños trabajan a partir de bases léxicas conocidas para combinar o aislar segmentos en este nivel es la presencia generalizada de justificaciones del significado a partir de ejemplos de usos comunicativos. Los niños pueden plantear contextos de uso para las bases léxicas, centrándose en el "yo" de la enunciación y en un aquí y ahora que remite a situaciones comunicativas cotidianas. Esto les permite, por ejemplo, justificar palabras como DESARMA y DESARMABLE por separado, o sea, sin abordar la relación derivativa que implica la presencia del sufijo -BLE. En los pocos intentos de parafrasear el significado que agrega el morfema derivativo encontramos un proceso de transición que anticipa una posibilidad mayor de reflexión característica del nivel siguiente. 


\section{Nivel II-II}

Los niños de este nivel pueden actuar a ambos lados de las bases léxicas pero alternadamente. Hay un avance con respecto al nivel anterior ya que se generaliza la posibilidad de partir primero de un modificador aislado (por ejemplo el prefijo SUB-) y pensar luego cómo puede combinarse con una base conocida (para alargar SUBOFICIAL o SUBMARINO). En las tareas de Alargar y de Acortar, los niños aún no pueden actuar coordinadamente a ambos lados de una ficha. Sin embargo, el hecho de que al inicio utilizaran tanto prefijos como sufijos posibilitó que durante el intercambio muchos de estos niños alcanzaran los alargamientos o cortes que denominamos "dobles". Es necesario advertir que en realidad se trata de nuevas acciones realizadas sobre bases léxicas ya alargadas o acortadas, lo que nuevamente nos ubica en la situación característica de este nivel de poder actuar a ambos lados de una base léxica conocida pero no en forma simultánea.

En términos de la centración cognitiva, los niños ahora pueden centrarse en las bases léxicas resultantes, pero también en las bases léxicas y los morfemas derivativos que las componen. Es decir, los niños justifican el significado de una palabra completa pero al mismo tiempo reconocen segmentos distintos dentro de estas. Una pista que nos ayudó a pensar esta nueva búsqueda de segmentos menores a la palabra con sus propios significados son los casos que denominamos interpretación de amalgama. Si bien se trata de pocos casos, todos ${ }^{38}$ están concentrados en este nivel II-II (o en niños que están en grupos no coincidentes pero en el nivel II para la tarea en la que elaboró la justificación de amalgama). La búsqueda de dos significados plenos pero yuxtapuestos en una misma palabra parece constituir el primer intento por encontrar segmentos "aislables" con sus respectivos significados.

Nuevamente se impone la pregunta acerca de qué son esos segmentos menores que sirven para alargar o para acortar palabras. Luna ( $4^{\circ}$ - nivel II-II) nos muestra la idea predominante en este nivel: un sufijo o un prefijo en realidad no es palabra pero es como que vos las ponés con las palabras y como que hacés una palabra. En este momento ya

\footnotetext{
${ }^{38}$ A excepción de Matías en la tarea de Alargar (ver sección 2.4)
} 
encontramos un rechazo generalizado a que las "partecitas" para alargar o acortar puedan designarse como palabras. Por otro lado, ya no se trata de un resto gráfico (letra, sílaba) faltante a una palabra, sino de un segmento diferente que sirve para "hacer palabras". Aun así, los niños en este nivel todavía rechazan la posibilidad de que un morfema derivativo signifique cuando está aislado.

Por último, consideramos que las justificaciones de paráfrasis que se generalizan en este nivel constituyen intentos de explicar el significado de un prefijo o un sufijo justamente mediante la elaboración de una frase que da cuenta de la idea implícita en los morfemas: DESARMABLE es que se puede desarmar como dice Diego ( $4^{\circ}$ - nivel II-II). Se trata, en todo caso, de una reflexión metalingüística interesante. De hecho, es común encontrar en gramáticas y textos lingüísticos el uso de la paráfrasis como una forma de dar cuenta de esas "parcelas de contenido léxico" (Pena, 1999:4324) asociadas a un morfema

derivativo. En la Nueva gramática de la lengua española encontramos, por ejemplo, la siguiente explicación: "el sufijo -ble tiene sentido pasivo y modal. Así, traducible admite la paráfrasis 'que puede ser traducido'” (2009:146).

\section{Nivel III-III}

En el momento más avanzado del proceso que estamos planteando para nuestros datos, los niños pueden actuar tanto alternada como simultáneamente a ambos lados de las bases léxicas. Aparecen entonces intentos de centración coordinada entre bases léxicas y morfemas derivativos, incluso situaciones en las que los niños interpretan coordinadamente la presencia de más de un morfema derivativo en una palabra (interpretar, por ejemplo, tanto la idea de negación como de potencialidad en la serie INOLVIDABLE). Un cambio con respecto al nivel anterior es que ahora los niños, además de poder parafrasear en sus justificaciones los significados que agregan los morfemas, también aceptan que el morfema cuando está aislado tenga significado: para Néstor $\left(6^{\circ}\right.$ nivel III-III) sub significa abajo, des es el negativo, ble significa que se podía hacer y on lo hace más grande.

Sin embargo, ¿significan estos segmentos de la misma forma que las bases que los niños distinguieron como palabras? La respuesta a esta pregunta parece ser negativa. Las 
palabras de Gerardo ( $6^{\circ}$ - nivel III-III) son reveladoras al respecto: cuando vos le ponés ese sufijo o prefijo [refiriéndose a -BLE] cambia el significado de la palabra pero ese sufijo prefijo no tiene significado, y más adelante agrega sobre el prefijo SUB- este conjunto de letras más que tener un significado le cambia el significado a las palabras. Se trata de un problema central que volveremos a tratar en las conclusiones finales de nuestro trabajo. Por ahora sólo adelantamos que, frente a la unidad morfema que la lingüística define como "la unidad mínima de significado", los niños parecen tratar a los morfemas derivativos como "modificadores del significado de la palabra".

Por otra parte, si nos centramos en cómo los niños designan a esos segmentos menores que no son palabras, veremos que en este nivel más avanzado aparecen términos como preposición, artículos o conectores que, aun cuando no son usados convencionalmente, dan cuenta de intentos de utilizar terminología escolar para designar ya no "partes de palabras" (como en el nivel inicial), sino un "tipo" distinto de segmento. Algunos niños incluso recurren a los términos prefijos y sufijos (como Gerardo que acabamos de citar). Lo que nos interesa marcar es que en este momento los niños distinguen dos tipos de segmentos - palabras frente a prefijos y sufijos- pero ya no centrados en una oposición "tienen significado" frente a "no tienen significado". El criterio principal para distinguir entre palabras y morfemas derivativos es que las primeras tienen significado y constituyen formas libres (por supuesto, no expresado por los niños en estos términos) mientras que los segundos modifican el significado de las palabras y además tienen que ir sí o sí con una palabra / no pueden ir separados, como dice Néstor $\left(6^{\circ}-\right.$ nivel III-III).

Este recorrido evolutivo da cuenta de los desafíos conceptuales que enfrentan los niños para reflexionar sobre los distintos segmentos que pueden encontrar dentro de las palabras. De todas maneras, es necesario considerar que estas reflexiones surgen en una situación comunicativa muy particular en la que invitamos a los niños a "hablar sobre el lenguaje" y en la que además disponemos de un número limitado de morfemas derivativos y palabras que los incluyen. Se trata, en definitiva, de un conjunto cerrado que presenta una serie de restricciones combinatorias y lingüísticas que contextualizan las 
reflexiones de los niños. En el próximo apartado trataremos de dar cuenta de los desafíos que plantearon cada uno de los morfemas derivativos objeto de nuestro estudio.

\subsection{Jerarquización evolutiva de los morfemas objeto}

Si bien los morfemas derivativos de la lengua española constituyen un conjunto tan numeroso que impide su abordaje en un único trabajo de investigación (Velázquez y Ferreiro, 2015), a partir del análisis presentado en los capítulos 3 y 4 podemos esbozar una jerarquización de los morfemas derivativos objeto de nuestro estudio. Esta jerarquización tiene en cuenta tanto la disponibilidad de cada uno de los morfemas para ser utilizado en las tareas propuestas, como también las dificultades que los niños enfrentaron a la hora de interpretarlos.

El sufijo -ON como aumentativo es el único morfema que todos los niños de distintos niveles pueden utilizar y justificar sin ninguna dificultad. Esto es coincidente con datos de investigación que muestran que incluso a nivel oral y desde la edad de 4 años el sufijo -ON ya está disponible (Rodríguez Cuevas, 2018). Un dato llamativo que la metodología utilizada nos permitió conocer es la variedad de matices que los niños dieron a la idea de "aumento de tamaño" en la derivación de CUENTON. Enfatizamos el valor heurístico de la metodología clínico-crítico, ya que se trata de respuestas que no previmos durante el diseño. Por otra parte, en niños de niveles II-II y III-III encontramos además referencias a la interpretación apreciativa de -ON y a la alternancia de interpretaciones aumentativas y lexicalizadas en series como PAPELON.

En segundo lugar, ubicamos a los sufijos denominales -ERO, -ISTA y -DOR. Los enunciamos como un bloque porque en los tres niveles estuvieron entre los morfemas más disponibles para combinar y aislar, aunque ciertamente presentan diferencias en cuanto a las justificaciones. Con el sufijo -ERO encontramos interpretaciones instrumentales estables para FLORERO (aunque registramos varias confusiones inesperadas con maceta) e interpretaciones agentivas estables para RELOJERO, FUTBOLERO O MARINERO. En 
cambio, el sufijo -DOR es claramente agentivo en ARMADOR, pero en series como ACTIVADOR o COMUNICADOR los niños alternaron interpretaciones instrumentales o agentivas, y solamente en el nivel avanzado elaboraron justificaciones que admitían ambas interpretaciones. En las justificaciones de los niños sobre las series COMUNICADOR y ACTIVADOR encontramos muchas referencias a dispositivos electrónicos o digitales del mundo contemporáneo lo que le otorga cierta primacía a las interpretaciones instrumentales. Por su parte, el sufijo denominal -ISTA recibió justificaciones adecuadas en series como FUTBOLISTA, FLORISTA o AUTOMOVILISTA. Aun así, encontramos cierta inestabilidad en las derivaciones de -ISTA con las bases léxicas FUTBOL, OFICIAL y AUTOMOVIL al generarse en la combinación la posibilidad de leer también la serie gráfica yuxtapuesta y con sentido pleno LISTA. En estos casos, encontramos por parte de los niños interpretaciones de amalgama o directamente ausencia de interpretación.

En tercer lugar, ubicamos el prefijo suB-. Por un lado, se trata del prefijo más disponible de nuestro diseño y, por otro lado, siempre recibió interpretaciones pertinentes tanto en su función de locativo (en la serie SUBMARINO) como para indicar rango inferior en una jerarquía (en SUBOFICIAL). Destacamos especialmente los matices que los niños elaboraron para justificar este segundo significado extendido del prefijo sUB- (y que tampoco previmos al inicio de nuestro trabajo): SUBOFICIAL puede ser estar en segundo lugar, un lugar abajo, ser casi oficial o incluso ser un oficial suplente.

Ubicamos luego al sufijo -BLE, ya que si bien se trató de un sufijo disponible para las acciones de combinar y aislar, los niños del nivel inicial encontraron varias dificultades a la hora de justificarlo e interpretar las series que lo incluían. En nuestro diseño disponíamos de varias series derivadas de verbos (ARMABLE, COMUNICABLE, ACTIVABLE, PINTABLE o PEGABLE) y otras que se forman a partir de la negación del adjetivo (INSOPORTABLE e INOLVIDABLE). Los niños de nivel inicial que utilizaron -BLE sobre bases verbales incluso plantearon en sus justificaciones que el agregado de otro segmento gráfico no cambiaba la interpretación verbal que daban a las bases, una solución de compromiso difícil de sostener ya que los mismos niños postulaban en otros casos que la modificación de un segmento en una palabra implica también un cambio en el significado. Creemos que 
coordinar las ideas de pasividad y potencialidad resultó realmente desafiante para los niños, ya que supone considerar la posibilidad de una acción en un tiempo futuro incierto.

Por último, en el nivel más alto de complejidad ubicamos a los prefijos negativos DES- e IN-. El primero de ellos no fue muy utilizado, pero estuvo disponible en niños de todos los niveles. La idea de reversión de una acción indicada por el prefijo en palabras como DESPEGA, DESARMA O DESACTIVA parece ser bastante opaca para los niños en general, aunque pueden elaborar ejemplos de uso pertinentes para justificarlos. El prefijo IN-, por su parte, fue poco utilizado y además no estuvo disponible para ningún niño del nivel inicial. Se trata entonces del único morfema derivativo que en nuestros datos fue totalmente opaco para algunos niños. Datos de una investigación en curso también confirman las dificultades que presentan estos morfemas negativos a niños preescolares en tareas orales, haciendo énfasis en que el prefijo IN- presentó muchas más dificultades que DES- (Monserrat Cuevas, 2018). En nuestros datos, solamente en los casos en que el prefijo IN- aparecía simultáneamente con el sufijo -BLE (en las series INSOPORTABLE e INOLVIDABLE) encontramos que los niños de los niveles II-II y III-III lograron acceder a la posibilidad tanto de aislar el prefijo como de interpretar la idea de negación que refiere.

Esta jerarquización de los morfemas se trata, en todo caso, de una pauta evolutiva de las dificultades que el conjunto limitado de morfemas derivativos utilizados en nuestro diseño presentó a los niños interrogados. A esto hay que agregar el hecho de que los prefijos y sufijos fueron presentados en combinación con bases léxicas particulares, seleccionando así sólo algunas restricciones combinatorias entre las muchas posibles.

\subsection{Análisis del desempeño de niños en niveles no coincidentes en las tareas de Alargar y de Acortar}

En el presente apartado realizaremos algunos comentarios sobre el desempeño y las reflexiones elaboradas por los niños que en el Cuadro 11 están ubicados en niveles no coincidentes para ambas tareas. Comencemos por ver qué sucedió con los niños que 
están ubicados en niveles no coincidentes y en una de las tareas se ubican en el nivel inicial. En primer lugar, son niños que pueden actuar sobre prefijos y sufijos alternadamente. Tal como desarrollamos en la sección 4.2, el aumentativo -ON, el denominal -ERO y el locativo SUB- están disponibles para que los niños los combinen o aíslen y reciben siempre interpretaciones adecuadas. En cambio, con otros morfemas encontramos cierta inestabilidad en las justificaciones. Luciano $\left(6^{\circ}\right)$, por ejemplo, es un niño que realiza combinaciones (2/2) y aísla morfemas (4/4) obteniendo como resultado series convencionales sobre las que siempre elabora alguna justificación. Pero en algunas series la presencia de otro segmento gráfico parece no alterar su interpretación centrada en las bases léxicas: ACTIVADOR yo diría cuando activás algo, ARMADOR cuando armás algo, ARMABLE como que ya está armado y DESARMABLE sería lo mismo que desarma. Es interesante la respuesta de Luciano al ser consultado por una de estas justificaciones en la tarea de Acortar:

Ent.: vos cortaste acá [señalando el corte DESARMA; BLE] / qué es desarma? Luciano: vos desarmás algo

Ent.: y desarmable?

Luciano: sería lo mismo que desarma

Laura: entonces por qué lo cortaste? [dirigiéndose a su compañero]

Luciano: quise achicar la palabra

Ent.: si yo pongo ble [señalando BLE en DESARMA|'BLE] no cambia nada? Luciano: no / no cambia

Una interpretación posible es que Luciano $\left(6^{\circ}\right)$, al igual que los niños que están en el nivel I de ambas tarea, esté considerando el morfema como un segmento que sirve para completar una palabra y, por lo tanto, para combinar o aislar segmentos se guía buscando bases léxicas conocidas. De hecho, cuando está trabajando en separar fichas que son palabras al inicio de la tarea de Alargar, Luciano deja afuera del tablero todas las fichas que son morfemas derivativos y comenta que lo hace porque tienen pocas letras y como que no tienen sentido, es decir que al criterio semántico (falta de sentido) se agrega un criterio gráfico (cantidad insuficiente de letras, criterio importante en niveles evolutivos previos al nivel alfabético). 
Gonzalo $\left(2^{\circ}\right)$ es un niño que también enfrentó dificultades para justificar el sufijo -BLE. En ambas tareas, el niño realizó acciones con -BLE: alargó PINTA|BLE y cortó DESARMA'BLE. Cuando se agrega un nuevo segmento gráfico a las bases léxicas, Gonzalo siempre explora diferencias semánticas para justificar las series resultantes. Sin embargo, en el caso de las combinaciones con -BLE, Gonzalo recurre a la interpretación agentiva que su compañera Josefina propuso para justificar adecuadamente ARMA|DOR, un alargamiento con otro morfema derivativo. Veamos el intercambio:

Josefina: armador es como un trabajador que arma cosas [señalando ARMA|DOR]

Ent.: mirá y acá qué quiere decir esto? [señalando la combinación PINTA|BLE en el tablero del niño]

Gonzalo: pintable

Josefina: no sé

Gonzalo: una máquina pintadora

Ent.: qué es cuando está solo? [señalando solo la ficha PINTA]

Josefina: pinta

Gonzalo: yo pinto

Josefina: estás pintando

Ent.: y si yo le pongo esta [señalando BLE] cambia?

Gonzalo: es un señor que pinta / hay uno que se Ilama Da Vinci

Gonzalo retoma, como "solución de compromiso", la justificación adecuada que su compañera elaboró para otra serie, y la reutiliza para resolver la interpretación de derivaciones con -BLE que le resultan opacas. De hecho, durante el intercambio, acepta dos combinaciones más con -BLE que propone el entrevistador y las justifica como:

- COMUNICA |BLE - algo que se comunica / es como comunicador

- $A R M A \mid B L E$ - es igual que armador

También con el sufijo -ISTA estos niños encontraron ciertas dificultades. Por un lado, aun cuando algunos pudieron utilizarlo en series como OFICIALISTA O AUTOMOVILISTA, durante el intercambio no pudieron elaborar justificaciones para sus combinaciones. Entre las justificaciones elaboradas, encontramos interpretaciones locativas no esperadas para la serie AUTOMOVILISTA: algo que se puede transitar con autos (Azul $-6^{\circ}$ ); el peaje (Luciano $\left.-6^{\circ}\right)$. Se trata de un nuevo "corrimiento" en la interpretación registrado también en los niños de nivel inicial (sección 3.4). 
En la tarea de Alargar nuevamente encontramos que el único morfema derivativo que no está disponible para combinar es el prefijo negativo $I N-$, aunque en la tarea de Acortar varios niños logran aislarlo. Esto nos pone en la pista de que las series adjetivas y negativas formadas con el esquema IN-/base verbal/-BLE facilitaron la centración de los niños en el prefijo (sección 3.4).

Otra dificultad general en este grupo de niños en niveles no coincidentes está vinculada con las bases léxicas que podían admitir más de una interpretación. Todos estos niños aislaron -ON en PAPELON, pero siempre elaboraron una justificación aumentativa o lexicalizada excluyente. Quienes interpretaron adecuadamente las combinaciones ACTIVADOR y COMUNICADOR también lo hicieron instrumental o agentivamente, pero en ningún caso plantearon ambas posibilidades.

Por otro lado, un rasgo común en estos niños es que la mayoría de ellos realizó intentos de combinaciones y cortes con todas las fichas disponibles, lo que significó que muchos realizaran alargamientos o cortes no esperados. Esta intención de realizar acciones sobre la totalidad del material es un indicador de una buena disposición para la exploración de las bases y los morfemas disponibles.

Por último, un problema que parece constituir una zona de transición es cómo están considerando estos niños a los morfemas derivativos. Al registrar sus combinaciones y sus cortes podemos constatar que logran actuar sobre una cantidad considerable de prefijos y sufijos, y además al analizar los intercambios, si bien encontramos algunas interpretaciones inestables, varios morfemas en distintas combinaciones reciben justificaciones aceptables. Lo que los niños parecen mostrarnos son intentos de explorar qué son esos segmentos menores que están encontrando dentro de las palabras. Florencia $\left(4^{\circ}\right)$, cuando propone un nuevo corte durante el intercambio, dice quedaría des arma y ble / como separada en sílabas. Agustín $\left(4^{\circ}\right)$ consultado por el significado del sufijo -DOR dice no tiene el significado de ninguna palabra / es una sílaba y más adelante agrega sobre otro sufijo en realidad ble es una sílaba que ayuda a armar palabras. Azul (6 $\left.6^{\circ}\right)$ también intenta justificar el agregado de -DOR diciendo que su significado depende de la palabra a la que le agregás la sílaba señalando la ficha DOR. Para el caso de estos tres 
sufijos (DES-, -BLE y -DOR) el término sílaba podría ser pertinente, sin embargo ¿están utilizando los niños el término en el mismo sentido que la lingüística define a la sílaba como unidad según sus propiedades sonoras? Creemos que los niños están en realidad explorando formas para designar a ese segmento menor que ayuda a armar palabras pero que no tiene el significado de ninguna palabra. Se trata de un trabajo de conceptualización desafiante que implica coordinar acciones e ideas sobre "unidades" que no están dadas de antemano para estos niños.

Consideremos ahora el segundo grupo conformado por los niños ubicados en niveles no coincidentes y que en una de las tareas se ubican en el nivel más avanzado. Se trata de niños que intentan actuar simultáneamente a ambos lados de las bases (realizando combinaciones o cortes dobles) al menos en una de las tareas, o que también pueden reutilizar bases léxicas con más de un morfema en la tarea de Alargar. No parece haber una incidencia del tipo de acción solicitada en cada una de las tareas, ya que encontramos tanto niños que actúan simultáneamente cuando combinan como cuando aíslan morfemas. Esto podría ser una pista de que lo que está guiando la acción simultánea de los niños no está relacionado con la tarea en sí, sino con la forma en que los niños están pensando los segmentos dentro del material disponible.

En este segundo grupo de niños en niveles no coincidentes encontramos generalizadas las interpretaciones adecuadas y estables para todos los morfemas derivativos. Ya no registramos ninguna situación en la que el agregado de un nuevo segmento no modifique el significado de la palabra. Tal es así que las interpretaciones no esperadas en este nivel están vinculados con justificaciones de amalgama: para Emiliano $\left(2^{\circ}\right)$, por ejemplo, FUTBOLISTA es un jugador más listo y más goleador / es como listo en el fútbol y para Luis $\left(2^{\circ}\right)$ OFICIALISTA es como el policía que te atiende y te da una lista. Los niños parecen asumir que el agregado del segmento -ISTA implica un agregado de significado y lo resuelven encontrando dos segmentos plenos yuxtapuestos en la misma palabra. Por otro lado, varios de estos niños ya pueden actuar directamente sobre los morfemas aislados tratando de elaborar justificaciones que den cuenta de cómo modifican el significado de las palabras que acompañan: 
- Tiago $\left(6^{\circ}\right)$ : -BLE significa como que se puede hacer tal cosa

- Lorena $\left(6^{\circ}\right)$ : des es lo contrario a la palabra

- Abril $\left(6^{\circ}\right)$ : on le aumenta el tamaño.

Si se trata entonces de niños que aceptan la existencia de segmentos con significados distintos dentro de las palabras, ¿qué problemas cognitivos enfrentan a la hora de tratar con esos segmentos que son morfemas derivativos para la lingüística? Ya vimos en el capítulo 3 (sección 3.3) la justificación que Laura $\left(6^{\circ}\right)$ dio para no realizar el corte de PAPELON afirmando que en la interpretación lexicalizada -ON no puede ser un sufijo aumentativo como en NARIZON o CUENTON. Lorena $\left(6^{\circ}\right)$ también enfrenta un problema parecido: justifica SUBMARINO como un transporte pero en el agua y SUBOFICIAL como un segundo oficial. Al ser consultada por la presencia del prefijo SUB-en ambas series Lorena dice que en el primer caso es una palabra mientras que en el segundo estarías usando un prefijo / un sufijo algo así. Se trata de niños que en algunas bases léxicas reconocen a los morfemas derivativos (SUB- es prefijo en SUBOFICIAL) pero que en otras bases léxicas los consideran parte inseparable de las palabras. En los ejemplos registrados, los niños enfrentan desafíos importantes a la hora de generalizar el significado que lograron atribuir al morfema en una derivación particular a otras palabras que también lo incluyen, ya sea con un significado lexicalizado (como en PAPELON) o con un significado cercano pero diferente (sUBMARINo no puede ser como un segundo barco, dice Lorena).

Un ejemplo destacado de este trabajo de conceptualización sobre los segmentos menores adentro de las palabras lo encontramos en Pablo $\left(4^{\circ}\right)$. Al iniciar la tarea de Alargar, mientras el niño selecciona las fichas que considera como palabras comenta que deja -ON afuera del tablero porque una palabra por lo menos tiene que ser más que dos letras. Para ejemplificar lo que está explicando, Pablo agrega los ejemplos orales en y lo diciendo: en / no es una palabra y lo / no es una palabra. Su justificación y sus ejemplos nos muestran la persistencia de la exigencia de cantidad mínima (Ferreiro y Teberosky, 1979) aún para Pablo que es un niño de $4^{\circ}$ grado que lee y escribe alfabéticamente. Al finalizar la tarea de Alargar, el entrevistador vuelve a consultar al niño para que ahonde en este aparente criterio gráfico que está utilizando para distinguir qué segmentos son 
palabras. El niño le propone al entrevistador que escriba la frase EL HOMBRE NOS HIZO JUGAR Y tomando el lápiz subraya la serie HOMBRE y sostiene que es palabra. Luego de ciertas dudas y por sugerencia de su compañera Lara $\left(4^{\circ}\right)$ subraya también HIZO y JUGAR. Sobre las series que no subrayó dice:

Pablo: los artículos son para nombrar palabras y objetos / porque el [señalando la serie EL] es el que acompaña para que hombre sea

Ent.: y esta? [señalando NOS]

Pablo: nos no / por más que tenga tres no importa porque también es un artículo / los artículos es para que la palabra funcione

El entrevistador vuelve a llamar la atención del niño sobre las fichas que utilizaron para alargar la serie FUTBOLERO y le recuerda que había dicho que -ERO no era una palabra. El intercambio continúa así:

Pablo: no / no puede ser [refiriéndose a que ERO esté aislada] / pero si va con esa [señalando FUTBOL] / es una palabra [señalando ERO en la serie FUTBOLERO]

Ent.: estas [señalando EL y NOS en la serie que escribió para el niño] vos me decís que no son palabras pero pueden ir solas

Pablo: sí / esas son para acompañar

Ent.: para acompañar como estas? [señalando ERO]

Pablo: no / distinto

Ent.: cómo distinto?

Pablo: nada de acompañar / esas [señalando ERO] solamente son de formar palabras / digamos no existen / solas no existen

Lo primero que sorprende en estos intercambios es la persistencia del requisito de cantidad mínima (Ferreiro y Teberosky, 1979) para que un segmento sea una palabra, en un niño de $4^{\circ}$ grado de primaria que ya se ha enfrentado numerosas veces (leyendo y escribiendo) con series de una y dos letras (preposiciones, conjunciones, artículos, pronombres). Esto ya fue abordado por Ferreiro (2000) en una investigación en la que proponía a niños de $2^{\circ}$ grado escuchar una serie de refranes (formas fijas y no modificables) y repetirlos. A continuación solicitaba a los niños contar cuántas palabras decían oralmente y luego escribir el refrán y contar cuántas palabras habían escrito (la investigación incluía también el proceso inverso: primero escribían el refrán y contaban las palabras y luego -sin tener a la vista lo escrito- decían el refrán y contaban las palabras). 
La situación predominante para estos niños con escrituras alfabéticas fue el desfasaje entre el conteo oral -predominantemente silábico- y el conteo escrito. Y en lo escrito, justamente, los niños no contaban los artículos ni las preposiciones.

"La exigencia de cantidad mínima (Ferreiro y Teberosky, 1979) que desempeña un papel tan decisivo en la evolución prealfabética de la escritura (Ferreiro, 1988), continúa vigente en los inicios de la escritura alfabética, convirtiéndose en una de las razones por las cuales es tan difícil generalizar el término palabra a todo lo que los niños deben segmentar para acomodarse (en el sentido piagetiano) al modelo externo, un modelo que aún no logran asimilar porque ello requiere una reelaboración de esquemas conceptuales previos" (Ferreiro, 2000:31).

Si tal como plantea Pablo el artículo EL y el pronombre NOS (que el niño también llama artículo) no son palabras porque para que un segmento sea palabra es necesario que tenga más de dos o tres letras, es evidente que varios morfemas derivativos quedan automáticamente descartados. Sin embargo, ¿qué sucede en la escritura con estos distintos segmentos? Mientras que algunos pueden constituir formas libres (los artículos y los pronombres, por ejemplo), otros no (todos los morfemas derivativos de nuestro diseño). La distinción que Pablo elabora entre series de letras que son para acompañar y series de letras que son de formar palabras parece ser una manera de conciliar un esquema interpretativo previo (un segmento con menos de tres letras no es palabra) con la información "inasimilable" que ha ido recibiendo en la escuela: LA y NOS se escriben separadas.

\subsection{Observaciones finales}

Luego de integrar los datos correspondientes a dos tareas distintas (Alargar y Acortar) que incluían en sus materiales morfemas derivativos comunes, encontramos que el trabajo y las reflexiones elaboradas por los niños nos dan pistas acerca de un proceso de reflexión metalingüística sobre los prefijos y sufijos que está relacionado con las acciones que los niños pueden realizar para segmentar los morfemas derivativos, las centraciones cognitivas que guían esas acciones y las justificaciones que los niños pueden 
elaborar. Aun así, se trata de una pauta evolutiva provisoria para los morfemas utilizados en nuestro diseño y bajo las restricciones lingüísticas que presentan las combinaciones con el número limitado de bases léxicas que dispusimos en ambas tareas. En este proceso distinguimos un momento inicial en el que los niños enfrentan el problema de encontrar segmentos dentro de las palabras y de poner en relación sus significados. Un avance importante se produce cuando los niños dan cuenta de que el agregado de un segmento modifica el significado de una forma y de que esa modificación puede ser parafraseada con distintas bases léxicas. El punto máximo que alcanzan los niños interrogados es aceptar la existencia de segmentos ligados a las palabras pero que no son concebidos como "unidades mínimas de significado" sino que funcionan como "modificadores del significado" de palabras que sí tienen significado por sí mismas. 


\section{Tarea de Contrastar}

\subsection{Materiales y consigna}

En la tarea de Contrastar, la última de nuestro diseño, los niños recibían tiras metálicas de $5 \mathrm{~cm}$. de alto por $32 \mathrm{~cm}$. de ancho que contenían frases nominales escritas con un espacio en blanco en el que se podían ubicar alternadamente pares de fichas imantadas con palabras contrastantes en cuanto a sus morfemas derivativos. El Cuadro 13 presenta las tres tiras con sus respectivos pares de fichas imantadas:

\begin{tabular}{|c|c|c|}
\hline \multicolumn{3}{|c|}{ Primer par } \\
\hline \multirow{2}{*}{ EL } & GRANDULOT & \multirow{2}{*}{ DEL SALON } \\
\hline & GRANDULON & \\
\hline \multicolumn{3}{|c|}{ Segundo par } \\
\hline \multirow{2}{*}{ UN } & FUTBOLERO & \multirow{2}{*}{ DE PRIMERA DIVISION } \\
\hline & FUTBOLISTA & \\
\hline \multicolumn{3}{|c|}{ Tercer par } \\
\hline \multirow{2}{*}{\multicolumn{2}{|c|}{ UNA SITUACION }} & INESPERADA \\
\hline & & DESESPERADA \\
\hline
\end{tabular}

Las fichas con las palabras para contrastar se presentaban por separado con el propósito de que los niños pudieran intercambiarlas y comparar cómo quedaría la frase completa en ambos casos. Todas las expresiones de las tiras son frases nominales, aunque en las dos primeras las palabras con morfemas contrastantes constituyen el núcleo de la frase mientras que en la última funcionan como complemento del núcleo. En cuanto a los contrastes esperados, el par de sufijos aumentativos -ON y -OTE es el único que puede ser considerado como sinónimo, aunque también admite la interpretación apreciativa. Por su parte, el par -ERO/-ISTA presenta derivaciones denominales que remiten a un contraste de persona en FUTBOLERO y FUTBOLISTA, comparación sobre la que además los niños ya tuvieron oportunidad de elaborar justificaciones en la tarea de Alargar (sección 2.5). Finalmente, el par de fichas con los morfemas IN- y DES- ofrece prefijos próximos desde el punto de vista 
semántico pero que en el contexto propuesto poseen significados muy distintos e incluso valoraciones contrastantes: mientras que DESESPERADA es claramente negativa, INESPERADA puede ser tanto positiva como negativa.

\section{Procedimiento}

Al inicio de esta tarea entregábamos a cada niño la primera y la segunda tira con sus pares de fichas respectivos. Luego planteábamos la siguiente consigna:

El otro día estábamos con unos chicos poniendo estos títulos en unas fotos de un álbum. Algunos me decían que con éstas [señalando respectivamente los pares de fichas para cada tira] quiere decir lo mismo y otros que no. ¿Ustedes qué piensan?

Los niños disponían de un tiempo para ubicar las fichas en las tiras y leerlas. A continuación iniciábamos un intercambio para que los niños compararan semejanzas y diferencias entre dos palabras parecidas (una base léxica común para dos morfemas derivativos) que pueden ocupar el mismo lugar en una expresión nominal. Al presentar la tercera tira se modificaba apenas la consigna:

¿Me ayudan ahora los dos juntos a ver si en este título quiere decir lo mismo o es distinto con estas? [señalando respectivamente las dos fichas para la tira].

Una observación general sobre esta tarea es que si bien en un principio nos propusimos dos momentos distintos para que primero los niños consideraran cada uno por separado una tira y luego ambos niños reflexionaran sobre el mismo par (DES-/IN-), lo cierto es que en todos los casos hubo una dinámica de interacción que hizo que las parejas trabajaran en simultáneo sobre las tres tiras. Dos nos parecen los motivos que favorecieron esta interacción: en primer lugar, el hecho de que a diferencia de las tareas anteriores de Alargar y de Acortar los niños ahora tenían un margen de acción más reducido con el material escrito propuesto (solo podían probar alternativamente dos fichas que iban en un único lugar); por otro lado, a esta altura de la entrevista los niños venían de largos períodos de intercambio sobre sus producciones y también sobre las producciones que realizaba su compañero. Todo esto parece haber influido para que los niños entablaran por su cuenta un trabajo conjunto sobre todas las tiras. 


\subsection{Justificaciones de los niños a los contrastes entre morfemas derivativos}

Para explicar las variables que utilizaremos en el análisis de las justificaciones revisaremos en este apartado los intercambios sobre las palabras con morfemas derivativos contrastantes de dos parejas. En principio, la consigna invitaba a los niños a evaluar si las palabras contrastantes significan lo mismo o no significan lo mismo en el contexto sintagmático propuesto. La primera variable tiene que ver con analizar si un niño enuncia igualdad de significado o diferencia de significado entre las fichas propuestas. Sin embargo, dadas las características metodológicas de la interrogación utilizada en nuestra investigación, es necesario considerar el proceso por el cual los niños llegan a enunciar la igualdad o la diferencia de significado. Es decir, hay niños que comienzan sosteniendo igualdad y durante el intercambio modifican su postura y finalizan enunciando diferencia de significado. Veamos el intercambio de la pareja de Julián y Clara (4º grado) sobre el contraste entre las fichas FUTBOLERO y FUTBOLISTA:

Ent.: y esta [señalando la tira UN DE PRIMERA DIVISIÓN] / vamos a ver esta que tiene Julián / contanos / cómo es con esa? [señalando FUTBOLERO]

Julián: un futbolero de primera división

Ent.: y con la otra? [señalando la ficha FUTBOLISTA]

Julián: un futbolista de primera división

Clara: no / no cambia

Julián: cambia

Ent.: por qué? / contame / a ver

Julián: y futbolero sería como te contamos antes [refiriéndose a la tarea de Alargar] / de que sería como

Clara: un chico

Julián: un director técnico y futbolista

Clara: ah sí / sí está bien

Julián: sería alguien que juega al fútbol

Clara: sí / sí cambia

Ent.: esta y esta [señalando ambas fichas respectivamente] / no es lo mismo? Julián: no

Julián comienza recuperando un contraste elaborado previamente en la tarea de Alargar (FUTBOLERO sería como un hombre que enseña a jugar al fútbol / sería el director técnico, mientras que FUTBOLISTA es un chico que juega al fútbol) y sostiene a lo largo del 
intercambio diferencia de significado. Clara, en cambio, comienza enunciando igualdad de significado, sin embargo, cuando su compañero recupera el contraste que habían elaborado previamente, modifica su enunciado. La variable metodológica del trabajo en parejas también interviene a la hora de considerar las justificaciones de los niños, por eso en adelante haremos referencia a la situación de concordancia o discrepancia de justificación entre los niños de cada pareja. Además, en el ejemplo de Julián y Clara también podemos ver la incidencia del trabajo previo con los morfemas objeto. Recordemos que la tarea de Contrastar es la última de nuestro diseño y todos los morfemas objeto que focalizamos en esta última tarea (-ON, $-\mathrm{OTE}^{39}$, -ERO, -ISTA, IN- y DES-) ya habían sido presentados en tareas anteriores. Por lo tanto, también se impone tener en cuenta en nuestro análisis cómo recuperan los niños las justificaciones elaboradas previamente sobre los morfemas.

Por otro lado, si bien la consigna invita a los niños a considerar la semejanza o diferencia de las palabras presentadas (la distinción "enuncia igualdad de significado" o "enuncia diferencia de significado"), también se dieron situaciones en la que los niños optaban por una de las formas como la correcta o que, aun inclinándose por sostener ya sea igualdad o diferencia de significado, expresaban oscilaciones y dudas entre ambas posturas. Veamos el siguiente intercambio entre Matías y Luna ( $4^{\circ}$ grado) sobre las fichas GRANDULON Y GRANDULOTE:

Ent.: es lo mismo? [señalando respectivamente ambas fichas]

Matías: [asiente] / excepto que este sería un poco más grande

Ent.: cuál es más grande?

Matías: grandulote [señalando GRANDULOTE]

Ent.: qué quiere decir grandulón?

Luna: no / pero esperá / primero yo no digo / porque nosotros dijimos que on era como que agrandaba las cosas / y acá [señalando GRANDULOTE] no dice on

Matías: grandulote sería que lo agranda un poco más

Luna: ay no lo sé

Matías: grandulón es grande / y si es grandulote es más grande

\footnotetext{
${ }^{39}$ La tarea de Alargar que desarrollamos y analizamos en el capítulo 2 estaba precedida por una tarea introductoria con el mismo procedimiento, aunque solamente con 3 morfemas objeto (-OTE, -ITO y PRE-) y 4 bases léxicas (PLATO, PLATO, AZUL y VENTA). Aunque esta tarea previa no es analizada en nuestra tesis porque fue diseñada como una tarea previa para situar a los niños en un contexto de "interpretación a través de la acción", señalamos que la misma incluía el sufijo-OTE que es retomado en la última tarea de Contrastar.
} 
Ent.: vos no estás convencida Luna / a ver contame

Luna: es que

Matías: yo pondría este [señalando GRANDULON]

Luna: es que / porque el primer juego / dijimos que on / para mí / que on era que agrandaba las cosas y él dijo que grandulote era más grande

Ent.: y vos decís que son iguales de grande?

Luna: son iguales las palabras / me entendés? / solamente que cambia el final / la palabras es como que

Matías: [interrumpiendo] cambia la letra [enfatizando]

Ent.: y puede ser que sean distintos finales [señalando ON y OTE en cada ficha respectivamente] y que quieran decir lo mismo?

Luna: puede ser [con inseguridad] / porque mirá / esto [señalando la tira] / es como que los dos explican lo mismo pero terminan distinto

Al inicio Matías parece enunciar que GRANDULON y GRANDULOTE tienen igualdad de significado, pero inmediatamente comienza a tratar de distinguirlos a partir de una gradación dentro de la dimensión aumentativa. El problema que enfrenta Matías es tratar de conciliar las similitudes (la base léxica común y el significado aumentativo que agregan ambos sufijos) con las diferencias (morfemas derivativos formalmente diferentes). Al finalizar el intercambio Matías termina optando por una de las fichas (GRANDULON), posiblemente porque su compañera recupera una justificación elaborada previamente sobre el sufijo -ON como aumentativo. Luna, en cambio, durante todo el intercambio da cuenta de las dudas que le genera considerar por un lado las diferencias formales entre las palabras (terminan distinta / cambia el final) con las similitudes semánticas (son iguales las palabras / las dos explican lo mismo).

Los dos ejemplos comentados nos muestran la necesidad de caracterizar el proceso mediante el cual los niños llegan a enunciar la igualdad o diferencia entre las formas, es decir, si recuperan justificaciones elaboradas en tareas anteriores, si coinciden o discrepan con su compañero, si modifican su justificación durante el intercambio y, principalmente, si dan cuenta de dudas y oscilaciones a la hora de considerar las semejanzas y diferencias entre los pares de palabras contrastantes. A continuación, presentaremos el análisis de las justificaciones elaboradas por los niños para cada uno de los pares de morfemas contrastantes, focalizando en las centraciones cognitivas (formales y semánticas) que orientan las justificaciones. 


\subsection{Contrastes entre los aumentativos -ON y -OTE}

De los tres pares de palabras contrastantes de nuestro diseño, el par GRANDULON / GRANDULOTE es el único que en principio admite la consideración de igualdad de significado a partir de la interpretación aumentativa de ambos sufijos. Aun así, también existe la posibilidad de que alguna de las formas sea interpretada apreciativamente. Veamos cómo interpretaron este par de sufijos las parejas de los distintos grados escolares.

\section{Cuadro 14 - Interpretación coincidente o discrepante del par-ON/-OTE por pareja interrogada, según grado escolar ( $n=30$ parejas en total, 10 parejas por grado escolar)}

\begin{tabular}{c|cc|} 
Grado escolar & $\begin{array}{c}\text { Interpretación } \\
\text { coincidente }\end{array}$ & $\begin{array}{c}\text { Interpretación } \\
\text { discrepante }\end{array}$ \\
\hline $\begin{array}{c}2^{\circ} \text { grado } \\
(n=10)\end{array}$ & 6 & 4 \\
\hline $\begin{array}{c}4^{\circ} \text { grado } \\
(n=10)\end{array}$ & 9 & 1 \\
\hline $\begin{array}{c}6^{\circ} \text { grado } \\
(n=10)\end{array}$ & 9 & 1 \\
\hline
\end{tabular}

El Cuadro 14 nos permite ver que en $4^{\circ}$ y $6^{\circ}$ grado encontramos una franca mayoría de interpretaciones coincidentes, y en $2^{\circ}$ grado encontramos un número cercano de interpretaciones tanto coincidentes como discrepantes. Estas discrepancias entre los niños más pequeños tienen que ver (como analizaremos a continuación) con las dificultades que encuentran a la hora de considerar conjuntamente el segmento equivalente (GRANDUL-) y los segmentos diferentes (-ON y -OTE) en las fichas presentadas. Ahora bien, ¿cómo interpretaron el par de palabras contrastantes todos los niños, más allá de la coincidencia o la discrepancia con su compañero? En una primera aproximación general, encontramos que 19/60 niños enunciaron diferencia de significado mientras que 41/60 sostuvieron igualdad de significado. El Cuadro 15 muestra estas interpretaciones distinguiendo los grados escolares (en el eje vertical) y los distintos procesos mediante los cuales los niños llegaron a elaborar su postura (en el eje horizontal):

- Enuncia diferencia de significado o bien Enuncia igualdad de significado: se trata de aquellos niños que inician y finalizan el intercambio con la misma interpretación. 
- Duda $\rightarrow$ Enuncia diferencia de significado o bien Duda $\rightarrow$ Enuncia igualdad de significado: son los niños que inicialmente expresan dudas o asumen parcialmente una interpretación y durante el intercambio la modifican.

- Enuncia diferencia de significado $\rightarrow$ Duda o bien Enuncia igualdad de significado $\rightarrow$ Duda: en este caso los niños plantean una interpretación sobre el contraste pero durante el intercambio y al finalizar expresan y mantienen sus dudas u oscilaciones.

CUadro 15 - Diferencia de significado e igualdad de significado para el par-ON/-OTE, según grado escolar ( $n=60$ niños, 20 niños por grado escolar)

\begin{tabular}{cc|c|c|c|c|c} 
& \multicolumn{2}{c|}{ Diferencia de significado } & \multicolumn{3}{|c}{ Igualdad de significado } \\
\cline { 2 - 5 } -ON / -OTE & $\begin{array}{c}\text { Enuncia } \\
\text { diferencia de } \\
\text { significado }\end{array}$ & $\begin{array}{c}\text { Duda } \rightarrow \\
\text { Enuncia } \\
\text { diferencia de } \\
\text { significado }\end{array}$ & $\begin{array}{c}\text { Enuncia } \\
\text { diferencia de } \\
\text { significado } \\
\text { Duda }\end{array}$ & $\begin{array}{c}\text { Enuncia } \\
\text { igualdad de } \\
\text { significado }\end{array}$ & $\begin{array}{c}\text { Duda } \rightarrow \\
\text { Enuncia } \\
\text { igualdad de } \\
\text { significado }\end{array}$ & $\begin{array}{c}\text { Enuncia } \\
\text { igualdad de } \\
\text { significado } \rightarrow \\
\text { Duda }\end{array}$ \\
\hline $\begin{array}{c}\mathbf{2}^{\circ} \text { grado } \\
(\mathrm{n}=20)\end{array}$ & 5 & 2 & 5 & 5 & 1 & 2 \\
\cline { 1 - 4 } $\begin{array}{c}\mathbf{4}^{\circ} \text { grado } \\
(\mathrm{n}=20)\end{array}$ & 0 & 0 & 4 & 13 & 1 & 2 \\
\cline { 1 - 4 } $\begin{array}{c}\mathbf{6}^{\circ} \text { grado } \\
(\mathrm{n}=20)\end{array}$ & 2 & 0 & 1 & 13 & 3 & 1
\end{tabular}

El Cuadro 15 nos permite constatar dos situaciones en cuanto a los niños que enuncian diferencia de significado: en primer lugar, de los 19/60 niños que sostienen que GRANDULOTE Y GRANDULON tiene diferencia de significado 12 pertenecen a $2^{\circ}$ grado; en segundo lugar, estos 19/60 presentan más casos de modificación o de duda que casos en que los niños sostuvieron la diferencia de significado sin modificar o sin dudar duran te el intercambio. Veamos qué justificaciones elaboraron estos niños que sostuvieron la diferencia de significado (19 niños sobre 60).

En primer lugar, 6/19 niños no logran elaborar una justificación por una centración exclusiva en las diferencias gráficas (mayormente niños de $2^{\circ}$ grado). Se trata de niños que señalan en las fichas los segmentos que son diferentes y que intentan "oralizar" esos segmentos distintos (no siempre en coincidencia con los morfemas objeto que estamos considerandos). No hay referencias a cambios en el significado. Veamos dos ejemplos:

- Carla $\left(2^{\circ}\right)$ - es diferente porque acá está la lon [señalando LON en GRANDULON] /y este el ote [señalando OTE en GRANDULOTE]

- Josefina $\left(2^{\circ}\right)$ - son parecidas / pero diferentes letras acá / mirá acá cambian las letras [señalando los finales de ambas fichas sin precisar los segmentos] / acá 
son las mismas [señalando las letras GRANDUL en ambas fichas] pero acá una ene [señalando la N final en GRANDULON] / que es otra letra que se puso / y acá hay dos letras que se pusieron [señalando ON en GRANDULON] / son diferentes

La centración exclusiva en las diferencias gráficas de ambas formas permite a los niños resolver la consigna en cuanto a evaluar la igualdad o diferencia entre las palabras, aun cuando no abordan el problema del significado en sí. Es llamativo ya que se trata de niños que en la tarea de Acortar (sección 3.5) lograron aislar y elaborar justificaciones aumentativas adecuadas en series que incluían el sufijo -ON.

En segundo lugar, 7/19 niños sostienen que ambas fichas son aumentativas pero una indica un grado mayor en la gradación aumentativa. Se trata de un buen intento de conciliar semejanzas (gráficas y semánticas) con diferencias (gráficas):

- Guadalupe $\left(2^{\circ}\right)$ - cambia porque uno es más grande y el otro es más chico / el más chiquito es grandulón

- Gerónimo $\left(2^{\circ}\right)$ - grandulote algo más grande que grandulón / [señalando GRANDULÓN] más chico

- Clara $\left(4^{\circ}\right)$ - el grandulote es un chico grande / grandulote significa que es un chico gordito del salón / y el grandulón es un chico alto / es como que el grandulón es un chico alto / puede ser alto / pero grandulote / porque el ote es como más grande

Creemos que se trata de un avance respecto de los niños que se centran exclusivamente en las diferencias gráficas, ya que expresan dudas y oscilaciones porque están tratando de centrarse alternativamente en las semejanzas (ambas series son aumentativas) y en las diferencias (formalmente tienen terminaciones distintas). Estos niños que exploran una distinción en la gradación del aumento de tamaño se centran mayormente en las palabras completas, es decir en la base léxica con los sufijos derivativos, sin embargo, en algunos casos aíslan oralmente y se centran en los sufijos: Clara $\left(4^{\circ}\right)$ en el ejemplo anterior sostiene que el ote es como más grande.

Por último, hay 6/19 niños que sostienen que ambas palabras son aumentativas pero una de ellas es además apreciativa (en esta categoría se encuentran los únicos 3 niños de $6^{\circ}$ grado que enunciaron diferencia de significado para el par de morfemas -on/ -OTE). Veamos algunos ejemplos: 
- Emiliano $\left(2^{\circ}\right)$ - uno es grande / grandulote / [GRANDuLon] es un chico grande que es malo

- Ezequiel $\left(6^{\circ}\right)$ - grandulón es alguien muy grande / grandulote sería alguien que se hace el malo / enojón

- Gerardo $\left(6^{\circ}\right)$ - me parece que sí [son diferentes] porque grandulote sería una persona que es grande / y grandulón creo que es como un agrandado / una persona que es medio agrandada / y suponte que se está haciendo mostrar

Se trata de niños que intentan coordinar semejanzas y diferencias entre las fichas: ambas remiten al "aumento de tamaño", pero una de ellas además agrega un significado apreciativo que la distingue. De esta manera, las diferencias formales suponen una especificación semántica en la idea de "aumentativo" que comparten las dos palabras.

Veamos ahora qué sucedió con las justificaciones de los 41/60 niños que sostuvieron la igualdad de significado entre GRANDULON y GRANDULOTE. En primer lugar, para 3 de estos 41 niños ambas fichas tienen el mismo significado aunque descartan una de ellas por considerarla incorrecta o poco habitual en el uso cotidiano. Se trata de una centración excluyente en una de las palabras, ya que el rechazo de la otra forma resuelve el problema de tener que comparar sus similitudes y sus diferencias:

- Genaro $\left(4^{\circ}\right)$-para mí es lo mismo / grandulote está mal dicho / sería también grandulón pero está mal dicho / pero es una forma de decirlo / el grande del salón // redactado sería / grandulote está mal redactado

- Luana $\left(6^{\circ}\right)$ - para mí es lo mismo porque en los dos te está diciendo que es grande la persona / pero yo siempre digo grandulón / para mí tiene más sentido grandulón

La justificación más extendida entre los 41/60 niños que enuncian la igualdad de significado es aquella centrada exclusivamente en las similitudes semánticas del aumentativo (31 justificaciones sobre estos 41 niños). Registramos entre ellos muchos casos en que los niños parten de expresar oscilaciones o que, aun enunciando al final del intercambio la igualdad de significado, dan cuenta de ciertas dudas en su postura. La dificultad más generalizada es cómo justificar dos formas gráficas distintas que tienen exactamente el mismo significado. 
- Lucas $\left(2^{\circ}\right)$ es lo mismo / porque grandulote y grandulón son / me parece que son lo mismo de grande

- Julián $\left(4^{\circ}\right)$ sería como / algo como la misma cosa / grandulón sería / un chico grande / por ejemplo que manda / y grandulote sería casi lo mismo

- Lorena $\left(6^{\circ}\right)$ se pueden usar las dos porque tienen el mismo significado / porque grandulote es como grandulón / grande / y grandulón es grandulón / lo podés usar / tienen el mismo significado

Por último, la justificación más avanzada es la registrada en $\mathbf{7}$ de estos 41 niños que enunciaron la igualdad de significado: GRANDULON y GRANDULOTE son diferentes formalmente pero tienen el mismo significado aumentativo, se trata de niños que aparecen aceptar la sinonimia. Veamos, como ejemplo, el siguiente intercambio de Darío y Paula (pareja de $4^{\circ}$ grado), niños que han recibido información sobre los sinónimos y que además pueden utilizarla adecuadamente en sus justificaciones:

Darío: es lo mismo [GRANDULON Y GRANDULOTE]

Paula: sí es lo mismo / nada más que con diferentes palabras

Darío: son sinónimos

Paula: grandote / que es muy grande

Ent.: qué son sinónimos? / contame

Darío: sinónimos es que significan lo mismo pero tienen

Paula: con distintas palabras

Darío: con distintos [sin completar la frase] / significan lo mismo

Paula: son totalmente iguales

Darío: significan lo mismo pero lo único que cambia

Paula: es la palabra

Darío: es la palabra

La aceptación de la sinonimia parece ser la solución más avanzada en estos intentos de coordinación de semejanzas y diferencias: los niños pueden centrarse en la base léxica común y en los morfemas derivativos diferentes, y al mismo tiempo postular la igualdad de significado (significan lo mismo / lo único que cambia es la palabra).

Ya sea que los niños enuncien que ambas formas tienen igualdad o diferencia de significado, el problema que enfrentan es cómo conciliar las semejanzas y las diferencias. El contexto sintagmático mínimo parece no incidir en las consideraciones de los niños sobre el contraste de los morfemas. El problema parece estar en cómo interpretar dos 
series que, desde el punto de vista formal -y gráfico- comparten un segmento igual (la base léxica) y segmentos diferentes (los morfemas derivativos -ON y -OTE) y, desde el punto de vista semántico, pueden ser consideradas semejantes (en tanto sufijos aumentativos) pero también diferentes (si se agrega a una de las formas la interpretación apreciativa). La centración excluyente en los aspectos gráficos o solamente en una de las palabras al descartar la otra por incorrecta, parece ser la respuesta menos avanzada. La aceptación de la sinonimia es problemática para estos niños ya que admitir que GRANDULOTE Y GRANDULON significan lo mismo implica dejar de lado las diferencias gráficas que observan en las fichas. Las interpretaciones que buscan diferenciar las palabras ya sea agregando a una de ellas un significado apreciativo o distinguiéndolas en una gradación aumentativa, constituyen una buena solución a este problema, en el sentido que permite a los niños centrarse alternadamente en lo que las fichas comparten (el significado aumentativo) y en lo que las diferencia (finales gráficos distintos). Solamente en el momento más avanzado los niños intentan centrarse coordinadamente en las semejanzas y en las diferencias: la sinonimia les permite justificar que palabras formalmente distintas puedan tener el mismo significado.

\subsection{Contrastes entre los denominales -ERO e -ISTA}

El par de sufijos contrastantes -ERO/-ISTA es el único que los niños habían abordado previamente en la tarea de Alargar ligados a la misma base léxica: FUTBOLERO y FUTBOLISTA (sección 2.5). Se trata de dos derivaciones agentivas diferentes: FUTBOLISTA, que categorialmente es sustantivo, y significa "jugador de fútbol"; y FUTBOLERo que puede ser tanto adjetivo ("perteneciente o relativo al fútbol") o sustantivo ("persona aficionada al fútbol"). A diferencia de lo ocurrido con el par de sufijos aumentativos -ON/-OTE (sección 5.3), en este caso no hay discrepancia entre las parejas de $2^{\circ}$ grado, y solamente encontramos algunos casos de discrepancia en parejas de $4^{\circ}$ y $6^{\circ}$ tal como se ve en el Cuadro 16: 
Cuadro 16 - Interpretación coincidente o discrepante del par -ERO/-ISTA por pareja interrogada, según grado escolar ( $n=30$ parejas en total, 10 parejas por grado escolar)

\begin{tabular}{c|cc|} 
Grado escolar & $\begin{array}{c}\text { Interpretación } \\
\text { coincidente }\end{array}$ & $\begin{array}{c}\text { Interpretación } \\
\text { discrepante }\end{array}$ \\
\hline $\begin{array}{c}2^{\circ} \text { grado } \\
(n=10)\end{array}$ & 10 & 0 \\
\hline $\begin{array}{c}4^{\circ} \text { grado } \\
(n=10)\end{array}$ & 7 & 3 \\
\hline $\begin{array}{c}6^{\circ} \text { grado } \\
(n=10)\end{array}$ & 8 & 2 \\
\hline
\end{tabular}

Si consideramos el total de los niños interrogados, 37/60 sostienen diferencia de significado entre FUTBOLERO y FUTBOLISTA mientras que 23/60 enuncian igualdad de significado. El Cuadro 17 muestra la distribución de estas interpretaciones según grado escolar y según el proceso mediante el cual llegaron a elaborar su justificación. Los niños de $2^{\circ}$ y de $4^{\circ}$ grado presentan una distribución similar en la interpretación de diferencia o igualdad de significado. Más de la mitad de los niños de $6^{\circ}$ grado sostuvo que entre las fichas hay diferencia de significado, y los únicos $6 / 20$ niños de $6^{\circ}$ que enunciaron igualdad de significado son niños que expresaron dudas y oscilaciones en su justificación.

Cuadro 17 - Diferencia de significado e igualdad de significado para el par-ERO/-ISTA, según grado escolar ( $n=60$ niños, 20 niños por grado escolar)

\begin{tabular}{|c|c|c|c|c|c|c|}
\hline \multirow[b]{2}{*}{$\begin{array}{l}\text {-ERO / } \\
\text {-ISTA }\end{array}$} & \multicolumn{3}{|c|}{ Diferencia de significado } & \multicolumn{3}{|c|}{ Igualdad de significado } \\
\hline & $\begin{array}{l}\text { Enuncia } \\
\text { diferencia de } \\
\text { significado }\end{array}$ & $\begin{array}{c}\text { Duda } \rightarrow \\
\text { Enuncia } \\
\text { diferencia de } \\
\text { significado } \\
\end{array}$ & $\begin{array}{c}\text { Enuncia } \\
\text { diferencia de } \\
\text { significado } \rightarrow \\
\text { Duda } \\
\end{array}$ & $\begin{array}{l}\text { Enuncia } \\
\text { igualdad de } \\
\text { significado }\end{array}$ & $\begin{array}{c}\text { Duda } \rightarrow \\
\text { Enuncia } \\
\text { igualdad de } \\
\text { significado }\end{array}$ & $\begin{array}{c}\text { Enuncia } \\
\text { igualdad de } \\
\text { significado } \rightarrow \\
\text { Duda } \\
\end{array}$ \\
\hline $\begin{array}{c}2^{\circ} \text { grado } \\
(n=20)\end{array}$ & 6 & 5 & 1 & 6 & 2 & 0 \\
\hline $\begin{array}{c}4^{\circ} \text { grado } \\
(n=20)\end{array}$ & 6 & 2 & 3 & 4 & 1 & 4 \\
\hline $\begin{array}{c}6^{\circ} \text { grado } \\
(n=20)\end{array}$ & 11 & 3 & 0 & 0 & 0 & 6 \\
\hline
\end{tabular}

Los $37 / 60$ niños que enunciaron diferencia de significado lograron centraciones coordinadas entre el segmento coincidente (FUTBOL) y los segmentos diferentes (los sufijos -ERO e -ISTA) en las fichas. En la mayor parte de los casos, las justificaciones elaboradas por 
los niños durante la tarea de Alargar (sección 2.5) parecen tener un peso relevante a la hora de considerar el contraste en el marco del contexto sintagmático propuesto. Veamos algunos ejemplos en los que los niños recuperan el contraste "FUTBOLERO=jugador profesional" vs. "FUTBOLISTA=aficionado o jugador amateur":

- Luis $\left(2^{\circ}\right)$ para mí esto cambia porque ya lo habíamos dicho / que futbolista es ser principiante / y futbolero [dudando] / sería al revés / profesional sería futbolista y futbolero sería el principiante

- Carmela $\left(4^{\circ}\right)$ como explicamos / un futbolista es alguien que juega / en cambio este [FUTBOLERO] puede ser un niño tranquilamente / pero este [FUTBOLISTA] juega y es bueno y le pagan

- Azul $\left(6^{\circ}\right)$ claro como decíamos antes / futbolista para nosotros o para mí es que juega al fútbol / que juega muy bien al fútbol y que le gusta / y futbolero es como que ve [enfatizando] el fútbol y le gusta mucho mirar el fútbol

En los tres casos los niños se remiten explícitamente a las justificaciones que habían elaborado previamente (ya lo habíamos dicho, como explicamos o como decíamos antes). Es más, algunos niños retomaron las justificaciones no esperadas que habían utilizado en la tarea de Alargar (sección 2.5):

- Lucas $\left(2^{\circ}\right)$ - un futbolero me parece que es de metegol / y futbolista de fútbol de verdad

- Emanuel $\left(2^{\circ}\right)$ - futbolero es como un atajero / el arquero / futbolista es el jugador

- Marcos $\left(4^{\circ}\right)$ - los futbolistas son muchos y futbolero es uno

- Agustín $\left(4^{\circ}\right)$ - cambia porque el futbolero es el que alcanza las pelotas / y el futbolista es un jugador deportivo que le gusta jugar al fútbol

Tanto los niños que elaboraron contrastes adecuadas como los que retomaron justificaciones no esperadas intentan centrarse coordinadamente en el segmento coincidente (la base léxica FUTBOL) y los segmentos diferentes de ambas fichas (los sufijos). Pero, ¿qué justificaciones elaboraron aquellos niños que sostuvieron que ambas series tienen igualdad de significado? Recordemos que se trata de 23 niños sobre un total de 60. La justificación más extendida es la oscilación entre la consideración de las semejanzas y las diferencias de las fichas (16/23). Se trata mayormente de niños que manifiestan dudas o van modificando su postura durante el intercambio. Los ejemplos que siguen dan cuenta 
de las dificultades que supone admitir igualdad en el plano semántico (ambas fichas significan "jugador de fútbol" o bien "aficionado al fútbol") cuando observan diferencias gráficas que además coinciden con segmentos aislados presentados en tareas anteriores:

- Josefina $\left(2^{\circ}\right)$ - a mí me parece que cambian las letras pero tienen la misma / o sea me parece / no cambian [en lo que significan] pero cambian las letras / cambian unas letras [señalando las letras finales de ambas series]

- Laura $\left(6^{\circ}\right)$ - cambia el ero y / ista [señalando las series finales en ambas fichas] / el ero y / ista / para mí es la misma palabra que esta acá / o algo así [en voz baja] / fútbol [señala la serie FUTBOL en ambas fichas] / empezamos por fútbol y después sí cambia / [en lo que significan] son iguales

Tanto Josefina $\left(2^{\circ}\right)$ como Laura $\left(6^{\circ}\right)$ oscilan entre centrarse en las diferencias gráficas (la niña de $6^{\circ}$, inclusive, segmenta adecuadamente a nivel oral los sufijos denominales) y en centrarse exclusivamente en el significado común de la base léxica. Una solución a este problema es la que plantean $7 / 23$ de los niños que sostienen la igualdad semántica: ambas palabras significan lo mismo, pero solamente una de ellas es correcta:

- Luna $\left(4^{\circ}\right)$ - yo pondría futbolista / es como que queda mejor / un futbolista de primera división / un futbolero / porque es como decir un futbolero y es como que / mmm no sé / yo pondría esta [FUTBOLISTA] es como que me suena más / quieren decir lo mismo

Si bien todos estos niños parecen optar por la palabra FUTBOLISTA, lo cierto es que los intercambios dan cuenta de oscilaciones y dudas en su argumentación, lo que descarta que simplemente estén centrándose excluyentemente en una de las palabras completas. En este momento del análisis, es necesario considerar si la conclusión final que los niños elaboran sobre el contraste entre FUTBOLERO y FUTBOLISTA en la tarea de Contrastar reafirma o modifica lo que cada niño planteó anteriormente en la tarea de Alargar.

El Cuadro 18 nos muestra que ningún niño de $2^{\circ}$ grado modificó el contraste que ya había elaborado previamente. En los otros grados la situación es diferente: la mitad de los niños de $4^{\circ}$ grado $(10 / 20)$ modificó su postura previa y en $6^{\circ}$ grado también encontramos casos de modificación de postura (6/20). 
Cuadro 18 - Reafirmación o modificación del contraste elaborado sobre FUTBOLERO y FUTBOLISTA en la tarea de Alargar, al concluir la tarea de Contrastar ( $n=60$ niños, 20 niños por grado escolar)

\begin{tabular}{|c|c|c|c|c|c|}
\hline \multirow{2}{*}{\multicolumn{3}{|c|}{ Contrastes entre FUTBOLERO y FUTBOLISTA }} & \multicolumn{3}{|c|}{ Grado escolar } \\
\hline & & & \multirow{2}{*}{$\begin{array}{c}2^{\circ} \text { grado } \\
(\mathbf{n}=20)\end{array}$} & \multirow{2}{*}{ 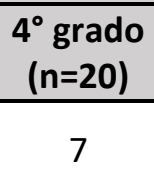 } & \multirow{2}{*}{$\begin{array}{c}\begin{array}{c}6^{\circ} \text { grado } \\
(n=20)\end{array} \\
13\end{array}$} \\
\hline \multirow{4}{*}{ 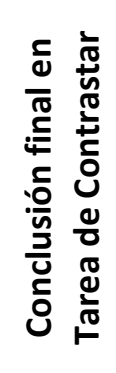 } & \multirow{2}{*}{$\begin{array}{l}\text { Diferencia } \\
\text { de } \\
\text { significado }\end{array}$} & $\begin{array}{l}\text { Reafirma tarea de } \\
\text { Alargar }\end{array}$ & & & \\
\hline & & $\begin{array}{l}\text { Modifica en tarea } \\
\text { de Contrastar }\end{array}$ & 0 & 4 & 1 \\
\hline & \multirow{2}{*}{$\begin{array}{l}\text { Igualdad } \\
\text { de } \\
\text { significado }\end{array}$} & $\begin{array}{l}\text { Reafirma tarea de } \\
\text { Alargar }\end{array}$ & 8 & 3 & 1 \\
\hline & & $\begin{array}{l}\text { Modifica en tarea } \\
\text { de Contrastar }\end{array}$ & 0 & 6 & 5 \\
\hline
\end{tabular}

Las modificaciones que llegan a la conclusión de diferencia de significado entre FUTBOLERO y FUTBOLISTA podrían considerarse como un avance con respecto de la tarea de Alargar, ya que los niños logran elaborar un contraste semántico adecuado. Más llamativo es el caso inverso, es decir, ¿por qué niños de $4^{\circ}$ y $6^{\circ}$ que habían elaborado contrastes adecuados en la tarea de Alargar modifican luego su postura para enunciar una igualdad de significado? En los ejemplos que siguen, podemos ver que en los niños que modificaron el contraste previo lo que prevalece es el peso del contexto sintagmático:

- Ulises $\left(4^{\circ}\right)$ : para mí esta es lo mismo / claro esto estuvimos viéndolo antes / para mí sería igual en este caso porque dice yo soy un de primera división / puedo decir un futbolero / para mí no cambia porque sería lo mismo en esta [enfatizando] oración

- Tamara $\left(6^{\circ}\right)$ es lo mismo pero para mí quedaría mejor un futbolista / porque es un futbolista es una persona que juega al fútbol / y futbolero / no sé / un futbolero de primera división [leyendo la ficha y dudando] / o sea para mí queda mejor un futbolista / o sea puede ser que tenga el mismo significado pero para mí en la oración queda mejor un futbolista

En la tarea de Alargar Ulises $\left(4^{\circ}\right)$ había elaborado un contraste adecuado: FUTBOLISTA es un hombre que juega al fútbol como por ejemplo Javier Mascherano ${ }^{40}$ mientras que si yo soy futbolero es como que a mí me gusta el fútbol / a mí me gusta jugar al fútbol pero no soy jugador. Es el contexto sintagmático propuesto (que él llama oración) lo que lo

\footnotetext{
40 Jugador profesional de la selección argentina de fútbol.
} 
lleva a reconsiderar ese contraste anterior. Tamara $\left(6^{\circ}\right)$, por su parte, recupera la justificación sobre FUTBOLISTA (es una persona que juega al fútbol) pero no así la que había elaborado previamente sobre FUTBOLERO: es el que le gusta el fútbol. Lo que distingue estas justificaciones es que los niños de $4^{\circ}$ grado parecen aceptar -con dudas y modificaciones durante el intercambio- que ambas fichas puedan ocupar el mismo lugar en el sintagma ya que significan lo mismo, en tanto que todos los niños de $6^{\circ}$ grado que modifican su postura finalizan optando por una ficha (FUTBOLISTA) o directamente rechazando que la palabra FUTBOLERO pueda ir acompañada del modificador DE PRIMERA DIVISIÓN. En todo caso, el contexto mínimo propuesto lleva a estos niños a una centración excluyente en las semejanzas semánticas, modificando un contraste adecuado que especificaba diferencias de significado para ambas fichas.

El siguiente intercambio de Ulises y Jazmín, pareja de $4^{\circ}$ grado, es interesante en tanto que los niños realizan una distinción entre contrastar las series cuando están aisladas (como en la tarea de Alargar) y hacerlo cuando están insertas en un contexto sintagmático (como en la tarea de Contrastar):

Ulises: para mí sería igual en este caso porque dice yo soy un de primera división [leyendo la tira] / puedo decir un futbolero

Jazmín: o un futbolista

Ulises: si yo digo futbolero en esta oración me va a quedar igual que decir futbolista Ent.: no cambia?

Ulises: para mí no cambia porque sería lo mismo en esta [enfatizando] oración / si lo digo con la palabra sola

Jazmín: [interrumpiendo] sí pero si le ponés aparte esto [separando las fichas FUTBOLERO y FUTBOLISTA de la tira] / para mí así sí es distinto [refiriéndose a cuando las fichas están aisladas]

Ulises: sí es muy distinto si lo ponés acá [refiriéndose a poner las fichas en la tira] Ent.: a ver / vamos a poner una acá / mirá [colocando la ficha FUTBOLISTA en la tira] Ulises: un futbolista de primera división es alguien que juega en el campeonato de primera división

Ent.: ajá

Jazmín: pero si vos lo ponés aparte [dudando]

Ulises: un futbolero sería [colocando la ficha FUTBOLERo en la tira]

Jazmín: lo mismo

Ulises: casi [enfatizando] lo mismo 
Para la justificación de las diferencias de significado, los niños recuperan los contrastes elaborados previamente en la tarea de Alargar. En su mayoría, se trató de la interpretación adecuada de la serie FUTBOLISTA como "jugador de fútbol" y de FUTBOLERO como "aficionado al fútbol", aunque también encontramos casos de interpretaciones no esperadas que incluyen contrastes singular/plural o animado/inanimado. Una situación más problemática encontramos en aquellos niños que enunciaron igualdad de significado entre las fichas. Se trata de niños con centraciones exclusivas en las semejanzas de significado de la base léxica, o que resuelven el problema de contrastar dos palabras similares optando por una de ellas. Lo que resulta llamativo son los casos de niños de $4^{\circ}$ y $6^{\circ}$ grado que modificaron los contrastes adecuados que habían elaborado previamente. Como acabamos de ver, las modificaciones están orientadas por el contexto sintagmático propuesto en esta última tarea.

\subsection{Contrastes entre los prefijos negativos IN- y DES-}

El primer dato llamativo con el par de prefijos negativos IN- y DES- es que, a diferencia de los pares contrastantes anteriores (sección 5.3 y 5.4), en todas las parejas entrevistadas hubo coincidencia en la interpretación (Cuadro 19):

Cuadro 19 - Interpretación coincidente o discrepante del par IN-/DES- por pareja interrogada, según grado escolar ( $n=30$ parejas en total, 10 parejas por grado escolar)

\begin{tabular}{c|cc|} 
Grado escolar & $\begin{array}{c}\text { Interpretación } \\
\text { coincidente }\end{array}$ & $\begin{array}{c}\text { Interpretación } \\
\text { discrepante }\end{array}$ \\
\hline $\begin{array}{c}2^{\circ} \text { grado } \\
(n=10)\end{array}$ & 10 & 0 \\
\hline $\begin{array}{c}4^{\circ} \text { grado } \\
(n=10)\end{array}$ & 10 & 0 \\
\hline $\begin{array}{c}6^{\circ} \text { grado } \\
(n=10)\end{array}$ & 10 & 0 \\
\hline
\end{tabular}

El análisis de las justificaciones muestra que prácticamente todos los niños sostuvieron la diferencia de significado entre INESPERADA y DESESPERADA: se trata de $\mathbf{5 6}$ niños 
sobre 60. En el Cuadro 20, además, podemos ver que hubo muy pocos casos de duda o modificación de esta justificación. Por otro lado, solamente 4 niños sobre 60 sostuvieron igualdad de significado entre las fichas presentadas. En el Cuadro 20 también podemos ver que en estos 4 casos los niños dudaron durante el intercambio.

Cuadro 20 - Diferencia de significado e igualdad de significado para el par IN-/DES-, según grado escolar ( $n=60$ niños, 20 niños por grado escolar)

\begin{tabular}{|c|c|c|c|c|c|c|}
\hline \multirow[b]{2}{*}{ IN - / DES- } & \multicolumn{3}{|c|}{ Diferencia de significado } & \multicolumn{3}{|c|}{ Igualdad de significado } \\
\hline & $\begin{array}{c}\text { Enuncia } \\
\text { diferencia de } \\
\text { significado }\end{array}$ & $\begin{array}{c}\text { Duda } \rightarrow \\
\text { Enuncia } \\
\text { diferencia de } \\
\text { significado }\end{array}$ & $\begin{array}{c}\text { Enuncia } \\
\text { diferencia de } \\
\text { significado } \rightarrow \\
\text { Duda } \\
\end{array}$ & $\begin{array}{l}\text { Enuncia } \\
\text { igualdad de } \\
\text { significado }\end{array}$ & $\begin{array}{c}\text { Duda } \rightarrow \\
\text { Enuncia } \\
\text { igualdad de } \\
\text { significado }\end{array}$ & $\begin{array}{c}\text { Enuncia } \\
\text { igualdad de } \\
\text { significado } \rightarrow \\
\text { Duda } \\
\end{array}$ \\
\hline $\begin{array}{c}2^{\circ} \text { grado } \\
(n=20)\end{array}$ & 15 & 1 & 2 & 0 & 2 & 0 \\
\hline $\begin{array}{c}4^{\circ} \text { grado } \\
(n=20)\end{array}$ & 17 & 1 & 0 & 0 & 2 & 0 \\
\hline $\begin{array}{c}6^{\circ} \text { grado } \\
(n=20)\end{array}$ & 19 & 1 & 0 & 0 & 0 & 0 \\
\hline
\end{tabular}

La justificación más extendida en el grupo de niños que enunciaron diferencia de significado es el contraste "inesperada=algo no esperado" vs. "desesperada=estado de alteración mental o emocional" (47 sobre 56 niños):

- Nicolás $\left(2^{\circ}\right)$ - no es lo mismo porque desesperada es como que una mujer está desesperada de tener un bebé / inesperada es algo inesperado / que si dicen los doctores que va a tener una mujer / tiene un varón al final / y eso es inesperado / porque eso vos no lo esperaste / no esperaste nada de eso lo que pasó

- Marcos $\left(4^{\circ}\right)$ - por ejemplo / algo inesperado es que cuando vayamos nosotros al aula haya una prueba / eso es algo inesperado / desesperada / estoy como preocupada

- Leonel $\left(6^{\circ}\right)$ - no es lo mismo / porque desesperado es que te está desesperando algo [haciendo gestos de alteración] / inesperada es que no te lo imaginabas a esto

En estos ejemplos podemos ver que DESESPERADA es interpretada negativamente como un estado de alteración, mientras que INESPERADA es parafraseada como no esperada e incluye ejemplos con una valoración que puede ser negativa (la justificación de Marcos $4^{\circ}$ ) o en todo caso neutra (la justificación de Nicolás $-2^{\circ}$ ). 
Una situación distinta se produjo en 9 niños sobre los 56 que enuncian diferencia de significado, quienes para tratar de conciliar las semejanzas y diferencias entre las formas partieron de la interpretación negativa del prefijo $\mathrm{IN}-\mathrm{y}$ a partir de esta opusieron una interpretación positiva del prefijo DES-:

- Martín $\left(2^{\circ}\right)$ - inesperada / o sea que no pensabas que iba a pasar esto / para mí desesperada era algo que ya sabías que iba a pasar

- Valeria $\left(2^{\circ}\right)$ - [INESPERADA] que no la esperan / [DESESPERADA] que ya sabían / no es lo mismo

- Clara $\left(4^{\circ}\right)$ - cambia / [INESPERADA] o sea que no lo espera / [DESESPERADA] que lo espera

Son casos llamativos, ya que cuando analizamos el desempeño de los niños en las tareas de Alargar (sección 2.5) y de Acortar (sección 3.5) vimos que el prefijo IN- fue el morfema derivativo que más dificultades presentó a la hora de ser utilizado para combinar o para ser aislado (y por ende para ser justificado). ¿Qué es lo que hace posible que en una tarea distinta algunos niños prefieran seleccionar IN-como el prefijo negativo? Lo que podemos constatar, por lo pronto, es que para estos niños la forma lexicalizada DESESPERADA resultó opaca en el contexto sintagmático propuesto. La interpretación (curiosa y llamativa) de la ficha DESESPERADA como "situación que sí es esperada" parece ser el resultado de un intento de conciliar las semejanzas (base léxica común) con las diferencias (un prefijo IN-al que puedan atribuirle una interpretación negativa).

Finalmente, veamos qué sucedió con los 4 niños que enunciaron igualdad de significado. Se trata de una pareja de $2^{\circ}$ y una pareja de $4^{\circ}$. Veamos el intercambio de Gonzalo y Josefina ( $2^{\circ}$ grado):

Ent.: es lo mismo con inesperada y con desesperada?

Gonzalo: me parece que sí

Josefina: es como si una madre estuviera desesperada

Gonzalo: porque perdió a su hijo

Josefina: tal vez

Ent.: inesperada también? [señalando INESPERADA]

Josefina: sí / puede ser

Ent.: es lo mismo si yo uso esta o esta? [señalando INESPERADA y DESESPERADA]

Josefina: es lo mismo / no son iguales pero vale lo mismo 
Lo que parece primar en los niños es la semejanza de significado negativo de ambos prefijos. Sin embargo, aunque los niños pueden centrarse en las similitudes semánticas (no son iguales pero vale lo mismo) no parece ser un caso de aceptación de sinonimia. La pareja de $4^{\circ}$ grado es aún más explícita: Pablo dice in y des son lo mismo. En todo caso, no parece tratarse de interpretaciones de sinonimia de base léxica común y morfemas diferentes como en los ejemplos analizados para los sufijos aumentativos -ON y -OTE (sección 5.3).

En general, las interpretaciones de los niños (con una franca primacía de "diferencia de significado") parecen indicar que en esta tarea las fichas INESPERADA y DESESPERADA fueron tratadas como palabras completas y familiares, aunque con un significado muy diferente.

\subsection{Observaciones finales sobre la tarea de Contrastar}

A modo de síntesis el análisis de las justificaciones de los niños en la tarea de Contrastar, podemos decir que:

- El caso de los sufijos -ON y -OTE, que pueden ser interpretados como aumentativos, permitió dar cuenta de los desafíos que enfrentan los niños para aceptar que las modificaciones formales en las series no supongan como correlato un cambio en el plano del significado. Las justificaciones centradas en elaborar una gradación dentro de la dimensión aumentativa o el agregado de una interpretación apreciativa a una de las formas aparecieron como soluciones previas a la aceptación de la sinonimia.

- En la justificación del contraste entre los morfemas denominales -ERO e -ISTA los niños recuperaron las interpretaciones adecuadas y también las interpretaciones inesperadas que habían elaborado previamente en la tarea de Alargar (sección 2.5). Resultó llamativa la modificación de contrastes adecuados previos que hicieron algunos niños de $4^{\circ}$ y de $6^{\circ}$ grado. En estos 
casos, el contexto sintagmático mínimo propuesto en la tarea de Contrastar parece generar dudas y sugerir la selección de la palabra FUTBOLISTA como la adecuada para completar el sintagma.

- Finalmente, el par de palabras con prefijos negativos contrastantes no generó problemas para que los niños puedan interpretarlos como dos palabras con significados diferentes. Las justificaciones de los niños parecen indicar que las fichas INESPERADA y DESESPERADA fueron tratadas como formas completas y familiares para los niños. 


\section{Conclusiones}

\subsection{Recapitulación de aportes destacados del análisis de las tareas}

Al inicio de este trabajo de investigación nos proponíamos conocer cómo niños que están en escolaridad primaria reflexionan sobre algunos morfemas derivativos del español, particularmente qué hipótesis pueden elaborar acerca de cómo una palabra puede incorporar varios significados en distintos segmentos. Para favorecer la reflexión metalingüística $-y$ porque nos interesa la relación entre esta reflexión y los procesos de lectura- elaboramos una serie de tareas con material escrito. Estas tareas presentaban problemas para que los niños focalizaran aspectos formales de la lengua española: los procesos morfológicos de derivación. La metodología de entrevista flexible utilizada nos permitió dar cuenta de las acciones (alargar, acortar y contrastar) que los niños realizaron con el material lingüístico que les presentábamos, así como también de las justificaciones verbales que los niños elaboraron en sus respuestas. ¿Qué hipótesis elaboraron los niños sobre la estructura de las palabras presentadas y los significados asociados a sus segmentos? Lo primero que podemos sostener es que la posibilidad de aislar los morfemas derivativos y de dar cuenta de su significado dependió de las tareas diseñadas, de los morfemas objeto en particular y también de las distintas bases léxicas en las que se presentaban estos morfemas. Comencemos por sintetizar los aportes principales de los capítulos que analizan las tareas de nuestro diseño.

La tarea de Alargar (capítulo 2) iniciaba con una consigna en la que todos los niños interrogados no mostraron dificultades para distinguir entre el material propuesto aquellos segmentos que eran palabras (formas autónomas con significado pleno) de aquellas que no lo eran porque constituyen de hecho morfemas derivativos (formas ligadas y sin significado pleno). Se trata de una constatación inicial interesante que retomaremos más adelante: todos los niños entrevistados reconocieron que los morfemas derivativos presentados no son palabras. El análisis del desempeño posterior de los niños 
en esta tarea nos permitió agruparlos en tres niveles teniendo en cuenta criterios cuantitativos (cantidad de combinaciones, selección y posición de los morfemas utilizados) y cualitativos (justificación e interpretación de las combinaciones, de los segmentos que las componían y de sus relaciones). Con respecto al eje cuantitativo, además de un incremento progresivo en la cantidad de combinaciones que los niños realizaban de un nivel a otro, también pudimos constatar una pauta en la selección y posición de los morfemas en las combinaciones: inicialmente los niños utilizaron casi exclusivamente sufijos, luego alternaron sufijos o prefijos en las bases, y solamente en el nivel más avanzado pudieron realizar combinaciones simultáneas con un prefijo y un sufijo sobre la misma base léxica. Por su parte, también en las justificaciones de los niños encontramos una progresión que inicia con la elaboración de ejemplos de uso comunicativo, es decir, intentos de interpretar el significado del morfema pero como un segmento no aislable de la palabra gráfica. Un avance en términos de la interpretación de segmentos con distintos significados dentro de una palabra lo constituyen las justificaciones de amalgama, en estas los niños "leen" dentro de la palabra gráfica dos segmentos con significado pleno (COMUNICABLE como comunicación por cable); es un avance en tanto que los niños buscan más de un significado al agregar un segmento gráfico a la base léxica. Las paráfrasis constituyen el siguiente paso, ya que en estos casos los niños elaboran justificaciones que dan cuenta de cómo los morfemas modifican a las bases: DESARMABLE es que se puede desarmar. Al final de esta línea de progresión ubicamos los intentos por explicar el significado de los morfemas derivativos aislados. Sin embargo, consideramos fundamental preguntarnos si se trata de niños que están aceptando que un morfema aislado tenga significado en sí mismo. Gerardo, niño de $6^{\circ}$ ubicado en el nivel más avanzado en esta tarea, nos ayuda a entender este problema: me parece que / este conjunto de letras [refiriéndose a SUB-] más que tener un significado le cambia el significado a las palabras.

El otro aspecto por destacar en la tarea de Alargar es que no todos los morfemas derivativos objeto parecen estar disponibles de la misma manera para los niños. Los sufijos denominales -ERO, -ISTA y -DOR se encuentran entre los más utilizados en las combinaciones, pero no recibieron justificaciones que intentaran explicar su significado 
cuando están aislados. Son interesantes las palabras de Pablo, niño de $4^{\circ}$ grado y del nivel más avanzado en la tarea, quien al ser consultado por el significado de -ERO sostiene que significa un montón de cosas porque acá es que vende [RELOJERO] acá es que juega al fútbol [FUTBOlERO] y acá es que navega [MARINERO] / el significado depende de la raíz. Por otro lado, el sufijo -ON no tuvo una frecuencia alta de utilización (ya que en nuestro diseño tenía un número muy limitado de bases léxicas con las que podía combinarse), sin embargo, niños de los tres niveles elaboraron justificaciones aumentativas sin ninguna dificultad. Por último, el prefijo negativo IN- se mostró particularmente opaco para los niños y apenas fue utilizado en algunas combinaciones por niños del nivel más avanzado (hecho que también es reportado, a nivel oral y con niños de 4 y 5 años, por Rodríguez Cuevas, 2018).

En la tarea de Acortar (capítulo 3) propusimos a los niños palabras escritas y tijeras con una consigna que los invitaba a realizar un corte y producir al menos dos segmentos menores con significados relacionados. El análisis del desempeño de los niños en esta tarea nos permitió agruparlos en tres niveles que dan cuenta de un incremento progresivo en la cantidad de cortes realizados, pero fundamentalmente, muestran un avance en la posibilidad de realizar cortes simultáneos de prefijo y sufijo sobre una misma base léxica. El análisis de las justificaciones, por su parte, nos permitió focalizarnos en las centraciones que orientaron los cortes. Inicialmente, los niños realizan cortes centrándose en un segmento menor de significado pleno dentro de la palabra escrita propuesta, es decir, en sus justificaciones se centran excluyentemente en bases léxicas menores que pueden ejemplificar y lo que queda como resultado del corte es una especie de resto gráfico del que no pueden dar cuenta. Un avance en las centraciones que orientan los cortes lo encontramos en aquellos niños que logran centrarse alternadamente en el segmento que cortan (bases léxicas que pueden justificar) y en ese mismo segmento unido a lo que quedó del corte (que es una base léxica derivada de la anterior y que también pueden justificar). Se trata de justificaciones que parafrasean las modificaciones semánticas de los morfemas derivativos a las bases. Por último, solamente en el nivel más avanzado los niños pueden centrarse coordinadamente en todos los segmentos resultantes de sus 
cortes, en sus significados cuando están aislados y en las relaciones semánticas que mantienen entre ellos.

De forma similar a algunas de las investigaciones reportadas en el capítulo 1 (Nagy, Diakidoy y Anderson, 1991; Zhang, 2014), en nuestro diseño incluimos ítems problematizadores para la tarea de Acortar que consistían en fichas que compartían letras pero no morfemas. La restricción de la consigna que los cortes tengan que ver con la palabra antes de ser cortada pareció funcionar como un condicionante para que los niños buscaran efectivamente formas vinculadas morfológicamente antes y después de cortar. A nivel metodológico, esta explicitación en la consigna parece contribuir a resolver la dificultad registrada por Velázquez (2017) quien presentó también a niños de escolaridad primaria una tarea de Acortar con ítems problematizadores que recibieron muchos cortes de formas plenas pero no relacionadas formal ni semánticamente con las palabras antes de ser cortadas $(2017: 127)^{41}$. La abstención generalizada de hacer cortes en fichas que no incluían morfemas derivativos también se diferencia de los resultados reportados por Nagy, Diakidoy y Anderson (1991) en una tarea similar, en la que a partir de pedir a niños de escolaridad primaria que encerraran en un círculo las raíces dentro de palabras escritas, encontraron una mayoría de casos en los que los niños encerraron segmentos que coincidían con otras palabras gráficas pero que no estaban relacionados morfológicamente. Más allá de estas diferencias resultativas, consideramos que lo más interesante es el análisis de los argumentos que orientan la decisión de abstenerse de realizar cortes, ya que también dan cuenta de una progresión. En un momento inicial, los niños no cortan porque no encuentran nada para cortar, es decir no encuentran una forma de significado pleno menor dentro de la ficha propuesta. Un avance en las argumentaciones lo encontramos en aquellos niños que recurren a justificaciones centradas en el aspecto semántico de los segmentos (no es posible cortar porque los segmentos resultantes del corte no tiene significado) o a criterios gráficos (no es posible

\footnotetext{
${ }^{41}$ En las "Conclusiones" de su trabajo Alejandro Velázquez reporta lo siguiente sobre la tarea de Acortar: "Queda como un aspecto a reflexionar los posibles ajustes a la consigna que hubieran permitido también focalizar los afijos y no solo las bases. Nos preguntamos aun sobre la importancia o no de hacer explícito en la consigna la relación formal-semántica que esperamos entre el resultado y la forma dada, esto es, incluir en la consigna que el resultado tenga que ver con el significado de la palabra gráfica original" (2017:130).
} 
cortar porque uno de los segmentos resultantes obtendría un final gráfico imposible en nuestra lengua). Por último, las justificaciones más avanzadas que registramos son aquellas centradas en la distinción entre palabras completas y palabras que tienen prefijos o sufijos, lo que sugiere que se trata de niños que distinguen entre segmentos de letras que son iguales pero solo en algunos casos son morfemas derivativos.

Los morfemas derivativos utilizados en la tarea de Acortar no presentaron la misma disponibilidad para ser aislados y justificados. En este sentido, también las bases léxicas utilizadas plantearon situaciones diversas. El sufijo aumentativo -ON, por ejemplo, fue aislado y justificado adecuadamente por niños de los tres niveles. Sin embargo, la palabra PAPELON nOS permitió explorar una situación problematizadora al posibilitar un contraste entre una derivación aumentativa (PAPELON como papel grande) y una forma plena lexicalizada (PAPELON como situación embarazosa o vergonzante). En palabras de Paula (niña de $4^{\circ}$ grado y del nivel más avanzado en esta tarea), la situación depende de cómo es la raíz: si PAPELON es un papel muy grande -ON sería un sufijo, mientras que si PAPELON significa que te portaste mal entonces sería una palabra completa.

Otra situación interesante se dio con el prefijo negativo IN-, que en la tarea de Alargar se había presentado como el más opaco para ser utilizado y justificado en combinaciones con las bases léxicas disponibles (sección 2.5). En la tarea de Acortar, en cambio, la presencia de IN- en palabras gráficas que también incluían el sufijo -BLE (INOLVIDABLE e INSOPORTABLE) pareció facilitar a los niños del nivel más avanzado la acción de aislar y justificar el significado negativo que aporta el prefijo. Una posible interpretación para esta diferencia en los datos obtenidos, es que la presencia del sufijo "refuerce" la negación del prefijo, es decir, si IN- puede ser parafraseado por no la presencia simultánea de -BLE podría sugerir la interpretación todavía no. Se trata de una doble modulación negativa que estaría colaborando para alcanzar la interpretación adecuada de un prefijo como IN-que en otros contextos resultó francamente opaco (sección 2.5).

El análisis integrado del desempeño de los niños en estas dos tareas de Alargar y Acortar (capítulo 4), tareas que compartían morfemas derivativos-objeto, nos permitió elaborar una pauta evolutiva que da cuenta del proceso de reflexión metalingüística 
considerando las acciones que realizaron los niños (combinar y aislar) con los morfemas derivativos y las bases léxicas, las centraciones cognitivas que orientaron esas acciones y las justificaciones que elaboraron para interpretar sus producciones. En este proceso distinguimos:

- Un momento inicial en el que los niños actúan casi exclusivamente a la derecha de las bases léxicas, es decir, combinando o aislando solamente sufijos. Algunas investigaciones han indicado una anterioridad evolutiva de los sufijos sobre los prefijos (Fezjo, 2016). Nuestra interpretación, considerando las tareas propuestas, es que en la situación de combinar los niños parten de una base léxica conocida y a partir de esta tratan de pasar a otra base léxica también conocida pero de mayor extensión (a partir de FUTBOl llegar a FUTBOLISTA), mientras que en la situación de aislar segmentos los niños parten de una base léxica conocida y a partir de esta aíslan un segmento menor que también es una base léxica conocida (partir de DESPEGABLE para aislar DESPEGA). ¿Qué elementos nos llevan a proponer esta interpretación? En primer lugar, las justificaciones de los niños en este momento son mayormente ejemplos de uso comunicativo que dan cuenta de la interpretación de las series como un todo, es decir, los niños justifican por un lado FUTBOL y luego, por otro, lado FUTBOLISTA. Se trata de centraciones exclusivas en series con significado pleno que pueden o no incluir un morfema derivativo. Estas justificaciones nos indican que los niños parecen aceptar sin dificultades que si se agrega un segmento gráfico que no es palabra (los morfemas derivativos) a otro que sí es palabra (las bases léxicas) algo en el orden del significado se modifica. Desde este momento inicial, entonces, el agregado gráfico tiene como correlato un cambio semántico. Sin embargo, lo que parece no ser todavía observable es la relación derivativa que supone el agregado del morfema. Esto nos lleva al segundo indicador que encontramos para plantear que los niños en este nivel orientan sus acciones centrados en bases léxicas conocidas: sabemos que los niños no presentaron ninguna dificultad para distinguir segmentos que son palabras de aquellos que no lo son, pero entonces, ¿qué son estos segmentos que no son 
palabras en este momento inicial? Las respuestas de los niños sugieren que se trata de una especie de "resto gráfico" (en este nivel los niños utilizan términos como letra o sílaba para referirse a los morfemas), es decir, segmentos que no tienen significado en sí mismos y que no pueden estar aislados. ¿Se trata solamente de segmentos que sirven para completar palabras? La respuesta de Josefina ( $2^{\circ}$ grado) es reveladora al respecto: consultada por el significado de los morfemas derivativos cuando están aislados la niña dice es como si estas fueran unas vocales de estas palabras / como si esa fuera una letra que faltaba en las otras palabras.

- En un segundo momento, los niños pueden actuar alternadamente a ambos lados de las bases léxicas, combinando o aislando tanto sufijos como prefijos. Un indicador de avance respecto del momento inicial son las justificaciones de amalgama, es decir, intentos de interpretar dentro de una serie completa dos segmentos con significado pleno: Emiliano $\left(2^{\circ}\right)$ justifica FUTBOLISTA como un jugador más listo y más goleador / es como listo en el fútbol (sección 2.5). Decimos que es un momento de transición ya que los niños no solamente aceptan que si se agrega un segmento (un morfema derivativo) a una base léxica conocida entonces el significado de la forma resultante cambia, sino que ahora además buscan segmentos con sus respectivos significados asociados. Esta búsqueda de más de un segmento dentro de una palabra derivada está relacionada con la aparición de centraciones alternadas: los niños al justificar se pueden centrar en el significado de las bases léxicas sin los morfemas derivativos y por otro lado también pueden centrarse alternadamente en el significado de esas bases léxicas más un morfema derivativo. El avance lo constituyen las justificaciones de paráfrasis que intentan dar cuenta de la relación derivativa ejemplificando la forma en que los morfemas modifican el significado de las bases. ¿Qué son en este segundo momento esas "partecitas" con las que están trabajando en las tareas? En este nivel ya no encontramos términos que se refieran a los morfemas como "partes de la palabra" (letra o sílaba). Luna $\left(4^{\circ}\right)$, consultada sobre el significado de un morfema aislado, 
dice en realidad no es palabra / es como que vos las ponés con las palabras y como que háces una palabra. Ya no se trata solamente de partes indispensables para completar una palabra, lo que los niños parecen sugerir en este momento es que esos segmentos que no son palabras sirven para hacer otras palabras y que para justificarlos se puede parafrasear cómo esos segmentos modifican el significado de las palabras.

- En el momento final de esta pauta evolutiva, los niños pueden actuar simultáneamente a ambos lados de las bases léxicas. A los intentos de paráfrasis del significado que agregan los morfemas, en las justificaciones de este nivel encontramos una generalización de los intentos de explicar el significado de los morfemas cuando están aislados. Néstor $\left(6^{\circ}\right)$, por ejemplo, sostuvo que sub significa abajo, des es el negativo, ble significa que se podía hacer y on lo hace más grande. ¿Se trata entonces de que los niños asignan un significado a los morfemas derivativos de la misma forma que lo hacen con los segmentos que reconocen como palabras? La respuesta a esta pregunta parece ser negativa. En este momento los niños distinguen dos tipos de segmentos: palabras con significado pleno y autonomía gráfica, frente a prefijos y sufijos (que también designan con términos no adecuados como preposición, conector o artículo pero que sugieren una referencia a un tipo distinto de segmento y ya no a una "parte" de un segmento) que modifican el significado de las palabras pero que, como nos dice Néstor $\left(6^{\circ}\right)$, tienen que ir sí o sí con una palabra / no pueden ir separados.

Aun restringiéndose al conjunto limitado de combinaciones de morfemas derivativos y bases léxicas utilizadas en nuestro diseño, se trata de una pauta evolutiva provisoria que da cuenta de los desafíos cognitivos que los niños enfrentaron para elaborar hipótesis sobre los segmentos que componen las palabras gráficas propuestas y los significados asociados a ellos.

Por último, en la tarea de Contrastar (capítulo 5) propusimos a los niños pares de palabras con bases léxicas coincidentes y morfemas derivativos contrastantes, que a su 
vez podían ocupar la misma posición en un sintagma nominal. Incluimos morfemas derivativos que ya habían sido presentados a los niños en las tareas anteriores, aunque en el caso de esta última tarea forman parte de un contexto sintagmático mínimo. El caso de los sufijos -ON y -OTE planteó un problema interesante ya que ambos pueden ser interpretados como aumentativos. Esta situación entra en conflicto con el supuesto de que una modificación formal en la palabra tiene como correlato una modificación en el plano del significado, algo que también fue reportado por Velázquez (2017) ${ }^{42}$. Algunos niños ensayaron intentos de diferenciación estableciendo una gradación dentro de la dimensión aumentativa (ambos son aumentativos, pero uno es más grande que el otro) o agregando a uno de los sufijos una interpretación apreciativa. Solamente entre los niños más grandes encontramos algunos intentos de coordinación de semejanzas y diferencias que sugieren la aceptación de la sinonimia: Darío $\left(4^{\circ}\right)$ sostiene que GRANDULON y GRANDULOTE significan lo mismo / son sinónimos / pero lo único que cambia es la palabra. En el par de sufijos denominales -ERO/-ISTA los niños recuperaron los contrastes que habían elaborado en la tarea de Alargar (sección 2.5) ya que se trataba de las mismas palabras: FUTBOLERO y FUTBOLISTA. Sin embargo, encontramos como dato llamativo que varios niños de $4^{\circ}$ y $6^{\circ}$ modificaron los contrastes adecuados que ya habían elaborado (FUTBOlERo como "aficionado al fútbol" y FUTBOLISTA como "jugador de fútbol") para sostener -con ciertas dudas y oscilaciones- que en el caso del contexto sintagmático propuesto ambas series podían significar lo mismo. Una explicación posible es que el modificador DE PRIMERA DIVISIÓN parece seleccionar la palabra FUTBOLISTA, lo que llevó a los niños a igualar el significado de la otra palabra o, en algunos casos, a rechazarla por incorrecta. Finalmente, en el par de palabras que incluía los prefijos negativos DES- e INconstatamos que los niños no encontraron mayores dificultades para justificar el significado negativo del prefijo en la palabra INESPERADA, a diferencia de lo que había sucedido en tareas anteriores en las que $\mathrm{IN}$ - se presentaba como un morfema poco disponible para ser utilizado y justificado. En todos los pares contrastantes de la tarea, los niños enfrentaron el problema de coordinar semejanzas (las bases léxicas y también los

42 "Los niños tienden a identificar diferencia gráfica con diferencia de significado; en consecuencia, la sinonimia aparece de modo tardío" (Velázquez, 2017:182). 
morfemas derivativos con significados próximos como los aumentativos -ON y -OTE) y diferencias (los morfemas derivativos y también las diferencias gráficas entre morfemas que pueden admitir significados próximos), tanto semántica como formalmente.

\subsection{Aportes específicos sobre el proceso de reflexión metalingüística en torno a morfemas derivativos del español}

Uno de los propósitos principales de nuestra investigación tiene que ver con buscar la superación de la noción de estados de conciencia (tener conciencia metalingüística/no tener conciencia metalingüística) imperante en las investigaciones experimentalistas de la morphological awareness. En este sentido, una de las características metodológicas distintivas de nuestro trabajo es tratar de entender tanto las acciones como las interpretaciones de los niños. Si bien nuestra investigación puede ser considerada un aporte incipiente a un eventual enfoque procesual de la reflexión metalingüística sobre los morfemas derivativos del español, consideramos que el cuestionamiento a la concepción de la toma de conciencia como un "mecanismo linterna" (sección 1.1) está íntimamente ligado al problema de la homogeneización y de la preexistencia de los morfemas en tanto unidades sobre la que los sujetos en desarrollo pueden reflexionar.

En el capítulo 4 esbozamos una jerarquización evolutiva de los morfemas objeto de nuestro diseño (sección 4.3), atendiendo especialmente al grado de complejidad que plantearon al ser utilizados e interpretados por los niños. En todas las tareas de nuestra investigación pudimos constatar que, más allá de las restricciones lingüísticas de las bases léxicas seleccionadas, los morfemas derivativos no parecen estar disponibles de la misma manera para los niños. El sufijo $-\mathrm{ON}$, por caso, ha sido reportado como un morfema utilizado a nivel oral por niños ya desde los 4 años (Pérez Pereira y Singer, 1984; Rodríguez Cuevas, 2018), y en los niños de escolaridad primaria que entrevistamos no encontramos mayores dificultades para que sea interpretado como aumentativo y, eventualmente, como apreciativo. Sin embargo, otros morfemas como -BLE, -DOR o -ISTA, aun cuando 
fueron utilizados y aislados por los niños en las tareas, se presentaron francamente opacos a la hora de ser interpretados. El punto máximo que los niños parecen alcanzar en sus interpretaciones es parafrasear con un ejemplo cómo el morfema modifica el significado de la base: ARMADOR es una persona que arma algo o INOLVIDABLE es que no se puede olvidar. Surge entonces una pregunta fundamental: ¿es aislable el significado de los morfemas ligados? En el caso del sufijo aumentativo -ON algunos niños dieron buenas justificaciones: on para mí es como que lo agranda a la palabra / o sea lo que estás diciendo como que lo agranda (Luana $-6^{\circ}$ ). Sin embargo, no encontramos ninguna justificación similar para un sufijo como -BLE o como -DOR. Podríamos preguntarnos qué diría un adulto -no lingüista- sobre un segmento como -BLE que agrega a las bases verbales la idea de potencialidad y pasividad, es decir indica que la acción se puede hacer sin afirmar ni negar que tal acción será llevada a cabo. O cómo explicaría un adulto -no lingüista- un morfema como -DOR que genera un cambio categorial al nominalizar bases verbales. Una situación parecida es reportada recientemente por Velázquez (2017) quien da cuenta de las dificultades que encuentran los niños para justificar morfemas flexivos aislados, es decir, separados de las palabras gráficas. ¿Qué son, entonces, los morfemas derivativos para los niños? Todos estos interrogantes nos instalan en una problemática psicolingüística fundamental: ¿qué relación hay entre las unidades teóricas definidas por la lingüística y las intuiciones de los hablantes en desarrollo?

El morfema es, ante todo, una unidad teórica elaborada por la lingüística, unidad mucho más potente y sistemática que la noción de palabra, y equivalente en cierta manera a lo que es el fonema para el tratamiento de la oralidad (Anderson, 1995; Kerleroux, 2006). Pero, ¿se trata de una unidad "natural" para los hablantes? Podríamos pensar en compararla con la sílaba, unidad cuyo papel en el proceso de aprendizaje conocemos bastante bien (Ferreiro, 2000 y 2002; Ferreiro y Zamudio, 2008). Sujetos adultos que no saben leer y escribir o niños que están en proceso de aprender a hacerlo no necesitan entrenamiento específico para segmentar en sílabas el habla (Morais, Alegría y Content 1987, Vernon y Ferreiro, 1999). Esta concepción pre-gráfica de la sílaba se va a ir modificando con el aprendizaje de la escritura alfabética de la lengua y esa unidad 
silábica construida previamente para equiparar elementos segmentables en el habla se va a reconvertir en una unidad más heterogénea y de extensión variable, apoyada ahora no en propiedades fónicas sino en su realización gráfica (Ferreiro, 2006). El morfema, por su parte, parece ser una unidad práctica para los niños desde muy pequeños, presente en las situaciones de "sobrerregularización" o "construcción por analogía" (Ervin, 1964; Miler y Ervin, 1964; Nunes y Bryant, 2006; Pérez Pereira y Singer, 1984), así como también en las situaciones esporádicas de reflexión epilingüísticas (Gombert, 1990). En la escritura, sin embargo, el morfema no presenta pistas gráficas que ayuden a reconocerlo. Como en los casos de morfemas derivativos objeto de nuestro diseño, los morfemas tienen una extensión gráfica variable (desde algunos unigráficos como $-s$ de plural hasta otros de seis letras como -miento), su composición silábica y acentual es variable, posicionalmente pueden anteceder o suceder a las bases a las que se adjuntan, algunos además coinciden con formas libres y plenas de la lengua (el prefijo reflexivo auto- o el sufijo adverbializador -mente), en algunos casos pierden o modifican su composición por restricciones gráficas (el prefijo in- en palabras como impensable o irrealizable) y en muchos casos quedan como rastros gráficos en formas que se han lexicalizado y han perdido su valor inicial (re- en recordar o des- en desesperada).

En nuestra investigación, constatamos que los niños no encuentran dificultades en distinguir los morfemas como segmentos que no son palabras. Sin embargo, las justificaciones registradas no sugieren que los niños están pensando los morfemas como "unidades mínimas de significado", tal como los define la lingüística. Las justificaciones parecen indicar que los niños conciben a los morfemas derivativos como "modificadores del significado de las palabras" más que como unidades mínimas de significado. Retomemos dos ejemplos por demás significativos: Paula ( $4^{\circ}$ grado) sostuvo que los morfemas significan palabras pero no son en sí palabras, y Gerardo, todavía más explícitamente, que los morfemas más que tener un significado le cambian el significado a las palabras. En todo caso, la definición teórica de los lingüistas puede ser tomada como un punto de referencia para la investigación psicolingüística, pero no puede ser el criterio 
exclusivo para afirmar que algunos niños logran aislar y explicar el significado de esos segmentos mínimos.

Dos señalamientos más nos parecen necesarios sobre el problema de la reflexión metalingüística sobre los morfemas. En primer lugar, gran parte de las investigaciones que tratan sobre la "conciencia morfológica" de los niños (sección 1.3) no incluyen reflexiones teóricas sobre las consecuencias del proceso histórico de constitución de la lengua escrita a la hora de elaborar distinciones como "morfema libre" / "morfema ligado" (Saenger, 1997). Como en el caso de la unidad "palabra", el morfema también mantiene una relación ambigua con la escritura que prácticamente no es tematizada ni en las investigaciones psicolingüísticas ni en las propiamente lingüísticas. En segundo lugar, consideramos necesario reflexionar en torno a las consecuencias del aprendizaje de la lengua escrita. El niño, como sujeto en desarrollo, aprende la lengua oral como instrumento de comunicación y luego mientras aprende a leer y a escribir se produce una reconversión de la lengua en objeto de reflexión. Como sostiene Ferreiro, este proceso:

"Supone el aislamiento de ciertas emisiones que, por el mismo hecho, son sacadas del uso inmediato y se convierten en objetos opacos sobre los cuales nuevas actividades intelectuales son posibles. Esos fragmentos de emisiones pueden convertirse en observables. Pero la conversión de algo externo en un observable para el sujeto supone cierto nivel de conceptualización. Además de ser objetos de acción, esos fragmentos de emisiones se transforman en objetos de análisis sobre los cuales es posible establecer comparaciones, es decir, determinar semejanzas y diferencias que conducirán a nuevas categorizaciones (2002:167)".

En la literatura experimentalista reseñada (sección 1.3) la cuestión de fondo acerca de cómo dar cuenta de la "toma de conciencia de los morfemas derivativos" por parte de los niños aparece vinculada a la "conciencia" que los niños tengan de los morfemas en la lengua oral, la exposición a la escritura o incluso a que aún antes de aprender a leer y a escribir los niños ya hayan elaborado la hipótesis de que la lengua escrita representa las unidades de la oral, entre ellas el morfema (Deacon y Bryant, 2005). Lo que subyace en estos planteos es la postulación del morfema como una unidad preexistente en la lengua 
oral, por eso la "toma de conciencia" de estas unidades es una cuestión de "alumbramiento" de esas unidades (es decir, que ya "están" en el sujeto, pero que todavía no son conscientes). En algunos estudios de morphological awareness la circularidad de los argumentos causales entre la llamada "conciencia morfológica" y el aprendizaje de la lectura es apenas moderada: explicitar el conocimiento morfológico es necesario para aprender a leer, y aprender a leer tiene un fuerte impacto en la explicitación del conocimiento morfológico (Fejzo, 2017; Nunes y Bryant, 2006) ${ }^{43}$.

En todo caso, podríamos plantear el problema, siguiendo a Ferreiro (1999), en términos "de sistemas jerárquicos que se constituyen sobre la base de otros, en donde las unidades de un nivel no se transforman necesariamente en las unidades del otro nivel" sino que de hecho "las unidades se redefinen en cada nivel" (1999a:70). El análisis de las justificaciones que los niños elaboraron sobre los morfemas parece indicar que el significado de los morfemas ligados no siempre es aislable. Queda pendiente seguir comprendiendo cómo el morfema, en tanto unidad práctica que los niños utilizan al aprender al hablar, se reconvierte durante el aprendizaje de la lengua escrita en una unidad de análisis de la palabra.

\subsection{Consecuencias metodológicas del diseño utilizado para la investigación}

\section{psicolingüística}

Una de las objeciones que puede recibir nuestra investigación frente a las de la literatura experimentalista tiene que ver con el problema de la objetividad. En nuestro diseño planteamos tareas a los niños y registramos sus respuestas, pero además iniciamos

\footnotetext{
43 Nunes y Bryant se refieren a esta postura como "two-way street" y sostienen que: “[...] children's knowledge about morphemes must be a powerful and necessary resource in learning to read and write. Morphological knowledge, according to this view, should have a strong effect on children's reading and spelling. Now we should also consider the possibility that cause and effect might take the opposite direction as well. Learning to read and write might alert children to morphemic distinctions that had escaped them before: Their experiences with written language also cause a change in their explicit awareness of morphemes" (Nunes y Bryant, 2006:24).
} 
con ellos un intercambio en el cual realizamos intervenciones específicas para conocer las justificaciones que ellos dan a sus acciones. Esto, sin lugar a dudas, complejiza la tarea y el tratamiento de los datos ya que no basta con contabilizarlos o calificarlos, sino que enfrentamos además la tarea de integrarlos y de interpretarlos cualitativamente. Nos apoyamos, en este sentido, en las investigaciones psicogenéticas previas sobre la adquisición del lenguaje que han insistido en recuperar el postulado piagetiano de que la objetividad no es un punto de partida sino un punto de llegada (Ferreiro, 1999a). Veamos a continuación cuáles pueden ser las ventajas metodológicas de una investigación como la presentada en esta tesis.

En primer lugar, destacamos el papel que jugó en el diseño el hecho de solicitar justificaciones a los niños sobre sus respuestas. Por una parte, esto nos permitió adentrarnos en las razones infantiles para aquellos casos que de otra manera hubiesen ido a parar a un conjunto de "respuestas incorrectas" que igualaba lo que podría ser diverso. Entre las interpretaciones no esperadas encontramos justificaciones que exploran matices sutiles para algunos morfemas derivativos (las diversas interpretaciones del contraste entre FUTBOLERO y FUTBOLISTA en la tarea de Alargar, sección 2.5). Por otra parte, también en el caso de las interpretaciones esperadas los intercambios posteriores a las tareas nos permitieron conocer las justificaciones y los argumentos que orientaron las acciones de los niños. Esto posibilitó, por ejemplo, conocer que los niños decidían no cortar las fichas problematizadoras en la tarea de Alargar por motivos muy distintos (sección 3.5), o también conocer las distinciones sutiles que los niños exploraron en el significado que agregan morfemas derivativos como -ON O SUB- con determinadas bases léxicas (ejemplos de CUENTON y SUBMARINO, sección 2.5). Nada de esto hubiese sido posible si nos hubiésemos limitado a registrar solamente las respuestas de los niños frente al material que les presentábamos en las distintas tareas. Es más, aun en investigaciones que no son psicolingüísticas ni evolutivas, sino que abordan problemáticas morfológicas desde una mirada lingüística, se indica que es probable que la mayor parte de los hablantes adultos (incluyendo hablantes alfabetizados) no puedan dar cuenta (no sean "conscientes") del significado que aportan los morfemas a las palabras (Zacarías, 2010). ¿Cómo dar cuenta 
entonces del conocimiento de los niños sobre los morfemas? Hemos reseñado que en algunas investigaciones de morphological awareness no solamente se califican las respuestas a partir de la dicotomía correcto/incorrecto, sino que a veces esa misma dicotomía no se construye sobre la base de la respuesta esperada sino sobre el tiempo que tarda un niño en elaborar la respuesta, es decir, no reciben puntuación aun cuando la repuesta sea correcta (Carlisle, 2000; Colé y otros, 2012). Asumiendo la dificultad posterior para la integración y el análisis de los datos, la metodología flexible utilizada en nuestras entrevistas permitió a los niños enfrentar los desafíos cognitivos implicados en las tareas y a nosotros, como investigadores, conocer mejor las justificaciones que los niños dan a sus respuestas ${ }^{44}$.

En segundo lugar, otra variable destacable de nuestro diseño fue la utilización de parejas de niños en las entrevistas. Como mencionamos en la introducción (sección 1.4), en trabajos de investigación anteriores (Dávalos, 2016; Kriscautzky, 2014; Möller, 2010; Velázquez, 2017) se pudo constatar que la participación simultánea de dos niños en la resolución de una misma tarea permite en principio que aparezcan respuestas diversas, lo que constituye en sí mismo un estímulo para la explicitación de las razones y los argumentos que orientan las posturas de los niños. Delia Lerner sostiene que:

"Al compartir la elaboración con otros sujetos, se producen conflictos sociocognitivos, conflictos que ya no son sólo intraindividuales [...] sino que se plantean entre sujetos diferentes que han realizado centraciones o acciones opuestas, que tienen puntos de vista contradictorios sobre el tema en cuestión" (2008:86).

Este valor destacado en la construcción del conocimiento por parte de los sujetos puede ser incluido como parte estructurante del diseño de investigación ya que colabora directamente con la intención de conocer las justificaciones que los niños dan a sus

\footnotetext{
${ }^{44}$ Destacamos en este sentido, una investigación reciente de Chen y Myhill (2016) sobre otros aspectos de la reflexión metalingüística que utiliza una metodología de entrevista denominada "metatalk or metalinguistic discussion" y que permite también conocer las justificaciones de los niños sobre las respuestas a determinados problemas gramaticales involucrados en la escritura.
} 
respuestas en un contexto en el que es más "natural" explicarle a un compañero que hacerlo con un adulto ${ }^{45}$.

En tercer lugar, la utilización de palabras aisladas o de palabras en contextos sintagmáticos mínimos no fue un impedimento para que los niños pudieran elaborar interpretaciones sobre los significados asociados a los distintos segmentos de la palabra (Velázquez, 2017). En particular, consideramos interesante enfatizar el contraste con la utilización de pseudo-palabras en las investigaciones experimentalistas reseñadas (que llega al extremo de incluir en algunos casos tareas con pseudo-afijos "derivativos" inventados, ver Colé y otros, 2012). Si el propósito es "controlar" el conocimiento que los niños como hablantes de su lengua pueden tener sobre el significado de las palabras que se utilizan en las tareas, un diseño de entrevista flexible como el que utilizamos permite en principio usar palabras -familiares, frecuentes y conocidas por los niños- y focalizar a los niños en los morfemas durante el intercambio y con intervenciones específicas. Este tipo de decisiones son fundamentales para investigaciones que tomen como objeto de estudio la lengua y las representaciones psicológicas que los sujetos tienen sobre la misma. En este sentido, trabajar con formas reales o propias del uso de la lengua frente a trabajar con formas inventadas (por más plausibles que sean) implica una decisión epistémica sobre lo que es el objeto lengua.

Por último, destacamos la utilización de material escrito en nuestras tareas y la consideración explícita del impacto que este puede tener en las justificaciones que elaboran los niños. La presentación de material escrito sirvió, fundamentalmente, como un apoyo para la reflexión metalingüística, posibilitando así la comparación y el contraste simultáneo de formas que los niños ya conocían y utilizaban en la lengua oral. El papel que la escritura puede jugar en los diseños de investigación continúa siendo un tema apenas tematizado en la literatura sobre morphological awareness reseñada (sección 1.3) aunque,

\footnotetext{
45 En un artículo reciente Kriscautzky y Ferreiro (2018) sostienen al respecto: “Interrogamos parejas niño/niña en lugar de realizar entrevistas individuales por razones metodológicas: cuando surgen discrepancias en la pareja [...] no es necesario que el adulto sugiera otros puntos de vista: los niños presentan espontáneamente argumentos para convencer al compañero. [...] Lograr que los niños dialoguen entre ellos es uno de los propósitos manifiestos del adulto, en lugar de que los niños expliquen al adulto, quien, por definición, 'ya sabe'. El adulto [...] problematiza, pero no califica" (2018:19-20)
} 
de hecho, se "filtra" tanto en los materiales seleccionados como en los análisis y las conclusiones elaboradas (Teberosky, 2002). Si bien nuestro diseño no incluyó tareas de escritura, los niños trabajaron con material escrito leyendo, combinando, acortando y contrastando pares de palabras en sintagmas. La presencia de material escrito es determinante para reflexionar al respecto de la reelaboración de las unidades morfológicas en la unidad palabra porque da estabilidad temporal a lo que, en lo oral, se desvanece después de la enunciación.

\subsection{Posibles extensiones para investigaciones psicolingüísticas dentro del marco epistémico utilizado}

En la presente investigación seleccionamos apenas una decena de morfemas derivativos atendiendo a variables como la frecuencia, la familiaridad, la productividad y la posibilidad de plantear contrastes entre algunos de ellos. Sin embargo, la morfología derivativa del español presenta una lista extensa de morfemas (Velázquez y Ferreiro, 2015) imposible de cubrir en una sola investigación. Por otra parte, también los procesos morfológicos de flexión y composición pueden ser explorados mediante un marco epistémico como el que utilizamos en nuestra tesis.

Una variable sobre la que se puede profundizar es la incidencia de las bases léxicas en la interpretación de los morfemas derivativos. En nuestros datos encontramos repuestas no esperadas cuando una base léxica podía recibir más de una interpretación categorial (los ejemplos de ARMADOR y de SUBOFICIAL en la tarea de Alargar, sección 2.5) así como también morfemas derivativos que con ciertas bases léxicas parecían francamente opacos mientras que con otras bases se tornaban más transparentes para los niños (el prefijo IN- en la tarea de Alargar, sección 2.5, y en la tarea de Contrastar, sección 5.5).

Otra posible extensión del trabajo es la focalización en "esquemas rivales" de formación de palabras (Zacarías, 2016). Los pares potencialmente contrastables que incluimos en nuestro diseño, como -ERO/-ISTA O IN-/DES-, permitieron la elaboración de 
justificaciones muy interesantes por parte de los niños. La construcción de ejes de diferenciación semántica que recurren a otras categorizaciones lexicales de la lengua como las oposiciones singular vs. plural o animado vs. inanimado (ver el ejemplo del contraste entre FUTBOLERO y FUTBOLISTA en la tarea de Alargar, sección 2.5), la interferencia de modalizaciones sobre estados de conocimiento previo en el contraste entre INESPERADA y DESESPERADA (sección 5.4) o el agregado de la dimensión apreciativa para distinguir dos aumentativos como -ON y -OTE (sección 5.3) sugieren que en la consideración de morfemas que rivalizan en la especificación de información léxica aparecen problemas de interpretación que no surgen cuando se consideran las formas por separado.

Otra posible extensión del trabajo tiene que ver con la cuestión de la sinonimia. En la tarea de Contrastar (capítulo 5), encontramos una afirmación generalizada principalmente entre los niños más pequeños: las modificaciones gráficas (formales) de las palabras tienen como correlato una modificación en el significado. La aceptación de la sinonimia se torna entonces muy problemática para estos niños. Datos similares son también reseñados recientemente por Velázquez (2017). El hecho de que los niños mayores aceptaran y justificaran que hay casos en la lengua en que dos formas distintas tienen el mismo significado podría ser una pista interesante para pensar evolutivamente la asimilación de la sinonimia.

Si relacionamos esta idea recurrente de que un cambio de significante implica un cambio de significado, pero atendemos particularmente a la interpretación de las bases léxicas, en nuestra investigación también registramos la situación de niños -incluso entre los más pequeños- que aceptaron que a un significante pueda corresponderle más de un significado (por ejemplo en las justificaciones de las bases léxicas PEGA y ARMA; o en la interpretación lexicalizada de PAPELON en la tarea de Acortar, sección 3.5). Si bien esto no forma parte de la focalización de nuestras intervenciones, en los intercambios registramos estas interpretaciones polisémicas en justificaciones que recurrían a ejemplos de la comunicación cotidiana o a descripciones de contextos pragmáticos que colaboran en la dilucidación del significado. Queda pendiente continuar indagando si la aceptación de la polisemia es evolutivamente temprana. 
Una cuestión más general, que abarca a las presentadas anteriormente, tiene que ver con la utilización de términos metalingüísticos por parte de los niños para "hablar" sobre la lengua. En las entrevistas registradas encontramos ejemplos de utilización de terminología gramatical propiamente escolar a lo largo de todos los grados interrogados. En algunos casos se trataba de términos bien asimilados por los niños, mientras que en otros casos la utilización de esos términos (sílaba, artículo, prefijo, sufijo, conector, familia de palabras), aunque no fuera la convencional, les permitía a los niños la necesaria tarea de ir "nombrando" elementos, unidades o relaciones entre estas, para dar cuenta de los problemas morfológicos que les planteábamos. Se trata de un terreno que aún no ha sido muy explorado.

\subsection{Reflexiones en torno a las implicancias educativas}

Una reflexión inicial para enmarcar las posibles derivaciones didácticas del trabajo presentado tiene que ver con reconsiderar que muchos saberes lingüísticos (como los conocimientos morfológicos indagados en nuestra tesis) no necesitan ser "enseñados", sino explicitados a través de problemas que posibiliten acciones de reflexión metalingüística. En este sentido, se impone la tarea de superar el tradicional "etiquetado" escolar sobre la lengua. Existe un consenso generalizado, aun en propuestas de intervención didáctica inspiradas en investigaciones experimentalistas (Nunes y Bryant, 2006), en la necesidad de que las prácticas de enseñanza incluyan progresivamente procesos de explicitación de los conocimientos morfológicos de la lengua.

Sin embargo, en la elaboración de recomendaciones didácticas para que los maestros o profesores ayuden a sus alumnos a reflexionar sobre aspectos de la lengua que ya saben utilizar en contextos de comunicación, es importante considerar las diversas dificultades que nosotros como investigadores encontramos para elaborar tanto las situaciones como las intervenciones más oportunas que posibilitaran instancias propicias para que los niños "hablen sobre la lengua". Trabajar con palabras aisladas para focalizar 
las unidades morfológicas y los procesos de significación implicados, comparar series de palabras con morfemas comunes para inferir y sistematizar los significados que aportan, contrastar bases léxicas con distintos morfemas, todas pueden ser en principio tareas fructíferas para la explicitación de los saberes metalingüísticos. Consideramos que es ineludible la elaboración de secuencias didácticas experimentales que puedan explorar en el aula las condiciones didácticas que promuevan la reflexión metalingüística y, sobre todo, las intervenciones docentes más adecuadas, ya que los niños necesariamente tienen conocimientos y usos diversos de la lengua fuera de la escuela. Castedo y Torres (2012) afirman que:

"La construcción del conocimiento didáctico deviene de un movimiento dialéctico entre la acción didáctica y la conceptualización de la acción. Muchas veces, los problemas de la acción de enseñanza llevan a buscar respuestas que solo más tarde son conceptualizadas como criterios, situaciones, tipos de intervenciones, etc. Otras, la concepción se origina en problemas de la misma teoría (didáctica o de referencia) y conduce a poner a prueba y reformular constantemente para validar en las aulas la posibilidad de desarrollo de lo que se concibe fuera de ellas" (2012:646).

Reflexionar sobre la lengua en la escuela constituye sin lugar a dudas un eje central en el aprendizaje escolar. Dentro de este marco, nuevas investigaciones didácticas son necesarias para conocer cuáles son las formas de presentación de problemas de reflexión metalingüística sobre los aspectos morfológicos de la lengua y, sobre todo, bajo qué condiciones didácticas es posible favorecer los aprendizajes en grupos escolares con conocimientos heterogéneos de la lengua. 


\section{Bibliografía}

ALVAR, Manuel y POTTIER, Bernard (1983). Morfología histórica del español. Madrid: Gredos.

ANDERSON, Stephen R. (1995). A-morphous morphology. Cambridge: Cambridge University Press.

ANDERSON, Stephen R. (2015). The Morpheme: Its Nature and Use. The Oxford Handbook of Inflection, Oxford University Press, pp. 11-33.

ANGLIN, Jeremy M. (1993). Vocabulary development: A morphological analysis. Monographs of the Society for Research in Child Development, 58, pp. 1-166.

APEL, Kenn (2014). A Comprehensive Definition of Morphological Awareness. Implications for Assessment. Topics in Language Disorder, 34:3, pp. 197-209.

APEL, Kenn y HENBEST, Victoria S. (2016). Affix meaning knowledge in first through third grade students. Language, Speech and Hearing Services in Schools, 47, pp. 148-156.

APEL, Kenn y LAWRENCE, Jessika (2011). Contributions of morphological awareness skills to word-level reading and spelling in first-grade children with and without speech sound disorder. Journal of Speech, Language, and Hearing Research, 54, pp. 13121327.

ARONOFF, Mark y FUDEMAN, Kirsten (2011). What is Morphology? Oxford: Blackwell.

BAEZ, Mónica (2009). Recursos gráficos y discursivos empleados por niños en la edición de tres textos específicos. Tesis de doctorado. DIE-CINVESTAV, México.

BAEZ, Mónica y FERREIRO, Emilia (2013). Los niños como editores de un texto publicitario. En E. Ferreiro, El ingreso a la escritura y a las culturas de lo escrito. Textos de investigación. México: Siglo XXI, pp.244-258.

BÉGUELIN, Marie-José (2012). Unidades de lengua y unidades de escritura. Evolución y modalidades de la segmentación gráfica. En E. Ferreiro, Relaciones de (in)dependencia entre oralidad y escritura. Barcelona: Gedisa, pp. 31-52. 
BLANCHE-BENVENISTE, Claire (1998). Algunas características de la oralidad. En Estudios lingüísticos sobre la relación entre oralidad y escritura. Barcelona: Gedisa, pp. 1928.

BLANCHE-BENVENISTE, Claire (2002). La escritura irreductible a un código. En E. Ferreiro, Relaciones de (in)dependencia entre oralidad y escritura. Barcelona: Gedisa, pp. 1530.

BRYANT, Peter; NUNES, Terezinha y BINDMAN, Miriam (1997). Backward readers' awareness of language: Strengths and weaknesses. European Journal of Psychology of Education, 12, p. 357-372.

BRYANT, Peter; NUNES, Terezinha y BINDMAN, Miriam (2000). The relations between children's linguistic awareness and spelling: The case of the apostrophe. Reading and Writing, 12, p. 253-276.

CARLISLE, Joanne F. (2000). Awareness of the structure and meaning of morphologically complex words: Impact on reading. Reading and Writing. An Interdisciplinary Journal, 12, pp. 169-190.

CARLISLE, Joanne F. (2003). Morphology matters in learning to read: A commentary. Reading Psychology, 24, pp. 291-322.

CASTEDO, Mirta y TORRES, Mirta (2012). Un panorama de las teorías de la alfabetización en América Latina durante las últimas décadas (1980-2010). En H. R. Cuccuza y Spregelburd, R. (coords.), Historia de la lectura en la Argentina. Del catecismo colonial a las netbooks estatales. Buenos Aires: Editoras del Calderón, pp. 615-667.

CHEN, Honglin y MYHILL, Debra (2016). Children talking about writing: Investigating metalinguistic understanding. Linguistics and Education, 35, pp. 100-108.

CHLIOUNAKI, Kalliopi y BRYANT, Peter (2003). Choosing the right spelling in Greek: Morphology helps. Revue française de linguistique appliquée, 8, pp. 35-45.

CHOMSKY, Noam y HALLE, Morris (1968). The sound pattern of English. Nueva York: Harper and Row. 
COLÉ, Pascale; BOUTON, Sophie; LEUWERS, Christel; CASALIS, Severine y SPRENGERCHAROLLES, Liliane (2012). Stem and derivational-suffix processing during reading by French second and third graders. Applied Psycholinguistics, 33, pp. 97-120

DA MOTA, Márcia (2008a). Algumas considerações a respeito do que as crianças sabem sobre a morfologia derivacional. Interação em Psicologia, 12:1, pp. 115-123.

DA MOTA, Márcia; ANIBAL, Márcia Maria y LIMA, Simone (2008b). A morfologia derivacional contribui para a leitura e escrita no português? Psicologia: Reflexão e Crítica, 21:2 pp. 311-318.

DÁVALOS, Amira (2016). La influencia de los marcadores textuales de modalidad en la evolución de los usos y explicaciones de la puntuación en niños de primaria. Tesis de doctorado. DIE-CINVESTAV, México.

DEACON, Hélène y BRYANT, Peter (2005). The strength of children's knowledge of the role of roots in the spelling of derived words. Journal of Child Language, 32:2, pp. 375389.

DEACON, Hélène y BRYANT, Peter (2006a). Getting to the root: Young writers' sensitivity to the role of root morphemes in the spelling of inflected and derived words. Journal of Child Language, 33:2, pp. 401-417.

DEACON, Hélène y BRYANT, Peter (2006b). This turnip's is not for turning: Children's morphological awareness and their use of root morphemes in spelling. British Journal of Developmental Psychology, 24, pp. 567-575.

DEACON, Hélène; KIRBY, John R. y BELL-CASSELMAN, Melissa (2009). How robust is the contribution of morphological awareness to spelling. Reading Psychology, 30:4, pp. 301-318.

DEFIOR, Sylvia; ALEGRÍA, Jesús; TITOS, Rosa y MARTOS, Francisco (2008). Using morphology when spelling in a shallow orthographic system: The case of Spanish. Cognitive Development, 23, pp. 204-215.

DI TULLIO, Ángela (2005). Manual de gramática del español. Buenos Aires: La isla de la luna. 
DIAMANTI, Vassiliki; GOULANDRIS, Nata; STUART, Morag y CAMPBELL, Ruth (2014). Spelling derivational and inflectional suffixes by Greek-speaking children with and without dyslexia. Reading and Writing, 27, pp. 337-358.

DOMINGUEZ, Alberto; CUETOS, Fernando y SEGUÍ, Juan (2000). Morphological processing in word recognition: A review with particular reference to Spanish data. Psicológica, 30:4, pp. 301-318.

EHRI, Linnea C. (1997). Learning to read and learning to spell are one and the same, almost. En C. A. Perfetti, L. Rieben y M. Fayol (eds.), Learning to spell. Research, theory and practice across languages, Mahwah, New Jersey: Lawrence Erlbaum, pp. 237-269.

ERVIN, Susan (1964). Imitation and structural change in children's language. En E. H. Lenneberg (ed.), New directions in the study of language. Cambridge: M.I.T. Press, pp. 163-189.

FEJZO, Anila (2016). The contribution of morphological awareness to the spelling of morphemes and morphologically complex words in French. Reading and Writing, 29, pp. 207-228.

FERREIRO, Emilia (1999a). Dicotomía oralidad/escritura en la psicolingüística contemporánea. En Vigencia de Jean Piaget, México: Siglo XXI, pp. 55-71.

FERREIRO, Emilia (1999b). El niño según Piaget: un interlocutor intelectual del adulto. En Vigencia de Jean Piaget, México: Siglo XXI, pp. 20-32.

FERREIRO, Emilia (2000). Entre la sílaba oral y la palabra escrita. Infancia y Aprendizaje, 89, pp. 25-37.

FERREIRO, Emilia (2002). Escritura y oralidad, unidades, niveles de análisis y conciencia metalingüística. En E. Ferreiro (comp.), Relaciones de (in)dependencia entre oralidad y escritura, Barcelona: Gedisa, pp. 151-171.

FERREIRO, Emilia (2006). La escritura antes de la letra. CPU-e Revista de Investigación Educativa (Universidad Veracruzana), 3, julio-diciembre [traducción al español del original publicado en francés "L'ecriture avant la lettre". En H. Sinclair (dir.), La 
production de notations chez le jeune enfant. Paris: Presses Universitaires de France, pp. 7-70, 1988].

FERREIRO, Emilia (2012). Comprensión del sistema alfabético de escritura. En M. Carretero y J. A. Castorina, Desarrollo Cognitivo y educación. Procesos del conocimiento y contenidos específicos, Buenos Aires: Paidós, pp. 243-266.

FERREIRO, Emilia (2013). Introducción general. El ingreso a la escritura y a las culturas de lo escrito. Textos de investigación. México: Siglo XXI, pp. 7-13.

FERREIRO, Emilia y TEBERSOKY, Ana (1979). Los sistemas de escritura en el desarrollo del niño. Buenos Aires: Siglo XXI.

FERREIRO, Emilia; PONTECORVO, Clotilde; RIBEIRO MOREIRA, Nadja y GARCÍA HIDALGO, Isabel (1996). Caperucita Roja aprende a escribir. Estudios psicolingüísticos comparativos en tres lenguas. Barcelona: Gedisa.

FERREIRO, Emilia y ZAMUDIO, Celia (2008). La escritura de sílabas CVC y CCV en los inicios de la alfabetización escolar. ¿Es la omisión de consonantes prueba de incapacidad para analizar la secuencia fónica? Rivista di psicolinguistica applicata, VIII:1-2, pp. 37-53.

FRITH, Uta (1985). Beneath the Surface of developmental dyslexia. En K. E. Patterson; J. C. Marsshall y M. Coltheart (eds.), Surface dyslexia: Neuropsychological and cognitive studies of phonological Reading, London: Lawrence Erlbaum, pp. 301-330).

GOMBERT, Jean E. (1990). Le développement métalinguistique. Paris: Presses Universitaires de France.

GONZÁLEZ SÁNCHEZ, Lorena; RODRÍGUEZ, Celestino y GÁZQUEZ, Jesús (2011). Aproximación al concepto de conciencia morfológica: concepto, desarrollo y relación con la lectura y la escritura. Magister. Revista miscelánea de investigación, 24, pp. 135-146.

HENDERSON, Edmund H. (1985). Teaching spelling. Boston: Houghton Mifflin.

KEMP, Nenagh y BRYANT, Peter (2003). Do beez buzz? Rule-based and frequency-based knowledge in learning to spell plural -s. Child Development, 74:1, pp. 63-74. 
KERLEROUX, François (2006). Les théories morphologiques à la fin du XXe siècle. En Sylvian Auroux (ed.), History of the Language Sciences, Vol. 3, Berlin: Walter de Gruyter, pp. 2313-2324.

KRISCAUTZKY, Marina (2014). Seleccionar información en internet. Problemas y soluciones de los nuevos lectores ante la confiabilidad de las fuentes digitales de información. Tesis de Doctorado. Departamento de Investigaciones Educativas, CINVESTAV, México.

KRISCAUTZKY, Marina y FERREIRO, Emilia (2018). Evaluar la confiabilidad de la información en Internet: cómo enfrentan el reto los nuevos lectores de 9 a 12 años. Perfiles educativos, 15:159, pp. 16-34.

KU, y ANDERON, Richard C. (2003). Development of morphological awareness in Chinese and English. Reading and writing, 16, pp. 399-422.

KUO, Li-jen y ANDERSON, Richard C. (2006). Morphological awareness and learning to read: A cross-language perspective. Educational Psychologist, 41:3, pp. 161.180.

LARA, Fernando (2006). Curso de lexicología. México: El Colegio de México.

LARA, Fernando (2012). La escritura como tradición y como instrumento de reflexión. En E. Ferreiro, Relaciones de (in)dependencia entre oralidad y escritura. Barcelona: Gedisa, pp. 53-61.

LÁZARO MORA, Fernando A. (1999). La derivación adjetiva. En DEMONTE, V. y BOSQUE I., Gramática descriptiva de la lengua española. Tomo III. Entre la oración y el discurso. Morfología. Madrid: Espasa Calpe, pp. 4645-4682.

LERNER, Delia (2008). La enseñanza y el aprendizaje escolar. Alegato contra una falsa oposición. En J. Castorina y otros., Piaget-Vigostky: contribuciones para replantear el debate. Buenos Aires: Paidós, pp. 69-118.

LEVIN, Iris; RAVID, Dorit y RAPAPORT, Sharon (2001). Morphology and spelling among Hebrew-speaking children: From kindergarten to first grade. Journal of Child Language, 28, 741-772.

MILER, Wick y ERVIN, Susan (1964). The Development of Grammar in Child Language. En Monograph of the Society for Research in Child Development, 29:1, pp. 9-34. 
MÖLLER, María Angélica (2010). Evolución de las conceptualizaciones infantiles sobre la puntuación de textos. Un enfoque psicogenético. Tesis de doctorado. Universidad Nacional de Córdoba, Argentina.

MÖLLER, María Angélica y FERREIRO, Emilia (2013). El diálogo en las historietas ¿Cómo elegir la puntuación apropiada? En E. Ferreiro, El ingreso a la escritura y a las culturas de lo escrito. Textos de investigación. México: Siglo XXI, pp.200-217.

MORAIS, José; CARY, Luz; ALEGRIA, Jesús y BERTELSON, Paul (1979). Does awareness of speech as a sequence of phones arise spontaneously? Cognition, 7, pp. 323-331.

MORAIS, José; ALEGRIA, Jesús y CONTENT, Alain (1987). The relationship between segmental analysis and alphabetic literacy: An interactive view. Cahiers de Psychologie Cognitive, 7:5, pp. 415-438.

NAGY, William E.; DIAKIDOY, Irene-Anna y ANDERSON, Richard C. (1991). The development of knowledge of derivational suffixes. Technical Report No. 357, University of Illinois, Center for the Study of Reading.

NUNES, Terezinha y BRYANT, Peter (2006). Improving literacy trough teaching morphemes. London: Routledge \& Kegan Paul.

NUNES, Terezinha; BRYANT, Peter y BINDMAN, Miriam (1997). Morphological spelling strategies: Developmental stages and processes. Developmental Psychology, 33, pp. 637-649.

OLSON, David (1994). The world on paper. The conceptual and cognitive implications of reading and writing. Cambridge: Cambridge University Press.

PARKES, Malcom B. (1993). Pause and Effect. Punctuation in the West, Cambridge: University Press.

PENA, Jesús (1995). Sobre la definición del morfema. Lingüística española actual, 17, 2, pp. 129-142.

PENA, Jesús (1999). Partes de la morfología. Las unidades del análisis morfológico. En I. Bosque y V. Demonte (dirs.), Gramática descriptiva de la lengua española, Madrid: Espasa Calpe, vol. III, cap. 66, pp. 4305-4366. 
PENA, Jesús (2000). Formación de palabras. En M. Álvar López (dir.), Introducción a la Lingüística española. Barcelona: Ariel, cap. 12, pp. 235-253.

PENA, Jesús (2003). La relación derivativa. ELUA (Estudios de Lingüística de la Universidad de Alicante), 17, pp. 505-517.

PEREZ PEREIRA, Miguel y SINGER, Dolores (1984). Adquisición de morfemas del español. Infancia y Aprendizaje, 27/28, pp. 205-221.

PIAGET, Jean (1974). La prise de conscience. Paris: Presses Universitaires de France.

PORTO DAPENA, José-Álvaro (2002). Complementos argumentales del verbo: directo, indirecto, suplemento y agente. Madrid: Arcos Libros.

RAE/ASALE (2009). Nueva gramática de la lengua española. Madrid: Espasa.

RAE/ASALE (2010). Ortografía de la lengua española. Madrid: Espasa.

RAVID, Dorit y SCHIFF, Rachel (2006). Roots and patterns in Hebrew language development: Evidence from written morphology analogies. Reading and Writing, 19, pp. 789-818.

READ, Charles; ZHANG, Y.; NIE, H. y DING, B. (1986). The ability to manipulate speech sounds depends on knowing alphabetic writing. Cognition, 24, pp. 31-44.

RIBEIRO MOREIRA, Nadja y PONTECORVO, Clotilde (1996). Chapeuzinho/Cappuccetto: variaciones gráficas y norma ortográfica. En E. Ferreiro, C. Pontecorvo, N. Ribeiro Moreria e I. García Hidalgo, Caperucita Roja aprende a escribir. Estudios psicolingüísticos en tres lenguas. Barcelona: Gedisa, cap. 3, pp. 87-125.

RODRIGUEZ CUEVAS, Monserrat (2018). Modificación de palabras orales por agregado de morfemas en niños preescolares. Presentación en el $2^{\circ}$ Coloquio de avances de tesis de Maestría, alumnos de la generación 2016-2018, DIE-CINVESTAV (documento interno).

De SAUSSURE, Ferdinand (1995). Cours de linguistique générale, comp. por Ch. Bally y A. Sechehaye. Ed. crítica de Tullio de Mauro, Paris: Payot. [publicado originalmente en 1916].

SAENGER, Paul (1997). Space between Words. The Origins of Silent Reading, California: Standford University Press. 
SINGSON, Maria; MAHONY, Diana y MANN, Virginia (2000). The relation between reading ability and morphological skills: Evidence from derivational suffixes. Reading and Writing: An Interdisciplinary Journal, 12, pp. 219-252.

TEBEROSKY, Ana (2002). Las "filtraciones" de la escritura en los estudios psicolingüísticos.

En E. Ferreiro (comp.), Relaciones de (in)dependencia entre oralidad y escritura, Barcelona: Gedisa, pp. 111-133.

TYLER, Andrea y NAGY, William (1985). The role of derivational suffixes in sentence comprehension. Technical Report No. 357, University of Illinois, Center for the Study of Reading.

TYLER, Andrea y NAGY, William (1987). The acquisition of English derivational morphology. Journal of Memory and Language, 28:6, pp. 649-667.

VAKIN-NUSBAUM, Vered; SARID, Miri y SHIMRON, Joseph (2016). Morphological awareness and reading in second and fifth grade: evidence from Hebrew. Reading and Writing, 29:2, pp, 229-244.

VARELA ORTEGA, Soledad (2005). Morfología léxica: la formación de palabras. Madrid: Gredos.

VELAZQUEZ, Alejandro (2017). Modalidades de reflexión morfológica en niños de primaria. Tesis de doctorado. DIE-CINVESTAV, México.

VELAZQUEZ, Alejandro y FERREIRO, Emilia (2015). Acercamiento a los procesos de toma de conciencia morfológica en niños hispanohablantes: el caso de RE-, DES-, -CION y -MENTE. Rassegna di Psicologia, 23:2, pp. 61-77.

VERNON, Sofía y FERREIRO, Emilia (1999). Writing Development: A Neglected Variable in the Consideration of Phonological Awareness. Harvard Educational Review, 69:4, pp. 395-415.

WOLTER, Julie A.; WOOD, Alexis y D'ZATKO, Kim W. (2009). The influence of morphological awareness on first-grade children's literacy development. Language, Speech and Hearing in Services in the Schools, 40:3, pp. 286-298.

ZACARÍAS PONCE de LEON, Ramón F. (2010). Esquemas rivales en la formación de palabras en español. Onomázein, 22, pp. 59-82. 
ZACARIAS PONCE de LEON, Ramón F. (2016). Rivalidad entre esquemas de formación de palabras. México: Instituto de Investigaciones Filológicas, Universidad Nacional de México.

ZAMUDIO MESA, Celia M. (2004). El papel de la transcripción en la construcción del dato lingüístico. Tesis de doctorado. México: El Colegio de México, Centro de Estudios Lingüísticos y Literarios.

ZAMUDIO MESA, Celia M. (2010). Las consecuencias de la escritura alfabética en la teoría lingüística. México: El Colegio de México.

ZHANG, Haomin (2014). Morphological awareness in vocabulary acquisition among Chinese-speaking children: Testing partial mediation via lexical inference ability. Reading Research Quarterly, 50:1, pp. 129-142 